\title{
ESTUDIO ABIERTO
}

\section{ALEATORIZADO DE LA}

\section{INTERVENCIÓN NO}

FARMACOLÓGICA EN

\section{EL CONTROL DE LA}

ASTENIA REFERIDA

POR LA ENFERMEDAD

\section{ONCOLÓGICA}

TESIS DOCTORAL

Universidad de Salamanca. Departamento de Medicina

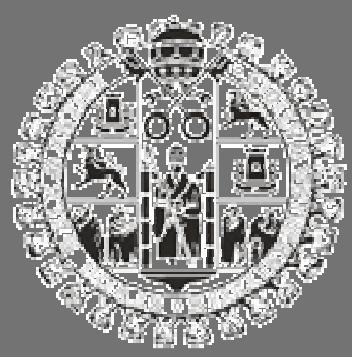




\section{UNIVERSIDAD DE SALAMANCA}

FACULTAD DE MEDICINA

DEPARTAMENTO DE MEDICINA

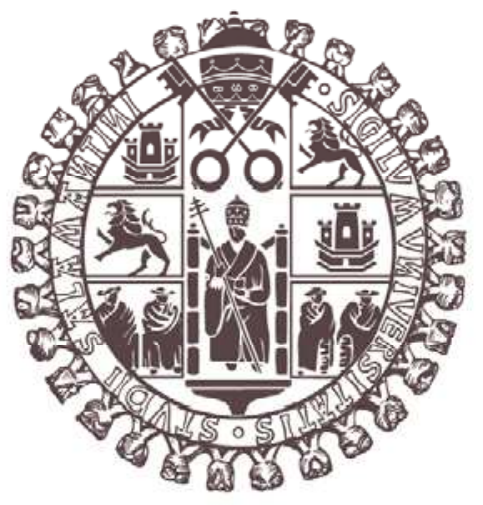

ESTUDIO ABIERTO ALEATORIZADO DE LA

INTERVENCIÓN NO FARMACOLÓGICA EN EL COTROL DE LA ASTENIA REFERIDA POR LA ENFERMEDAD

ONCOLÓGICA

TESIS DOCTORAL

AUTOR: D. EDUARDO JOSÉ FERNÁNDEZ RODRÍGUEZ

DIPLOMADO EN TERAPIA OCUPACIONAL

DIRECTORES:

DR. JUAN JESÚS CRUZ HERNÁNDEZ

DEPARTAMENTO DE MEDICINA. CATEDRÁTICO DE MEDICINA DE LA UNIVERSIDAD DE SALAMANCA

DRA. MARÍA ISABEL RIHUETE GALVE

DEPARTAMENTO DE CIENCIAS DE LA SALUD. PROFESORA ASOCIADA DE LA UNIVERSIDAD DE SALAMANCA 


\section{AGRADECIMIENTOS}

A mi familia, sin vosotros no hubiera sido posible. Gracias por ayudarme en todo.

A Celia, por y para ti, por tu constante apoyo y motivación. Gracias.

A la Doctora María Isabel Rihuete Galve, esta tesis sin tu ayuda no habría existido. Gracias por enseñarme y adentrarme en el mundo de la investigación.

Al Profesor Juan Jesús Cruz, por haberme dado la oportunidad de crecer profesional y personalmente, y por haber creído siempre en este estudio.

A todos los que forman parte de la extensa familia del Servicio de Oncología, por vuestra ayuda, vuestro ánimo y todo lo que he aprendido a vuestro lado.

A los pacientes y sus cuidadores familiares, sin vosotros no hubiera sido posible y por vosotros fue realizado. Me habéis cambiado la forma de ver la vida. 


\section{ÍNDICE}

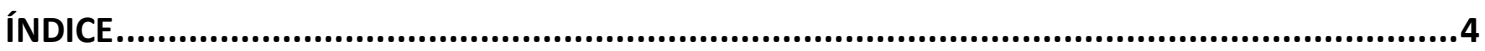

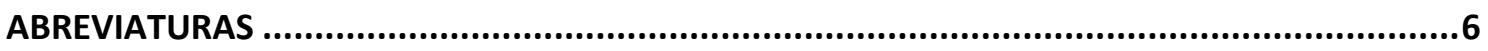

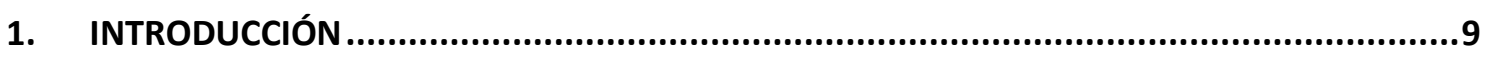

1.1. TRATAMIENTO DE SOPORTE Y CUIDADOS PALIATIVOS EN EL ENFERMO ONCOLÓGICO ...............10

1.2. ASTENIA. CONCEPTO

1.3. ASTENIA RELACIONADA CON EL CÁNCER. CONCEPTO Y EPIDEMIOLOGÍA ......................22

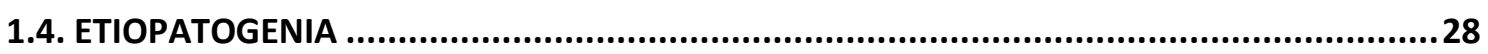

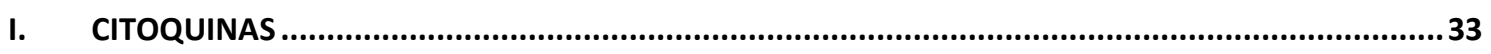

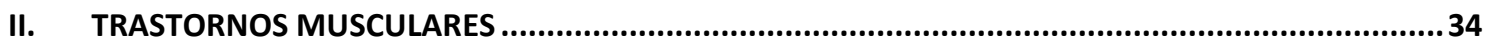

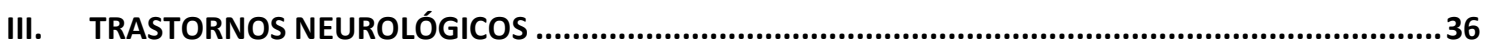

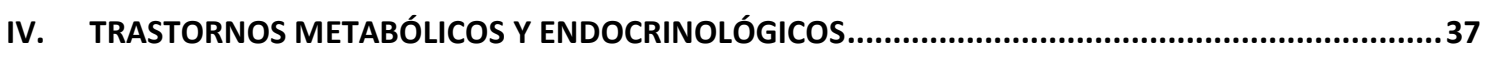

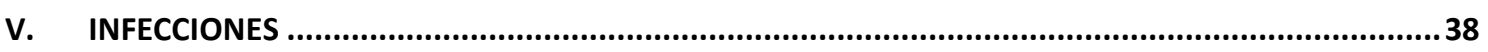

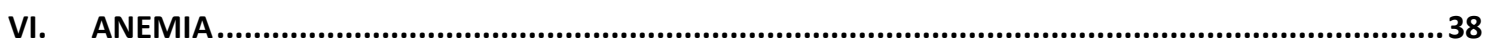

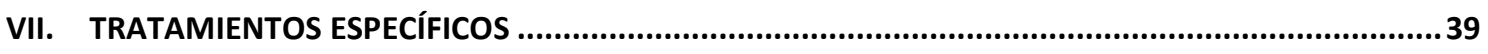

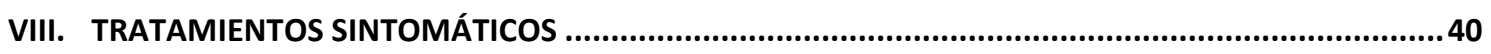

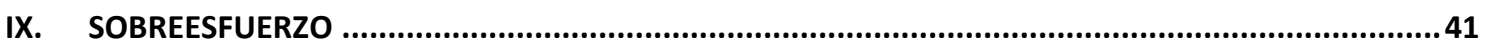

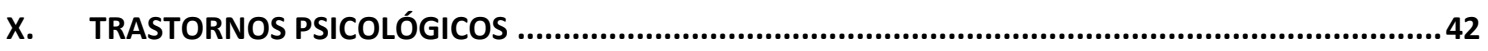

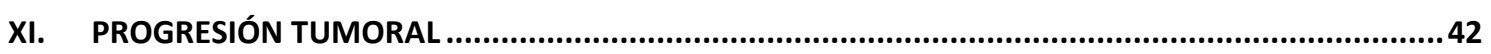

XII. ASTENIA TUMORAL DESPUÉS DEL TRATAMIENTO .....................................................................43

1.5. BASES BIOLÓGICAS DE LA ASTENIA ASOCIADA AL CÁNCER ......................................47

LA CONDUCTA DE ENFERMO O “THE SICKNESS BEHAVIOUR”............................................................53

1.6. INSTRUMENTOS DE EVALUACIÓN DE ASTENIA RELACIONADA CON EL CÁNCER..............56

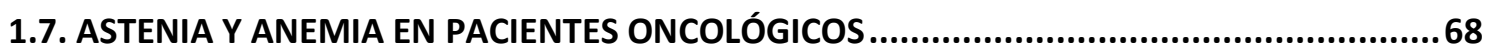

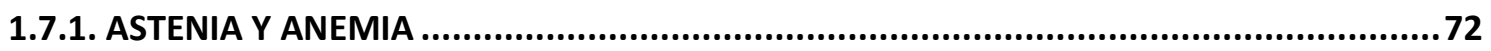

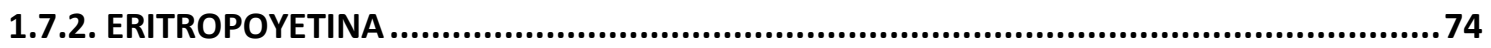




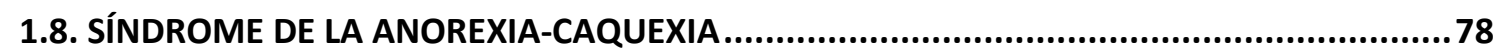

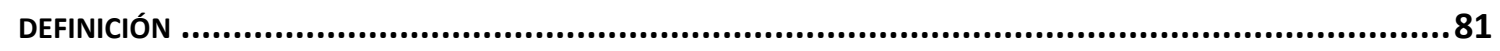

INCIDENCIA

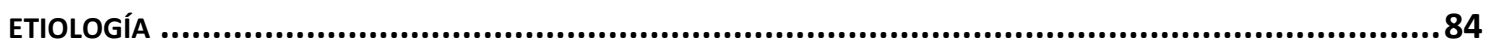

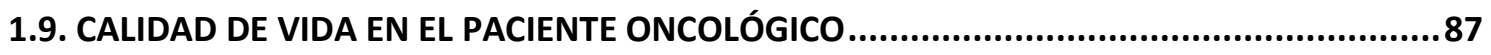

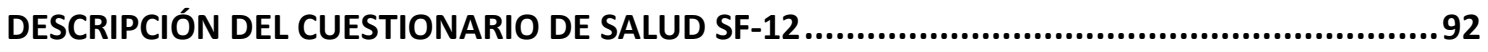

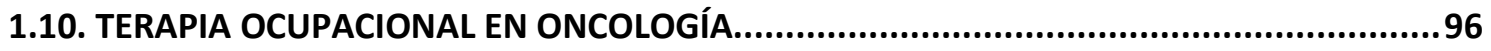

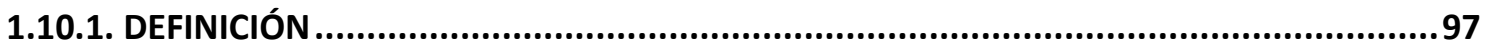

APLICACIÓN PRÁCTICA DE LA TERAPIA OCUPACIONAL .................................................................................. 100

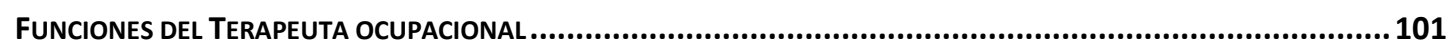

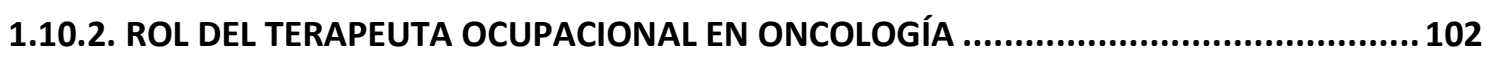

¿QUÉ PRETENDE LA TERAPIA OCUPACIONAL EN EL PACIENTE? .......................................................... 106

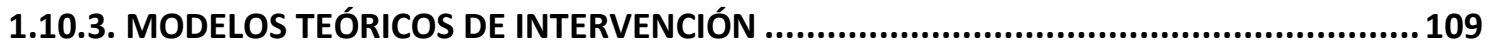

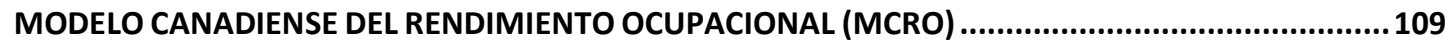

MODELO DE LA OCUPACIÓN HUMANA (MOHO) ..........................................................................119

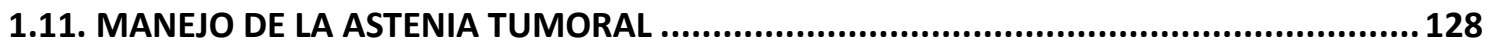

1.11.1. TRATAMIENTO DE LOS FACTORES PREDISPONENTES ............................................ 130

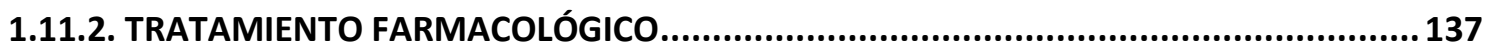

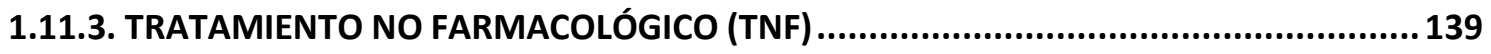

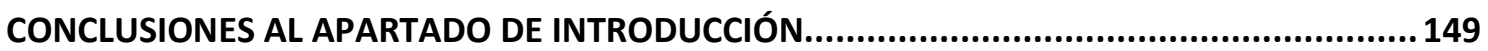

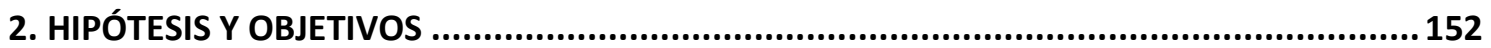

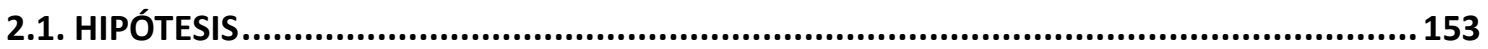

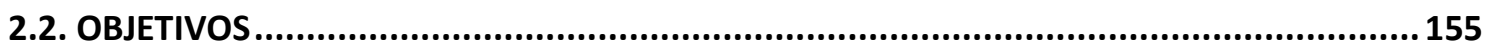

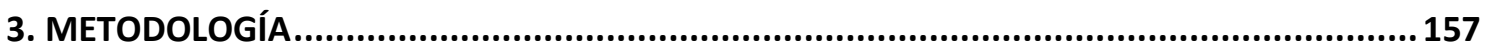

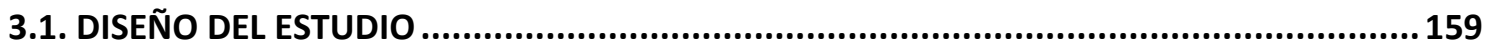

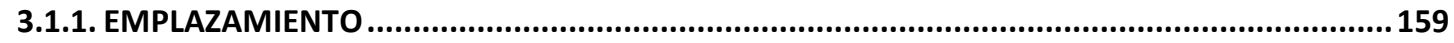

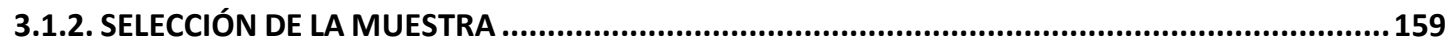


3.1.2.1. CRITERIOS DE INCLUSIÓN .............................................................................. 161

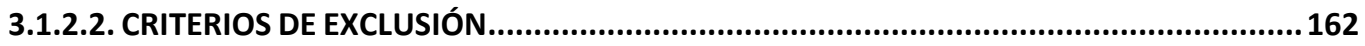

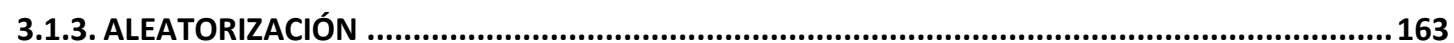

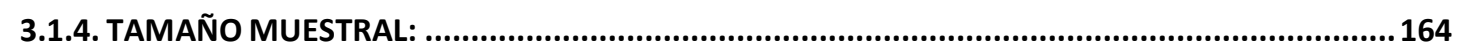

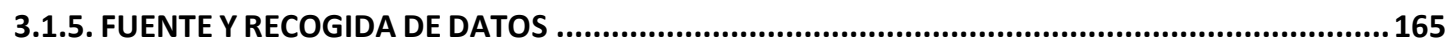

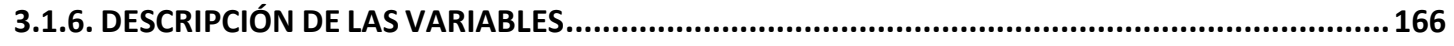

3.1.7. INSTRUMENTOS DE EVALUACIÓN Y RECOGIDA DE RESULTADOS:........................................ 167

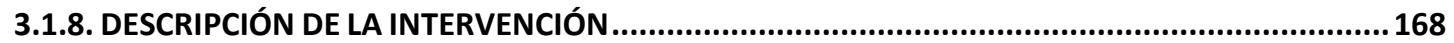

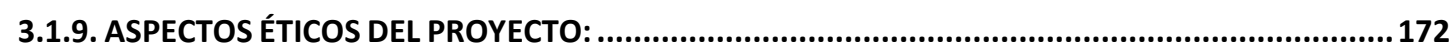

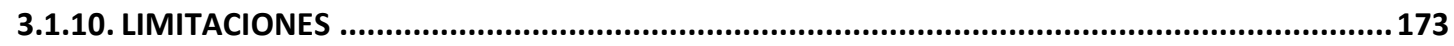

3.2. METODOLOGÍA ESTAdÍSTICA................................................................. 174

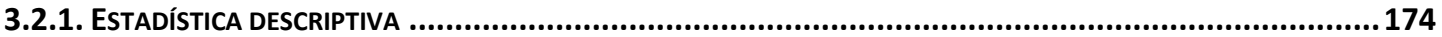

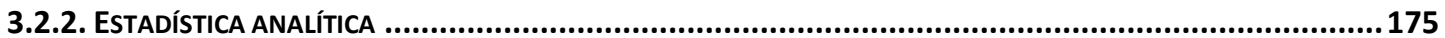

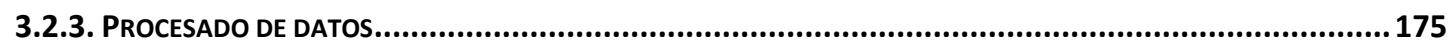

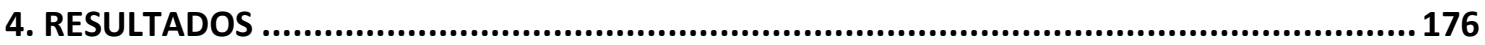

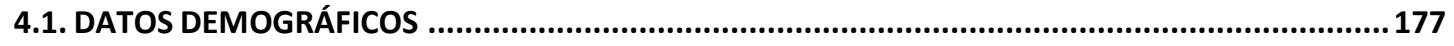

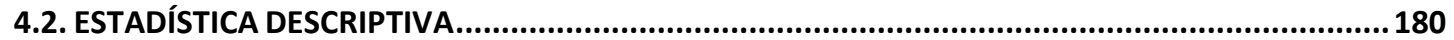

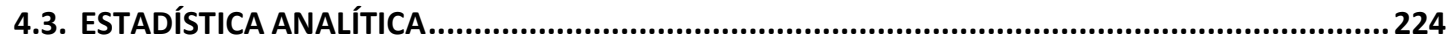

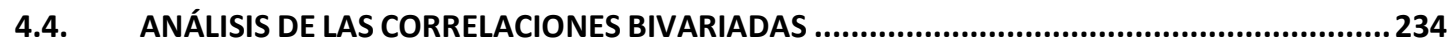

5. DISCUSIÓN ............................................................................................. 244

6. CONCLUSIONES .................................................................................... 271

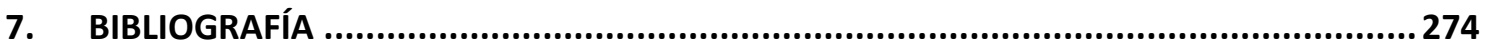

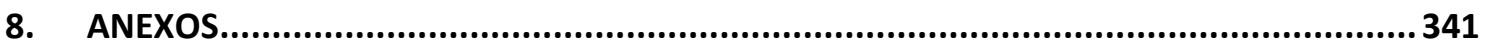




\section{ABREVIATURAS}

TO: Terapia Ocupacional

OMS: Organización Mundial de la Salud

RAE: Real Academia Española de la lengua

CIE: Clasificación Internacional de Enfermedades

NCCN: National Comprehensive Cancer Network

TNF: Factor de Necrosis Tumoral

ATP: Adenosintrifosfato

CK: Creatinquinasa

HHA: Hipotálamo-Hipófisis-Adrenal

IL: Interleuquina

BHE: Barrera Hemato-encefálica

SNC: Sistema Nervioso Central

EVA: Escala Visual Analógica

PERFORM: Percepción de la Fatiga en Pacientes Oncológicos su Realidad y Medición

CVRS: Calidad de Vida Relacionada con la Salud

EORTC: European Organisation for Research and Treatment of Cancer

EPO: Eritropoyetina 
QT: Quimioterapia

RT: Radioterapia

WFOT: Federación Mundial de Terapeutas Ocupacionales

AOTA: Asociación Americana de Terapeutas Ocupacionales

CAOT: Asociación Canadiense de Terapeutas Ocupacionales

COTEC: Comité Europeo de Terapeutas Ocupacionales

APETO: Asociación Profesional Española de Terapeutas Ocupacionales

TOBE: Terapia Ocupacional Basada en la Evidencia

AVD: Actividades de la Vida Diaria

ABVD: Actividades Básicas de la Vida Diaria

AIVD: Actividades Instrumentales de la Vida Diaria

MCRO: Modelo Canadiense del Rendimiento Ocupacional

MOHO: Modelo de la Ocupación Humana

TNF: Tratamiento No Farmacológico o Terapia No Farmacológica

ASCO: American Society of Clinical Oncology

ASH: American Society of Hematology

TAE: Técnicas de Ahorro de Energía 
1. INTRODUCCIÓN 
1.1. TRATAMIENTO DE SOPORTE Y CUIDADOS PALIATIVOS EN EL ENFERMO ONCOLÓGICO 


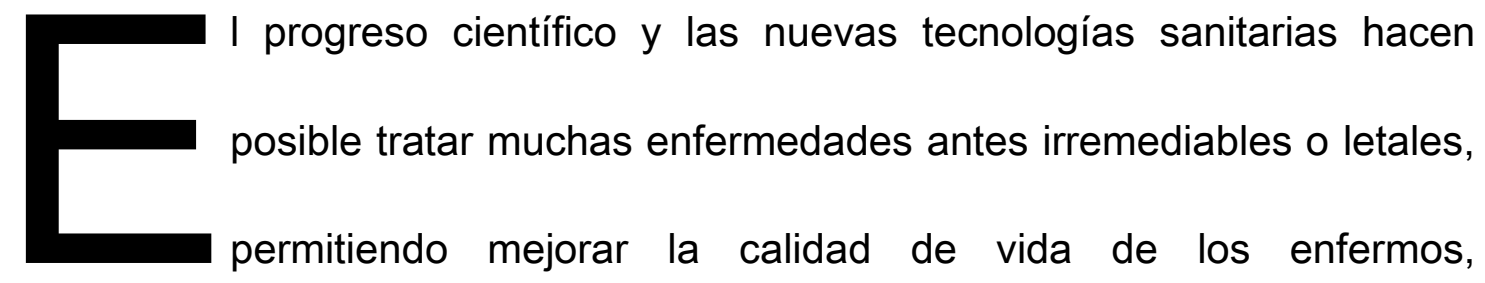
prolongando su supervivencia ${ }^{1}$. El actual patrón demográfico y de morbilidad hace esperar que en los próximos años, además del número de personas con cáncer, aumenten las personas con enfermedades degenerativas y el número de adultos mayores. Por tanto, cada vez es mayor el número de personas que pueden verse enfrentadas a una situación crónica 2 .

Partiendo de esa hipótesis tiene especial importancia las estrategias de cuidados continuos. La filosofía de estos cuidados parte de que la intervención en este tipo de patologías debe ser interdisciplinar y precoz, comenzando en los inicios de la enfermedad y prolongándose hasta la fase final de la misma. Siempre enfatizando los recursos empleados y su intensidad en función de las necesidades.

Debemos diferenciar dos conceptos, el de tratamiento de soporte y el de cuidados paliativos: 
1. Tratamientos de soporte: Aquellos que se integran asistencialmente para la mejora de los síntomas y el apoyo social a los pacientes y sus cuidadores en cualquiera de las fases de la enfermedad, siendo aplicados de forma concomitante con las terapias específicas antineoplásicas ${ }^{3}$.

2. Cuidados paliativos: Aquellas actuaciones que mejoran la calidad de vida de los pacientes y sus familiares, a través de la prevención y el alivio del sufrimiento en aquellos enfermos en los que no se administran tratamientos oncológicos específicos ${ }^{3}$.

Para la Organización Mundial de la Salud $(\mathrm{OMS})^{4}$ el tratamiento paliativo tiene por objeto:

- Reafirmar la importancia de la vida, considerando la muerte como un proceso normal.

- Establecer un proceso que no acelere la llegada de la muerte, pero que tampoco la posponga.

- Proporcionar alivio del dolor y de otros síntomas.

- Integrar los aspectos psicológicos y espirituales del tratamiento del paciente.

- Ofrecer un sistema de apoyo para ayudar a los pacientes a llevar una vida lo más activa posible hasta que sobrevenga la muerte. 
- Ofrecer un sistema de apoyo a la familia para que pueda afrontar la enfermedad del paciente y sobrellevar el período del duelo.

Para ello se redactaron los "Principios de los cuidados continuos y paliativos", los cuales se llevarán a cabo gracias a la actuación de un equipo interdisciplinar ${ }^{3}$.

\section{PRINCIPIOS DE LOS CUIDADOS CONTINUOS Y PALIATIVOS}

a. Atención integral del enfermo: Que tenga en cuenta los aspectos físicos, emocionales, sociales y espirituales.

b. El enfermo y la familia son la unidad a tratar: La familia es el núcleo fundamental del apoyo al enfermo y como tal requiere unas medidas específicas de atención en esta fase tan compleja.

c. Fomento de autonomía y dignidad del enfermo.

d. Concepción terapéutica activa y rehabilitadora.

e. Objetivos de los cuidados: Bienestar y Calidad de Vida.

f. Importancia del ambiente: Una atmósfera de respeto, confort, soporte y comunicación influyen de manera decisiva en el control de síntomas.

Figura 1. Principios de los cuidados continuos y paliativos según la OMS

Esta serie de tratamientos de soporte y cuidados continuos debe contar con equipo interdisciplinar especializado que se haga cargo de los mismos, este equipo estará formado por 5 : 


\section{EQUIPO INTERDISCIPLINAR EN ONCOLOGÍA Y CUIDADOS PALIATIVOS}

- Atención primaria.

- Servicios especializados (oncología, radioterapia, cirugía).

- Cuidados paliativos.

- Enfermería.

- Terapia Ocupacional.

- Trabajo social.

- Fisioterapia.

- Aspectos espirituales.

Figura 2. Equipo interdisciplinar en oncología y cuidados paliativos

Analizando los datos presentes en el GLOBOCAN, actualmente la prevalencia en cáncer es de casi tres casos por cada mil habitantes en todo el planeta, siendo la segunda causa de muerte en el mundo; en 2008 causó 7,6 millones de defunciones (aproximadamente un 13\% del total). Los que más muertes causan cada año son los cánceres de pulmón, estómago, hígado, colon y mama ${ }^{6}$.

Aproximadamente un $30 \%$ de las muertes por cáncer son debidas a cinco factores de riesgo conductuales y dietéticos: índice de masa corporal elevado, ingesta reducida de frutas y verduras, falta de actividad física, consumo de tabaco y consumo de alcohol.

El consumo de tabaco es el factor de riesgo más importante, y es la causa del $22 \%$ de las muertes mundiales por cáncer en general, y del $71 \%$ de las muertes mundiales por cáncer de pulmón. 
Los cánceres causados por infecciones víricas, tales como las infecciones por virus de las hepatitis $B(\mathrm{VHB})$ y $\mathrm{C}(\mathrm{VHC})$ o por papilomavirus humanos $(\mathrm{PVH})$, son responsables de hasta un $20 \%$ de las muertes por cáncer en los países de ingresos bajos y medios.

Aproximadamente un $70 \%$ de las muertes por cáncer registradas en 2008 se produjeron en países de ingresos bajos y medios.

Se prevé que las muertes por cáncer sigan aumentando en todo el mundo y alcancen la cifra de 13,1 millones en $2030^{6}$. 


\section{GLOBOCAN}

Incidencia, prevalencia, mortalidad y expectativa de vida en cáncer

\begin{tabular}{|c|c|c|c|}
\hline WORLD & Male & Female & Both sexes \\
\hline Population (thousands) & 3414566 & 3358715 & 6773281 \\
\hline Number of new cancer cases (thousands) & 6617.8 & 6044.7 & 12662.6 \\
\hline Age-standardised rate $(\mathrm{W})$ & 202.8 & 164.4 & 180.8 \\
\hline Risk of getting cancer before age $75(\%)$ & 21.1 & 16.5 & 18.6 \\
\hline Number of cancer deaths (thousands) & 4219.6 & 3345.2 & 7564.8 \\
\hline Age-standardised rate $(\mathrm{W})$ & 127.9 & 87.2 & 105.6 \\
\hline Risk of dying from cancer before age $75(\%)$ & 13.4 & 9.1 & 11.1 \\
\hline 5-year prevalent cases (thousands, end 2008) & 13514.9 & 15288.3 & 28803.2 \\
\hline Proportion (per 100,000) & 395.8 & 455.2 & 425.2 \\
\hline \multicolumn{4}{|l|}{5 most frequent cancers } \\
\hline & Lung & Breast & Lung \\
\hline & Prostate & Colorectum & Breast \\
\hline & Colorectum & Cervix uteri & Colorectum \\
\hline & Stomach & Lung & Stomach \\
\hline & Liver & Stomach & Prostate \\
\hline
\end{tabular}

Figura 3. GLOBOCAN: Incidencia, prevalencia, mortalidad y expectativa de vida en cáncer 


\section{GLOBOCAN}

\section{Incidencia y mortalidad del cáncer en hombres y mujeres}

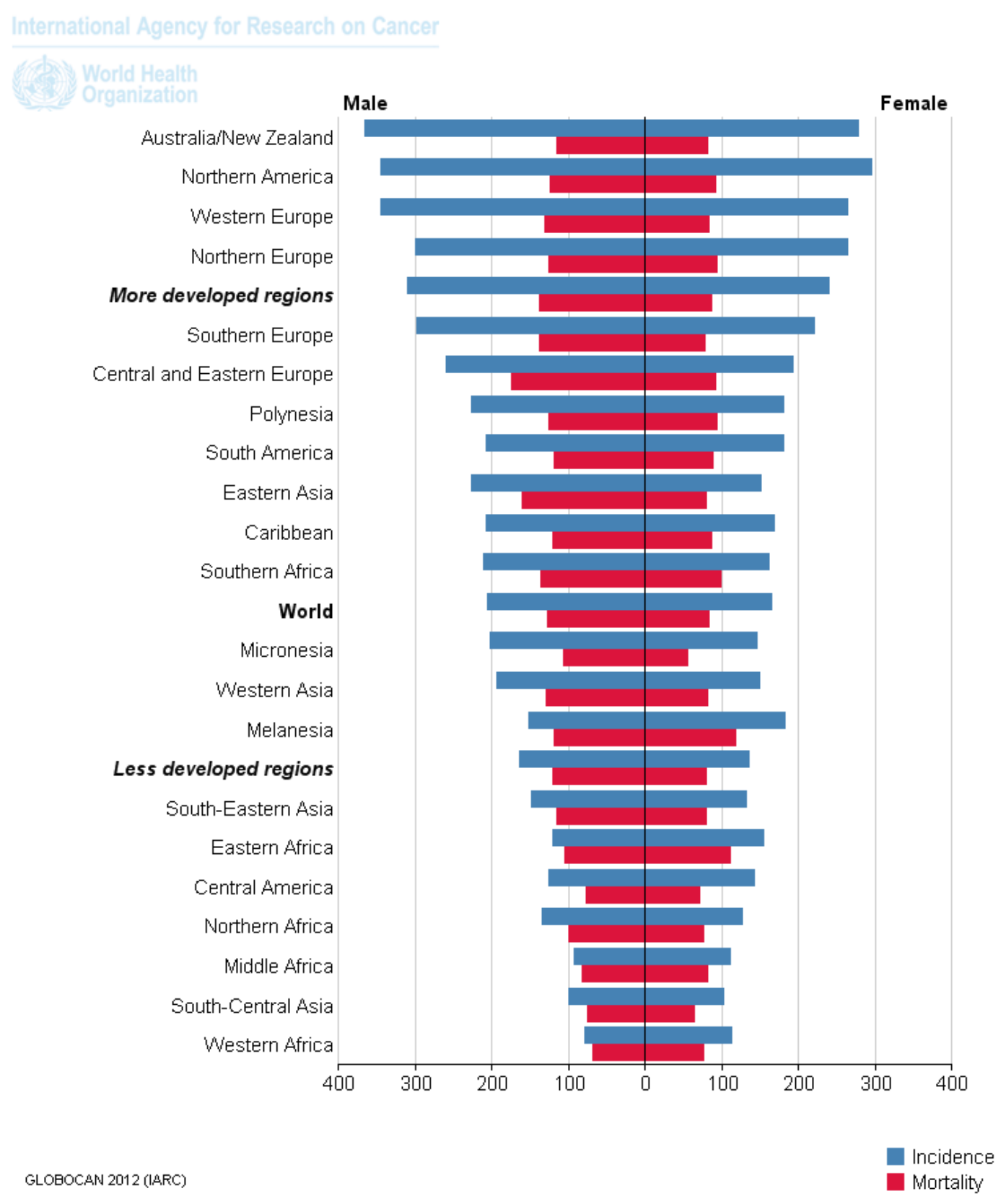

Figura 4. GLOBOCAN, incidencia y mortalidad del cáncer en hombres y mujeres 
El hecho de que hablemos de la enfermedad oncológica como un proceso crónico, nos lleva a prestar especial importancia a la sintomatología derivada de la misma. La cual puede mermar la funcionalidad y calidad de vida relacionada con la salud de los individuos.

Teniendo en cuenta esto, debemos prestar especial atención a un síntoma, el más prevalente, incidente e incapacitante en el caso del paciente con cáncer, el de la astenia tumoral 7 . 
1.2. ASTENIA. CONCEPTO 


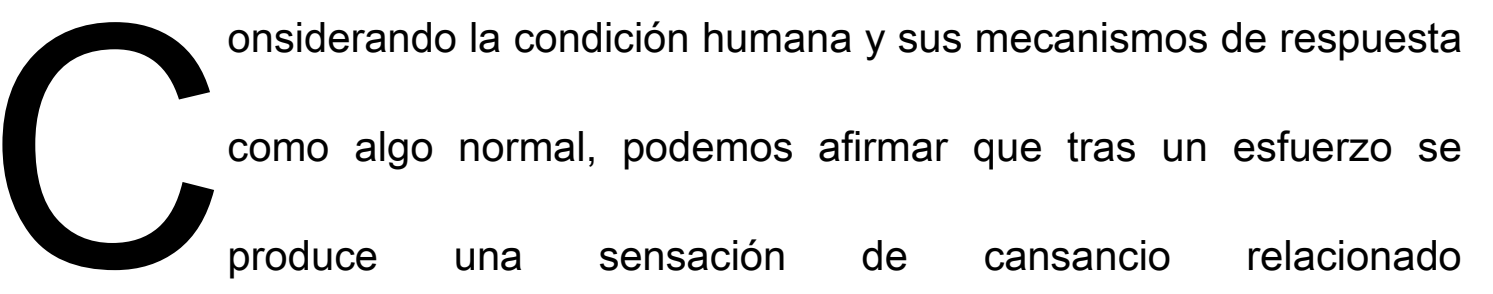
cuantitativamente con él. Tras ese cansancio y transcurriendo un tiempo de espera razonable en función de la forma física de la persona podemos decir que éste desaparecería. Sin embargo, existe un cansancio patológico que tras esa manifestación de actividad y transcurriendo ese tiempo de espera prudencial esa sensación de cansancio no desaparece, ese agotamiento continúa y merma las posibilidades del individuo.

Es una manifestación muy común en múltiples enfermedades de muy distinta naturaleza, tales como: fibromialgia, miastenia gravis o anemia, entre otras. Otra de las enfermedades en las que se presenta es en el cáncer, conociéndose en este caso con el término de astenia tumoral ${ }^{8}$.

La astenia la podemos definir, utilizando para ello la $22^{\mathrm{a}}$ edición del diccionario de la Real Academia Española de la Lengua (RAE), como "falta o decaimiento de fuerzas caracterizado por apatía, fatiga física o ausencia de iniciativa ${ }^{9}$. 
El término astenia suele confundirse o emplearse indiscriminadamente con el de fatiga o el de debilidad. Algunos han querido afinar los términos y han llegado a diferenciar la astenia (sensación de lasitud subaguda o crónica que confronta un sentimiento de debilidad indebida antes de iniciar cualquier actividad) de la fatiga (grado de cansancio anormal después de una actividad voluntaria breve o mantenida) o de la debilidad (deterioro de la capacidad para realizar un acto motor voluntario debido a una disminución del poder muscular) 10.

Todas estas definiciones se acercan mucho a las que se emplean en los libros de Medicina Paliativa, en los que cuando se habla del término de astenia se hace referencia a dos grupos sintomáticos ${ }^{11}$ :

1. El primero de ellos será la "fatigabilidad fácil con disminución de la capacidad para mantener una actividad normal”.

2. El segundo sería una "sensación anticipatoria de dificultad para iniciar determinada actividad".

Es decir la consideran como una debilidad sistémica con manifestaciones tanto físicas como mentales, incluyendo, en lo somático, debilidad generalizada, disminución de la fuerza y mayor fatigabilidad; y en lo psicológico, disminución de la capacidad cognitiva, labilidad emocional y apatía ${ }^{12}$. 
1.3. ASTENIA RELACIONADA CON EL CÁNCER. CONCEPTO Y EPIDEMIOLOGÍA 


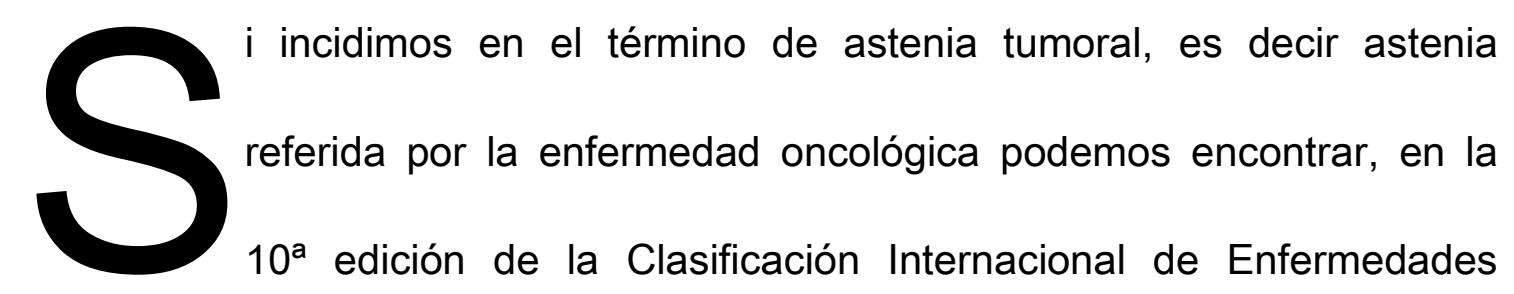

(ICD-10) los siguientes criterios diagnósticos para la astenia tumoral 13. 


\section{CRITERIO DE LA CIE-10 PARA LA ASTENIA RELACIONADA CON EL CÁNCER}

A. Los siguientes síntomas han estado presentes cada día o casi todos los días durante el mismo período de dos semanas en el último mes:

Fatiga crónica significativa, disminución de la energía o aumento de la necesidad de echarse, fuera de proporción con cualquier modificación reciente del grado de actividad; además de cinco o más de los siguientes:

1. Quejas de debilidad general, extremidades pesadas.

2. Concentración o atención disminuida.

3. Disminución de la motivación o del interés de participar en las actividades habituales.

4. Insomnio o hipersomnia.

5. Sueño que no refresca ni restaura.

6. Percepción de que se necesita luchar para superar la inactividad.

7. Reactividad emocional marcada (por ejemplo, tristeza, frustración o irritabilidad) ante la sensación de cansancio crónico.

8. La dificultad de llevar a cabo tareas cotidianas se le atribuye a la sensación de cansancio.

9. Percepción de que hay problemas con la memoria a corto plazo.

10. El cansancio después del ejercicio extenuante dura varias horas.

B. Los síntomas ocasionan una alteración clínicamente significativa, o debilidad, o un deterioro en el funcionamiento social, profesional o de otras áreas importantes del comportamiento.

C. Hay signos en la historia clínica, el reconocimiento médico o el resultado de análisis de que los síntomas surgen como consecuencia del cáncer o del tratamiento del mismo.

D. Los síntomas no surgen principalmente como consecuencia de trastornos psiquiátricos simultáneos, como una depresión intensa, trastorno de somatización, o delirium.

Figura 5. Criterio de la ICD-10 para la astenia relacionada con el cáncer 
La astenia tumoral es considerada el síntoma más duradero y quebrantador para los pacientes con cáncer y tiene el mayor impacto en los parámetros de calidad de vida. Es una sensación subjetiva que se expresa de manera física (energía disminuida), cognitiva (atención y concentración disminuida) y afectiva (motivación disminuida) ${ }^{14}$.

La astenia tumoral es el síntoma más común asociado al cáncer y a su tratamiento. La prevalencia estimada varía entre el $60-90 \%$, dependiendo de los criterios diagnósticos utilizados. La astenia es considerada el síntoma más duradero y quebrantador de los pacientes con cáncer y tiene el mayor impacto en los parámetros de calidad de vida ${ }^{15}$.

La National Comprehensive Cancer Network (NCCN) Fatigue Practice Guidelines Panel ha definido la astenia tumoral como "una sensación subjetiva de cansancio relacionado con el cáncer o con su tratamiento, inusual, persistente, y que interfiere con la actividad normal" 16.

Analizando diferentes estudios podremos mostrar con mayor exactitud la frecuencia, incidencia y prevalencia de este fenómeno, tanto en comparación con otros grupos sintomáticos, como en relación a las diferentes fases de la enfermedad oncológica.

En un estudio acerca de la percepción de astenia en pacientes con cáncer en España, un $97,8 \%$ refería haber experimentado este síntoma a lo largo del 
tratamiento oncológico, lo que afectaba notablemente a su estado de ánimo. Además la astenia era considerada el síntoma más limitante para la mayoría de los pacientes, independientemente del sexo o del tipo de tumor ${ }^{17}$.

El 78-96\% de los pacientes oncológicos presenta astenia, sobre todo durante los tratamientos 18 . La astenia aparece en el $50-100 \%$ de los pacientes dependiendo del protocolo de tratamiento al que estén sometidos, pudiendo persistir incluso después de finalizar los mismos. La tasa de aumento de este síntoma está relacionada proporcionalmente con el aumento del número de ciclos de quimioterapia o con los volúmenes de irradiación. El 35-100\% de los pacientes que reciben radioterapia, refieren astenia y su severidad depende de la extensión del volumen que se irradia, independientemente de la localización y del tipo de tumor ${ }^{19,} 20$.

Estos datos demuestran que la astenia es un problema frecuente dentro de la

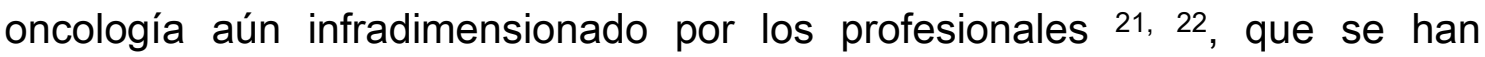
polarizado con el dolor ${ }^{23}$ y la supervivencia libre de recaída, a pesar del gran impacto que aquélla tiene para los pacientes en su calidad de vida.

Paralelamente, la depresión, como desorden que provoca astenia, tampoco recibe la atención adecuada por parte de los oncólogos 24,25 .

Los mismos problemas los encontramos en la sintomatología de anemia, que aún siendo realmente fácil su diagnóstico, observamos cómo se encuentra 
infratratada, a pesar del conocimiento que poseemos con estudios controlados desde hace tiempo, que hablan de que la corrección de las cifras de hemoglobina tienen un efecto altamente positivo en la disminución de los parámetros de astenia, y consecuentemente, en calidad de vida relacionada con la salud 26 .

Gabrilove y sus colaboradores analizaron en cerca de 3.000 pacientes la influencia de la utilización de eritropoyetina, en dos esquemas de administración, a pacientes en tratamiento quimioterápico, y encontraron importantes aumentos en los niveles de hemoglobina, con la consecuente disminución de los requerimientos transfusionales, de la astenia tumoral y un aumento en parámetros de funcionalidad y calidad de vida ${ }^{27}$.

Los oncólogos y los pacientes tienen una diferente percepción acerca de la importancia de la astenia, y, por lo tanto, esta peculiaridad afecta a la prevalencia hallada en las distintas series publicadas 28 . En equipos interdisciplinares, la opinión de los oncólogos es que el dolor es un síntoma clínico más relevante que la astenia (61\% contra $37 \%)$, mientras que por el contrario, los pacientes, cuya opinión se debe priorizar frente a las demás, creen que la astenia afecta mucho más a sus actividades de la vida diaria $(61 \%$ contra $16 \%){ }^{29,} 30$. 
1.4. ETIOPATOGENIA 
ablar de las causas que llevan a inducir el fenómeno de astenia tumoral en los pacientes es cuanto menos complejo, parece ser un fenómeno multifactorial en el que intervienen numerosos mecanismos que lo desencadenan aunque aún hoy en día no podemos afirmar con rotundidad el fenómeno exacto que lo produce.

La hipótesis que se baraja es que existe una interrelación entre las múltiples causas fisiológicas y las psicosociales, estas se agravan mutuamente y el resultado es la presentación compleja de la astenia en personas con cáncer ${ }^{31}$. Ahlberg y colaboradores, en el año 2003, revisaron la literatura existente sobre las causas de la astenia relacionada con el cáncer. Ellos sugieren que hay una serie de causas fisiológicas, físicas y psicológicas que se interrelacionan ${ }^{32}$.

I. Las causas fisiológicas de ésta, relacionándola con el cáncer pueden incluir: 
- Anemia.

- Efectos de los tratamientos para el cáncer (radioterapia, quimioterapia o bioterapia).

- Caquexia y anorexia.

- Carga tumoral (tamaño, lugar y estadio del tumor, así como la presencia o no de metástasis a distancia).

- Aumento en la producción de citocinas.

I. Los factores físicos que intervienen en el desarrollo de esta astenia tumoral son:

- Deterioro pulmonar.

- Disfunción neuromuscular.

- Dolor.

- Deficiencias nutricionales.

- Infección.

- Deshidratación.

- Enfermedad médica simultánea.

- Insuficiencia cardíaca.

Por último, en los estudios sobre la posible implicación de los factores psicológicos que conllevan astenia en el paciente, no está claro si estos son las causas, efectos, o ambos, del síntoma. 
Sin embargo, los factores psicológicos que se han encontrado que tienen una correlación positiva con la presencia de astenia en pacientes con cáncer incluyen:

- Ansiedad.

- Depresión.

- Alteración del ciclo sueño-vigilia o dificultades para conciliar el sueño.

- Situación laboral (ya sea por combinar el trabajo con la enfermedad o por la pérdida del mismo causada por la neoplasia).

- Reducción del funcionamiento físico (reducción de la actividad física o eliminación de la misma).

Estudios más actuales de González Barón y sus colaboradores hablan de la etiopatogenia de la astenia tumoral como un fenómeno multifactorial mucho más complejo, que se resumirá en la figura expuesta a continuación, la cual pasaremos a analizar más adelante ${ }^{33}$. 


\section{ETIOPATOGENIA DE LA ASTENIA TUMORAL}

1. Producción de citoquinas.

2. Trastornos musculares.
a. Pérdida de masa muscular.
b. Acumulación de ácido láctico.
c. Depleción de sustancias energéticas.
d. Alteración en la distribución de isoenzimas musculares.
e. Poliomiositis

3. Trastornos neurológicos.
a. Disfunción de la formación reticular.
b. Síndromes paraneoplásicos.

4. Trastornos metabólicos y endocrinológicos.
a. Diabetes mellitus.
b. Trastornos hidroelectrolíticos.
c. Hipotiroidismo.
d. Insuficiencia suprarrenal.
e. Hipopituitarismo.

5. Infecciones.
a. Víricas.
b. Bacterianas.
c. Fúngicas.

6. Anemia.

7. Tratamientos específicos.
a. Quimioterapia.
b. Radioterapia.
c. Bioterapia.

8. Tratamientos sintomáticos.
a. Opioides.
b. Benzodiacepinas.
c. Antieméticos.
d. Antihistamínicos.
e. Neurolépticos.

9. Sobreesfuerzo.

10. Trastornos psicológicos.

11. Comorbilidad.

12. Progresión tumoral.

13. Astenia después del tratamiento.

Figura 6. Etiopatogenia de la astenia tumoral
A continuación pasaremos a analizar cada uno de los puntos más detalladamente: 


\section{Citoquinas}

Se ha investigado la relación entre la astenia tumoral y los niveles de citoquinas presentes en los individuos, tales como IL-1, IL-2, IL-3, IL-6, TNF e interferones, aunque aún no se conoce el mecanismo exacto que aporte la evidencia necesaria para asociarlo ${ }^{34}$.

Además, sí que hay evidencia científica de que las transfusiones de sangre de individuos con astenia reproducen este síntoma en el sujeto que las recibe ${ }^{35}$, siendo este un hallazgo de gran importancia que nos acerca más a conocer la etiopatogenia de la misma, a partir del cual se comenzó a especular con la existencia de unas sustancias, las "asteninas", que serían sustancias producidas por el mismo paciente y responsables de este fenómeno de astenia tumoral. Estas "asteninas" serían a la astenia tumoral, lo que las "caquectinas" fueron a la caquexia tumoral, con resultados bien diferentes, ya que estas últimas dieron lugar al Factor de Necrosis Tumoral (TNF) identificado posteriormente ${ }^{36}$.

En la actualidad los últimos estudios se realizan partiendo de que las citoquinas proinflamatorias, como TNF- $\alpha$, IL-1 $1 \beta$ o IFN- $\alpha$, participan en la mayoría de los mecanismos propuestos como desencadenantes de la astenia asociada al cáncer, especialmente en supervivientes ${ }^{37}$. El cáncer y sus tratamientos se asocian con una elevación de los niveles plasmáticos de citoquinas, implicadas 
en el desarrollo de anemia, caquexia, anorexia, fiebre, infecciones y depresión, lo que favorece la aparición de astenia ${ }^{38}$.

\section{Trastornos musculares}

La debilidad muscular y la fatigabilidad prematura son dos de las manifestaciones de la astenia, aunque su patogenia aún se desconoce. Hasta ahora tenemos resultados científicos sobre la relación de la astenia tumoral con la pérdida de masa muscular, la malnutrición, la acumulación de sustancias de desecho en músculos, la depleción de sustratos energéticos, la distribución de isoenzimas musculares y la atrofia selectiva de miofibrillas ${ }^{39}$.

a. La pérdida de masa muscular y la malnutrición como causa de astenia: Esta pérdida de masa muscular sólo explicará parcialmente la fatigabilidad. Es bastante frecuente que ambas coexistan, pero también es cierto que hay pacientes oncológicos que sufren astenia en ausencia de malnutrición, como en mujeres con cáncer de mama o pacientes con linfomas. Prueba de ello es un estudio en mujeres con cáncer de mama en el cual no se encuentra relación alguna entre el grado de astenia tumoral y el estado nutricional 40 . Por otro lado, también podemos observar malnutrición severa sin cansancio, tanto en patologías oncológicas como en aquellas no tumorales, en el caso de la anorexia nerviosa. 
b. El exceso en la producción de sustancias de desecho en el músculo se ha relacionado con la astenia: En el momento en el que la actividad muscular se ejercita con déficit de oxígeno se produce ácido láctico, considerando a esta sustancia como la responsable de, al menos en parte, el cansancio. En el caso de pacientes con cáncer, hay evidencia científica de que esta sustancia se encuentra aumentada, sin embargo no se correlaciona con la carga tumoral expresada ${ }^{41}$.

c. La depleción de sustratos energéticos necesarias para la actividad muscular; proteínas, grasa, carbohidratos y sustancias de alto valor energético (adenosintrifosfato, ATP, y creatinquinasa, CK), considerados como el "combustible" para desarrollar actividad muscular, ha sido considerada como causa de astenia.

d. Los trastornos en la distribución de isoenzimas musculares y la atrofia selectiva de miofibrillas como causa de astenia tumoral: La fatigabilidad de la fibra muscular se relaciona directamente con su potencial metabólico oxidativo. Partimos de que existen dos tipos de fibras musculares:

1. Fibras rojas o tipo I: poseen un metabolismo fundamentalmente oxidativo.

2. Fibras blancas o tipo II: poseen un metabolismo anaeróbico glicolítico y se fatigan rápidamente. 
Varios estudios han demostrado, en biopsias obtenidas de pacientes con cáncer una atrofia más marcada de las fibras musculares tipo II, aún en ausencia de pérdida de peso o disminución de la ingesta ${ }^{42}$. A partir de estos resultados observamos como la atrofia es claramente selectiva, pudiendo incidir en el desarrollo de astenia, pero carecemos de estudios más importantes que correlacionen científicamente ambos fenómenos.

Además de lo expuesto, hemos de mencionar una enfermedad muscular conocida como polimiositis, que cursa con debilidad de los músculos proximales de los miembros, especialmente en caderas y muslos. Su etiología es desconocida por el momento, aunque se sospecha implicaciones con factores genéticos. Los tumores más frecuentes con este fenómeno son por orden de incidencia: pulmón, ovario, mama y tubo digestivo. Esta patología también podría contribuir a la aparición de astenia 43.

\section{Trastornos neurológicos}

Dentro de este apartado encontramos dos supuestos que inducirían astenia en el paciente oncológico, la disfunción de la formación reticular y los síndromes paraneoplásicos.

a. Disfunción de la formación reticular: La formación reticular del sistema nervioso central es la encargada de controlar la percepción de 
cansancio, por lo tanto la estimulación crónica de la formación reticular genera astenia tumoral, como resultado de una respuesta anormal de este sistema reticular a estímulos ambientales, corticales y hormonales. Si aplicamos esta hipótesis a la práctica clínica diaria es consecuente ver como el $70 \%$ de los pacientes que reciben radioterapia holocraneal se encuentren cansados después del tratamiento ${ }^{44}$. Por lo que podemos afirmar científicamente que una alteración de la formación reticular cursa con astenia tumoral.

b. Síndromes paraneoplásicos: Los síndromes neurológicos paraneoplásicos son muy poco frecuentes. En el caso de la astenia tumoral, hay un síndrome paraneoplásico que la desencadena, este es el síndrome de Lambert-Eaton. Consiste en un trastorno del componente presináptico de la transmisión neuromuscular. La neoplasia más comúnmente asociada a este síndrome es el carcinoma microcítico de pulmón. La sintomatología presente es de astenia y debilidad simétrica de predominio proximal, con mayor incidencia en miembros inferiores ${ }^{45}$.

\section{Trastornos metabólicos y endocrinológicos}

En este apartado encontramos cinco supuestos que inducen o pueden inducir astenia al paciente, diabetes mellitus, trastornos hidroelectrolíticos, 
hipotiroidismo, insuficiencia suprarrenal, hipopituitarismo. Es muy importante detectar todas estas situaciones ya que son potencialmente tratables.

\section{Infecciones}

Hoy en día conocemos que la caquexia y la infección comparten como mediador bioquímico el factor de necrosis tumoral (TNF). La hipótesis que se postula es que esto mismo ocurra entre astenia e infección, es decir, que otra de las citoquinas liberadas en los procesos infecciosos ("astenina") pudiera ser la causante de la astenia en los pacientes. Sin embargo, esta asociación aún no se ha encontrado por lo que no podemos hablar de evidencias científicas, sino de hipótesis ${ }^{46}$.

\section{Anemia}

Tanto la enfermedad neoplásica en sí misma como combinada con su tratamiento pueden producir concentraciones bajas de hemoglobina en sangre por lo que dada su relevancia y los numerosos estudios que se han desarrollado al respecto hablaremos detalladamente de la anemia en el apartado 1.7. 


\section{Tratamientos específicos}

Es bien conocido que los tratamientos antineoplásicos producen astenia en los pacientes como efecto secundario. El mecanismo por el cual la producen aún no es del todo conocido y es diferente en función de cada una de las intervenciones. Estamos hablando tanto de cirugías, quimioterapia, radioterapia como de bioterapias.

a. Quimioterapia: La astenia experimentada por los pacientes con tratamiento de quimioterapia mieloablativa sigue un patrón cíclico: comienza en los primeros días del ciclo, alcanza su máximo nivel coincidiendo con el "nadir" leucocitario y disminuye en la semana posterior para reaparecer con el siguiente ciclo. Esta astenia tiende a empeorar con la administración de cada nuevo ciclo, lo que sugiere como hipótesis que se trata de un efecto secundario acumulativo dosisdependiente. Además también debemos hablar de la neutropenia afebril, un fenómeno muy presente en cada tratamiento quimioterápico, este fenómeno neutropénico desencadena grandes intensidades de astenia tumoral en los pacientes. El motivo de estos niveles asténicos no están bien claros pero todo parece indicar que el recuento de leucocitos también podría tener relación con la sensación de bienestar de los pacientes ${ }^{47}$. 
b. Radioterapia: La astenia asociada al tratamiento radioterápico se debe al aumento de las necesidades de energía empleadas en la reparación de los epitelios lesionados por el tratamiento. En este caso la intensidad de la astenia tumoral es muy aguda, comienza presentándose en altos niveles de cansancio pero dura poco tiempo, siendo independiente del tipo de tumor o región irradiada ${ }^{48}$. Además no debemos olvidar el hecho ya mencionado en el apartado III de que la radioterapia holocraneal producía una disfunción de la formación reticular, la cual era causante de astenia tumoral 49 .

\section{Tratamientos sintomáticos}

En general las intervenciones en astenia tumoral se realizan desde un punto de vista farmacológico, los fármacos más normalmente empleados son los corticoesteroides y los psicoestimulantes.

Los primeros han demostrado una disminución de la astenia, aunque su mecanismo de acción no es bien conocido. Sin embargo, el uso prolongado de éstos puede contribuir a la astenia por inducir miopatía, infección y otras complicaciones 50 .

Los segundos se han utilizado para tratar la somnolencia inducida por los opioides, reducir la intensidad del dolor, tratar la depresión y mejorar la 
cognición. La ventaja de éstos es su acción rápida, pero sus desventajas serán efectos secundarios como la agitación, la ansiedad y el insomnio. Todos estos pueden favorecer secundariamente el aumento de los parámetros de astenia.

Además, los opioides, las benzodiacepinas, los antieméticos, los antihistamínicos y los neurolépticos son fármacos utilizados con frecuencia en los pacientes oncológicos. Todos ellos tienen un efecto sobre el sistema nervioso central y pueden contribuir a desarrollar esta sensación de cansancio 51.

\section{Sobreesfuerzo}

El "sobreesfuerzo" es una causa frecuente de astenia en la población general, por lo que partiendo de esta premisa creemos debemos tenerlo en cuenta en el caso de pacientes oncológicos. No es infrecuente encontrar personas que, a pesar de estar sometidos a tratamientos agresivos y de presentar patologías oncológicas, intentan mantener su mismo ritmo de vida social y laboral. Cierto es que el intento de llevar una vida activa contribuye a no desarrollar astenia tumoral en los pacientes, pero este sobreesfuerzo también puede conllevar el efecto contrario, por lo que se debe racionalizar los esfuerzos con las capacidades de cada persona. 


\section{Trastornos psicológicos}

En la sociedad actual, la causa más frecuente de astenia en la población sana son los trastornos psiquiátricos, entre el $40-60 \%$ de los pacientes que acuden a Atención Primaria acusando un cansancio "crónico" presenta un trastorno de ansiedad o depresión ${ }^{52}$. Estudios realizados en pacientes oncológicos han encontrado una prevalencia de sintomatología depresiva en pacientes oncológicos que oscila entre el $15-25 \%{ }^{53}$. En el trabajo del que hablábamos en el punto (II a.) un proyecto realizado en mueres con cáncer de mama avanzado, se intentó correlacionar la astenia con diversas variables; de todas ellas sólo se halló correlación estadísticamente significativa con la depresión ${ }^{54}$.

\section{Progresión tumoral}

Conforme progresa la patología oncológica pueden aparecer diversas complicaciones que inciden en la aparición de la sintomatología de astenia, estás son: derrame pleural o pericárdico, ascitis, metástasis cerebrales y hepáticas, síndrome de vena cava superior. Su clínica característica puede inducir secundariamente astenia tumoral. 


\section{Astenia tumoral después del tratamiento}

Podemos definir la astenia referida después del tratamiento como aquella que experimentan los pacientes que se encuentran libres de enfermedad tumoral pasados seis o más meses de terminar la quimioterapia.

La etiología de este fenómeno es desconocida, pero se piensa que debe ser diferente a la que padecen los pacientes con enfermedad neoplásica o que están recibiendo tratamiento activo. Aunque aún no se puede establecer una hipótesis que avale este hecho, el único camino a descartar será el de la patología psiquiátrica.

La mayor parte de las investigaciones sobre astenia en las personas con cáncer se ha llevado a cabo en grupos de personas bajo tratamiento para el cáncer, y unos pocos estudios se enfocan hacia las personas que reciben cuidados paliativos. Por último algunas investigaciones se han realizado en grupos de personas que han terminado el tratamiento. En general se ha informado que la astenia relacionada con el tratamiento del cáncer está presente en $14 \%$ a $96 \%$ de las personas que se encuentran en tratamiento ${ }^{55}$.

En un estudio transversal realizado en Noruega se comparó la prevalencia de la astenia en pacientes con cáncer de testículo supervivientes a largo plazo ( $\mathrm{n}$ $=1.431)$ con un promedio de 11 años después del tratamiento con la incidencia de astenia en hombres de la misma edad en la población general noruega $(n=$ 
1.080). La prevalencia de astenia crónica relacionada con el cáncer fue de $17,1 \%$ (95\% intervalo de confianza [IC], 15,2-19,1\%) en los supervivientes de cáncer de testículo, comparada con 9,7\% (IC 95\%, 8,0-11,5\%) en la población general. La astenia crónica relacionada con el cáncer también se relacionó con varios problemas psicosociales, síntomas somáticos y una calidad de vida precaria 56 .

En la actualidad se siguen formulando más hipótesis acerca de causas que conllevan astenia en pacientes oncológicos. En un reciente estudio Rodríguez y colaboradores, en el año 2012, establecen una serie de mecanismos fisiopatológicos implicados en la aparición de la astenia relacionada con el cáncer ${ }^{57}$, estos quedan expresados en la figura expuesta a continuación:

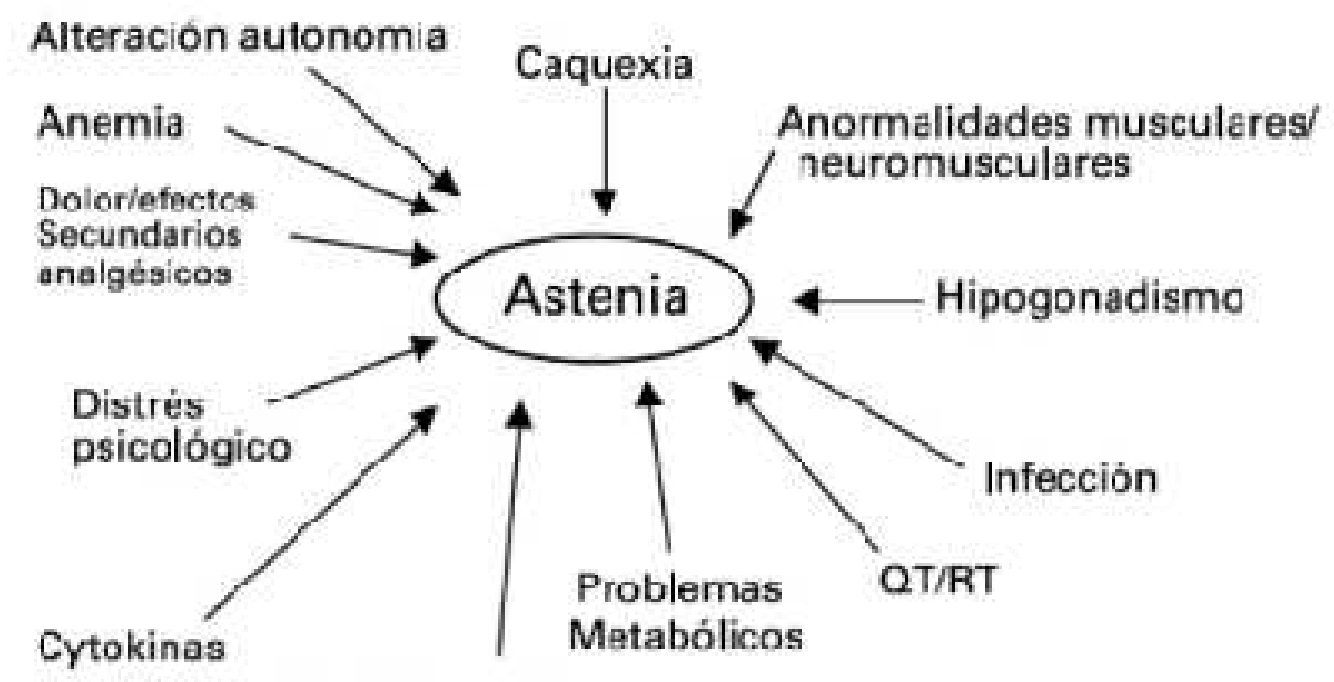

Deshidratación

Figura 7. Fisiopatología de la astenia relacionada con el cáncer 
La mayoría de ellos han sido tratados anteriormente en diversos puntos, pero en ese mismo artículo se abordan tres nuevas hipótesis causales que nos llevarían a presentar astenia tumoral, estas son: Disfunción del eje hipotálamohipófisis-adrenal, alteración del ritmo circadiano y activación de las vías vagales aferentes.

$\checkmark$ Disfunción de eje hipotálamo-hipófisis-adrenal (HHA): El eje HHA es el encargado de regular la liberación de cortisol en respuesta al estrés físico o psicosocial. Se ha observado como la astenia se asocia a niveles bajos de de cortisol, que podrían ser debidos a una supresión directa del eje HHA por el tratamiento antitumoral (quimioterapia, corticoides o radioterapia) o a cambios en $5-\mathrm{HT}$, disminuyendo su estimulación y causando problemas en la liberación de la hormona liberadora de corticotropina $(\mathrm{CRH})^{58}$.

$\checkmark$ Alteración del ritmo circadiano: En los pacientes oncológicos se han demostrado cambios en el ritmo circadiano, que incluyen cambios en los ritmos hormonales (secreción de cortisol), los procesos metabólicos (niveles circulantes de proteínas o temperatura corporal), en el sistema inmune (niveles leucocitarios) o en los patrones de actividad descanso 59. 
$\checkmark$ Activación de vías vagales aferentes: Tanto la propia patología oncológica, como sus tratamientos pueden inducir la liberación periférica de agentes neuroactivos que estimulan vías vagales aferentes. Esta liberación provocará la supresión de la actividad de la musculatura somática y la inducción de una "conducta de enfermedad" 60 , un estado que se manifiesta clínicamente con sintomatología de somnolencia, falta de apetito, dificultad de concentración y malestar general. En este caso hablamos de una hipótesis reciente que carece de estudios aplicados directamente sobre seres humanos, no así en animales de laboratorios. 


\subsection{BASES BIOLÓGICAS DE LA ASTENIA ASOCIADA AL CÁNCER}


os principios moleculares de la astenia asociada al cáncer son poco conocidos y menos integrados en un cuerpo de conocimiento concreto. Los estudios sobre astenia tumoral van enfocados hacia otras vertientes, más clínicas, evaluando su incidencia o su etiopatogenia, pero aún no se han desarrollado los modelos animales adecuados para el estudio de este síntoma.

Este síntoma conductual representa una lucha de estrategias biológicas de elevadísima complejidad molecular entre el huésped y la neoplasia, en un intento de supervivencia evolutiva entre ambas especies químicas. La armonía entre las redes de señalización química precisas para el desarrollo de una homeostasis normal queda alterada con la presencia de la enfermedad neoplásica, lo que genera una gran cantidad de sustancias químicas que alteran el complejo sistema de comunicación intra e intercelular ${ }^{61}$.

Las citoquinas proinflamatorias: interleuquina 1 (IL-1), interleuquina 6 (IL-6), los interferones (IFN) o el factor de necrosis tumoral alfa (TNFa) se liberan activando un sistema de señalización neuronal que transmitirá señales aferentes, siendo también secretadas al torrente sanguíneo alcanzando la barrera-hemato-encefálica (BHE). Ésta se encuentra inusualmente 
impermeable al paso de cualquier sustancia, lo que permite que penetren tanto en el Sistema Nervioso Central (SNC), como en los óganos periventriculares (OPV) y en el plexo coroideo, lo que como consecuencia activará una segunda vía de señalización neuronal que alcanzará el complejo amigdalino, modificando la conducta. Con esto queremos decir que existen evidencias suficientes que sugieren que la astenia asociada al cáncer puede estar producida por múltiples mediadores bioquímicos 62 .

De forma muy general se han dividido estos mecanismos básicos de la astenia tumoral en dos grupos 63 :

1. Mecanismos periféricos: Todos aquellos que modifican el estatus energético del huésped.

2. Mecanismos centrales: En los que se incluyen alteraciones en las funciones neurales del eje hipotálamo-hipófiso-adrenal, y las alteraciones intrínsecas en los circuitos neuronales implicados en la percepción de astenia 64.

Esta clasificación se encuentra limitada por el hecho de que los mediadores bioquímicos implicados en los mecanismos periféricos son también producidos por el sistema nervioso central. Además, éstos son capaces de atravesar la BHE y ejercer su efecto en el SNC modificando sus parámetros de actividad. 
Por ello, debemos comprender esta visión única y exclusivamente para clarificar la posterior exposición, pero nunca como dos sistemas distintos.

Salvo en la anemia inducida por la quimioterapia, se desconoce el mecanismo responsable de este cansancio crónico en las personas con cáncer. Entender las causas del cansancio en los pacientes de cáncer es un reto especial debido a que cada individuo experimenta múltiples causas posibles del cansancio crónico de manera simultánea. Esta hipótesis etiológica multifactorial se hace presente en los distintos modelos que se propusieron en el estudio del cansancio crónico. Se desconoce el mecanismo preciso que causa o que fomenta la fatiga en los pacientes de cáncer, es probable que muchos

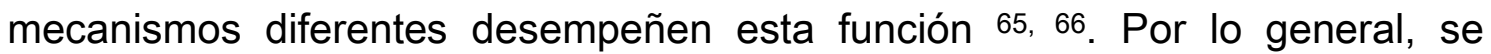
incorpora en estos modelos el balance energético, la tensión, las demandas en actividades de la vida diaria, el sueño, los cambios neurofisiológicos, interrupción del ritmo circadiano, afecciones cardíacas y cambios neuroinmunitarios, sobre la base de que estos factores se relacionan con el cansancio en otros contextos diferentes al cáncer 67 . La literatura sobre el cáncer respalda algunas de estas variables.

Hay una cantidad creciente de pruebas, en particular de mujeres con cáncer de mama y hombres con cáncer de próstata, en que el cansancio se relaciona con marcadores que indican un aumento en la actividad inflamatoria inmunitaria. Cuando las personas con cansancio crónico y antecedentes de cáncer de 
mama se les compara con supervivientes de cáncer sin este tipo de cansancio, surgen patrones diferentes con respecto a la interleucina 6 , interleucina 1 , receptores antagonistas, proteína reactiva $\mathrm{C}$, neopterin y el receptor-II del factor de necrosis tumoral soluble 68, 69 70. Aunque se desconoce la relación precisa (y el significado clínico de estas relaciones), es probable que el aumento de citocinas contribuya con los síntomas de cansancio, astenia y letargo, según lo confirman estudios llevados a cabo en modelos animales, inducidos mediante citocinas a una conducta de enfermedad 71,72 , al igual que en humanos ${ }^{73}$. Aún no se han realizado estudios grandes bien controlados que evalúen los efectos de fármacos antiinflamatorios generales sobre el cansancio o los biomarcadores de citocina.

Otros estudios muestran un cambio en la regulación del cortisol por el eje hipotálamo-hipófisis suprarrenal. Un estudio clave sometió a supervivientes de cáncer de mama con cansancio o sin este, a una serie de pruebas de tensión en el entorno controlado de un laboratorio. Los supervivientes sin cansancio crónico presentaron un aumento significativo del cortisol en respuesta a la tensión aguda, mientras que los supervivientes con cansancio crónico presentaron una respuesta menos activa 74 . Otro estudio mostró que las supervivientes de cáncer de mama redujeron los picos de cortisol, al presentar índices más altos de este hacia el final del día, que los supervivientes que no presentaban cansancio crónico 75 . Es la desregulación del eje hipotálamo- 
hipofisario suprarrenal (HHS) la que podría ser responsable de la inflamación prolongada en el entorno citocínico. Entender la respuesta corporal a numerosos tensionantes crónicos durante el cáncer podría ayudar al manejo del cansancio crónico.

Otra teoría es que las citocinas inciden de forma negativa en la serotonina a través de la exposición crónica a citocinas proinflamatorias. Una hipótesis es que la relación entre las concentraciones de serotonina en el sistema nervioso central y el cansancio mantiene una relación en forma de herradura, lo que indica que las concentraciones de serotonina ya sean muy altas o muy bajas, podrían estar relacionadas con el cansancio crónico o fatiga relacionada con el cáncer ${ }^{76}$. Sin embargo, hay estudios que evaluaron fármacos serotonérgicos que no logran mostrar beneficio alguno contra el cansancio crónico ${ }^{77}$. Queda por entenderse del todo la función y la relación que desempeñan mucho de los neurotrasmisores importantes tales como la dopamina, norepinefrina y serotonina con el funcionamiento del eje HHS y la expresión de la citocina ${ }^{13}$. 


\section{LA CONDUCTA DE ENFERMO O "THE SICKNESS BEHAVIOUR"}

Los esfuerzos encaminados a ofrecer una posible luz en la patogenia molecular de la astenia asociada al cáncer han confluido hacia la conclusión de que no es posible obtener una explicación única para un síndrome producido por patologías tan heterogéneas como son los tumores malignos ${ }^{78}$. Además, la elevación aislada de ciertas citoquinas no siempre conlleva la inducción de astenia, como se ha demostrado en algunos estudios. Por otro lado, la mayoría de los estudios llevados a cabo en humanos han determinado niveles séricos de citoquinas que, como ya hemos comentado, son capaces de alcanzar el SNC y producir cambios conductuales severos ${ }^{79}$.

Si excluimos específicamente a los síndromes asteniformes inducidos por fármacos, estamos hablando de astenia asociada a anemia inducida por quimioterapia, insuficiencia suprarrenal inducida por esteroides y otros, el hipercatabolismo y la destrucción muscular provocada por ciertas citoquinas puede jugar un papel importante en la astenia asociada al cáncer ${ }^{80}$.

Todo esto lo único que nos hace sacar en claro es que existe una compleja red de señalización química, originada tanto en diversos niveles del huésped como 
en el tumor, lo que provoca respuestas coordinadas, a pesar de que las entendamos como síndromes patológicos, en términos clínicos.

En los últimos años ha surgido una importante corriente de pensamiento basada en estudios de infusión de citoquinas proinflamatorias en modelos animales que ha intentado integrar todos los datos de comportamiento y sintomatología neuropsíquica asociada, y que, tras su extrapolarización a la patología humana, ha concluido con la definición del "Sickness behaviour" o "conducta de enfermos" 81.

Cada vez hay más evidencia de que muchos síntomas físicos y psíquicos de los pacientes con cáncer tienen un componente biológico, que surge ante los intentos del propio organismo de luchar contra la patología neoplásica a la vez que intenta mantener una homeostasis integral. El "Sickness behaviour" es una constelación de conductas que acompañan a la enfermedad en general y en particular a la inflamación. Las citoquinas proinflamatorias que se liberan durante la respuesta a la transformación maligna, producen esta "conducta de enfermo", incluyendo tanto a la astenia tumoral como a estado de ánimo depresivo, enlentecimiento psicomotor, aislamiento social, alteraciones del sueño, disfunción cognitiva e incremento en la sensibilidad al dolor 82 - 95 .

Como conclusión, podemos decir que no puede entenderse la astenia como una sintomatología aislada sin comprender que está incluida dentro de un 
síndrome molecular parcialmente caracterizado y que, puede producir otros síntomas muy relevantes en el paciente con enfermedad neoplásica progresiva. La enfermedad puede considerarse como un estado motivacional que reorganiza la percepción y la acción. El paciente no tiene las mismas prioridades que un individuo sano y esta reorganización de prioridades está mediada por los efectos que las variaciones en los patrones de expresión de citoquinas, independientemente de sus fuentes de producción, producen en su SNC 96. 


\subsection{INSTRUMENTOS DE EVALUACIÓN DE ASTENIA RELACIONADA CON EL CÁNCER}


a evaluación de la astenia tiene un carácter multidimensional. Existen una gran cantidad de instrumentos elaborados originalmente para la investigación de la astenia crónica que en la actualidad también se usan en la práctica clínica. La mayoría de estos instrumentos incluyen dimensiones de síntomas, además de la intensidad, tales como la incidencia y consecuencias de la astenia crónica, momento del cansancio, síntomas relacionados con esto y acciones para el autocuidado 97,98 .

Tanto la carencia de medios óptimos específicos que se encargan de evaluar los niveles de astenia, como la ambigüedad de la literatura existente han creado siempre múltiples dificultades en el establecimiento concreto de pautas de evaluación y control de este problema. La evaluación integral del paciente con cansancio crónico comienza con la obtención de una anamnesis detallada para describir la modalidad del cansancio del individuo e identificar todos los factores que contribuyen a su presentación 99.

En el paciente oncológico debe valorarse la presencia de astenia desde la primera visita, realizando posteriormente reevaluaciones periódicas con el fin de iniciar, si es necesario, un tratamiento precoz y eficaz 100. 
Se han utilizado diferentes técnicas y desarrollado diversos instrumentos para evaluar la astenia. Aunque muchos investigadores consideran que la astenia es un fenómeno multidimensional, el número y las dimensiones siguen debatiéndose y ello queda reflejado en los instrumentos utilizados.

Para la elección de un instrumento en la práctica clínica pensamos se deben valorar las siguientes características:

- Brevedad y sencillez.

- Fácil de aplicar.

- Fiable y válido para el grupo poblacional al que va dirigido.

- Sensible a los cambios en el tiempo.

Existen multitud de escalas que sirven para valorar astenia, tanto en el paciente oncológico, como en otro tipo de patologías. En la siguiente figura las resumimos 101: 


\section{INSTRUMENTOS DE VALORACIÓN DE ASTENIA}

\section{POBLACIÓN GENERAL \\ 1. Pearson and Byars Fatigue Feeling Check list 102. \\ 2. Profile and Mood States (POMS)} Fatigue and Vigor subscales 103.

3. Rhoten Fatigue Scale 104.

4. Fatigue Severity Scale ${ }^{105 .}$

5. Multidimensional Fatigue Inventory (MFI) 106.

6. Escala analogical visual (EVA).

7. The Profile Mood States Fatigue/Inertia Subscale.

8. Lee's Visual Analogue Scale for Fatigue ${ }^{107 .}$

9. Fatigue Impact Scale 108.
PACIENTE ONCOLÓGICO

1. EORTC QLQ-C30 109, 110.

2. Fatigue Symptom Checklists of Kogi, adapted by Kobashi 111 .

3. Piper Fatigue Scale (PFS) 112, 113.

4. Edmonton Functional Assessment Tool (EFAT) ${ }^{114}$.

5. Escala de Moran ${ }^{115}$.

6. Schwartz Cancer Fatigue Scale 116, 117 .

7. Functional Assessment of Cancer Therapy-Fatigue (FACT-F) 118, 119.

8. Fatigue Sympton Inventory (FSI) 120, 121.

9. Multidimensional Fatigue Sympton Inventory (MFSI) 122.

10. Brief Fatigue Inventory (BFI) ${ }^{123,}$ 124.

11. The Functional Assessment of Cancer Therapy-Anemia ${ }^{125}$.

12. Cancer Fatigue Scale ${ }^{126 .}$

13. Multidimensional Fatigue Inventory 127.

14. Fatigue Scale ${ }^{128}$.

15. Cuestionario para la Percepción de la Fatiga en Pacientes Oncológicos su Realidad y Medición (PERFORM) ${ }^{129 .}$ 
Detallamos a continuación las características de las escalas más utilizadas en la actualidad para medir la incidencia de astenia tumoral en los pacientes oncológicos:

I. Fatigue Scale: Escala autoaplicada, desarrollada por Chalder y sus colaboradores en 1993, cuyo objetivo era valorar la gravedad o intensidad de la astenia. Se compone de 14 ítems, que incluyen la astenia física (8 ítems) y la astenia mental (6ítems). Muestra propiedades psicométricas buenas y estables entre poblaciones ${ }^{130}$, una adecuada fiabilidad y consistencia interna (Alfa de Cronbach 0,8903). Su gran limitación es que los descriptores de cansancio mental son muy limitados.

II. The EORTC quality of life questionnaire QLQ-C30 110: Fue desarrollada por Aaranson y sus colaboradores en el año 1993. Contienen las siguientes dimensiones: física, psicológica, social, funcional y global, con 30 ítems totales, su problema, es que resulta demasiado larga. En cuanto a su fiabilidad presenta un Alfa de Cronbach de entre 0,52-0,89, test-retest $0,70-0,85$. Su adaptación la llevaron a cabo Arraras JL y sus colaboradores.

III. Functional Assessment of Cancer Therapy (FACT) 120, 121: Fue desarrollada en el año 1993. Contiene las siguientes dimensiones: física, psicológica, social, funcional y de relación con el médico. Consta de 33 
ítems, su principal problema es su gran extensión. Presenta una fiabilidad Alfa de Cronbach de 0,89, test-retest 0,82-0,88. Con una gran sensibilidad al cambio. Existe una subescala utilizada actualmente por el grupo ASTHENOS.

IV. The Piper Fatigue Scale 112: Fue desarrollada por Piper y sus colaboradores en el año 1989. Consta de 22 ítems y cuatro subescalas. El Alfa de Cronbach para la escala completa es de 0,97 , indicando la excelente fiabilidad para un instrumento estable. El problema de esta escala es que su actualización no se ha llevado a cabo, lo que la ha hecho desaparecer de los estudios más actuales sobre astenia tumoral.

Para la realización de nuestro estudio hemos tenido en cuenta una serie de variables fundamentales a la hora de escoger cuestionario de evaluación de astenia tumoral.

- Brevedad.

- Amplitud de dimensiones a valorar.

- Autoaplicación del paciente, para evitar los sesgos propios de las entrevistas.

Por ello, hemos escogido el Cuestionario para la Percepción de la Fatiga en Pacientes Oncológicos su Realidad y Medición (PERFORM) (ANEXO I), 
desarrollado por el grupo ASTHENOS, grupo de trabajo para el estudio de la astenia tumoral.

\section{Cuestionario para la Percepción de la Fatiga en Pacientes Oncológicos su Realidad y Medición (PERFORM)}

Hasta la elaboración del cuestionario PERFORM, no se conocía un instrumento para evaluar la astenia relacionada con el cáncer que hubiera sido desarrollado y validado íntegramente en España, lo que significaba que ciertos aspectos, relevantes para nuestros pacientes oncológicos, no estarían siendo valorados al utilizar cuestionarios procedentes de otros contextos socioculturales. Estos cuestionarios reflejan y evalúan un determinado concepto de CVRS que puede no encajar con la realidad de los pacientes españoles, porque el concepto de CVRS puede diferir según el entorno cultural ${ }^{11 .}$

El objetivo de este cuestionario era desarrollar el primer cuestionario español para evaluar las percepciones sobre la astenia relacionada con el cáncer en pacientes oncológicos, para uso en la práctica clínica diaria.

El proceso de construcción del Cuestionario PERFORM empezó en el año 2004 y fue desarrollado en diversas fases sucesivas, que permitieron que el cuestionario cumpliera con los estándares y requisitos establecidos por Comité Científico Asesor del Medical Outcomes Trust (MOT) ${ }^{132 .}$ Las fases del desarrollo del cuestionario se describen a continuación 133: 


\section{Primera fase (2004)}

En una primera fase se obtuvo el contenido del cuestionario y la definición de las características básicas del mismo mediante la revisión de los principales cuestionarios existentes para la evaluación de la astenia relacionada con el cáncer. Adicionalmente, se realizó una reunión con expertos clínicos y expertos en la medida de resultados en salud para determinar las características que debería tener el cuestionario. También se realizaron grupos de discusión con pacientes oncológicos en distintos lugares de España. Del análisis de la información obtenida a partir de las anteriores iniciativas, se generó un listado inicial de ítems potenciales para el cuestionario que evaluaban la percepción de los pacientes oncológico respecto a la astenia ${ }^{134}$.

\section{Segunda fase (2004 - 2005)}

Durante la fase de construcción de medidas centradas en el paciente es habitual generar más ítems que los que se van a utilizar en realidad en la versión final de dichos cuestionarios, para poder elegir una combinación óptima de ítems que pasan a constituir el contenido final del cuestionario. La selección de dichos ítems se realizó siguiendo criterios estadísticos y metodológicos principalmente, seleccionando únicamente aquellos ítems que cumplen unos determinados requisitos psicométricos (fiabilidad, validez y sensibilidad al cambio), a lo largo de un proceso largo y complejo. Esto fue precisamente lo 
que se llevó a cabo durante la segunda fase del proyecto: se redujo la cantidad inicial de ítems candidatos a formar parte del cuestionario, mediante un estudio de campo en el cual se administró el conjunto inicial de ítems a 250 pacientes oncológicos con astenia de diferente intensidad. Los sucesivos análisis realizados en el marco de esta recogida de datos permitieron seleccionar 12 ítems de entre los 75 enunciados iniciales. Estos 12 ítems se distribuyeron en 3 dimensiones: Actividades habituales, Limitaciones físicas, y Actitudes y creencias.

\section{Tercera fase. Validación (2005-2007)}

Una vez identificado el contenido del Cuestionario PERFORM, llegó el momento de comprobar que sus 12 ítems funcionaban realmente como una herramienta de medida. El proceso de validación es un requisito imprescindible antes de utilizar cualquier cuestionario o herramienta de medida centrada en el paciente, pues aporta evidencias de que el grupo de ítems que constituyen el cuestionario se comportan de forma coherente a como deberían comportarse si el cuestionario fuera efectivamente una herramienta de medida. La validación de un cuestionario suele centrarse en la evaluación de sus propiedades psicométricas: su fiabilidad, validez y sensibilidad al cambio.

La validación del Cuestionario PERFORM fue realizada con el objetivo de comprobar su correcto funcionamiento psicométrico. Para ello, el nuevo 
Cuestionario PERFORM fue administrado a una muestra de 437 pacientes oncológicos con astenia relacionada con el cáncer ${ }^{135}$. Durante esta fase, el cuestionario mostró propiedades psicométricas adecuadas y sólidas para ser utilizado en práctica clínica habitual ${ }^{136}$.

Las principales características del cuestionario derivadas del estudio de validación pueden resumirse del siguiente modo:

a. El Cuestionario PERFORM mostró una buena viabilidad: el promedio de ítems perdidos por paciente fue inferior a 1 , y el $80 \%$ de pacientes completó la totalidad del cuestionario. El tiempo medio necesario para la administración del cuestionario fue inferior a 9 minutos. Más del $80 \%$ de pacientes consideraron el cuestionario fácil o muy fácil de completar. Las puntuaciones extremas fueron muy infrecuentes $(<5 \%)$, siendo esto un indicador de que el cuestionario cubre bien el rango de intensidad del síntoma de la muestra estudiada.

b. La consistencia interna de la medida fue muy satisfactoria, tanto a nivel global como por dimensiones con un valor Alfa de Cronbach global de 0,935 .

c. La fiabilidad test-retest en el grupo de pacientes definidos como estables también fue muy satisfactoria, tanto a nivel global como por dimensiones con un coeficiente de correlación intraclase global de 0,832. 
d. Además, el cuestionario presenta evidencias sólidas de validez de modo que se correlaciona de forma consistente con medidas de salud debidamente desarrolladas y validadas, como el cuestionario específico FACT-F (correlación 0,8) y el cuestionario genérico Perfil de Salud de Nottingham (correlación 0,69). Se correlaciona también de forma consistente con variables relacionadas con el estado de salud, como el índice Karnofsky, la intensidad de la astenia medida por escala analógica visual o el nivel de cuidados requeridos. Adicionalmente se asoció de forma significativa con los niveles de hemoglobina del paciente $(p=0,0163)$.

e. Finalmente, tanto la puntuación global como las puntuaciones de las dimensiones del Cuestionario PERFORM se mostraron sensibles a los cambios en el estado de salud autopercibido por el paciente, especialmente cuando este cambio suponía un empeoramiento.

En conclusión, podemos afirmar que el cuestionario PERFORM ha sido desarrollado según los estándares internacionalmente aceptados para el desarrollo y la validación de herramientas de medida centradas en el paciente.

Es una herramienta que ha probado ser viable, fiable, válida y sensible al cambio, y cuya corta extensión (sólo 12 ítems) la hace muy adecuada para su uso en la práctica clínica especializada, unas de las variables que teníamos 
nosotros en cuenta a la hora de escoger instrumento de medida, para así evitar que el paciente se sienta "agredido" ante tanta evaluación.

Los ítems del cuestionario se distribuyen en 3 dimensiones: actividades habituales (4 ítems), actitudes y creencias (4 ítems) y limitaciones físicas (4 ítems). Lo que hace que el cuestionario nos muestre valores no solo sobre la incidencia de la sintomatología de la astenia en sí misma, sino que también establece parámetros de funcionalidad de los pacientes.

Por lo que podemos afirmar que actualmente se dispone de un test ajustado a la realidad de los pacientes oncológicos con astenia tumoral en España.

Además, a pesar de que la publicación definitiva del cuestionario es muy reciente, existen ya estudios, con una gran metodología que comienzan a dar resultados sobre los índices de astenia tumoral en los pacientes oncológicos y su correlación con diferentes variables 137 - 140 . 


\subsection{ASTENIA Y ANEMIA EN PACIENTES ONCOLÓGICOS}




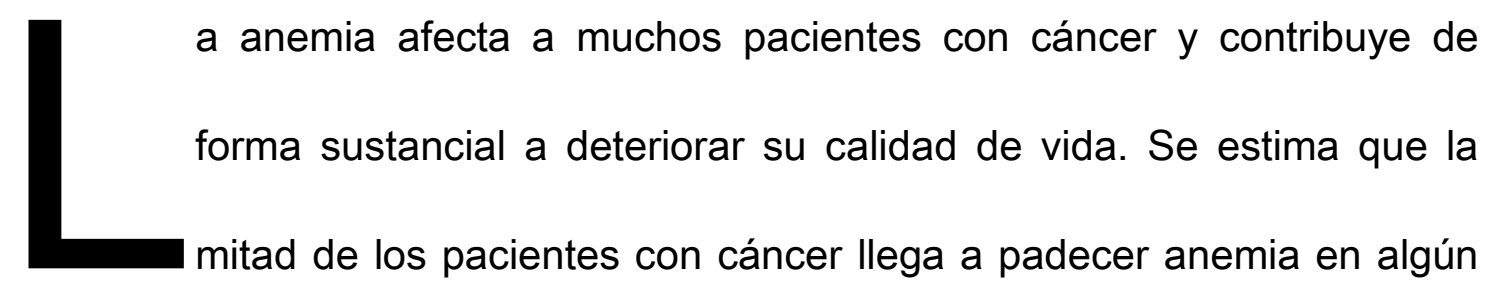
momento de su evolución, porcentaje muy superior en aquéllos con tumores avanzados 141,142 . Las causas posibles son múltiples, pero entre ellas destacan los trastornos crónicos, la toxicidad debida a quimioterapia, la radioterapia o la cirugía y las pérdidas crónicas ${ }^{143}$. Con una menor frecuencia observamos invasión medular por tumor, déficit de hierro o vitamina B12 o un hiperesplenismo. Aunque es muy habitual que coexistan dos de estos factores en el mismo momento, como puede ser el caso de la anemia inducida por los trastornos crónicos y aquella inducida por los tratamientos. 


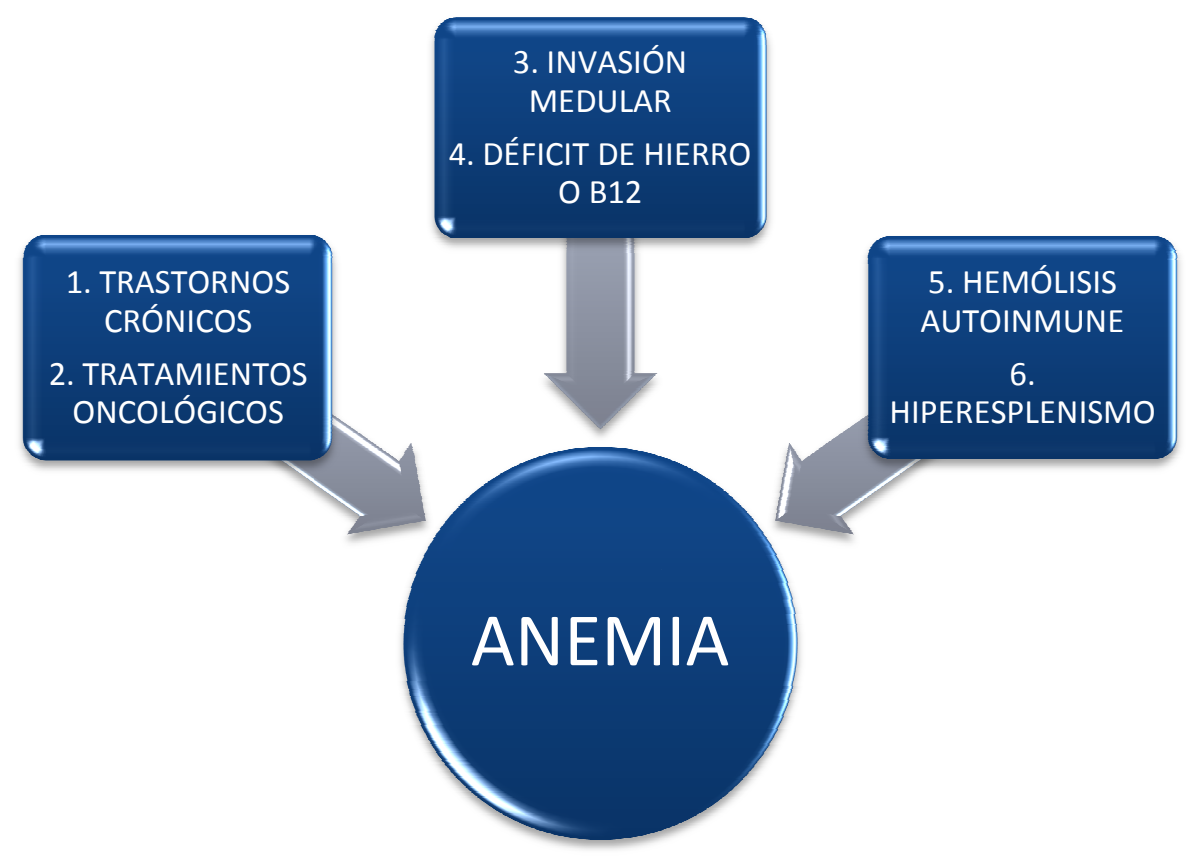

Figura 9. Causas de anemia en el cáncer

La anemia de trastornos crónicos está directamente producida por el tumor, que induce la sobreproducción de algunas citocinas, como es el caso de la interleucina 1, interferones beta y gamma, factor de necrosis tumoral alfa 0 factor transformante del crecimiento beta 144 .

Cualquier tipo de tumor puede acabar produciendo una anemia de trastornos crónicos, aunque determinados tumores tienen una mayor tendencia a presentar síndromes anémicos desde estadios precoces: leucemias, cáncer de pulmón, tumores del tubo digestivo o cáncer de riñón. Por el contrario, los tumores cerebrales no dan lugar a este tipo de problemas por si solos, mientras que los sarcomas de partes blandas o el cáncer de mama sólo la ocasionan en estadios avanzados de la enfermedad ${ }^{145}$. 
Cuando se habla de la incidencia de la anemia, también debemos tener en cuenta de qué grado de anemia estamos valorando. No será lo mismo presentar valores de anemia grado 3 (niveles de hemoglobina entre 6,5 y 8 $\mathrm{g} / \mathrm{dl}$ ) y grado 4 (niveles de hemoglobina menores a $6,5 \mathrm{~g} / \mathrm{dl}$ ), que valores leves de síndrome anémico (niveles de hemoglobina entre 9,5-11 g/dl); siendo la frecuencia del síndrome anémico leve la mayor, y en muchos casos infratratada e infravalorada, con el riesgo que ello conlleva en forma de comorbilidades, cuyo caso más evidente será el de la astenia tumoral ${ }^{146 .}$

Revisamos algunos estudios sobre incidencia de anemia en cáncer.

- En una revisión de anemia relacionada con quimioterapia se encuentra, que los esquemas de quimioterapia para cáncer de pulmón ocasionaba anemia de grados 1 y 2 en porcentajes ciertamente variables, tornándose en un $50 \%$. Aunque en alguna serie prácticamente afectaba a todos los pacientes de la muestra; esto mismo sucedía en carcinomas de mama avanzado, colon, ovario y cabeza y cuello 147.

- En un estudio con una muestra n=1064 pacientes, más de la mitad de los enfermos presentaba anemia después de tres ciclos de quimioterapia 148.

- En el caso de la radioterapia, hay estudios que datan un $48 \%$ de pacientes con anemia antes del tratamiento físico; mientras que eleva 
esa incidencia hasta el $57 \%$ en el caso de haber transcurrido la intervención ${ }^{149}$.

Tras todo esto, hemos de mencionar que la astenia tumoral es el síntoma más frecuente de la anemia, si bien, como hemos visto en apartados anteriores, la anemia no es ni mucho menos la única causa de astenia en los pacientes oncológicos. Pero su importancia reside en que en este caso, el tratamiento existe y es válido.

\subsubsection{ASTENIA Y ANEMIA}

La astenia es uno de los síntomas más constantes en los pacientes que presentan anemia. Se puede afirmar que existe una relación lineal entre ambos síntomas, pero aún no podemos precisarla completamente, científicamente hablando, por problemas metodológicos de los estudios existentes. Aún así, en los estudios desarrollados se sitúa en $12 \mathrm{~g} / \mathrm{dl}$ el límite a partir del cual los pacientes comienzan a presentar síntomas ${ }^{150}$.

Obviamente, el nivel de hemoglobina refleja con total exactitud el grado de anemia. En el caso de que se presente una anemia severa, el paciente presentará astenia; pero esto no tiene que ser siempre así en los casos en los que se dé una situación intermedia en cuanto a niveles de anemia. 
Tras plantearse esta problemática se procedió a desarrollar escalas de valoración de anemia junto a otros síntomas relacionados con la astenia.

Hay dos escalas ampliamente implantados hoy en día:

1. La europea QLQ-C30 (de la European Organisation for Research and Treatment of Cancer, EORTC) ${ }^{151 .}$

2. La Americana, Functional Assessment of Cancer Therapy (FACT) 152.

Ambas escalas provienen de estudios realizados sobre calidad de vida, el problema es que el concepto de calidad de vida es un tanto difuso y abarca varias esferas: física, emocional, social y espiritual. Por lo que la validez de estas escalas en cuanto a la sintomatología de astenia es escasa.

Por todo ello, en el caso de la FACT, se ha intentado aumentar la especificidad de la escala mediante el diseño de una subescala específica para anemia, FACT-an, que consta de 20 ítems ${ }^{120}$, de los cuales 13 se encuentran directamente relacionados con la astenia. 


\subsubsection{ERITROPOYETINA}

Hasta la llegada de la eritropoyetina (EPO), la única opción disponible para tratar la anemia era la transfusión de hematíes. Este hecho hacía, que debido a factores tales como la escasez de sangre o el riesgo de transmisión de infecciones, el momento de transfusión se demoraba hasta que la anemia era muy sintomática, con valores por debajo de $9 \mathrm{~g} / \mathrm{dl}$ de hemoglobina.

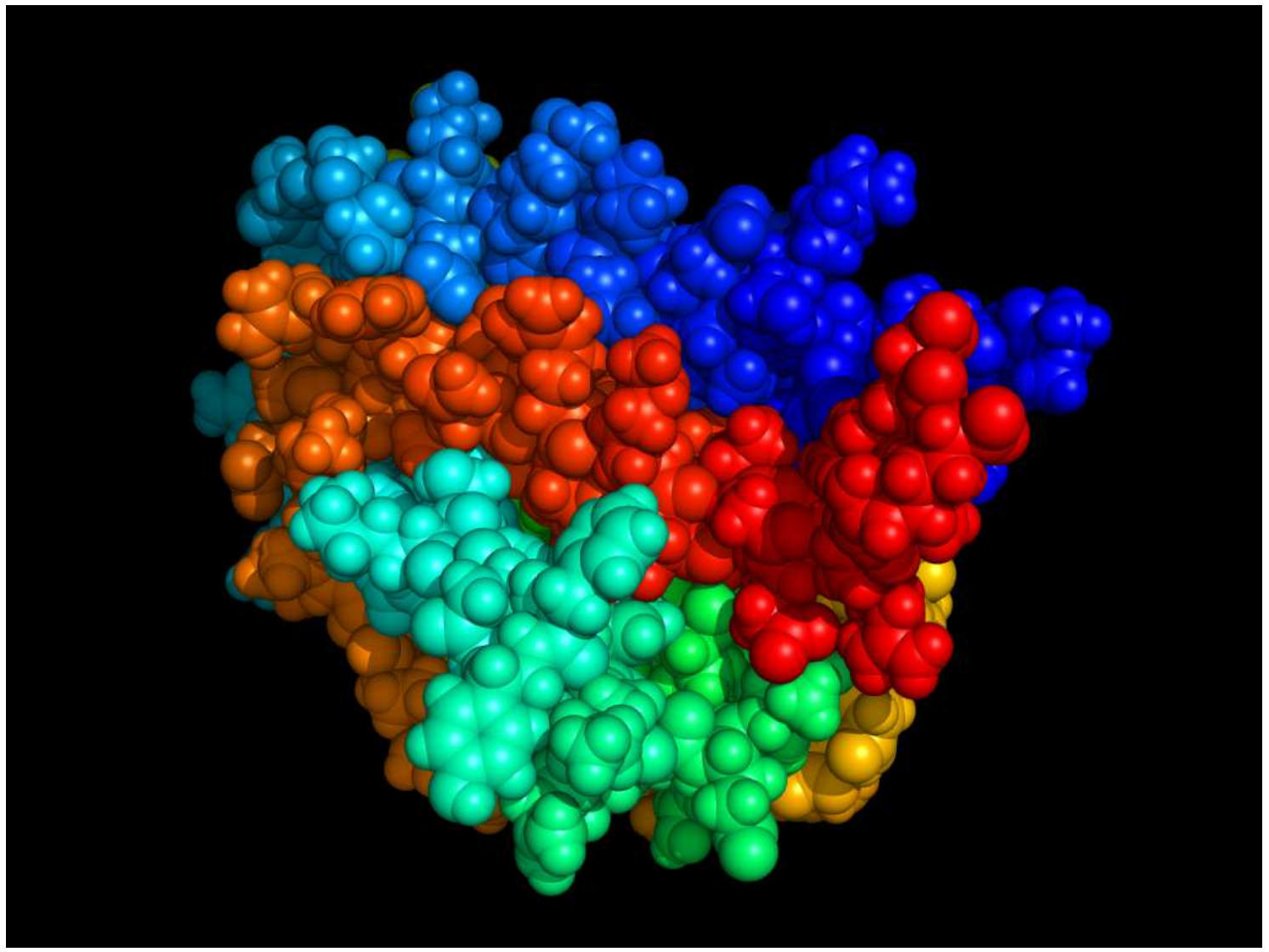

Figura 10. Eritropoyetina (EPO)

La EPO ha venido a resolver este problema en los pacientes que responden a su administración. Su mecanismo de actuación es el de impedir la apoptosis de los precursores de eritroides a través de la estimulación de bcl-2 y bcl- $\mathrm{X}_{\mathrm{L}}{ }^{153}$. 
La ventaja de la EPO con respecto a las trasfusiones radica en que en el caso de la primera, el tratamiento para la anemia puede llevarse a cabo incluso con niveles de hemoglobina superiores a $9 \mathrm{~g} / \mathrm{dl}$. Sin embargo, no tiene mucho sentido administrar EPO a pacientes con cifras de hemoglobina muy bajas, entre $8-9 \mathrm{~g} / \mathrm{dl}$, puesto que el efecto beneficioso tardaría demasiado tiempo en observarse, y en estos casos los pacientes necesitan una solución rápida, ya que entre otras cosas presentarán unos índices de astenia tumoral ciertamente elevados y fácilmente solucionables. Por el contrario, tampoco se plantea la transfusión cuando la cifra de hemoglobina se encuentre en valores comprendidos entre los 11-12g/dl.

El resumen de todo esto es que en el caso de astenia inducida por anemia, el tratamiento a llevar a cabo será el de control de la anemia, ya sea mediante intervención transfusional o uso de EPO, pero lo que si queda ampliamente demostrado es que la astenia se corrige de forma significativa en el caso de que se corrija la anemia en los pacientes 154, 155, 156.

La eficacia de la EPO para corregir la anemia está suficientemente demostrada, el problema que se plantea es el hecho de que no todas las personas responden a esta sustancia. SI tuviéramos que hacer algún tipo de definición para la respuesta a la EPO esta sería "elevación en la cifra de hemoglobina de al menos $2 \mathrm{~g} / \mathrm{dl}$ sin que medie una transfusión después del primer mes de tratamiento. La mayoría de los pacientes que va a responder lo 
hace después de los dos primeros meses de tratamiento, si bien un aumento en la dosis puede aumentar ese tiempo de actuación dos tercios de los mismos no lo harán, bien sea con la dosis inicial de $150 \mathrm{U} / \mathrm{kg}$ tres veces por semana (50\% de respuestas) o al duplicar la dosis (dos tercios) 157, 158.

Por lo que aquí tenemos un gran inconveniente a la hora de usar este tipo de estrategias que contribuirá primariamente al control de la anemia y secundariamente a las comorbilidades consecuentes de la misma, la astenia tumoral 159 .

Por lo que, tras lo expuesto, la principal asignatura pendiente en el tratamiento de la anemia con EPO es la identificación precoz de los pacientes que no responderán; además de conocer los motivos por los cuales los pacientes no responden y si es posible desarrollar otro tipo de sustancias útiles en tal circunstancia.

Otro de los detalles importantes a tener en cuenta es la posibilidad de que la EPO favorezca el crecimiento de tumores, como algunos autores han presentado en forma de hipótesis aun sin una respuesta científicamente objetiva.

Como conclusión no debemos olvidar que la anemia es sólo una de las causas de astenia en el paciente oncológico. Las demás causas, especialmente el síndrome de caquexia están menos estudiadas, pero cada vez tienen una 
repercusión mayor en el desarrollo de proyectos de investigación que nos lleven a conocer mejor esta sintomatología y nos ayuden a controlarla. 
1.8. SÍNDROME DE LA

ANOREXIA-CAQUEXIA 
a regulación del apetito y de los patrones alimenticios está mediada por diferentes factores psicológicos, gastrointestinales, metabólicos y nutricionales, así como por distintos mecanismos neuronales y endocrinos. El paciente canceroso anoréxico experimenta una sensación de saciedad precoz y una disminución del apetito. Las causas de estas son múltiples y entre ellas destacamos 160:

- El propio tratamiento anticanceroso (quimioterapia, radioterapia o inmunoterapia), que pueden inducir náuseas y vómitos en diferentes grados.

- Alteraciones en la percepción de la comida.

- Causas psicológicas (depresión).

En ocasiones la anorexia puede deberse a un efecto directo del tumor, cuando éste se localiza en el hipotálamo o en el propio aparato digestivo ${ }^{161}$. Sin embargo, en la mayoría de los casos el origen de la anorexia asociada a 
caquexia parece ser las alteraciones metabólicas que sufre el paciente como consecuencia de la presencia del tumor.

La ingestión de alimentos es una función compleja, en cuyo control se integran a nivel hipotalámico diferentes señales periféricas y centrales, tanto neuronales como endocrinas, participando en ella el sistema nervioso central, el hígado y el tracto gastrointestinal, entre otros.

Entre los mediadores principales destaca el neuropéptido $Y$, molécula clave en la respuesta hipotalámica que induce la ingesta y disminuye el gasto energético 162.

Otra molécula clave es el factor liberador de corticotropina, un neuropéptido hipotalámico de carácter catabólico que induce anorexia e incrementa la actividad del sistema nervioso simpático, con el consiguiente aumento del gasto energético.

También se ha sugerido que los elevados niveles plasmáticos de lactato, ácidos grasos libres y algunos aminoácidos (como el triptófano), o las alteraciones en el ambiente endocrino, pueden tener un papel en la anorexia.

Asimismo, diferentes factores tanto de origen humoral y segregados por el huésped en respuesta al crecimiento tumoral, o bien segregados por las propias células tumorales, podrían jugar un papel importante en la respuesta anoréxica. Entre los primeros destaca el factor de necrosis tumoral-alfa, una 
citoquina que parece ser la responsable de la mayor parte de las alteraciones metabólicas características de la caquexia cancerosa ${ }^{163}$.

\section{Definición}

La anorexia-caquexia es un síndrome metabólico complejo que resulta del efecto opuesto entre dos fuerzas: uno el intento del tumor por alterar el metabolismo del huésped en su provecho y otro el intento desesperado del huésped de aislar, deprivar de nutrientes y matar a las células tumorales. Los componentes primarios de este síndrome son: anorexia, pérdida de peso, pérdida y atrofia de masa muscular 164.

Estos síntomas pueden aparecer antes de hacer el diagnóstico del tumor. La malnutrición conduce a complicaciones en el tratamiento tanto quirúrgico como médico, con tendencia a infecciones y disminución de la respuesta inmune. La adecuada administración de calorías y nutrientes y el soporte nutricional es ineficaz y no consigue revertir el proceso.

La pérdida involuntaria de peso (mayor del $5 \%$ ), el consumo de la masa magra, el bajo "performance status" y la anorexia constituyen el síndrome de la caquexia cancerosa. En el momento del diagnóstico el $80 \%$ de los pacientes con tumores gastrointestinales y el $60 \%$ de los pacientes con cáncer de pulmón han experimentado una pérdida sustancial de peso. En más del $20 \%$ de los pacientes la caquexia es la causa de la muerte ${ }^{165}$. Una vez que el síndrome 
anorexia-caquexia se ha instaurado es irreversible, a pesar de un aporte hipercalórico y proteico adecuado por vía enteral o parenteral 166. Esta circunstancia nos obliga a tener que tomar medidas nutricionales preventivas desde que el paciente con cáncer es diagnosticado.

Los orígenes de la anorexia-caquexia han de buscarse en dos aspectos fundamentales 167 :

1. Incremento en la demanda calórica debido a la presencia del tumor.

2. Malnutrición debida a la anorexia.

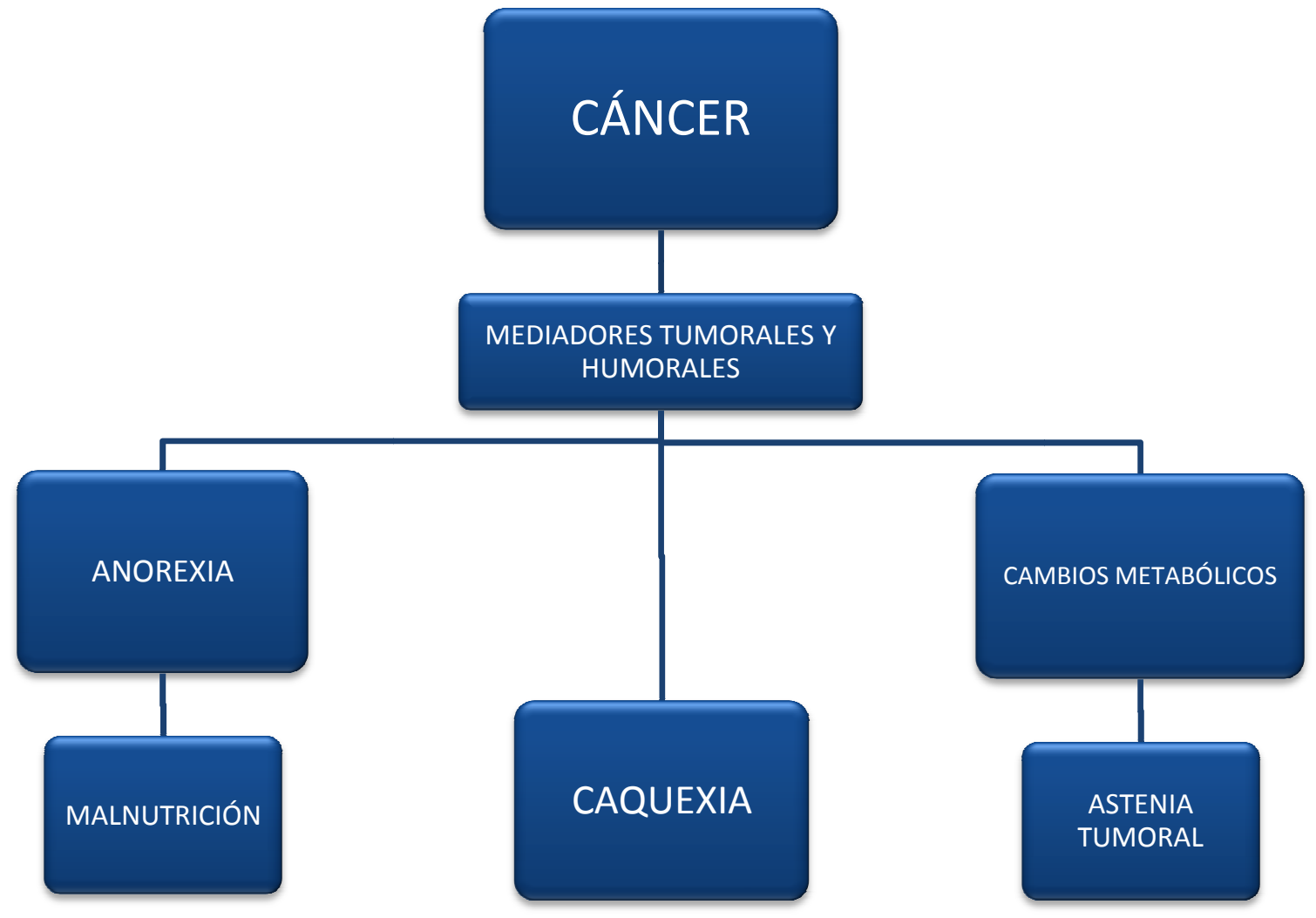

Figura 11. Mediadores del proceso caquéctico 
La respuesta caquéctica asociada al cáncer se caracteriza tanto por la presencia de anorexia como por profundas alteraciones metabólicas que conducen a una acelerada pérdida de peso y debilitamiento muscular del paciente. Ambas cosas, sin ningún género de dudas contribuirán en desarrollar el fenómeno de astenia tumoral en los individuos. Lo que como consecuencia desarrollará una merma en su funcionalidad y calidad de vida.

\section{Incidencia}

La pérdida del deseo de comer (anorexia) se presenta en el $15 \%$ al $25 \%$ de todos los pacientes en el momento del diagnóstico y posteriormente se agrava con los tratamientos oncológicos y la progresión de la enfermedad.

Es de causa multifactorial incluyendo factores tumorales, del huésped y del tratamiento oncológico específico. El síndrome paraneoplásico multiorgánico sistémico más frecuente en cáncer es el de anorexia-caquexia, que conduce a la malnutrición calórico-proteica marcada y la pérdida de peso. En el reciente estudio nutricional NUPAC (2000) en 772 pacientes con cáncer avanzado o metastático, realizado en Unidades o Servicios de Oncología Médica, Oncología Radioterápica o Cuidados Paliativos. 
En España, la prevalencia de malnutrición y/o pérdida de peso es del 52\%, estos datos son similares a los referidos en relación con la pérdida de peso en el año 1980 por Dewys y sus colaboradores 168 .

\section{Etiología}

La etiología es múltiple e intervienen también factores del tratamiento quimioradioterápico y quirúrgico. La anorexia del cáncer está inducida por un aumento de la actividad serotonérgica en el hipotálamo. Además de otros factores como alteraciones del gusto y del olfato, retraso del vaciamiento gástrico, aversión por determinados alimentos, los tratamientos de cirugía, radioterapia y quimioterapia contribuyen a la anorexia y pérdida de peso de los pacientes. La quimioterapia (QT) citotóxica es una piedra angular del tratamiento oncológico, que en la actualidad es curativa en el $20 \%$ de los pacientes y ayuda a paliar la enfermedad en el $80 \%$ restante. Hoy en día podemos decir que casi el 100\% de los pacientes con cáncer recibirán QT en algún momento de la evolución de su enfermedad ${ }^{169}$. Al contrario que la cirugía y la radioterapia, la QT es un tratamiento sistémico del cáncer y afecta a todo el organismo, incluyendo las células sanas en fase proliferativa, por lo que tiene más efectos no deseados y más diversos que las terapias locales. Los efectos secundarios de la QT que afectan al aparato gastrointestinal tienen repercusiones relevantes sobre la nutrición, como son: los cambios en la 
percepción de olores y sabores, las náuseas y vómitos, la anorexia, la saciedad precoz, la mucositis, la diarrea y/o estreñimiento 170 .

\section{Anormalidades metabólicas asociadas al síndrome caquexia-anorexia} 171

\begin{tabular}{|c|l|}
\hline \multirow{4}{*}{ Metabolismo proteínas } & Síntesis muscular disminuida \\
\cline { 2 - 2 } & Degradación muscular aumentada \\
\cline { 2 - 2 } & Aumento turnover proteico \\
\cline { 2 - 2 } & Aumento síntesis proteica hepática \\
\hline \multirow{4}{*}{ Metabolismo carbohidratos } & Gluconeogénesis aumentada (aa y lactato) \\
\cline { 2 - 2 } & Resistencia a la insulina \\
\cline { 2 - 2 } & Aumento reutilización glucosa \\
\hline Metabolismo grasas & Lipolisis aumentada \\
\cline { 2 - 2 } & Hiperlipedemia (ácidos grasos libres) \\
\cline { 2 - 2 } & Aumento turnovcr gliccrol \\
\cline { 2 - 2 } & Lipogénesis disminnuida \\
\cline { 2 - 2 } & Actividad lipoproteínlipasa disminuida \\
\hline Metabolismo basal & Aumentado \\
\hline
\end{tabular}

Figura 12. Anormalidades metabólicas en la caquexia

Las consecuencias sobre el paciente de la malnutrición energético- proteica (PEM) son múltiples, intensas y a diferentes niveles.

Comprometen no sólo el estado de salud (inmunosupresión), sino también la calidad de vida percibida y la respuesta terapéutica de la enfermedad. El personal sanitario se ocupa de las dolencias físicas pero suele descuidar las reacciones emocionales de sus pacientes 172, 173. En el plano emocional se produce miedo y ansiedad y en el plano cognitivo el individuo cree que el 
tratamiento no es efectivo y tiene sensación de avance de la enfermedad. El cambio de imagen, la astenia intensa y la pérdida de fuerza conducen a una autoestima baja. En el plano conductual la persona se aísla socialmente y puede abandonar el tratamiento ${ }^{174}$.

Una buena prevención puede ayudar a evitar que se ponga en marcha todo el proceso. Una vez más es válido el aforismo "más vale prevenir que curar". 


\subsection{CALIDAD DE VIDA EN EL PACIENTE ONCOLÓGICO}




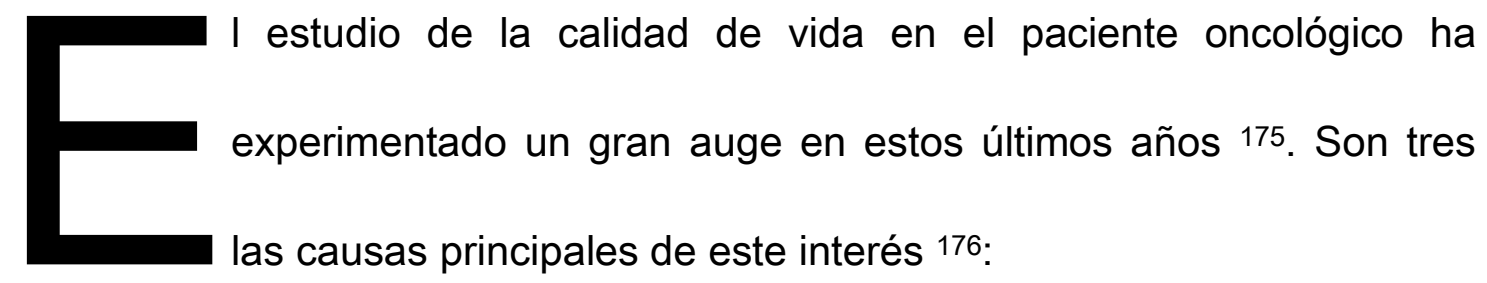

1. En primer lugar, el reconocimiento de que muchos tumores avanzados no pueden curarse, lo cual ha llevado a potenciar los cuidados paliativos.

2. En segundo lugar, el aumento de independencia del paciente a la hora de la toma de decisiones: mientras que los médicos persiguen la prolongación de la supervivencia de los enfermos incurables (a veces a costa de mucha toxicidad), éstos suelen estar más interesados en no perder su autonomía física y en padecer el menor número de síntomas.

3. En tercer y último lugar, en tercer y último lugar la optimización de los recursos económicos que exige la incorporación de nuevos fármacos o nuevas técnicas terapéuticas cuyo objetivo sea al menos conseguir un beneficio sintomático apreciable aunque no siempre puedan prolongar la supervivencia.

La calidad de vida es un objetivo en salud que está adquiriendo cada vez mayor importancia ${ }^{177}$ y ha comenzado a utilizarse como medida de resultados 
en salud ${ }^{178}$, especialmente en situaciones en que las actuaciones en salud ya no pueden ir principalmente dirigidas a prolongar la duración de la vida, como ocurre en las personas de edad avanzada con pluripatologías crónicas ${ }^{179}$.

Diversos autores han definido el concepto de calidad de vida, siendo la subjetividad siempre un componente esencial de esas definiciones. Por ejemplo, para la OMS 180 la Calidad de Vida es «la percepción que cada individuo tiene de su posición en la vida en el contexto del sistema cultural y de valores en que vive y en relación con sus metas, expectativas, estándares y preocupaciones». Éste es un concepto amplio, del que forman parte elementos como la salud física, el estado psicológico, el nivel de independencia, las relaciones sociales de la persona y su relación con el ambiente que le rodea.

El estudio de la calidad de vida es complicado por cuanto su concepto resulta difícil de definir. En el bienestar de un sujeto intervienen múltiples factores, pero los que nos interesan son los relacionados con la salud, y por consiguiente, a partir de ahora en adelante hablaremos del concepto de calidad de vida relacionada con la salud (CVRS). La CVRS, más utilizada en ciencias de la salud, "evalúa la repercusión de la enfermedad o estado de salud, su tratamiento y otros cuidados sanitarios en la dimensión social y personal del paciente" 181. 
En la mayoría de los casos estos niveles de CVRS se relacionan con los niveles de funcionalidad, cognición u ocupación de los individuos. El estudio de todos los factores implicados ha llevado al uso de escalas complejas y a la aparición de una bibliografía profusa y cada vez más especializada.

La calidad de vida tiene interés en cuanto que se puede medir. Para este fin se han desarrollado diferentes cuestionarios o escalas. Estas escalas suelen incluir tanto preguntas generales sobre el bienestar como otras referidas a síntomas más concretos, como el de fatiga o el dolor.

Las más primitivas fueron el índice de Karnofsky ${ }^{182}$ (hoy se considera insuficiente porque solo sólo atiende a la esfera física) y el de Katz ${ }^{183}$ (considerado demasiado escaso en términos de información).

Actualmente se recurre a escalas generales que cuentan con subescalas para distintos tumores; entre ellas destacan la Europea de la European Organisation for the Research and Treatment of Cancer (EORTC) 184, 185 y la norteamericana Functional Assessment of Cancer Treatment (FACT) ${ }^{186}$, por ser las más difundidas y estar validadas en Español.

Estas dos escalas y sus variantes son aplicables a población general de pacientes con cáncer, especialmente con enfermedad activa o tratamiento en marcha. No son útiles en las siguientes circunstancias: 
- Fase final de la vida: en la fase que precede a la situación de agonía los pacientes no toleran cuestionarios largos. Además las preocupaciones espirituales cobran especial importancia, mientras que los síntomas físicos aumentan en número y cambian cada poco tiempo.

- Secuelas a largo plazo: los supervivientes del cáncer se enfrentan a problemas laborales, sociales y económicos, además de prestar atención a las deformidades o incapacidades que haya dejado la enfermedad. Esto ha obligado a crear cuestionarios especiales ${ }^{187}$.

- Personas que cuidan a los pacientes con cáncer: se han desarrollado herramientas específicas para los cuidadores ${ }^{188}$.

Decidimos excluir estos cuestionarios debido a su extensión y a la utilización en nuestro estudio de otros instrumentos de evaluación de la sintomatología y problemas que acompañan a la astenia

Existe otro cuestionario validado y muy empleado para la medición de calidad de vida en los pacientes, este es el SF-36. El SF- 36 se convirtió en la encuesta de salud más utilizada en todo el mundo, porque es breve, pero completa, y de probada utilidad en la medición del estado de salud y su seguimiento en las poblaciones, tanto generales como específicas. Sin embargo, incluso el SF- 36 se consideró demasiado largo, por lo que en respuesta a estas cuestiones, se elaboró su versión reducida, el SF-12 V2 (ANEXO II), el cual utilizaremos en nuestro estudio. 


\section{DESCRIPCIÓN DEL CUESTIONARIO DE SALUD $\mathrm{SF}-12$}

El cuestionario de Salud SF-12 es la adaptación realizada para España por Alonso y colaboradores 189,190 del SF-12 Health Survey ${ }^{191,}$ 192. El SF-12 es una versión reducida del Cuestionario de Salud SF-36 diseñada para usos en los que éste sea demasiado largo. El SF-12 se contesta en una media de inferior a dos minutos, mientras que el SF-36, su administración oscilará de un tiempo de entre 5 y 10 minutos mínimos.

El SF-12 ha demostrado ser una alternativa útil cuando el tamaño de muestra es elevado (200 individuos o más) debido a la pérdida de precisión con respecto al SF-36.

Existen dos versiones del Cuestionario de Salud SF-12. La versión 1 se desarrolló en EE.UU. en 1994 y la versión 2 en 2002, con el objetivo principal de permitir obtener puntuaciones de las ocho dimensiones del SF-36 (la versión 1 sólo permite obtener dos puntuaciones sumario). En nuestro estudio utilizaremos la segunda versión.

Las modificaciones respecto a la versión 1 son básicamente de dos tipos:

1. Mejoras en instrucciones y presentación destinadas a facilitar la autoadministración.

2. Número de opciones de respuesta. 


\section{Concepto medido}

Este instrumento proporciona un perfil del estado de salud y es una de las escalas genéricas más utilizadas en la evaluación de los resultados clínicos, siendo aplicable tanto para la población general como para pacientes con una edad mínima de 14 años y tanto en estudios descriptivos como de evaluación. Incluyendo en ellos a los pacientes con patología oncológica.

\section{Administración}

Se trata de un cuestionario auto-administrado, lo que elimina posibles sesgos a la hora de llevarlo a cabo por parte del entrevistador; aunque también se ha utilizado administrado mediante un profesional en entrevista personal, telefónica o mediante soporte informático. El tiempo de cumplimentación es inferior a dos minutos.

Dimensiones e ítems

Consta de 12 ítems provenientes de las 8 dimensiones del SF-36:

1. Función Física.

2. Función Social.

3. Rol físico.

4. Rol Emocional. 
5. Salud mental.

6. Vitalidad.

7. Dolor corporal.

8. Salud General.

Las opciones de respuesta forman escalas de tipo Likert que evalúan intensidad o frecuencia.

El número de opciones de respuesta oscila entre tres y seis, dependiendo del ítem.

\section{Cálculo de las puntuaciones}

La versión 1 sólo permite obtener dos puntuaciones sumario. La versión 2 permite obtener, además de las puntuaciones sumario, las ocho dimensiones del SF-36.

Las dos puntuaciones resumen son: medida sumario física y mental.

Para facilitar la interpretación éstas puntuaciones se estandarizan con los valores de las normas poblacionales, de forma que 50 (desviación estándar de 10) es la media de la población general. Los valores superiores o inferiores a 50 deben interpretarse como mejores o perores, respectivamente, que la población de referencia. 
Para cada una de las 8 dimensiones, los ítems son codificados, agregados y transformados en una escala que tiene un recorrido desde 0 (el peor estado de salud para esa dimensión) hasta 100 (el mejor estado de salud).

Tanto para la recodificación de ítems como para la obtención de la puntuación de las escalas son necesarios los algoritmos de puntuación documentados o el software disponible, emitido por Quality-metric. 


\subsection{TERAPIA OCUPACIONAL}

EN ONCOLOGÍA 


\subsubsection{DEFINICIÓN}

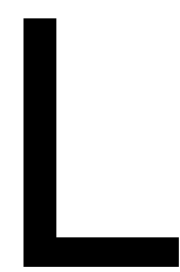

a implantación de la terapia ocupacional en España es bastante reciente, y aún hoy en día es ciertamente desconocida por la población en general. Para acercarnos al concepto y lo que conlleva enunciaremos las principales definiciones obtenidas de organismos nacionales e internacionales:

La Terapia Ocupacional es, según la definición de la Organización Mundial de la Salud (OMS) ${ }^{193:}$

"El conjunto de técnicas, métodos y actuaciones que, a través de actividades aplicadas con fines terapéuticos, previene y mantiene la salud, favorece la restauración de la función, suple los déficits invalidantes y valora los supuestos comportamentales y su significación profunda para conseguir la mayor independencia y reinserción posible del individuo en todos sus aspectos: laboral, mental, físico y social". 
La Federación Mundial de Terapeutas Ocupacionales (WFOT) por su parte dice 194:

"La terapia ocupacional es una profesión sanitaria centrada en el cliente interesado en promover la salud y el bienestar a través de la ocupación. El objetivo principal de la terapia ocupacional es permitir a la gente participar en las actividades de la vida diaria. Los terapeutas ocupacionales logran este resultado mediante el trabajo con las personas y las comunidades para mejorar su capacidad de participar en las ocupaciones que quieren, necesitan, o se espera que lo haga, o mediante la modificación de la ocupación o el medio ambiente para apoyar mejor su participación en el trabajo".

La Asociación Americana de Terapeutas Ocupacionales (AOTA) la define como 195:

"La Terapia Ocupacional es la utilización terapéutica de las actividades de autocuidado, trabajo y lúdicas para incrementar la función independiente, mejorar el desarrollo y prevenir la discapacidad. Puede incluir la adaptación de las tareas o el ambiente para lograr la máxima independencia y mejorar la calidad de vida".

La definición de la Asociación Canadiense de Terapeutas Ocupacionales (CAOT) dice 196: 
"Terapia ocupacional es una profesión de las ciencias de la salud que provee servicios a los individuos cuya capacidad para funcionar en su vida cotidiana está alterada como consecuencia de enfermedad o daños físicos, de problemas del desarrollo, del proceso de envejecimiento, de enfermedades mentales o problemas emocionales. Los objetivos de la Terapia Ocupacional son asistir al individuo para que alcance un estilo de vida independiente, productivo y satisfactorio. Los terapeutas ocupacionales utilizan actividades adaptadas para incrementar el funcionamiento del individuo y su productividad".

El Comité Europeo de Terapeutas Ocupacionales (COTEC) define la Terapia Ocupacional como 197:

"Profesión de la salud que se fundamenta en el conocimiento y la investigación de la relación que existe entre la salud, la ocupación y ambiente en el bienestar de la persona ante la presencia de limitaciones físicas, cognitivas, sociales, afectivas y/o ambientales que alteran su potencial de desarrollo y su desempeño ocupacional; que utiliza actividades significativas para la persona teniendo como objetivo final restaurar, mantener y/o desarrollar habilidades necesarias para integrarse y participar en su esfera biopsicosocial". 
Según la Asociación Profesional Española de Terapeutas

Ocupacionales (APETO) la terapia ocupacional es ${ }^{198:}$

"Disciplina socio-sanitaria que evalúa la capacidad de la persona para desempeñar las actividades de la vida cotidiana e interviene cuando dicha capacidad corre un riesgo o está dañada por cualquier etiología".

\section{Aplicación práctica de la Terapia ocupacional}

El terapeuta ocupacional presta sus servicios a personas con algún problema que interfiere en el desempeño satisfactorio de su ocupación; llevar a cabo ocupaciones significativas para la persona es fundamental para su bienestar 199

\section{Práctica centrada en el usuario}

Busca proporcionar a la persona control sobre su vida. Hay una participación activa de la persona en su proceso terapéutico. La historia ocupacional se elabora durante la terapia.

\section{Práctica centrada en la ocupación}

La terapia ocupacional constituye una ayuda para participar en las ocupaciones que el paciente valora. La ocupación es fundamental para que la persona construya su identidad. Para que la práctica se lleve a cabo de forma correcta 
es precisa una evaluación sistemática de las prioridades e intereses de la persona.

Práctica basada en la evidencia: Terapia Ocupacional Basada en la Evidencia (TOBE)

Se trata de basar las decisiones de intervención en el "uso concienzudo, explícito y prudente de la mejor evidencia científica actual". Se trata de integrar la evidencia de la investigación en el proceso clínico para así poder predecir unos posibles resultados. El profesional de terapia ocupacional debe saber de qué modo acceder, evaluar e interpretar la investigación relevante, debe tener la capacidad para reunir datos relevantes que apoyen sus intervenciones y comunicar los resultados probables de la intervención para que el paciente decida si desea recibir esa intervención 200.

\section{Funciones del Terapeuta ocupacional}

Las funciones de los profesionales de la disciplina de la terapia ocupacional quedan resumidas en los siguientes apartados 201:

$\checkmark$ Valoración Funcional.

$\checkmark$ Entrenamiento en Actividades de la Vida Diaria (AVD).

$\checkmark$ Adaptación/Readaptación funcional.

$\checkmark$ Estimulación y reeducación cognitiva. 
$\checkmark$ Estimulación e integración sensorial.

$\checkmark$ Prevención del agravamiento de una enfermedad crónica.

$\checkmark$ Promoción y recuperación de las funciones biopsicosociales.

$\checkmark$ Valoración, diseño y entrenamiento de ortesis y productos de apoyo.

$\checkmark$ Adaptación del Hogar y del puesto de trabajo.

$\checkmark$ Orientación/reorientación laboral.

$\checkmark$ Asesoramiento en ocio y tiempo libre.

\subsubsection{ROL DEL TERAPEUTA OCUPACIONAL EN ONCOLOGÍA}

El terapeuta ocupacional como profesional sanitario llevará a cabo su intervención en todos aquellos pacientes que presenten una sintomatología o unas características concretas que así lo requieran. En el caso del paciente oncológico estamos hablando su intervención no se basará en atacar directamente la neoplasia para evitar su desarrollo o para eliminarla, sino que se ceñirá a actuar como miembro del equipo interdisciplinar de trabajo, encargado de controlar la sintomatología adyacente al proceso oncológico, proporcionar el apoyo social necesario tanto a los pacientes como a sus cuidadores, así como de llevar a cabo actuaciones que mejoren la calidad de vida del individuo. Dentro de este último concepto, el de calidad de vida, el cual fue desarrollado en el tercer bloque, abordaremos una serie de factores que lo 
determinan (Figura), y que sin ellos la persona no poseerá este bien tan preciado, los resumimos en la siguiente figura 202:

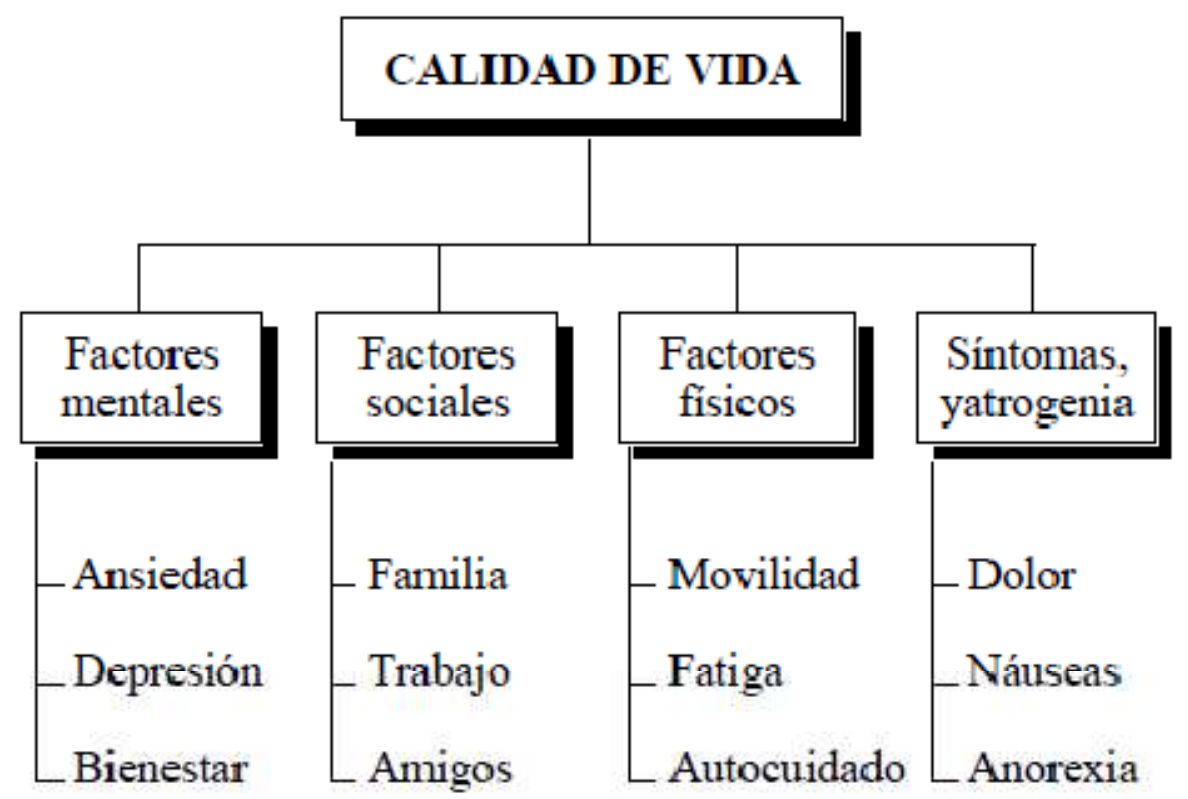

Figura 13. Esquema multifactorial de calidad de vida

Los síntomas a los cuales el terapeuta ocupacional contribuirá a su mejora o adaptación del paciente oncológico se pueden resumir en los siguientes 203:

Astenia tumoral.

- Patologías respiratorias como consecuencia de procesos oncológicos:

Disnea.

Ansiedad.

- Patologías neurológicas como consecuencia de procesos oncológicos.

- Patologías cognitivas asociadas a procesos oncológicos. 
- Dolor.

- Depresión.

- Insomnio.

Todos ellos, sin una correcta actuación generarán en el individuo dependencia y fomentarán un deterioro importante en su autonomía, con su consecuente empeoramiento en términos de calidad de vida.

Por tanto, el papel de la terapia ocupacional en oncología será el de "rehabilitar y readaptar a un individuo, con el objetivo de lograr su mayor desempeño funcional, físico o cognitivo, en sus actividades de la vida diaria, independientemente de su esperanza de vida" 204.

Debido a la singularidad y complejidad de la ocupación humana, cada persona diagnosticada con cáncer experimentará diferentes limitaciones en sus ocupaciones y restricciones en su participación comunitaria, las cuales variaran a lo largo del curso de la enfermedad.

El cáncer y su tratamiento pueden causar interrupciones en las rutinas diarias que afectan a la forma en la que los individuos llevan a cabo su autocuidado, su trabajo, su ocio o sus actividades sociales. Por ejemplo, las personas pueden experimentar dificultades con las actividades de cuidado personal, como bañarse o vestirse. Otros pueden experimentar dificultades para realizar las funciones esenciales del trabajo tales como levantar, cargar, o tener la 
suficiente resistencia tanto física como cognitiva para llevar a cabo un trabajo a tiempo completo. Algunas personas con cáncer pueden experimentar dificultades con las actividades de ocio, mientras que otros pueden experimentar dificultades para socializarse con amigos y/o familiares 205 .

Los individuos con cáncer pueden experimentar estas dificultades como resultado de la enfermedad o de los efectos de su tratamiento.

Los efectos secundarios comunes del cáncer o su tratamiento incluyen fatiga, dolor, debilidad, dificultades cognitivas, ansiedad o depresión, y los cambios en la autoestima o la propia imagen de uno mismo. Los terapeutas ocupacionales abordan estos efectos a través de la intervención dirigida a restaurar estas funciones. Esto lo llevarán a cabo mediante el desarrollo de programas de ejercicios en casa para mejorar la fuerza y movilidad, modificaciones en sus actividades cotidianas, con técnicas de ahorro energía que las personas realizarán durante las actividades diarias importantes, o la modificación de entornos como el lugar de trabajo, el hogar o la comunidad 206. 


\section{¿QUÉ PRETENDE LA TERAPIA OCUPACIONAL EN EL PACIENTE?}

Enseñar a la persona a enfrentarse con sus reservas funcionales gravemente disminuidas, a fin de recuperar la capacidad para desempeñar sus roles ocupacionales dentro de su margen potencial 207.

Actúa sobre la calidad de vida del enfermo, ya que, mejora su funcionamiento en domicilio y en el entorno donde vive. Los pacientes refieren una mejoría de su estado anímico, sentimientos de optimismo, autocontrol y autoestima, con la consecuente disminución de su ansiedad 208.

Los beneficios de la terapia ocupacional se aprecian en 209 :

$\checkmark$ La calidad de vida y el bienestar general del individuo.

$\checkmark$ El estado general de salud, tanto relacionado con los síntomas respiratorios como en la tolerancia al ejercicio presente.

$\checkmark$ La independencia, el paciente aumenta su autonomía y consecuentemente su sentimiento de autovalía.

$\checkmark$ La habilidad para desempeñar sus roles ocupacionales en la sociedad.

Por lo que las funciones del terapeuta ocupacional en oncología serán 210:

1. Gestión de las actividades básicas de la vida diaria (AVD), como bañarse y vestirse a través de adaptaciones a la actividad y medio ambiente, y / o el uso de la tecnología de asistencia. 
2. El estilo de vida tales como la salud preventiva, mejorar el estado físico. Esto puede incluir la educación enfatizando fortalezas de la persona y las estrategias de afrontamiento positivas que le permitan o ella para estar en control de las opciones de estilo de vida.

3. Sueño y gestión de la fatiga como la educación y la demostración de la conservación de energía y la relajación técnicas de gestión para apoyar la salud y la capacidad de participar en actividades significativas.

4. Estrategias cognitivas para abordar la memoria, déficit de la función ejecutiva de la organización, y las tareas de baja energía que se centran en la restauración de la participación en las ocupaciones diarias, tales como sentarse en el parque, leer un periódico, o conversar con un amigo.

5. El ejercicio terapéutico y posicionamiento para mantener el rango de movimiento funcional, la movilidad y la fuerza, como el hogar programas de ejercicio, férulas, ajuste la silla de ruedas, colocación de cama etc, para ofrecer apoyo y consuelo.

6. La gestión de linfedema para reducir inflamación de las extremidades, lo que puede limitar el rango de movimiento y la capacidad de moverse y AVD completos.

Por todo ello considero que el terapeuta ocupacional tiene mucho que decir en la colaboración en estos cuidados continuos y paliativos, ya que según lo 
expuesto anteriormente cumpliría todos los "Principios de los cuidados continuos y Paliativos" 211.

1. Atención integral.

2. El enfermo y la familia son la unidad a tratar.

3. Fomento de la autonomía y dignidad del enfermo.

4. Concepción terapéutica activa y rehabilitadora.

5. Objetivos de los cuidados: bienestar y calidad de vida.

6. Importancia del ambiente o entorno. 


\subsubsection{MODELOS TEÓRICOS DE INTERVENCIÓN}

\section{MODELO CANADIENSE DEL RENDIMIENTO OCUPACIONAL (MCRO)}

Los documentos publicados entre 1983 y 1993 por la Asociación Canadiense de Terapia Ocupacional (CAOT) en colaboración con el Ministerio de Salud Nacional y de Bienestar Social (MSNBS) constituyen la vanguardia que introduce una práctica centrada en el cliente y en el rendimiento ocupacional, los dos conceptos básicos que soportan el denominado, posteriormente, Modelo Canadiense del Rendimiento Ocupacional (MCRO) 212.

Como indican los orígenes, el MCRO es un documento cuyo objetivo será la orientación de la práctica clínica. Ofrece una perspectiva de la terapia ocupacional en la que se articulan tres conceptos básicos: la práctica centrada en el cliente, el rendimiento ocupacional y la habilitación.

A pesar de proponer un modelo general, aplicable a todos los ámbitos de la práctica, a diferencia del modelo de Reed y Sanderson, éste constituye una guía detallada para la práctica clínica y, además, desarrolla herramientas de evaluación como la medida canadiense de rendimiento ocupacional, además de realizarse proyectos de investigación para contrastar su repercusión en la profesión ${ }^{213}$. 
Más que desarrollar protocolos o normas de actuación, su pretensión es promover una práctica clínica articulada desde la reflexión, desde la aplicación de la teoría en el ejercicio profesional cotidiano y desde la contribución que la experiencia puede aportar al corpus epistemológico de la materia.

\section{MARCO DE REFERENCIA}

Hagedorn en el año 1997 subraya la influencia del pensamiento de Reed y Sanderson en el modelo canadiense 214 :

[...], pero el modelo tiene su origen principal en la presentación de Reed y Sanderson de los fundamentos conceptuales de la práctica, y en su visión del desempeño ocupacional como consistente en un equilibrio entre trabajo, ocio y autocuidado. La adaptación se ve como $<<u n$ concepto unificador central en la práctica de la terapia ocupacional centrada en el cliente>>.

El MCRO conceptualiza a las personas como seres espirituales, con capacidad para determinar, elegir y participar en ocupaciones en su entorno habitual. El potencial del ser humano le permite elegir, organizar e implicarse en ocupaciones significativas que le procuran satisfacción. Así mismo, a través de la consecución del equilibrio ocupacional, la persona puede expresarse y desarrollarse como ser único.

La perspectiva definida para el modelo es una visión holística de la persona en la que ésta es considerada un todo que adquiere sentido en su relación con el 
entorno humano y no humano. Así, las dimensiones del rendimiento ocupacional vienen determinadas por lo que experimenta, piensa y hace.

Asimismo, considera que el individuo puede ser un partenaire activo de la práctica centrada en el cliente, las creencias, valores y objetivos del sujeto se encumbran a un lugar esencial en la experiencia terapéutica.

Además, al conceptualizar al sujeto consideran que las experiencias sociales y culturales son aspectos subjetivos de suma importancia en el desarrollo vital de un sujeto. Estos aspectos influyen en la percepción que tiene el sujeto de sí mismo y le permiten establecer vínculos con otras personas y con su entorno. Además, las personas trasforman su entorno social, cultural, institucional y físico cuando se relacionan con los otros.

\section{ARGUMENTOS Y PRINCIPIOS FUNDAMENTALES DEL MODELO \\ El concepto central del modelo canadiense es el de rendimiento ocupacional, de él toma el nombre y en él se engarzan los tres conceptos clave del modelo, a saber: persona, entorno y ocupación.}

La definición dada a "rendimiento ocupacional" es ${ }^{215}$ :

"El resultado de la relación dinámica que se establece a lo largo de la vida entre la persona, el entorno y la ocupación".

La representación de este concepto persigue como veremos enfatizar la interdependencia entre la persona, el entorno y la ocupación; así, el 
rendimiento ocupacional es el resultado de la interacción de la persona con su entorno, al que ésta se halla enteramente ligada.

De esta forma, un cambio en cualquiera de los elementos que conforman ese equilibrio dinámico tiene como fruto cambios en cualesquiera del resto de los componentes y, por ende, en el rendimiento ocupacional.

La interacción entre la persona y el entorno se transforma a lo largo del curso vital; así, desde el nacimiento hasta la vejez, las experiencias ocupacionales se acumulan constantemente, desarrollando nuevas ocupaciones y abandonando antiguas. En determinadas áreas, el desarrollo ocupacional puede transformarse de forma paulatina, aumentando en complejidad (p.ej., en el ámbito laboral), mientras que en otras los cambios pueden ser más rápidos (p.ej., en el autocuidado). De esta forma, la congruencia entre la persona, su entorno y sus ocupaciones permite optimizar el rendimiento ocupacional.

Las deficiencias, los retrasos del desarrollo, la enfermedad, los traumas o el envejecimiento determinan el curso del desarrollo ocupacional en los sujetos, de manera que pueden alejar a la persona del desarrollo esperado según los estadios del ciclo evolutivo normalizado.

En definitiva, el rendimiento ocupacional está asociado al desarrollo evolutivo de la persona, a la integridad de su sustrato biológico y a los condicionantes del medio en que cada sujeto se desenvuelve. 
Además, pueden delimitarse las dimensiones del rendimiento ocupacional al analizar el de un sujeto. Éstas son 216:

Afectiva. Comprender todas las funciones sociales y relacionales de la implicación en ocupaciones.

Cognitiva. Comprender todas las funciones intelectuales.

Física. Comprender todas las funciones sensoriales, motoras y sesoriomotoras.

Resumidas las características elementales del concepto del sujeto, principal en el modelo y revisando anteriormente al hablar del marco de referencia, veamos a continuación las particularidades de los otros dos conceptos, la ocupación y el entorno.

\section{CONCEPTO DE OCUPACIÓN:}

El modelo canadiense define ocupación como 217:

La ocupación hace referencia al conjunto de actividades y tareas de la vida cotidiana a las cuales los individuos y las diferentes culturales dan un nombre, una estructura, un valor y un significado. La ocupación comprende todo aquello que hace una persona para cuidar de ella misma (cuidado personal), divertirse (ocio) y contribuir a la construcción social y económica de la colectividad (productividad). 
Así definida por el modelo canadiense, la ocupación constituye una necesidad fundamental de la persona, a la que ésta debe consagrarse tanto para sobrevivir como para obtener satisfacción y divertirse.

Sin embargo, en este modelo son muchas más las facetas que se asocian con la ocupación: posibilita organizar el comportamiento, regir el tiempo (a lo largo del día y de la vida), expresar y asumir la identidad personal, sentirse partícipe de la sociedad, alcanzar objetivos significados personales o culturales; favorece el sentimiento de control de la realidad; organiza la materia y el espacio, y puede constituirse en una fuente de recursos (económicos, en particular).

La clasificación de las ocupaciones sigue, con sutiles matices sin apenas relevancia, el tradicional encasillamiento entre cuidado personal, productividad y ocio.

\section{CONCEPTO DE ENTORNO}

En entorno se define como los contextos y situaciones que se manifiestan en el exterior del individuo y que suscitan respuestas de su parte. El modelo clasifica el entorno respecto a atributos culturales, institucionales, físicos y sociales 218 .

Las relaciones entre el entorno y el sujeto no se contemplan de forma unidireccional. El primero influye en el segundo, pero el sujeto también incide 
en el entorno. De igual forma, la ocupación se ve influida por aspectos ambientales; sin embargo, la acción individual y colectiva modifica a su vez el entorno.

En la medida en que la interacción de la persona con su entorno tiene como resultado un rendimiento ocupacional determinado, el análisis de los aspectos ambientales, siempre cambiantes, permitirá determinar si éstos lo entorpecen, impiden o facilitan.

\section{EL PAPEL DE LA TERAPIA OCUPACIONAL EN LA SALUD}

El modelo parte de una premisa general, que afirma que la salud individual se ve determinada por aquello que los sujetos hacen cotidianamente; es decir, la ocupación es un determinante de la salud.

El papel fundamental de la terapia ocupacional es promover la ocupación, promover la salud a través de la ocupación. El terapeuta ocupacional colabora con los individuos tratados para ayudarles a elegir, organizar y cumplir las ocupaciones que consideran útiles o significativas en un determinado entorno.

De manera general, a través del análisis de las características y necesidades de los sujetos y de las características de las ocupaciones, el terapeuta ocupacional puede poner en marcha planes de tratamiento articulados alrededor de la ocupación como medio terapéutico en intervenciones individuales, grupales y comunitarias. El análisis de la ocupación permite 
clasificarla según su grado en relación con el número de sujetos implicados (individual o grupal), del tiempo requerido para efectuarla, de los lugares en que se lleva a cabo y de la complejidad y útiles implicados en su realización. Así mismo, permite examinar los elementos culturales, institucionales, físicos y sociales que suponen un obstáculo al rendimiento ocupacional.

Uno de los conceptos que más enfatiza el modelo es el de la práctica centrada en el cliente, es decir, promover la ocupación en colaboración con los individuos tratados más que hacer cosas por ellos.

El término <<práctica centrada en el cliente >> fue acuñado por Carl Rogers y tuvo un especial desarrollo durante las décadas de 1940, 1950 y 1960219.

En esencia, la práctica centrada en el cliente se fundamenta en una perspectiva filosófica que pone de relieve la capacidad y responsabilidad del sujeto que demanda tratamiento para contribuir y colaborar en el curso terapéutico.

Así, se propone la habilitación frente al tratamiento; se preconiza una práctica clínica en la que las acciones son realizadas con el cliente más que para el cliente. La habilitación durante el proceso terapéutico en terapia ocupacional transforma al paciente en participante.

Así, la práctica centrada en el cliente enfatiza el derecho del individuo a recibir toda la información necesaria para elegir los servicios que respondan mejor a 
sus necesidades; éstas, así como sus creencias, opiniones y deseos, deben ser respetadas a lo largo de todo el proceso terapéutico. La autodeterminación del sujeto se convierte en el eje alrededor del que gira la relación terapéutica, caracterizada por la flexibilidad. Así, el terapeuta alienta al cliente para que tome responsabilidad y movilice sus recursos, ajustándose al grado de participación particular de cada sujeto tratado. Terapeuta y cliente se asocian para movilizar los recursos y potencialidades del individuo, el fin último es el encuentro del sujeto con sus propia respuesta, no la imposición de las nuestras.

En resumen, ayudar al individuo a definir sus dificultades en materia de rendimiento ocupacional, planificar de forma conjunta las intervenciones a realizar teniendo en cuenta la opinión del sujeto, discutir los resultados de las intervenciones realizadas, aportarle la información y formación necesaria para facilitarle sus elecciones personales y ayudarle a alcanzar sus objetivos respecto a su rendimiento ocupacional son los principios clave de la práctica centrada en el cliente.

\section{METODOLOGÍA PARA LA EVALUACIÓN E INTERVENCIÓN}

La descripción del proceso metodológico constituye un modelo de práctica en la medida en que posibilita la aplicación de los conceptos del MCRO. Éste se considera como un abordaje sistemático a través de una secuencia de etapas que incluyen la demanda, la evaluación, la planificación de un programa, la 
intervención, el alta, el seguimiento y la evaluación de los resultados del tratamiento.

Exponemos a continuación las siete etapas descritas:

1. Definición, validación y ordenación, según prioridades, de las dificultades en materia de rendimiento ocupacional.

2. Selección de los abordajes teóricos.

3. Determinación de las dimensiones del rendimiento ocupacional y de las condiciones ambientales en juego.

4. Determinación de la potencialidad y de los recursos del cliente y del terapeuta ocupacional.

5. Negociación de los resultados diana y elaboración de planes de intervención.

6. Puesta en juego de los planes de intervención a través de la ocupación.

7. Evaluación de los resultados de la intervención en materia de rendimiento ocupacional. 


\section{MODELO DE LA OCUPACIÓN HUMANA (MOHO)}

A lo largo de la década de 1970 se fue fraguando lo que hoy se conoce como el Modelo de la Ocupación Humana (MOHO). En 1980 se publicó por primera vez en la revista americana de terapia ocupacional (American Journal of Occupational Therapy). Esto nos proporciona una idea de su magnitud, del tamaño del efecto, y no sólo acerca de la significación estadística en cuanto a su repercusión en los planes de estudios, teoría y programas de intervención de la disciplina. Sin embargo, para poder decir esto de forma rigurosa, sería muy adecuado realizar un diseño de investigación basado en el meta-análisis, para estudiar y cuantificar exactamente la repercusión que este modelo de práctica tiene en la disciplina y compararlo con otros modelos.

\section{MARCOS DE REFERENCIA}

El modelo de la ocupación humana se basa en distintos marcos teóricos de referencia, fundamentalmente en la ecología humana, teoría de sistemas, psicología cognitiva y psicología humanista 220. Como Mosey, basa la explicación del desempeño ocupacional en la satisfacción de necesidades.

\section{ARGUMENTOS Y PRINCIPIOS FUNDAMENTALES DEL MODELO}

El modelo parte del principio de que la actividad humana es necesaria para la vida. Entiende que el ser humano es, sobre todo, un ser activo y que la actividad puede ser entendida fundamentalmente como espontánea e intrínseca a la naturaleza humana. A través de su actividad el hombre puede 
cambiar tanto el entorno como a sí mismo. Sin embargo, cabría preguntarse: ¿para qué necesita el individuo cambiarse a sí mismo o al entorno? A esta pregunta da respuesta otro principio básico del modelo: la adaptación. El ser humano está continuamente adaptándose, precisamente por los cambios que ocurren en la vida, y a través de éstos, el individuo puede autodesarrollarse. Es decir, no se entiende la adaptación en un sentido conformista, sino en un sentido positivo, que proporciona crecimiento personal y que mejora el entorno. El modelo de la ocupación humana propone que el fin de la terapia ocupacional es, precisamente, proporcionar y/o facilitar un cambio en la vida del paciente, de modo que facilite la adaptación a sus circunstancias personales y contextual 221.

El autor Kielhofner $(1985,1995,2002)$ 222, 223, 224 propone, que el objeto de estudio de la terapia ocupacional sea la ocupación. Otorga una gran importancia al individuo, a su visión de la realidad y en concreto a su situación ocupacional.

El modelo está estructurado como un sistema, en el que se distinguen elementos externos (entorno, demanda externa y retroacción por el desempeño) y los propios del sujeto o internos (subsistemas motivacional, de habituación y de ejecución). 
Para Kielhofner es fundamental la interacción con el entorno. El entorno se puede entender al menos de tres formas ${ }^{225}$ :

1. Físico: Está formado por los objetos.

2. Social: En el que incluye a las personas, grupos sociales, etc.

3. Entorno cultural. Formado por la cultura (tradiciones, normas, estándares de calidad) y los hechos externos.

El primer subsistema, también conocido como el de la voluntad o subsistema volutivo o motivacional, es responsable de las disposiciones y autoconocimiento que predispone y capacita a las personas para anticipar, elegir, experimentar e interpretar el comportamiento ocupacional.

En segundo lugar, el subsistema de la habituación proporciona una organización interna al sistema, a través de los hábitos y los roles.

El subsistema de desempeño, también conocido como sistema mente-cerebrocuerpo, se refiere a las distintas capacidades y habilidades del ser humano, lo que la American Occupational Therapy Association (AOTA) (1991) denomina componentes ocupacionales ${ }^{226}$.

El sujeto al <<actuar >> satisface las expectativas y las necesidades sociales mediante una participación productiva y recreativa. De esta forma, expresa sus 
necesidades, motivaciones, roles, hábitos y habilidades. Por el contrario, una persona puede estar en un período disfuncional cuando no satisface las demandas y expectativas sociales, alterando el proceso interno y abandonando la realización de sus ocupaciones.

La función y la disfunción son los extremos de un continuo en el que se distinguen distintos niveles.

Dentro de los niveles de funcionalidad se distinguen el logro, la competencia y la exploración. El logro es entendido como el esfuerzo por mantener y mejorar el desempeño en las ocupaciones con unos <<estándares>> adecuados.

La competencia requiere adecuarse a las circunstancias, personales y contextuales, de una demanda y satisfacerla de forma adecuada. Y, por último, la exploración, el nivel inicial, es el vehículo del tratamiento.

Por lo tanto, el modelo aporta dos perspectivas: por un lado, permite conocer la estructura de la ocupación y, por otro, los procesos que se producen cuando una persona realiza una determinada ocupación.

METODOLOGÍA PARA LA EVALUACIÓN

Este modelo es probablemente uno de los que más instrumentos de evaluación ha desarrollado 227 . Éstos están basados sobre los distintos componentes del mismo. 
El objetivo final es identificar los puntos fuertes y débiles de los distintos elementos de la ocupación, es decir, del entorno, del sistema interno y de la interacción de ambos, evaluando y analizando cada componente del sistema.

Tiene una visión dinámica y evolutiva, lo que quiere decir que los instrumentos intentan ayudar al clínico a llegar a conclusiones que faciliten identificar la disfunción y establecer un adecuado diagnóstico ocupacional, dependiendo de la historia ocupacional, analizando el pasado, presente y teniendo en cuenta las propias expectativas del paciente.

\section{METODOLOGÍA PARA EL TRATAMIENTO}

Desde el modelo de la ocupación humana se entiende que la intervención o abordaje debe ser integral, es decir, sobre el conjunto de los elementos que constituyen la ocupación. Sin embargo, señala que la intervención que puede realizar la terapia ocupacional es sobre el entorno y no sobre el propio sistema interno o individuo. A través de la modificación del entorno, se proporciona un cambio que afecta a todo el conjunto del sistema humano.

Según este modelo, el origen del problema ocupacional radica en la disfunción de algunos de los tres subsistemas o en el entorno.

Los principios generales para la aplicación del modelo parten de la idea de que cualquier déficit, enfermedad, discapacidad, dará lugar a cambios en el sistema humano. La propia compensación de los déficits irremediables o secuelas 
incluye la alteración de las rutinas o hábitos diarios, las metas y otros factores afectados por la capacidad alterada. A continuación se citan los principios generales 228 :

$\checkmark$ La terapia ocupacional ayuda al individuo a producir el cambio más adaptativo a su situación o circunstancias.

$\checkmark$ La terapia ocupacional es un acontecimiento que se produce en la vida del individuo y debe ser entendida y realizada en un contexto determinado, el más adecuado para la consecución de los objetivos.

$\checkmark$ El núcleo para el cambio debe ser la acción o el progreso subyacente del sistema humano.

$\checkmark$ El cambio no significa simplemente más o menos, se refiere a una nueva organización.

$\checkmark$ El cambio puede y debe ocurrir en los distintos elementos del sistema humano simultáneamente.

$\checkmark$ Los cambios inicialmente producen desorden. La teoría dinámica de sistemas enfatiza que el estado caótico es frecuentemente necesario para la transición de un estado ordenado a otro. 
$\checkmark$ La terapia debe dar la posibilidad de experimentar o practicar para encontrar la mejor solución.

$\checkmark$ La única herramienta que los terapeutas tienen a su disposición es cambiar el ambiente, para apoyar o precipitar un cambio en el sistema humano.

Los principios específicos para la intervención son los siguientes ${ }^{229}$ :

$\checkmark$ Los cambios en las destrezas deberían ser algo primario en la terapia. Hay que tener en cuenta que la relación entre la capacidad subyacente y la ejecución está lejos de ser perfecta. Es decir, más que centrarse sobre la capacidad, la terapia ocupacional debe dirigirse a la habilidad.

$\checkmark$ Los cambios en la ejecución pueden incluir el aprendizaje de nuevas habilidades.

$\checkmark$ Las ocupaciones tienen una poderosa influencia sobre los cambios en las habilidades. Es importante concretar en el tratamiento aquellas ocupaciones que sean significativas para el paciente. 
Los hábitos y roles son por naturaleza resistentes al cambio, ya que su función básica es preservar los patrones de conducta. Por lo tanto, la práctica mantenida o repetida es necesaria para producir un cambio en la habituación.

$\checkmark$ La habituación organiza el comportamiento para contextos específicos. En nuevos contextos hay que aprender nuevos hábitos.

$\checkmark$ La pérdida de roles y hábitos requiere una rápida sustitución por otros, ya que, si no, se produce desorientación y disrupción.

$\checkmark$ Adquirir un nuevo rol y hábito es un proceso de socialización y negociación.

Un aspecto básico de las preferencias ocupacionales es la significación. Esto influye sobre el subsistema motivacional, la experiencia, la interpretación y determinará la elección de una determinada ocupación.

A través del tratamiento se pretende promover la "autoorganización" del sistema.

El contexto, junto a las "formas ocupacionales", son dos aspectos básicos para el cambio. 
La intervención se debe producir a través de un continuo funcional (exploración, competencia y logro). Los programas deberían reflejar el nivel de función que puede ser esperado por la participación en ellos.

El proceso de tratamiento que propone Kielhofner es similar al de otros autores de la disciplina. Según él, el tratamiento debe basarse en un proceso en espiral, formado por cuatro fases: análisis de la situación, establecimiento de metas, planificación y desarrollo del programa, e implementación y evaluación 230.

Dentro del análisis de la situación hay que incluir la determinación del contexto de tratamiento y de la población. En la segunda fase se establece el núcleo del tratamiento, especificando el programa y la recuperación que se estima. La planificación y el desarrollo del programa incluyen el desarrollo de las acciones, la especificación del método de evaluación y recogida de daros y, por último, generar y seleccionar las opciones del servicio de terapia ocupacional. 


\subsection{MANEJO DE LA ASTENIA TUMORAL}




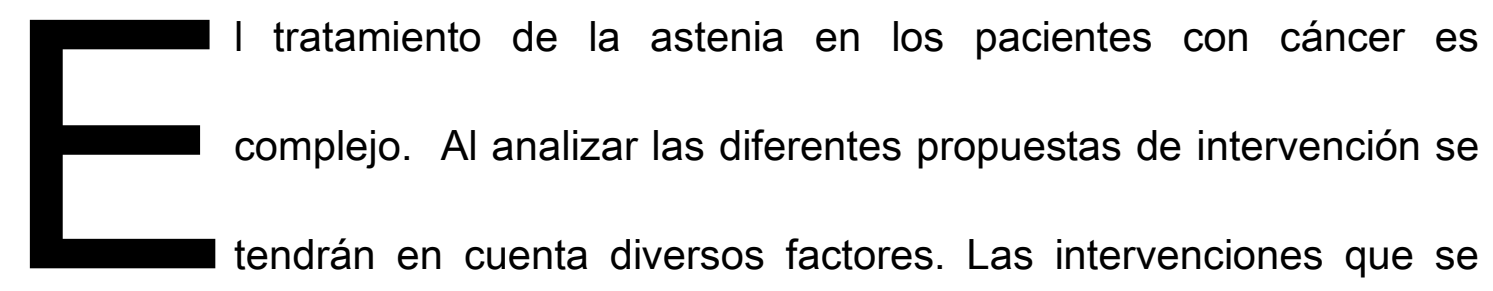
analizarán serán:

1. Tratamiento de los factores predisponentes.

2. Tratamiento farmacológico.

3. Tratamiento no farmacológico (TNF).

Antes de llevar a cabo cualquiera de las actuaciones se debe proceder a la realización de una detallada evaluación de este síndrome asténico, en esta evaluación se deberá analizar concienzudamente intensidad, duración y etiología, en caso de que sea conocida. La pregunta que nos debemos hacer ahora es, en nuestra práctica clínica diaria ¿se evalúan los índices de astenia o simplemente nos basamos en poner si el paciente se encuentra o no fatigado? Partiendo de estas suposiciones, realmente, sin una correcta evaluación ¿podremos llevar a cabo un correcto tratamiento? 
Además de una correcta evaluación debemos tener en cuenta otros factores a la hora de llevar a cabo cualquier tipo de intervención. Es imprescindible conocer en qué momento se encuentra la enfermedad, ya que las actuaciones serán diferentes en caso de encontrarse en tratamiento activo o no, así como en una fase paliativa. Los objetivos a plantearse serán diferentes. No debemos olvidar que la astenia tumoral puede estar presente, incluso, años después de que la enfermedad desaparezca.

A continuación pasaremos a analizar los diferentes mecanismos de actuación que podemos llevar a cabo.

\subsubsection{TRATAMIENTO DE LOS FACTORES PREDISPONENTES}

Como hemos mencionado la etiología de la astenia tumoral es amplia y desconocida, lo que nos llevará a una gran dificultad a la hora de encontrar tratamientos específicos para controlarla. Ante un paciente con astenia severa, los clínicos buscarán causas que puedan justificar el cuadro. En esta búsqueda tan amplia, debido a la variedad etiología que puede producirlo se llevarán a cabo diferentes actuaciones. La etiología de la astenia, desconocida, en muchos casos, y la dificultad en la actualidad para encontrar tratamientos específicos frente a la patogenia del síntoma, hace que la intervención 
terapéutica más sencilla y eficaz sea el tratamiento de los factores predisponentes potencialmente reversibles 231, 232, 233.

Esto puede conllevar la retirada de fármacos que actúan en el sistema nervioso central que no sean necesarios, el tratamiento del dolor o de la insuficiencia cardíaca y el tratamiento de la anemia o de otras alteraciones metabólicas ${ }^{234}$, 235.

En los algoritmos de estudio de la astenia tumoral de la National Comprehensive Cancer Network (NCCN) se identifican cinco factores considerados como primarios en la etiopatogenia de la astenia tumoral y que deberían ser evaluados y tratados de forma correcta en todo paciente con cáncer y con astenia moderada o severa 236 .

- Dolor.

- Anemia.

- Alteraciones del sueño.

- Trastornos del humor.

- Alteraciones tiroideas.

La elección de estos factores se debía a que todos ellos son fácilmente reversibles con terapias actuales, y están presentes de forma habitual en los pacientes con astenia, especialmente las alteraciones del sueño y del dolor 237. 
De especial importancia es el control adecuado del dolor, que con el uso adecuado de la escala analgésica de la Organización Mundial de la Salud (OMS) consigue porcentajes de éxito de entre el 70-90\% 238, 239.

Por otra parte, el hipotiroidismo como causa de astenia es poco frecuente pero muy fácilmente tratable, y debería sospecharse en pacientes con antecedentes de cirugía o radioterapia cervical 240 .

Analizaremos más detenidamente, dada su especial relevancia y controversia, la intervención en caso de anemia y de trastornos del humor, con prioridad absoluta para la depresión mayor.

\section{INTERVENCIÓN EN ANEMIA:}

Como vimos en el apartado 1,7, la anemia, era definida por la OMS como "una concentración de hemoglobina igual o inferior a 12g/dl” 241, es una complicación frecuente en los pacientes con cáncer, especialmente en aquellos en curso de quimioterapia mielosupresora, en donde puede alcanzar hasta al $100 \%$ de los pacientes, dependiendo del esquema quimioterápico utilizado 242.

Su etiología en el paciente con cáncer es multifactorial, pudiendo ser consecuencia de 243 :

- Invasión tumoral de la médula ósea.

- Producción de citoquinas por el tumor. 
- Efectos mielosupresores directos o indirectos de la quimioterapia.

- Déficits nutricionales.

- Cuadros de hemólisis o pérdidas agudas o crónicas de sangre.

Por lo tanto será necesaria una correcta evaluación previa a la consecución de su tratamiento.

En algunos casos, la anemia es responsable del llamado Síndrome Anémico, cuyas consecuencias traducidas en términos de sintomatología serán principalmente disnea de esfuerzo y astenia, acompañados o no de palpitaciones, vértigo, cefalea o alteraciones del sueño $244,245$.

Distintos estudios han mostrado una relación directa entre el grado de anemia y la calidad de vida general, incluyendo dentro de ella la astenia en particular 246 , 247,248 .

El tratamiento de la anemia en los pacientes con cáncer clásicamente se ha realizado con la transfusión de unidades de hematíes, obteniéndose una rápida pero provisional mejoría de los parámetros hematológicos y de la sintomatología anémica. La tasa de éxito habitualmente es alta con la transfusión, y las complicaciones son escasas, con un coste económico bajo 249, 250, 251, 252. Sin embargo, las transfusiones repetidas pueden ser molestas para los pacientes, y los riesgos de transmisión de infecciones pueden ser una causa de preocupación. 
Como alternativa en el tratamiento de la anemia existen los agentes eritropoyéticos 253 .

La recomendación de eritropoyetina en anemia inducida por quimioterapia se produjo tras los resultados de distintos ensayos aleatorizados que demostraron un aumento en los niveles de hemoglobina con el tratamiento con eritropoyetina y una disminución del $50-60 \%$ en los requerimientos transfusionales 254, 255, 256, 257, 258.

Como llamativo cabe resaltar que la mejoría sintomática en algunos estudios no se producía en los niveles más bajos de hemoglobina, sino en la franja de 11-12 g/dl, recalcando la importancia del tratamiento precoz del síndrome anémico 259 .

Las recomendaciones conjuntas de la American Society of Clinical Oncology (ASCO) y de la American Society of Hematology (ASH) ${ }^{260}$, establecieron el uso de la eritropoyetina como alternativa terapéutica a la transfusión de hematíes en el tratamiento de la anemia inducida por quimioterapia, especialmente para niveles de hemoglobina menores de $10 \mathrm{~g} / \mathrm{dl}$, dejando la indicación de acuerdo a las circunstancias clínicas para los niveles de hemoglobina entre 10-12 g/dl, al disminuir las necesidades transfusionales y aumentar los niveles de hemoglobina de forma significativa. 


\section{INTERVENCIÓN EN TRASTORNOS DEL HUMOR: DEPRESIÓN MAYOR}

Existe una relación compleja y poco conocida entre los trastornos del humor, fundamentalmente los trastornos depresivos, y el desarrollo de un cuadro de astenia crónica 261.

En la población general, las causas no orgánicas constituyen el $40-60 \%$ de los casos de astenia crónica, siendo la ansiedad y depresión las causas psiquiátricas más comunes 262 .

Aunque hay pocos estudios epidemiológicos, probablemente la frecuencia sea menor en los pacientes con cáncer, con porcentajes de diagnóstico de trastorno depresivo de entre el $15-25 \%$, dependiendo de las series 263 .

Por desgracia, a pesar de su frecuencia, la depresión en los pacientes con cáncer está infradiagnosticada e infratratada; un ensayo publicado mostró que, a pesar de afectar a un cuarto de los pacientes, sólo un $2 \%$ de éstos recibía medicación antidepresiva 264.

Es un síndrome incapacitante, con una gran afectación de la calidad de vida, y cuyo reconocimiento es fundamental para el clínico, ya que con las terapias actuales se consigue un control adecuado en el $80 \%$ de los pacientes 265,266 . 
Los síntomas psicológicos abarcan la disforia, la anhedonia, los sentimientos de culpa y de baja autoestima y los pensamientos de muerte o suicidio. Los síntomas físicos incluyen astenia, trastornos del sueño, pérdida de libido, disminución de concentración y trastornos psicomotores ${ }^{267}$.

Existen tres grupos de fármacos antidepresivos: los antidepresivos tricíclicos, los inhibidores selectivos de la recaptación de serotonina y los antidepresivos atípicos. Un grupo farmacológico relacionado son los psicoestimulantes. No existe ningún antidepresivo de elección, ya que ninguno ha mostrado más eficacia que el resto 268 .

La elección dependerá de la historia médica previa del paciente, de la sintomatología depresiva predominante y de la respuesta previa a la medicación antidepresiva 269, 270.

Como conclusión, debemos decir que ante todo enfermo oncológico con astenia habrá que descartar la presencia de un trastorno depresivo subyacente. El inicio del tratamiento con fármacos antidepresivos debe iniciarse en cualquier paciente con astenia y algún grado de sintomatología depresiva. Dada su eficacia y seguridad, probablemente los inhibidores de la recaptación de serotonina y algunos antidepresivos atípicos sean los fármacos de elección. En el caso de pacientes con expectativas de vida limitada, hay que valorar el 
uso de fármacos psicoestimulantes, dada su rapidez de acción, eso sí, siempre valorando sus efectos secundarios.

\subsubsection{TRATAMIENTO FARMACOLÓGICO}

En la mayoría de los casos se tiende a una intervención en astenia tumoral desde un punto de vista farmacológico. Los fármacos más normalmente empleados son los psicoestimulantes, corticoides y los antidepresivos.

\section{PSICOESTIMULANTES:}

Son fármacos estimuladores del sistema nervioso central, cuya administración produce una sensación de bienestar, una disminución de los niveles de fatiga y, a corto plazo, un aumento del apetito 271,272 .

El uso de los psicoestimulantes en la astenia tumoral sin trastorno del humor asociado, está apoyado únicamente en observaciones clínicas y en el efecto beneficioso en la astenia de la esclerosis múltiple y de la enfermedad del sida 273.

El problema del uso de este tipo de intervención radica en sus efectos secundarios. Es bien conocido que los más frecuentes son ansiedad, insomnio, euforia y labilidad emocional; además dosis elevadas o la administración de forma crónica pueden producir anorexia, pesadillas, paranoia e incluso complicaciones cardíacas 274 . 
Todo esto nos lleva a hacer un razonamiento al respecto, el cual no es otro que el hecho de que si nos paramos a analizar detenidamente estos efectos secundarios nos damos cuenta de que la mayoría de ellos, como la ansiedad o el insomnio, pueden agravar los niveles de astenia tumoral.

\section{CORTICOIDES}

Algunos datos de pequeños ensayos clínicos sugieren la utilidad de las dosis bajas de corticoides para el tratamiento de la astenia, preferentemente en situaciones de cáncer avanzado 275, 276.

Las frecuentes complicaciones con su uso a largo plazo como la miopatía corticoidea, la inmunosupresión, las alteraciones óseas y la hiperglucemia, que pueden empeorar el cuadro de astenia desaconsejan su uso de forma mantenida, excepto en pacientes con expectativa de vida limitada 277 .

\section{ANTIDEPRESIVOS:}

En este caso, los inhibidores de la recaptación de la serotonina, se han relacionado en algunos casos con disminución de la astenia, independientemente de los cambios en el estado de ánimo. Esta es la razón por la que se han administrado a pacientes sin patología depresiva con astenia severa de forma empírica, pero su uso sólo se recomienda en casos de astenia grave y refractaria a los tratamientos más habituales 278 . 


\section{OTROS FÁRMACOS}

Por último, y basándonos en la experiencia en pacientes con esclerosis múltiple, debemos mencionar un último fármaco empleado en el manejo de astenia tumoral, es el caso de la amantidina. Se suele administrar en casos graves de astenia refractaria al tratamiento habitual, con retirada del fármaco transcurrido un mes si no se observan cambios significativos 279 .

\subsubsection{TRATAMIENTO NO FARMACOLÓGICO $(\mathrm{TNF})$}

Después de analizar detalladamente las intervenciones en astenia desde un punto de vista farmacológico y de tratamiento de los factores predisponentes, pasaremos a las terapias no farmacológicas (TNF).

En la práctica clínica diaria observamos como éstas últimas son las menos empleadas, a pesar de que en el caso de las farmacológicas, como ya hemos explicado, su nivel de evidencia no es el idóneo, además de sus riesgos por los efectos secundarios de los mismos. Y si hablamos del tratamiento de los factores predisponentes observamos cómo sólo podrían ser utilizados en esos casos tan específicos (anemia, depresión...). 
Por lo que a continuación analizaremos las TNF. Si queremos basarnos en la evidencia de estudios realizados, veremos cómo no todas las terapias han sido tan estudiadas. Estás terapias no farmacológicas las resumimos en:

- Ejercicio físico.

- Medidas educativas.

- Intervenciones psicosociales.

- Medidas nutricionales.

- Otras: yoga, técnicas de relajación muscular.

Para el empleo de las mismas, habrá que tener en cuenta el momento en el que se encuentre la enfermedad, no será lo mismo que la persona se encuentre en tratamiento activo que no, o que sea una intervención con rasgos más paliativos.

Dentro de las terapias no farmacológicas las más estudiadas han sido el ejercicio físico, las medidas educativas y las intervenciones psicosociales, mostrando gran evidencia para el tratamiento de la astenia, otras como las medidas nutricionales o el yoga aún tienen poco soporte científico 280 .

A continuación se analizarán cada una de ellas: 


\section{EJERCICIO FÍSICO:}

El ejercicio físico probablemente sea la medida no farmacológica más frecuentemente estudiada y con resultados más positivos 281 .

El cáncer y su tratamiento producen en los pacientes una disminución de su reserva física, que tienden a compensar con una disminución de la actividad. Cuando los pacientes tienen que realizar alguna actividad de la vida diaria el resultado final es astenia. El efecto beneficioso del ejercicio físico parece secundario a una normalización de la eficiencia física en estos enfermos. Tras él, observamos un aumento de la masa muscular y del volumen plasmático, una mejora de la ventilación y perfusión pulmonar, un aumento de la reserva cardíaca y mayores concentraciones de las enzimas oxidativas pulmonares, que contrarrestan la acción de la neoplasia y de los tratamientos oncológicos. Esta mejoría teórica no sólo se limita al aparato cardiopulmonar y muscular, promueve los sentimientos de autocontrol, de autoestima y de independencia, mejorando las acciones sociales de forma secundaria $282,283$.

Existen grandes estudios que demuestran de forma científica la validez de este tipo de intervenciones:

- En un meta-análisis publicado en la National Comprehensive Cancer Network (NCCN), en la guía elaborada en 2013 sobre astenia tumoral, en el cual se incluyen 70 estudios con un total de 4881 pacientes 
oncológicos en tratamiento, se observa como los niveles de astenia tumoral fueron disminuidos, utilizando el ejercicio físico, con un efecto significativo de 0.32 y 0.38 , durante y posterior al tratamiento, respectivamente ${ }^{284}$.

- $\quad$ En un análisis publicado en Cochrane en 2012, en el cual se incluían 56 estudios randomizados, con una muestra total final de 4826 individuos, se observan resultados estadísticamente significativos en niveles de astenia tumoral tras la intervención con ejercicio físico 285 .

- Además estudios menores de autores como Cramp, Duijts, Kangas, McMillan o Velthuis y colaboradores nos muestran resultados muy satisfactorios 286, 287, 288, 289, 290.

Aún así debemos decir que la duración y tipo de ejercicio físico utilizado varía ampliamente. No existe información suficiente para clarificar cuál es el programa de ejercicio físico más apropiado para estos enfermos. Este programa debería considerar la edad y sexo del paciente, el tipo de cáncer y su tratamiento, y el estado físico del paciente ${ }^{291 .}$

El ejercicio físico debe ser utilizado con precaución en pacientes con alguno de los siguientes problemas: metástasis óseas, trombocitopenia, anemia, fiebre o infección activa. 


\section{MEDIDAS EDUCATIVAS}

La educación del paciente sobre el significado de la astenia, sus características y su relación con algunos tipos de tratamiento puede beneficiar a un número importante de pacientes.

La clara disposición a administrar una educación clara y oportuna constituye un componente crucial en cualquier programa de gestión de la astenia. Pacientes que reciben consejos para mejorar el impacto que tiene la astenia en su vida manifiestan experiencias menos negativas en la afectación de la misma que otras personas que no han sido aconsejadas.

Parte del manejo de la astenia crónica en los pacientes con cáncer radica, principalmente, en la adaptación a la propia condición sintomatológica, mediante técnicas de conservación o ahorro de energía. Desgraciadamente la información que se tiende a dar a los pacientes de la astenia es escasa; pongamos por ejemplo un estudio de Love y colaboradores, en el cual se observa cómo tan solo el $8 \%$ de los pacientes que van a comenzar una intervención con quimioterapia prevenían que la astenia fuera un problema, pero el $86 \%$ al terminarla la consideraron como lo más desagradable 292.

Ream y sus colaboradores elaboraron un informe en el que se barajaba la posibilidad de inclusión de un programa de educación para los pacientes oncológicos que presentaran astenia. Ellos encontraron que los pacientes 
tienden a encontrar la información sobre la preparación para la astenia como muy útil, sin embargo, el asesoramiento en materia de gestión de la misma no fue declarado como muy útil. Esto tiene implicaciones importantes para el profesional al considerar el tiempo que debe emplear en el asesoramiento 293.

Una técnica útil para el manejo de esta astenia tumoral es la realización de un diario de astenia por parte del paciente, mediante el cual se puede identificar el patrón de fatiga y las actividades exacerbadoras y paliativas de la sintomatología. Se pueden planificar unos diarios de actividad y reposo, identificando momentos en los que es más fácil realizar una actividad. La gran mayoría de pacientes se benefician de educación sobre técnicas de higiene del sueño 294. 


\section{MEDIDAS HIGIÉNICAS PARA LOS TRASTORNOS DEL SUEÑO EN LOS PACIENTES CON CÁNCER}

- Mantener un ritmo sueño-vigilia lo más regular posible, sobre todo a la hora de despertar.

- Evitar medicación estimulante y otras sustancias antes de dormir.

- Mantener un buen control analgésico nocturno, preferiblemente con analgésicos de larga vida media.

- Evitar estar tiempo innecesario en la cama durante el día; para pacientes encamados, proporcionar estímulos físicos y cognitivos a lo largo del día.

- Minimizar interrupciones nocturnas por ruidos, administración de medicación u otras condiciones ambientales.

- Eliminar estímulos desagradables, como relojes, de la habitación.

- Evitar estar en la cama durante la noche despierto, intentando dormir; realizar alguna actividad relajante (leer), fuera de la cama preferiblemente, hasta que aparezca somnolencia.

- Evitar siestas es las últimas horas de la tarde.

- Usar medicación hipnótica tras una correcta evaluación del trastorno del sueño y evitar su sobreuso.

Figura 14. Medidas higiénicas para los trastornos del sueño en pacientes oncológicos 295

En cuanto a la evidencia aportada por la literatura en este tipo de intervenciones observamos un estudio de Barsevick y sus colaboradores, con una muestra de 296 individuos, en tratamiento activo, los cuales reportaron importantes disminuciones en los niveles de astenia tumoral tras haber recibido 
medidas educativas, principalmente técnicas de conservación o ahorro energético, antes y durante su tratamiento 296.

\section{INTERVENCIONES PSICOSOCIALES}

Para analizar este tipo de intervenciones nos hemos basado en la clasificación que hace de ellas la última versión, elaborada en el año 2013, de la Guía de astenia tumoral de la National Comprehensive Cancer Network. Esta habla de cómo los pacientes deben ser asesorados acerca del afrontamiento de síntomas como la ansiedad o el distrés, que comúnmente son asociados al cáncer o a su tratamiento. Además, estos pacientes deben ser capaces de controlar su estado emocional, el cual cuando es negativo afecta a los niveles de astenia tumoral.

Estas intervenciones psicosociales se agrupan en tres:

- Terapias cognitivas.

- Psicoterapias.

- Terapias de apoyo.

Esta clasificación se elaboró después de examinar los últimos tres metaanálisis realizados sobre el tipo y la eficacia de las intervenciones psicosociales $297,298,299$. 
En muchos de los estudios examinados en estos meta-análisis, se observa como la fatiga era un ítem secundario de estudio. Se mide sólo como consecuencia de la evaluación del estado emocional o la calidad de vida. Por lo tanto, los pacientes incluidos en estos estudios pueden o no haber tenido niveles significativos de astenia, lo que limita el impacto potencial de la intervención.

Aún así si examinamos más detenidamente las series, observamos cómo se analizan 41 estudios con una muestra de 3620 individuos. Hay tres metaanálisis principales:

- Kangas y colaboradores 300 hablan de un efecto de 0.31 de las intervenciones psicosociales en los niveles de astenia tumoral.

- Goedendorp y sus colaboradores ${ }^{301}$ analizan 27 estudios randomizados, de esos, 7 muestran beneficios estadísticamente muy significativos en la mejora de los niveles de astenia.

- Jacobsen and colleagues 302 analizan 30 estudios randomizados y encontraron un efecto significativo en las intervenciones psicosociales, pero no en los programas basados en la actividad.

\section{MEDIDAS NUTRICIONALES}

La relación entre la astenia tumoral y las alteraciones nutricionales es desconocida ${ }^{303}$. 
Si consideramos la astenia como un déficit de energía, ésta se produce cuando las demandas energéticas del organismo superan sus reservas energéticas, como podría ocurrir en la malnutrición ${ }^{304}$.

Los déficits nutricionales son extraordinariamente frecuentes en los pacientes con cáncer, por tres mecanismos fundamentales:

- Aumento de las necesidades energéticas: por fiebre o hipercatabolismo tumoral.

- Disminución de la absorción de nutrientes: por vómitos, anorexia o diarrea.

- Incapacidad de utilizar los nutrientes: síndrome de caquexia-anorexia.

La necesidad de conseguir una adecuada hidratación y nutrición en los pacientes con cáncer es una parte importante del tratamiento de estos enfermos, mediante antianoxígenos, suplementos alimentarios, rehidratación o incluso consejo por una dietista si fuera necesario.

Aún así todavía no hay estudios que comparen este tipo de medidas nutricionales con los niveles de astenia tumoral, o si los hay carecen de la metodología y el rigor científico suficiente como para basarnos en su evidencia. 


\section{CONCLUSIONES AL APARTADO DE INTRODUCCIÓN}

Tras haber analizado las diferentes intervenciones utilizadas para el manejo de la astenia tumoral, hemos llegado a las siguientes conclusiones:

En el caso del tratamiento de los factores predisponentes podemos afirmar que este es efectivo, exclusivo y excluyente; efectivo por sus buenos resultados, exclusivo por su única aplicación en determinados factores etiológicos, y excluyente ya que no puede ser utilizado en numerosas causas que conllevan sintomatología de astenia.

Si se habla de las terapias farmacológicas tenemos que hacer especial mención a los factores secundarios derivados de las mismas, ya que éstos (ansiedad, alteraciones del sueño o miopatía corticoidea), pueden inducir e incluso aumentar los niveles de astenia.

Por lo que en el estudio propuesto intentaremos analizar más profundamente el uso de intervenciones no farmacológicas. Estas intervenciones serán siempre personalizadas para cada individuo en función de las necesidades, pero carecerán de algunos métodos tradicionales de actuación empleados. Pongamos por ejemplo el ejercicio físico, la evidencia nos muestra como la realización de ejercicio físico por parte de los pacientes (caminar, correr...) 
conllevan beneficios en términos de fatiga. Pero ¿realmente es necesario ese tipo de entrenamiento para un paciente con cáncer?

Nuestra propuesta se basará en un Programa de Reeducación al Esfuerzo, el cual hará especial hincapié en que el individuo sea capaz de ser independiente en sus Actividades de la Vida Diaria (AVD). Proporcionaremos junto con las terapias no farmacológicas descritas un programa de Reentrenamiento en Actividades de la Vida Diaria.

La metodología de trabajo estará basada en la Terapia Ocupacional basada en la integración funcional. Es un nuevo método de intervención en pacientes en fase aguda y subaguda, basado fundamentalmente en el tratamiento de la disfunción con función.

Este método surgió para dar respuesta a las continuas demandas de pacientes y cuidadores en el servicio de geriatría, orientadas hacia la necesidad de conseguir una mayor independencia del paciente. Existía una desmotivación de los pacientes hacia la realización de tratamientos terapéuticos convencionales centrados en el déficit. Para ello fue preciso crear un nuevo método de intervención que lograse la mayor funcionalidad posible en el menor período de tiempo, buscando tratamientos mucho más eficaces, rápidos y dinámicos.

La movilidad funcional será el eje central del tratamiento. 
Con la terapia ocupacional basada en la integración funcional, el refuerzo de la ganancia funcional del paciente será inmediato, por lo que, tanto él como su familia/cuidador se implicarán más con el tratamiento. Se puede decir que aumenta el nivel de colaboración, consiguiendo que durante el resto del día, en el cual el paciente no recibe intervenciones, se continúen potenciando los beneficios obtenidos (es lo que se puede denominar como "terapia 24 horas"), estimulando y movilizando al paciente fuera de la habitación, (deambulando, en silla de ruedas) llevándolo al baño, dejando que coman solos... en definitiva fomentando su independencia y evitando la pérdida de funcionalidad consecuente de la sintomatología de astenia que secundariamente empeorará la calidad de vida del individuo. 
2. HIPÓTESIS Y

OBJETIVOS 


\subsection{HIPÓTESIS}

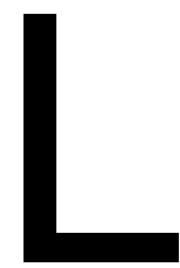

a revisión bibliográfica realizada sobre el tratamiento de los pacientes oncológicos diagnosticados de la sintomatología de astenia tumoral pone de manifiesto la necesidad de utilizar, además del tratamiento tradicional farmacológico, otras medidas no farmacológicas que mejoran la funcionalidad de los pacientes favoreciendo su autonomía. En la mayoría de los casos los pacientes refieren cierta mejoría en los niveles de astenia con el tratamiento farmacológico pero esta mejoría no se correlaciona positivamente con una mejora en la autonomía, por lo que la pregunta que debemos hacernos sería la siguiente, ¿es suficiente la mejora sintomática de la astenia tumoral tras el tratamiento farmacológico, o por el contrario, si esa mejora no se correlaciona con el aumento de la funcionalidad estamos ante una mejora insustancial?

Para comprobar la utilidad de estas medidas se decide realizar un estudio controlado que permita comprobar la eficacia de estas intervenciones.

En base a las consideraciones anteriores hemos formulado la siguiente hipótesis: 
“Las intervenciones no farmacológicas de la Terapia Ocupacional disminuyen los niveles de astenia tumoral en los pacientes oncológicos, aumentando su autonomía y, consecuentemente a todo ello, mejoran su calidad de vida relacionada con la salud" 


\subsection{OBJETIVOS}

El objetivo principal del estudio será comprobar la eficacia de las medidas de tipo no farmacológico para el control de la astenia referida por el enfermo oncológico.

Objetivos secundarios:

I. Comprobar si los pacientes que reciben tratamiento farmacológico y no farmacológico para el control de la astenia referida por la enfermedad oncológica obtienen mejores parámetros de calidad de vida relacionada con la salud que los pacientes que solo reciben tratamiento farmacológico.

II. Determinar si la utilización de medidas farmacológicas y no farmacológicas específicas para el control de la astenia favorece la realización de las actividades de la vida diaria frente a la utilización de medidas solo farmacológicas.

III. Analizar las posibles diferencias en las correlaciones entre los niveles de astenia tumoral y los niveles de hemoglobina de los pacientes 
oncológicos que recibirán tratamiento farmacológico y no farmacológico y las diferencias en los mismos niveles en los pacientes que recibirán solo tratamiento farmacológico.

IV. Determinar la relación entre los niveles de astenia tumoral con el número de líneas de tratamiento empleadas en cada paciente.

V. Describir las características sociales de los pacientes oncológicos.

VI. Describir las características sociales de los cuidadores de los pacientes oncológicos.

VII. Analizar la relación entre el cuidador principal y la funcionalidad y autonomía de los pacientes con astenia referida por enfermedad tumoral. 
3. METODOLOGÍA 


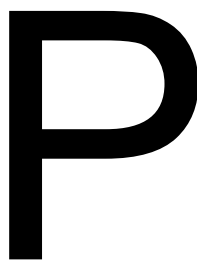

ara medir el efecto de la intervención y calcular de esta manera el tamaño muestral necesario, se realizó un estudio piloto, expuesto en el ANEXO III, de una duración de cuatro meses con los pacientes ingresados en la Unidad de Oncología del Complejo Hospitalario Universitario de Salamanca durante ese período de tiempo $(n=34)$. En este estudio piloto, los sujetos fueron asignados de forma aleatoria a la condición de experimental (Grupo I) y a la condición de control (Grupo II). Los sujetos que conformaban el grupo experimental recibieron una intervención de tipo no farmacológico para el manejo de la astenia tumoral consistente en una "reeducación al esfuerzo":

- Movilización progresiva del paciente: Ejercicio físico.

- Reeducación en actividades de la vida diaria (AVD).

- Educación individualizada: Técnicas de ahorro de energía (TAE).

- Restructuración de los períodos de descanso.

- Valorar la necesidad de producto de apoyo que facilite la movilización del paciente. 
En el estudio observamos que tanto los niveles de astenia tumoral como los parámetros de calidad de vida en este Grupo I de intervención mejoraban de forma significativa (como se muestra en el ANEXO III), por lo que a la vista de los resultados se decide realizar un estudio experimental con un aumento tanto del número de pacientes como del tiempo de intervención, que posibilita además el análisis de variables como la realización de actividades instrumentales de la vida diaria, los niveles de hemoglobina o el número de líneas de tratamiento farmacológico empleadas en cada enfermo.

\subsection{DISEÑO DEL ESTUDIO}

Se ha diseñado un estudio experimental, aleatorizado, estratificado, prospectivo longitudinal mediante un esquema paralelo de asignación fija con grupo experimental y grupo control.

\subsubsection{EMPLAZAMIENTO}

El ámbito del estudio será el Servicio de Oncología Médica del Complejo Hospitalario Universitario de Salamanca.

\subsubsection{SELECCIÓN DE LA MUESTRA}

El estudio se realizará conforme a lo expuesto en el ANEXO IV (cronograma) en el Hospital Clínico Universitario de Salamanca, en la Unidad de Oncología. 
Previa autorización por parte del paciente manifestada con el consentimiento informado leído, comprendido y firmado se procederá a la randomización. Los sujetos serán asignados de forma prospectiva, al estudio, mediante un proceso de asignación al azar, utilizando números aleatorios generados por ordenador, a las dos condiciones del estudio: Condición control: Grupo I y Condición experimental: Grupo II.

En el primero, el control, se procederá a la realización de una evaluación exhaustiva en el momento de ingreso y al momento de alta, la cual constará del análisis de los niveles de astenia tumoral, mediante el cuestionario PERFORM y la escala triple EVA; los parámetros de calidad de vida relacionada con la salud CVRS, se medirán gracias al cuestionario SF-12; el nivel de AVD, medido con la escala Lawton y Brody, además de valorar una serie de variables intervinientes recogidas en una base de datos.

En el segundo, el experimental, además de realizar la misma valoración en el momento de ingreso y al alta que en el grupo control, se llevará a cabo con cada individuo una sesión individualizada diaria de una duración aproximada de 30 minutos en la cual se utilizarán las medidas no farmacológicas descritas anteriormente para el control de la astenia referida por la enfermedad oncológica. 


\subsubsection{CRITERIOS DE INCLUSIÓN}

Pacientes del Grupo Experimental y Grupo Control

1. Tener entre los motivos de ingreso un diagnóstico anatomopatológico de enfermedad oncológica de estadio IV de nuevo diagnóstico o en recaída.

2. Tener una patología oncológica mamaria, pulmonar o del aparato digestivo.

3. Estar ingresados en el Servicio de Oncología del Hospital Universitario de Salamanca.

4. Firmar un consentimiento informado en el que autorizan su participación voluntaria en el estudio. 


\subsubsection{CRITERIOS DE EXCLUSIÓN}

Pacientes del Grupo Experimental y Grupo Control

1. No tener entre los motivos de ingreso un diagnóstico anatomopatológico de enfermedad oncológica de estadio IV de nuevo diagnóstico o en recaída.

2. Aún teniendo un diagnóstico de enfermedad oncológica, no presentar patología de tipo mamaria, pulmonar o relacionada con el aparato digestivo.

3. No firmar un consentimiento informado, y por lo tanto no autorizar su participación en el estudio.

4. Presentar un diagnóstico de metástasis óseas.

5. No disponer de un adecuado estado cognitivo para comprender y llevar a cabo las órdenes que se le faciliten.

6. Presentar niveles de astenia superiores a 45 en escala PERFORM o superiores a 7 en EVA.

7. Llevar a cabo un número de sesiones de rehabilitación inferior a 5.

8. Presentar unos niveles de hemoglobina inferiores a $10 \mathrm{~g} / \mathrm{dl}$. 


\subsubsection{ALEATORIZACIÓN}

El propósito primario de la aleatorización es garantizar que la posible inferencia causal observada al final del estudio no se deba a otros factores Se ha elegido un proceso de aleatorización frente a la asignación no probabilística (sistemática, secuencial, por facilidad o por conveniencia), ya que esta no puede asegurar el equilibrio entre los grupos. La aleatorización tiene como propósito prevenir la existencia de diferencias entre los grupos que no sean derivadas de los tratamientos que se están comparando. De esta manera, cuando se produce un equilibrio de las posibles variables que pudiera modificar el efecto del tratamiento sobre la variable de desenlace, las diferencias que se encuentran se deben considerar estrictamente como debidas a la maniobra bajo estudio.

El proceso de aleatorización se realizará por el método de la asignación aleatoria simple, utilizando una tabla de números aleatorios generada mediante el programa Microsoft Excel $2007 \AA$. El listado de números aleatorios ordenados (Anexo V), generado por este programa, servirá para asignar por orden de inclusión en el estudio a los pacientes en el momento del alta hospitalaria, grupo experimental si le corresponde un número par y grupo control si el correspondiente es impar. 


\subsubsection{TAMAÑO MUESTRAL:}

Para determinar el tamaño muestral del proyecto, y puesto que se trata de un estudio de contraste de hipótesis, hemos tenido en cuenta varios aspectos: la definición de la hipótesis (unilateral o bilateral), la magnitud de la diferencia a detectar, la seguridad del estudio y el poder estadístico.

Previo, y como se ha comentado, se realizó un estudio piloto en el cual se incluyeron 34 individuos.

Los resultados obtenidos, expuestos en el ANEXO I, han servido para calcular el tamaño muestral a obtener.

El efecto de la intervención experimental es del $31 \%$ con respecto al $11 \%$ del grupo control.

En cuanto a la magnitud de la diferencia a detectar, se ha considerado la mínima: 15\%.

Se ha decidido que la hipótesis debe ser unilateral porque se ha considerado que en los parámetros a comparar entre ambos grupos solo es posible el efecto en una dirección.

Por lo que teniendo en cuenta todo lo anterior, el número de individuos por grupo debe ser no inferior a 69 . 
A partir de ese dato, introducimos la corrección de la muestra ajustada a las pérdidas, según la fórmula, $\mathrm{n}(1 / 1-\mathrm{R})$. Dónde consideramos a $\mathrm{n}$ como el número de sujetos necesarios y $\mathrm{R}$ la proporción de pérdidas que se estiman (teniendo en cuenta el piloto), en nuestro caso es de un $15 \%$.

$138(1 / 1-0,15)=162,3$

Por lo que el tamaño muestral estimado deberá ser de 162, 3 individuos (81 en cada grupo aproximadamente).

Se decide incluir más pacientes para compensar las diferencias que pueden suceder al utilizar números aleatorios generados por ordenador en la randomización.

Por lo que se decide un tamaño muestral final total $n=180$ individuos.

\subsubsection{FUENTE Y RECOGIDA DE DATOS}

La muestra de pacientes procederá del Servicio de Oncología Médica del Complejo Asistencial Universitario de Salamanca, en el momento de hospitalización de los mismos.

Se utilizará una base de datos para la recogida y almacenamiento de datos en Microsoft Access $®$, diseñada específicamente para este estudio. 


\subsubsection{DESCRIPCIÓN DE LAS VARIABLES}

\subsubsection{Variable independiente:}

La variable independiente será la intervención desde un punto de vista rehabilitador de Terapia Ocupacional el paciente oncológico, mediante la utilización de terapias de tipo no farmacológico para el control de la astenia referida por la enfermedad oncológica.

\subsubsection{Variable dependiente:}

- Niveles de astenia tumoral.

- Calidad de vida relacionada con la salud.

- Actividades de la vida diaria.

3.1.6.3. Variables intervinientes:

- Edad

- Sexo

- Diagnóstico

- Nivel cultural

- Cuidador principal

- Línea de tratamiento

- Niveles de hemoglobina 


\subsubsection{INSTRUMENTOS DE EVALUACIÓN Y RECOGIDA DE}

RESULTADOS:

Para evaluar las diferentes variables dependientes en ambos grupos utilizaremos las siguientes hojas de registro, escalas y cuestionarios.

Niveles de astenia tumoral:

- Cuestionario PERFORM (percepciones de la fatiga en pacientes oncológicos, su realidad y medición).

Escala triple EVA de astenia.

Calidad de vida relacionada con la salud: Cuestionario SF-12.

Actividades de la vida diaria (AVD): Escala de Lawton y Brody.

Variables intervinientes: se ha utilizado una hoja de registro para cada paciente, en la cual se anotaran todos los datos referentes a los parámetros referidos. 


\subsubsection{DESCRIPCIÓN DE LA INTERVENCIÓN}

Para analizar la intervención que se ha llevado a cabo en el grupo experimental, la dividiremos en tres apartados:

I. Ingreso del paciente.

II. Tiempo que permanece ingresado en el Servicio de Oncología Médica del Hospital Universitario de Salamanca.

III. Momento del alta hospitalaria del paciente.

\section{INGRESO DEL PACIENTE}

Después del ingreso del paciente en la Unidad de Hospitalización del Servicio de Oncología tras considerar que cumple los criterios de inclusión y exclusión propuestos procederemos a la aleatorización, la cual determinará a qué grupo va a pertenecer, ya sea al grupo control o al grupo experimental.

Posteriormente le ofreceremos la posibilidad de participar en el estudio, la cual autorizará siempre y cuando firme el consentimiento informado, mostrando de forma libre y voluntaria su intención de participar en el mismo.

A continuación se procederá a la evaluación inicial exhaustiva del enfermo. Para evitar sesgos subjetivos provenientes de una entrevista en la cual el profesional pudiera o pudiese interferir en los resultados del individuo, se han seleccionado escalas o cuestionarios validados que son autoadministrables, 
todos a excepción de la escala de Lawton y Brody. Este apartado será el mismo tanto en el grupo control como en el experimental. Se le entregará al paciente los cuestionarios para que los autocomplete dejándole un tiempo de una hora para que lo lleve a cabo. Una vez haya transcurrido el tiempo, y ya solo en el grupo experimental, se procederá a una entrevista entre el terapeuta ocupacional y el paciente en la cual se pactará y explicará al usuario en que va a consistir la intervención, así como se llegará a un acuerdo entre los objetivos que plantea la persona y los que considera el profesional.

Además se le entregará a cada individuo una hoja de seguimiento (ANEXO VI), en la cual se deberá anotar los niveles de actividad llevados a cabo, para diariamente poder modificarlos conforme avance el proceso rehabilitador.

\section{TIEMPO QUE PERMANECE INGRESADO EN EL SERVICIO DE ONCOLOGÍA MÉDICA DEL HOSPITAL UNIVERSITARIO DE SALAMANCA}

Durante el tiempo que permanezca ingresado en la unidad, y siempre considerando que hablamos del grupo experimental, cada usuario recibirá diariamente una sesión de terapia ocupacional de duración aproximada a 45 minutos. En ella se llevara a cabo el programa propuesto de reeducación al esfuerzo, el cual tendrá como apartados fundamentales los siguientes:

Movilización progresiva del paciente: Ejercicio físico.

Reeducación en actividades de la vida diaria (AVD). 
Educación individualizada: Técnicas de ahorro de energía (TAE).

Restructuración de los períodos de descanso.

Valorar la necesidad de producto de apoyo que facilite la movilización del paciente.

Además, también de forma diaria se revisará la hoja de seguimiento administrada, intentando hacer un seguimiento completo del paciente para que se lleve a cabo ese programa de rehabilitación "24 horas" del que hablamos en el apartado de "manejo de astenia tumoral". Con esto se intentará involucrar tanto al paciente como a su cuidador en la rehabilitación. Esta implicación del cuidador pretende conseguir que la intervención sea más efectiva.

\section{MOMENTO DEL ALTA HOSPITALARIA DEL PACIENTE}

En el momento en el que se considera posible el alta hospitalaria se procederá a la evaluación final del usuario.

Al igual que en la evaluación inicial, se le entregarán a los usuarios, en este caso tanto a aquellos que pertenecen al grupo experimental como a aquellos que pertenecen al grupo control, los cuestionarios y escalas de medida. Se les dejará una hora para que las completen recogiendo así los resultados finales.

Por último debemos decir que en aquellos que pertenecieron al grupo experimental se le darán una serie de recomendaciones que podrán llevar a 
cabo en sus domicilios, facilitando su reinserción a su actividad cotidiana y intentando evitar posibles recaídas, haciéndoles conscientes de que ellos deben ser los primeros que deben modificar ciertos hábitos o rutinas que pueden llevar a desencadenar la sintomatología. 


\subsubsection{ASPECTOS ÉTICOS DEL PROYECTO:}

"Los proyectos que impliquen la investigación en humanos o la utilización de muestras de origen humano deberán atenerse a lo dispuesto en la Ley 14/2007, de 3 de julio, de Investigación Biomédica".

Por ello se solicitó la autorización por parte Comité Ético de Investigación Clínica del área de salud de Salamanca para proceder a la realización del proyecto de investigación propuesto.

Su resolución positiva para llevarlo a cabo aparece en el ANEXO VII. 


\subsubsection{LIMITACIONES}

La escala de Lawton y Brody no pudo ser autoadministrada, pudiendo haber una interferencia subjetiva en los resultados por parte del entrevistador sanitario. Además consideramos que en este caso, este tipo de actividades, al no poderse realizar dentro del ámbito hospitalario pueden estar sujetas a información subjetiva por parte del paciente que puede que en el momento de llevarse a cabo no se correlacione con la situación real en su actividad cotidiana. 


\subsection{METODOLOGÍA ESTADÍSTICA}

Los objetivos principales del estudio son comprobar la eficacia de las medidas de tipo no farmacológico para el control de la astenia referida por la enfermedad oncológica en la disminución de los niveles de astenia de los pacientes, comparando la diferencia presente en estos niveles entre el Grupo Control (Grupo I) y el Grupo Experimental (Grupo II).

Previamente a esto se realizará un estudio descriptivo de las variables generales de los pacientes.

\subsubsection{Estadística descriptiva}

En la estadística descriptiva analizaremos las variables cuantitativas procedentes tanto de las pruebas y cuestionario de evaluación de astenia tumoral, calidad de vida relacionada con la salud y funcionalidad, como de las diferentes variables de tipo intervinientes descritas anteriormente.

Las variables cuantitativas que seguían una distribución normal fueron definidas por media, desviación típica e intervalo de valores. 
Para evaluar si una variable seguía una distribución normal, se comprobó que presentaba una curva equivalente a la campana de Gauss y se comprobó mediante el test de Kolmogorov-Smirnoff $(p<0,05)$.

\subsubsection{Estadística analítica}

La comparación de variables cuantitativas con cualitativas se realizó mediante el método "t" de Student para muestras independientes (comparación de dos medias), cuando las variables cuantitativas seguían una distribución normal.

Finalmente se realizará el análisis de las correlaciones bivariadas mediante la prueba de correlación de Pearson.

Se consideran como significativos valores de $p<0,05$, y como estadísticamente muy significativos aquellos con valores $p<0,001$.

\subsubsection{Procesado de datos}

El proceso de análisis de los datos se llevará a cabo utilizando para ello el paquete de datos SPSS 21.0. 
4. RESULTADOS 


\subsection{DATOS DEMOGRÁFICOS}

Se han incluido en el estudio, todos los pacientes seleccionados de forma prospectiva, que cumplían los criterios de inclusión del estudio. El estudio se realizó durante el periodo comprendido entre Junio de 2011 y Enero de 2013.

El estudio cuenta con un total de 331 individuos, de entre los cuales hubo 192 que cumplieron los criterios de inclusión y 139 que fueron excluidos por diferentes motivos.

De entre los excluidos los motivos fueron varios:

- 51 de ellos por presentar metástasis óseas y conllevar un riesgo de fractura ósea en la movilización, lo cual desaconsejaba cualquier tipo de intervención rehabilitadora.

- 11 de ellos por presentar un estadio precoz de la enfermedad, ya que en los criterios de inclusión se habla de pacientes con diagnóstico anatomopatológico oncológico de estadio avanzado.

- 30 de ellos por presentar niveles de hemoglobina inferiores a $10 \mathrm{~g} / \mathrm{dl}$. Se decidió excluir a estos ya que eran susceptibles de recibir transfusiones sanguíneas para combatir estos niveles tan bajos de hemoglobina, con la consecuente mejoría de los niveles de astenia.

- 24 de ellos por presentar niveles bajos de astenia tumoral, no considerándose como sintomatología significativa. 
- 9 de ellos por presentar imposibilidad en movilización, con la consecuente imposibilidad de realización de la reeducación al esfuerzo propuesta.

- 3 por no autorizar de forma voluntaria su participación en el estudio tras no firmar el consentimiento informado.

- 11 por presentar un déficit cognitivo grave, lo que le impide poder llevar a cabo la intervención propuesta.

Un total de 192 pacientes fueron inicialmente seleccionados y aleatorizados para el estudio. De ellos se perdieron en el proceso 12, de los cuales 10 fueron por éxitus y a 2 se le detectó un diagnóstico de metástasis óseas.

Los 180 individuos restantes se distribuyeron en dos grupos, 91 individuos en el Grupo Experimental (Grupo I) y 89 en el Grupo Control (Grupo II).

A continuación se expone un gráfico donde se puede observar todo el proceso de selección de individuos a la muestra. 


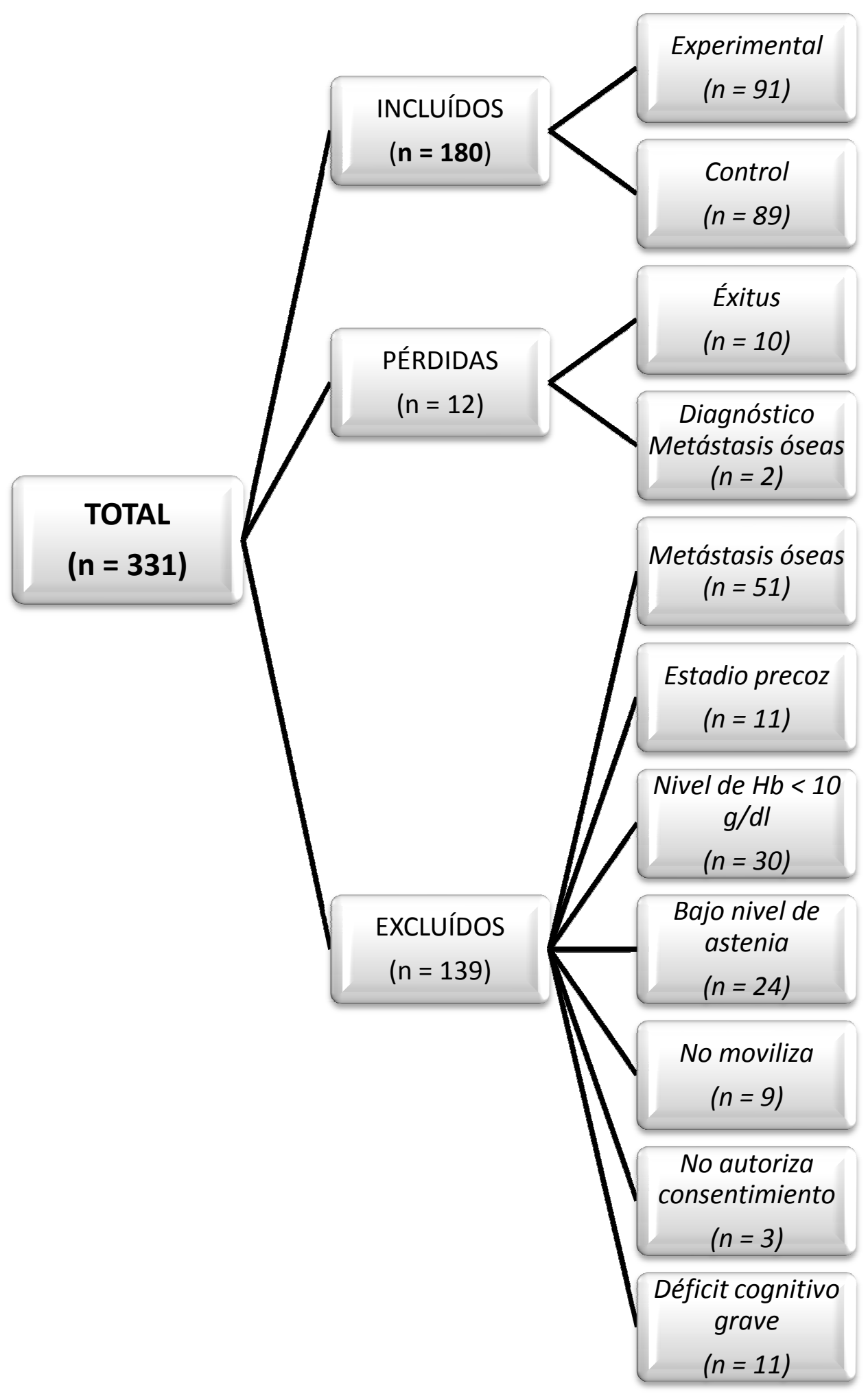

Figura 15. Distribución demográfica de los individuos al estudio 


\subsection{ESTADÍSTICA DESCRIPTIVA}

\subsubsection{VARIABLES INTERVINIENTES}

\subsubsection{ANATOMÍA PATOLÓGICA}

Los enfermos incluidos en el estudio presentaban diferentes diagnósticos oncológicos. Observamos como la patología prevalente es aquella relacionada con el aparato digestivo con un total de 82 individuos, a continuación en incidencia situamos la patología pulmonar con 57 y por último patología mamaria con 41 individuos. A continuación llevaremos a cabo un análisis más exhaustivo, en el cual abordaremos la incidencia anatomo-patológica en los diferentes grupos control y experimental.

\begin{tabular}{|c|c|c|c|c|c|}
\hline & & Frecuencia & Porcentaje & $\begin{array}{l}\text { Porcentaje } \\
\text { válido }\end{array}$ & $\begin{array}{l}\text { Porcentaje } \\
\text { acumulado }\end{array}$ \\
\hline \multirow{4}{*}{ Válidos } & Patología Mamaria & 21 & 23,1 & 23,1 & 23,1 \\
\hline & Patología Pulmonar & 30 & 33,0 & 33,0 & 56,0 \\
\hline & Patología Digestiva & 40 & 44,0 & 44,0 & 100,0 \\
\hline & Total & 91 & 100,0 & 100,0 & \\
\hline
\end{tabular}

Tabla 1. Estadísticos descriptivos de la relación de diagnósticos oncológicos en la muestra experimental 


\begin{tabular}{|ll|c|c|c|c|}
\hline & Frecuencia & Porcentaje & $\begin{array}{c}\text { Porcentaje } \\
\text { válido }\end{array}$ & $\begin{array}{c}\text { Porcentaje } \\
\text { acumulado }\end{array}$ \\
\hline \multirow{4}{*}{ Válidos } & Patología Mamaria & 20 & 22,0 & 22,5 & 22,5 \\
& Patología Pulmonar & 27 & 29,7 & 30,3 & 52,8 \\
& Patología Aparato & 42 & 46,2 & 47,2 & 100,0 \\
& Digestivo & 89 & 97,8 & 100,0 & \\
Perdidos & Sotal & 2 & 2,2 & & \\
Total & Sistema & 91 & 100,0 & & \\
\hline
\end{tabular}

Tabla 2. Estadísticos descriptivos de la relación de diagnósticos oncológicos en la muestra

control

\section{Diagnostico_E}

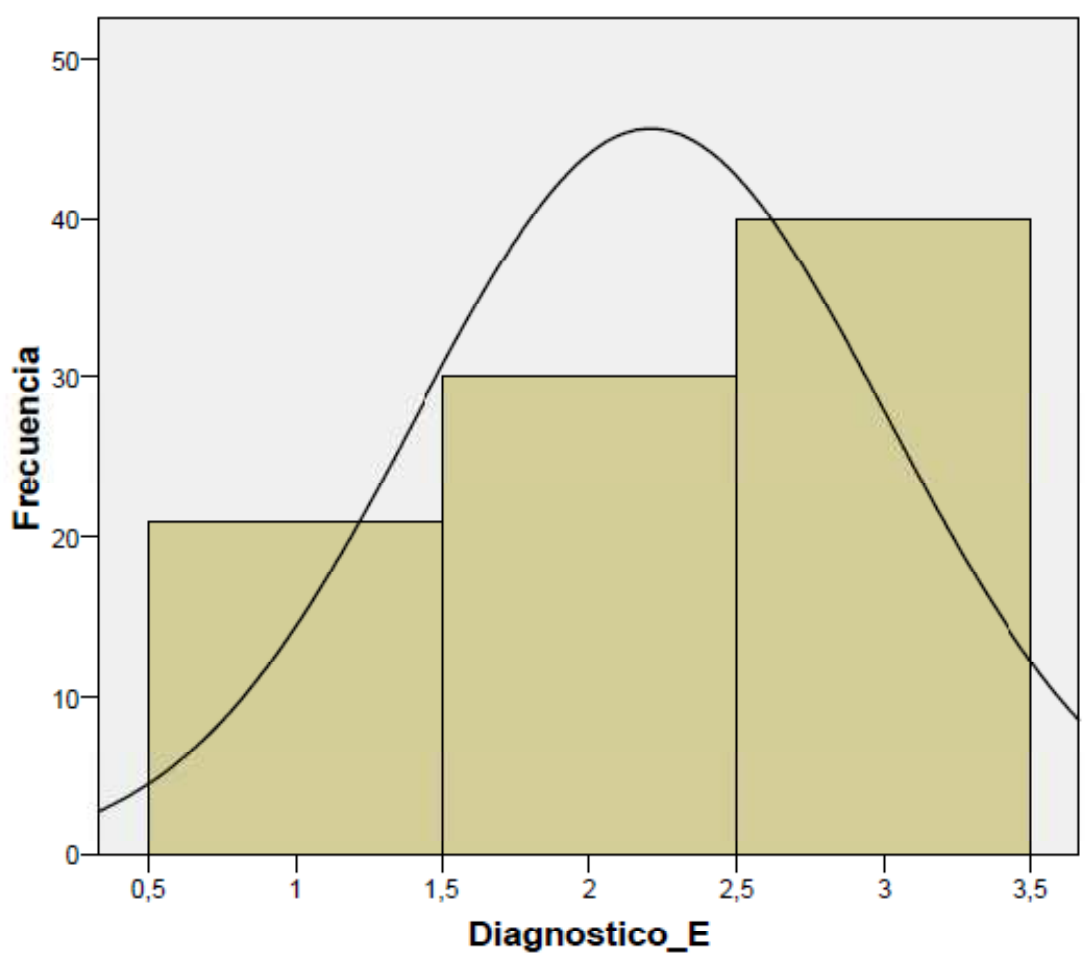

Media $=2,21$

Desviación típica $=0,796$

Figura 16. Representación Gráfica de los diferentes diagnósticos anatomo-patológicos en

Grupo Experimental. $(1=$ Mama, 2 = Pulmón, 3 = Aparato digestivo $)$ 


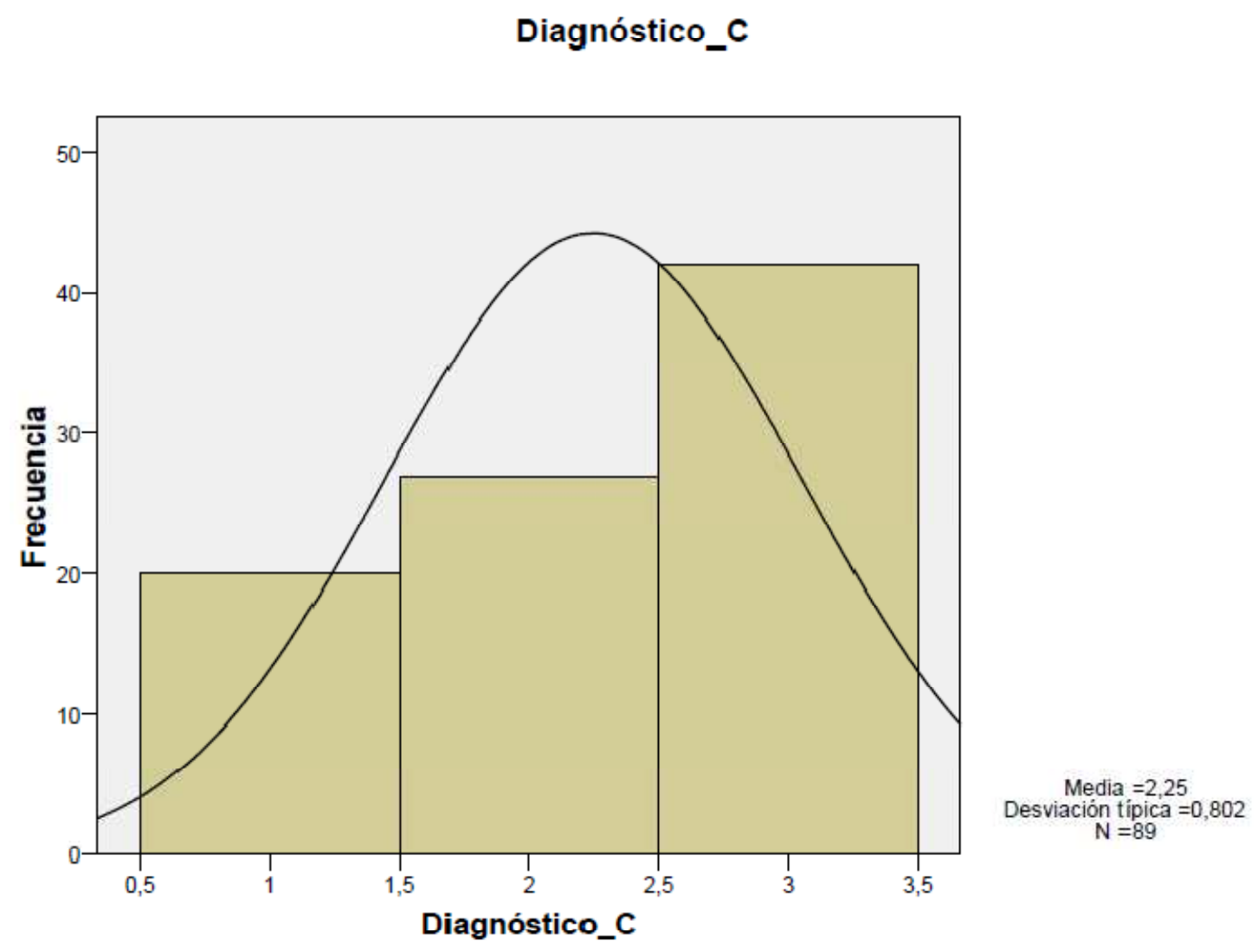

Figura 17. Representación Gráfica de los diferentes diagnósticos anatomo-patológicos en Grupo Control. (1 = Mama, 2 = Pulmón, 3 = Aparato digestivo) 


\subsubsection{EDAD}

La edad media del total de la muestra fue de 68 años (mínimo 41 - máximo 92).

El Grupo Experimental presentó una edad media de 69,79 años, mientras que los individuos del Grupo Control presentaron una edad media de 67,15 años. No hay diferencias entre los grupos en cuanto a la variable interviniente edad.

La representación gráfica de los rangos de la Variable "Edad Total de la Muestra" de cada grupo (Grupo Experimental y Grupo Control) puede verse en las siguientes figuras.

\begin{tabular}{|c|c|c|c|c|c|}
\hline GRUPO & $\mathrm{N}$ & MEDIA & $\begin{array}{c}\text { DESVIACIÓN } \\
\text { TÍPICA }\end{array}$ & MÍNIMO & MÁXIMO \\
\hline EXPERIMENTAL & 91 & 69,79 & 9,714 & 41 & 92 \\
\hline CONTROL & 89 & 67,15 & 11,168 & 41 & 87 \\
\hline TOTAL & 180 & 68,47 & 10,441 & 41 & 92 \\
\hline
\end{tabular}

Tabla 3. Estadísticos descriptivos (Medias y desviaciones típicas) de la Variable "Edad de los pacientes" del Grupo Experimental (Grupo I) y del Grupo Control (Grupo II) 


\section{Edad_E}

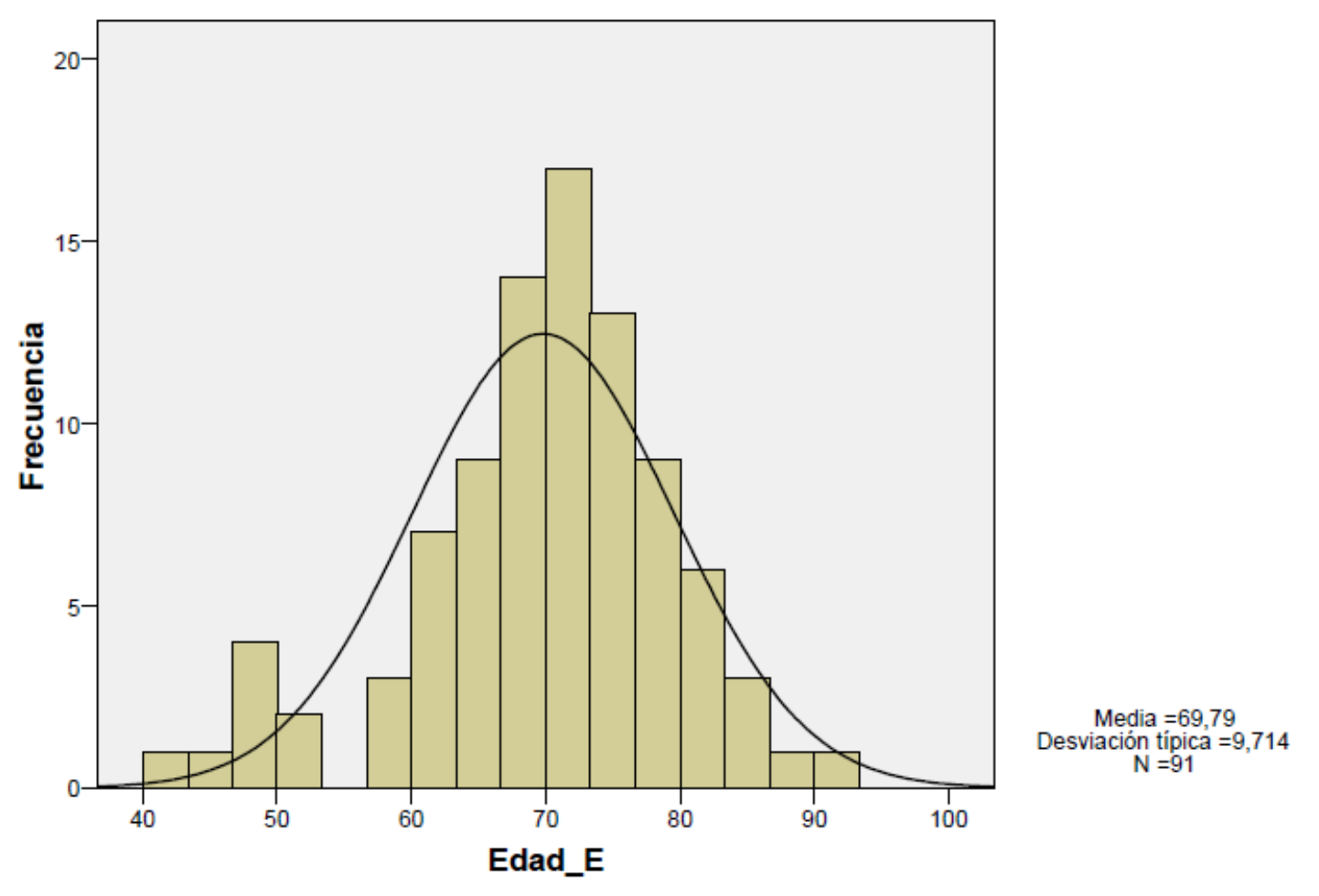

Figura 18. Representación Gráfica de la Variable "Edad de los pacientes" en Grupo Experimental 


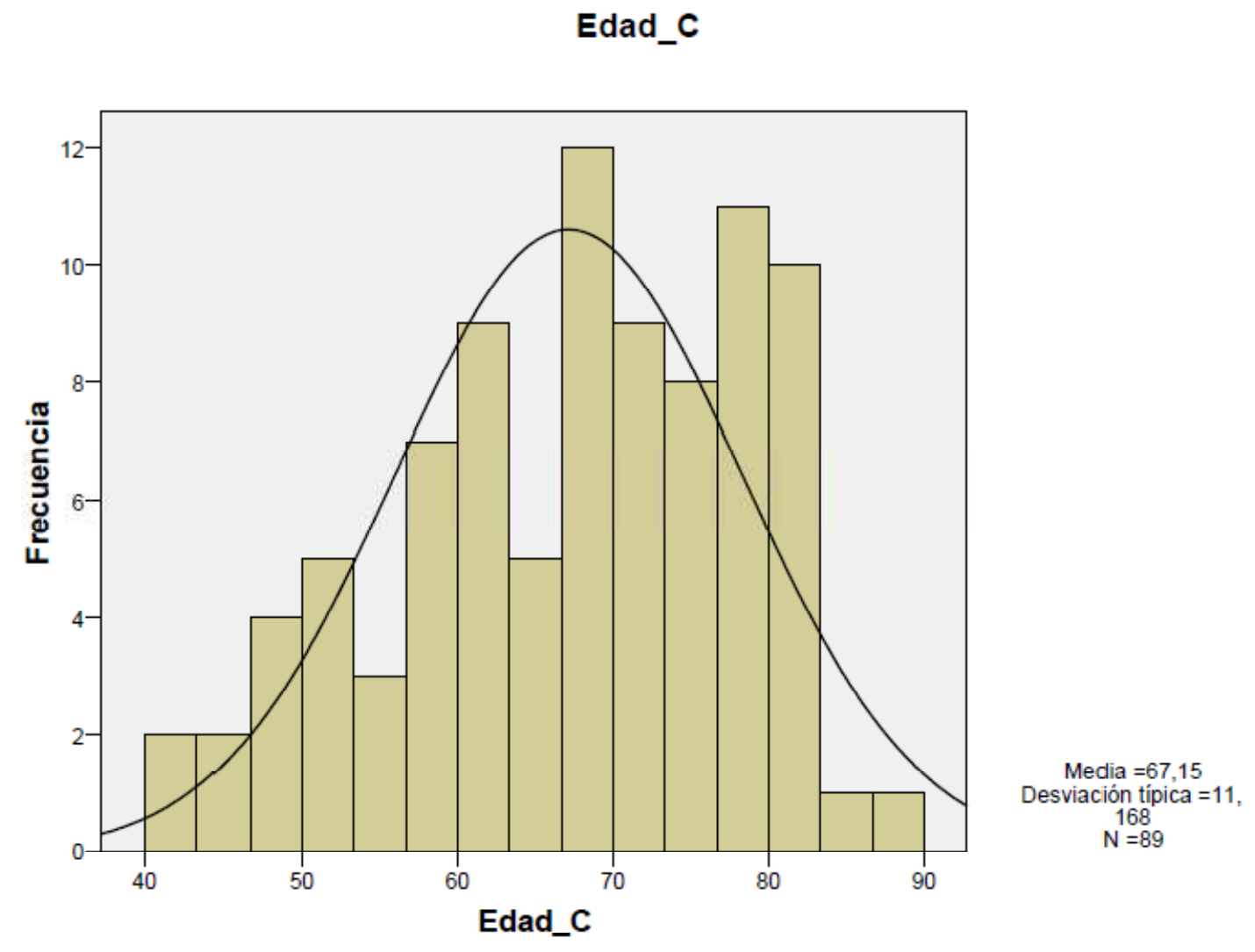

Figura 19. Representación Gráfica de la Variable "Edad de los pacientes" en Grupo Control 


\subsubsection{GÉNERO}

En cuanto al género de los pacientes, en el Grupo Experimental (Grupo I) hay 49 hombres y 42 mujeres y en el Grupo Control (Grupo II) hay 46 hombres y 43 mujeres. No hay diferencias significativas entre ambos grupos en cuanto al género. Su distribución de frecuencias puede verse en la Tabla y su representación gráfica en la Figura.

\begin{tabular}{|c|c|c|c|}
\hline GÉNERO & $\begin{array}{c}\text { GRUPO } \\
\text { EXPERIMENTAL }\end{array}$ & $\begin{array}{c}\text { GRUPO } \\
\text { CONTROL }\end{array}$ & TOTAL \\
\hline MASCULINO & 49 & 46 & 95 \\
\hline FEMENINO & 42 & 43 & 85 \\
\hline TOTAL & 91 & 89 & 180 \\
\hline
\end{tabular}

TABLA 4. Distribución de frecuencias de la Variable "Género de los pacientes" del Grupo Experimental (Grupo I) y del Grupo Control (Grupo II) 


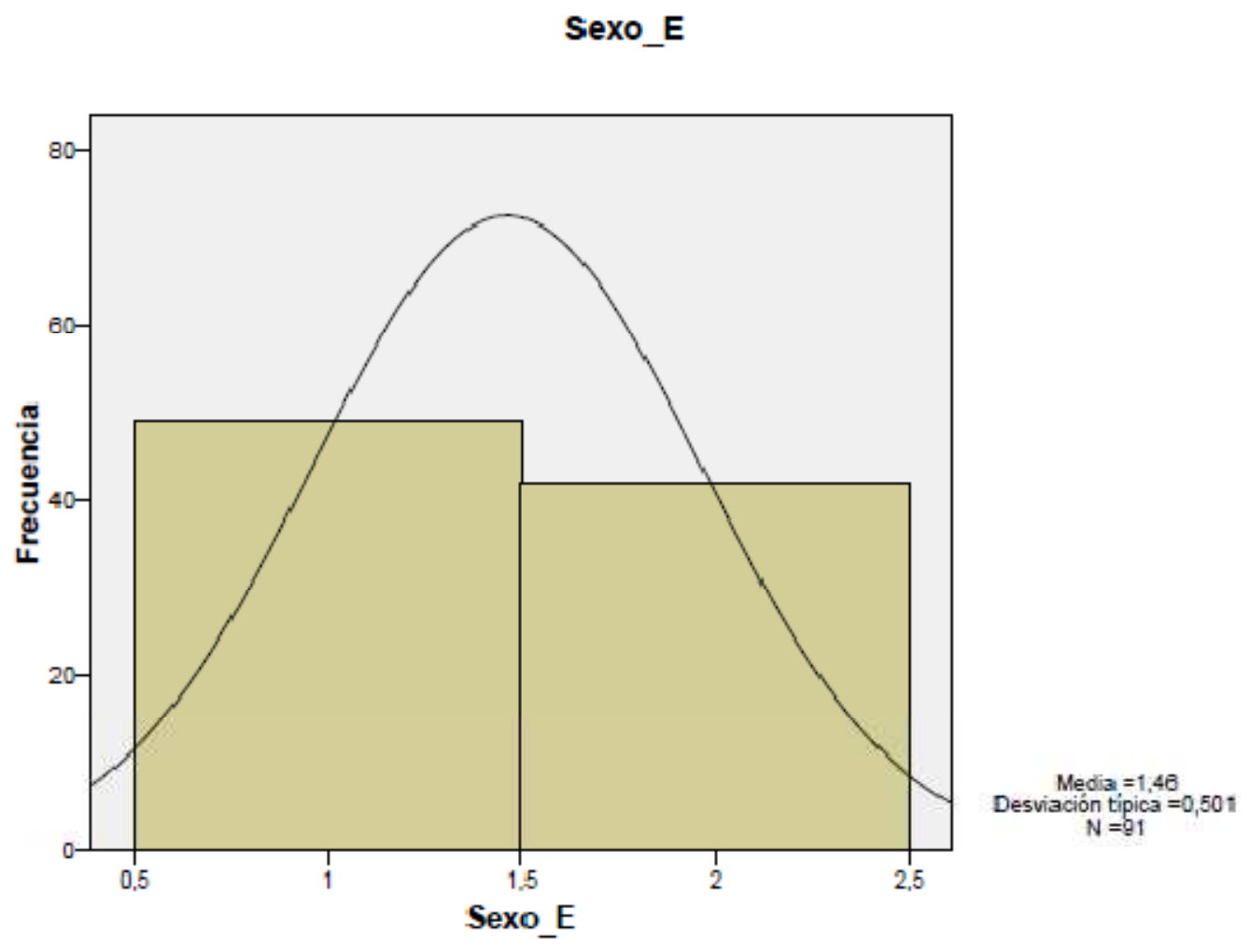

Figura 20. Representación Gráfica de la Variable "Género de los pacientes" en Grupo Experimental. $(1=$ masculino, $2=$ femenino $)$ 


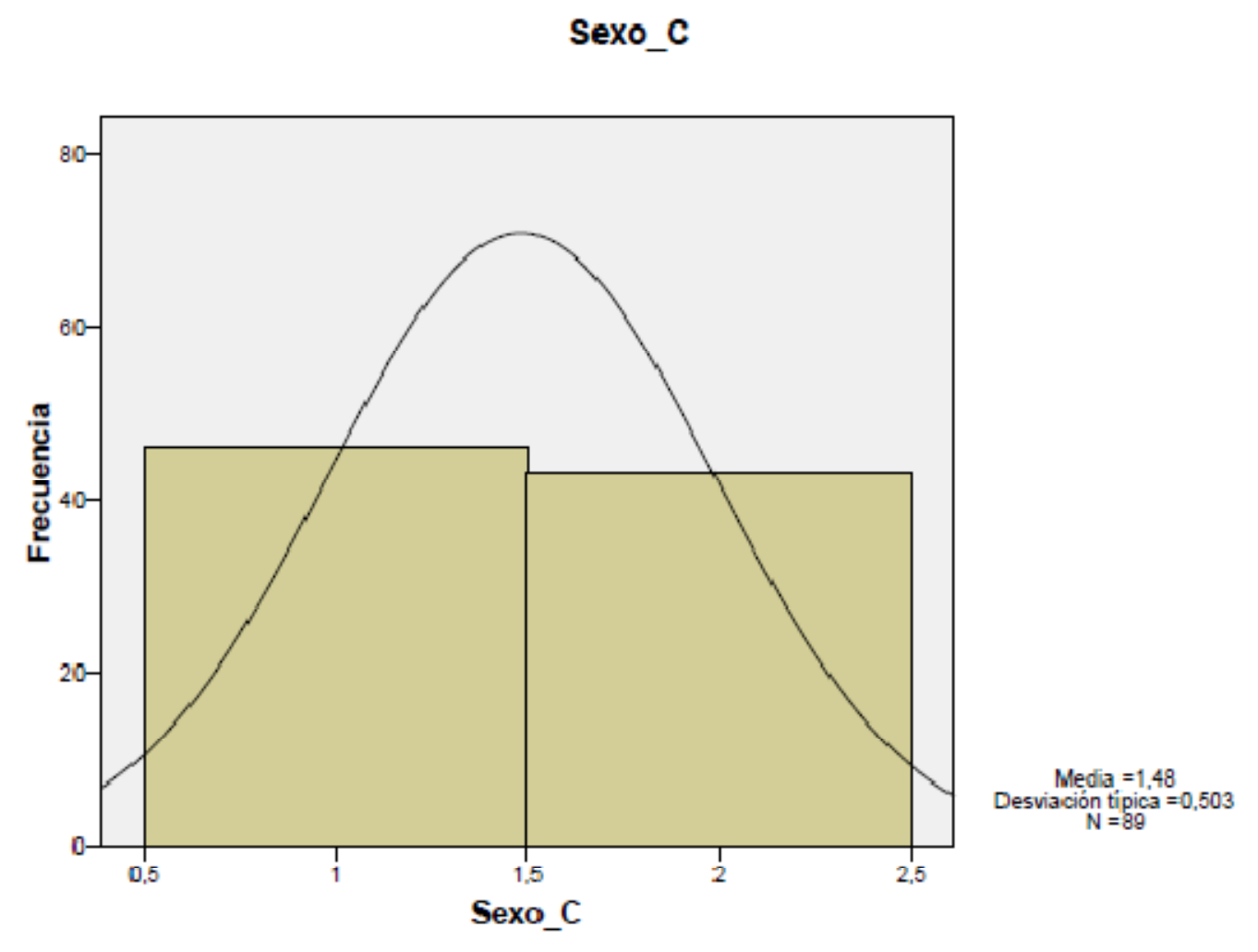

Figura 21. Representación Gráfica de la Variable "Género de los pacientes" en Grupo Control.

$$
\text { (1 = masculino, } 2 \text { = femenino })
$$




\subsubsection{NIVEL CULTURAL}

Respecto al nivel de estudios de los individuos, valorado según categorías ordenadas donde:

$1=$ Estudios primarios

2 = Estudios secundarios.

3 = Estudios superiores.

Los pacientes del Grupo experimental (Grupo I) tienen una media de estudios de 1,69 y los pacientes del Grupo control (Grupo II) tienen una media de estudios de 1,79. Por lo que no podemos afirmar que exista una diferencia significativa entre la media de estudios de los sujetos del Grupo Experimental frente a los sujetos del Grupo Control. En la Tabla figuran los estadísticos descriptivos de la variable interviniente "Nivel cultural" de los individuos de los Grupos Experimental (Grupo I) y Control (Grupo II) y en las Figuras su representación gráfica por grupos.

Nivel_cultural_E

\begin{tabular}{|c|c|c|c|c|c|}
\hline & & Frecuencia & Porcentaje & $\begin{array}{l}\text { Porcentaje } \\
\text { válido }\end{array}$ & $\begin{array}{l}\text { Porcentaje } \\
\text { acumulado }\end{array}$ \\
\hline \multirow{4}{*}{ Válidos } & Estudios primarios & 37 & 40,7 & 40,7 & 40,7 \\
\hline & Estudios secundarios & 45 & 49,5 & 49,5 & 90,1 \\
\hline & Estudios superiores & 9 & 9,9 & 9,9 & 100,0 \\
\hline & Total & 91 & 100,0 & 100,0 & \\
\hline
\end{tabular}

Tabla 5. Estadísticos descriptivos de la Variable "Nivel de estudio de los cuidadores" de los Grupos Experimental (Grupo I) y Control (Grupo II) 
Nivel_cultural_C

\begin{tabular}{|cc|c|c|c|c|}
\hline & & Frecuencia & Porcentaje & $\begin{array}{c}\text { Porcentaje } \\
\text { válido }\end{array}$ & $\begin{array}{c}\text { Porcentaje } \\
\text { acumulado }\end{array}$ \\
\hline \multirow{4}{*}{ Válidos } & Estudios primarios & 30 & 33,0 & 33,7 & 33,7 \\
& Estudios secundarios & 48 & 52,7 & 53,9 & 87,6 \\
& Estudios superiores & 11 & 12,1 & 12,4 & 100,0 \\
Perdidos & Total & 89 & 97,8 & 100,0 & \\
& Sistema & 2 & 2,2 & & \\
& Total & 91 & 100,0 & & \\
\hline
\end{tabular}

Tabla 6. Estadísticos descriptivos de la Variable "Nivel de estudio de los cuidadores" de los Grupos Experimental (Grupo I) y Control (Grupo II)

\section{Nivel_cultural_E}

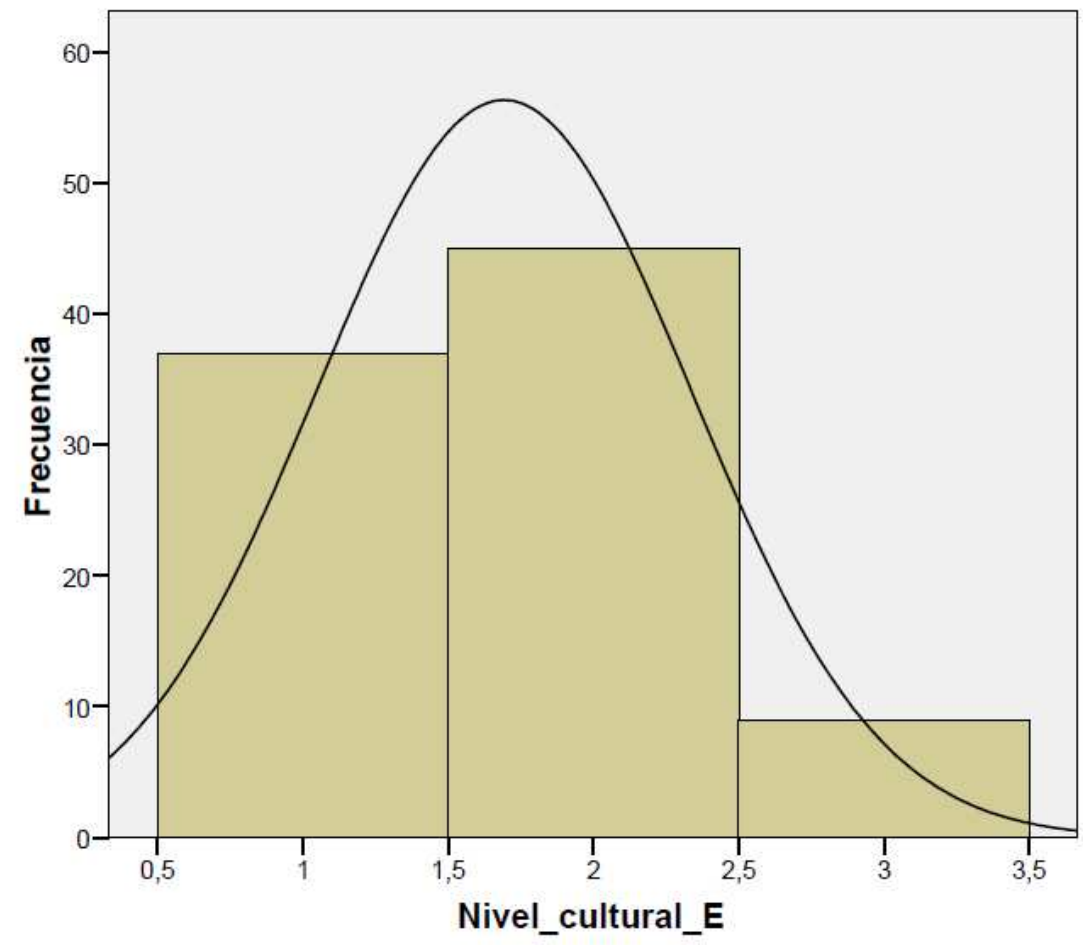

Media $=1,69$

Desviación típica $=0,645$ $\mathrm{N}=91$

Figura 22. Representación Gráfica de la Variable "Nivel cultural" en Grupo Experimental. (1 = estudios primarios, 2 = estudios secundarios, 3 = estudios superiores) 


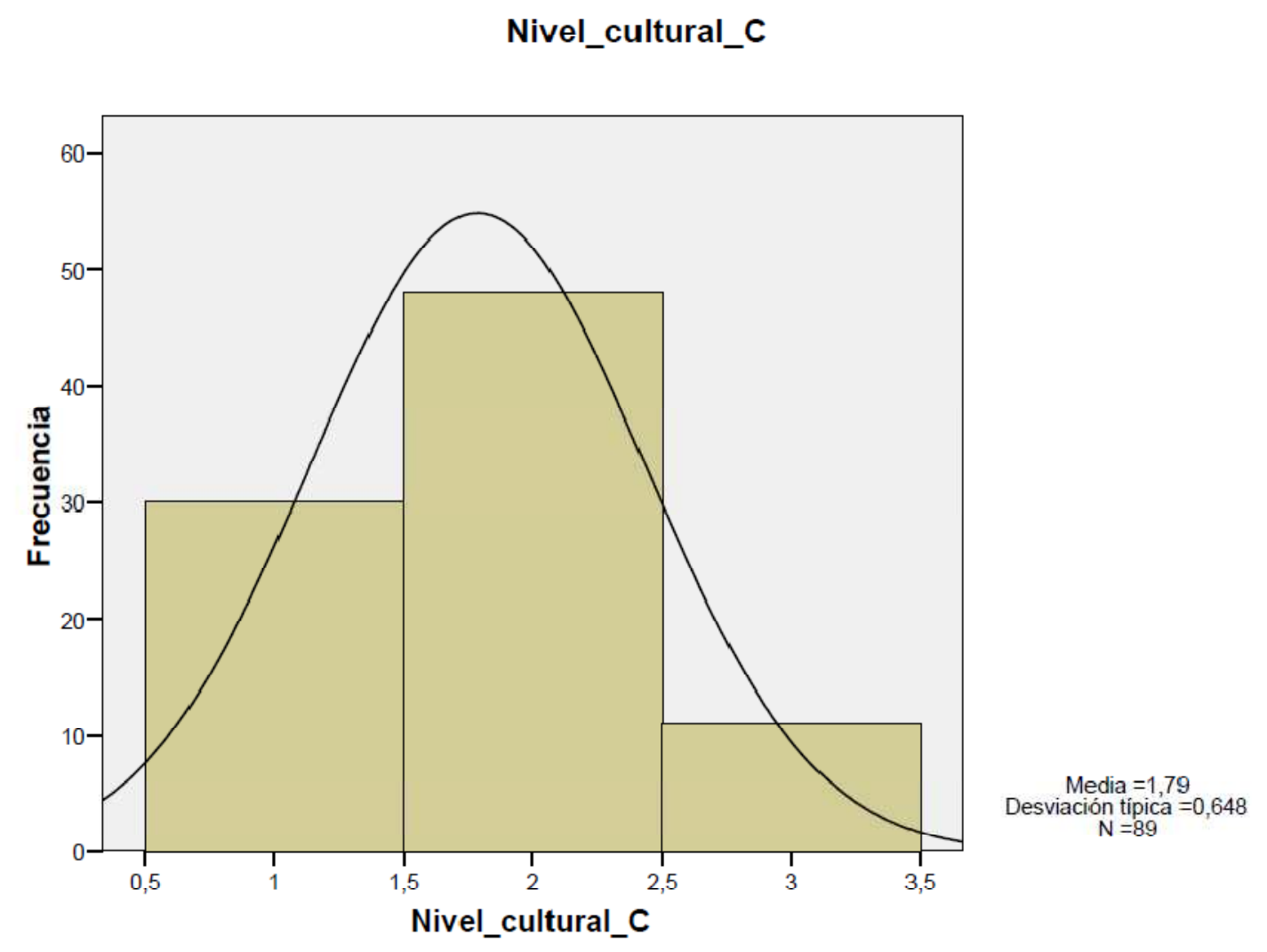

Figura 23. Representación Gráfica de la Variable "Nivel cultural" en Grupo Control. 11 = estudios primarios, 2 = estudios secundarios, 3 = estudios superiores) 


\subsubsection{CUIDADOR PRINCIPAL}

Hemos distribuido el vínculo de los cuidadores en tres categorías:

$$
\begin{aligned}
& 1 \text { = Primer grado } . \\
& 2 \text { = Segundo grado } . \\
& 3=\text { Cuidador contratado } .
\end{aligned}
$$

No se han encontrado en el estudio ningún Cuidador contratado, por lo que lo eliminamos de las posibilidades y analizaremos las otras dos categorías.

Los cuidadores de los pacientes del Grupo Experimental (Grupo I) son 85 de Primer grado y 6 de Segundo grado. En el Grupo Control (Grupo II) la distribución es la siguiente, 83 de Primer grado, 6 de Segundo grado. No hay diferencia en ambos grupos en el vínculo de los cuidadores.

Los datos se detallan de forma global, y específica a cada grupo anatomopatológico a continuación en la Tabla. Su representación gráfica puede verse en las Figuras. 


\begin{tabular}{|c|c|c|c|c|c|c|c|c|}
\hline $\begin{array}{c}\text { VÍNCULO DE } \\
\text { LOS } \\
\text { CUIDADORES }\end{array}$ & \multicolumn{2}{|c|}{$\begin{array}{c}\text { PATOLOGÍA } \\
\text { MAMARIA }\end{array}$} & \multicolumn{2}{|c|}{$\begin{array}{c}\text { PATOLOGÍA } \\
\text { PULMONAR }\end{array}$} & \multicolumn{2}{|c|}{$\begin{array}{c}\text { PATOLOGÍA } \\
\text { APARATO } \\
\text { DIGESTIVO }\end{array}$} & \multicolumn{2}{|c|}{ TOTAL } \\
\cline { 2 - 10 } & $\begin{array}{c}\text { Grupo } \\
\text { I }\end{array}$ & $\begin{array}{c}\text { Grupo } \\
\text { II }\end{array}$ & $\begin{array}{c}\text { Grupo } \\
\text { I }\end{array}$ & $\begin{array}{c}\text { Grupo } \\
\text { II }\end{array}$ & $\begin{array}{c}\text { Grupo } \\
\text { I }\end{array}$ & $\begin{array}{c}\text { Grupo } \\
\text { II }\end{array}$ & $\begin{array}{c}\text { Grupo } \\
\text { I }\end{array}$ & $\begin{array}{c}\text { Grupo } \\
\text { II }\end{array}$ \\
\hline $\begin{array}{c}\text { PRIMER } \\
\text { GRADO }\end{array}$ & 20 & 20 & 28 & 25 & 37 & 38 & 85 & 83 \\
\hline $\begin{array}{c}\text { SEGUNDO } \\
\text { GRADO }\end{array}$ & 1 & 0 & 2 & 2 & 3 & 4 & 6 & 6 \\
\hline $\begin{array}{c}\text { CUIDADOR } \\
\text { CONTRATADO }\end{array}$ & 0 & 0 & 0 & 0 & 0 & 0 & 0 & 0 \\
\hline
\end{tabular}

Tabla 7. Estadísticos descriptivos de la Variable "Vínculo Cuidador Principal" de los Grupos Experimental (Grupo I) y Control (Grupo II). De forma total y en los diferentes grupo anatomopatológicos. 


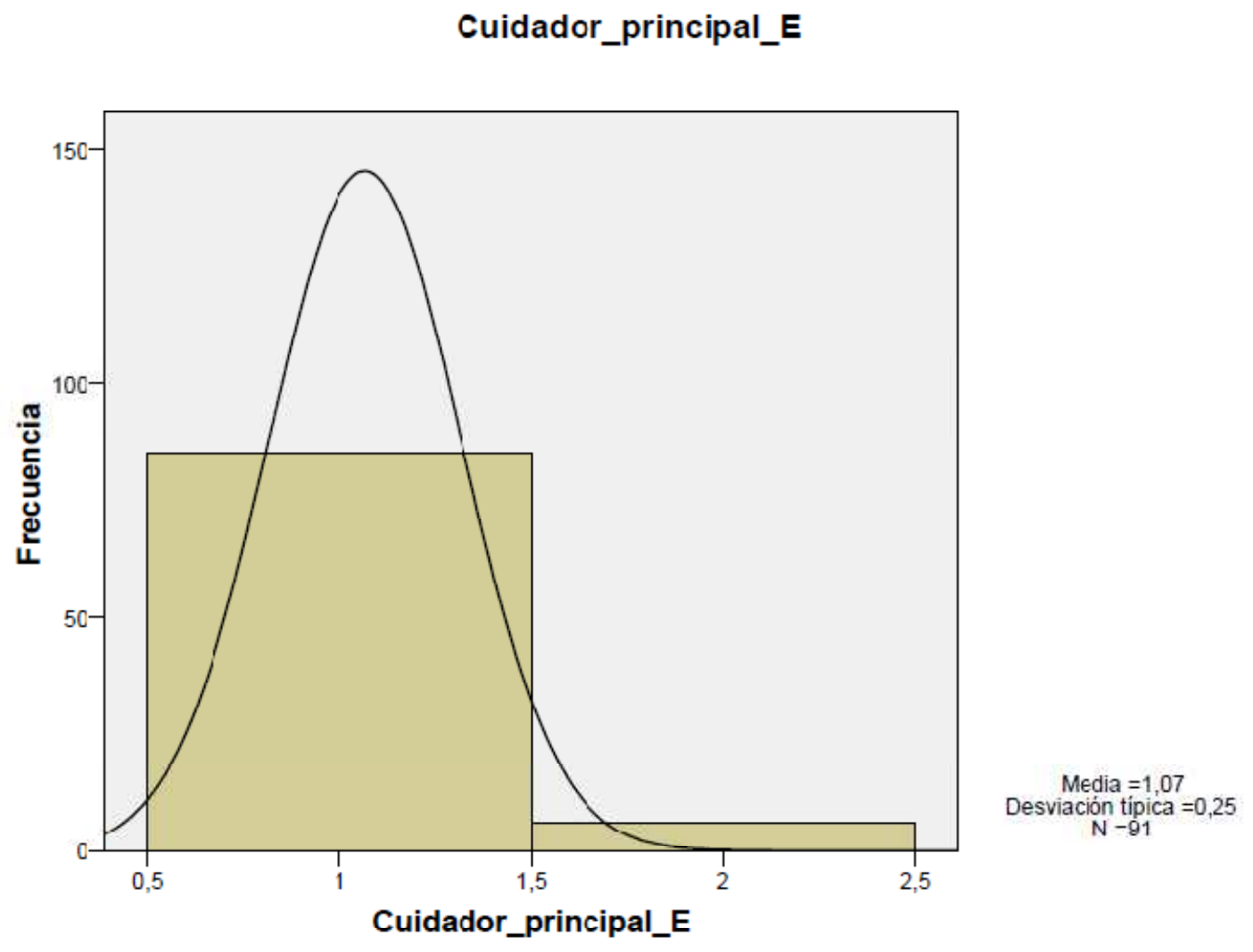

Figura 24. Representación Gráfica de la Variable "Vínculo Cuidador Principal” en Grupo Experimental. $(1=$ primer grado, $2=$ segundo grado, 3 = cuidador contratado $)$ 


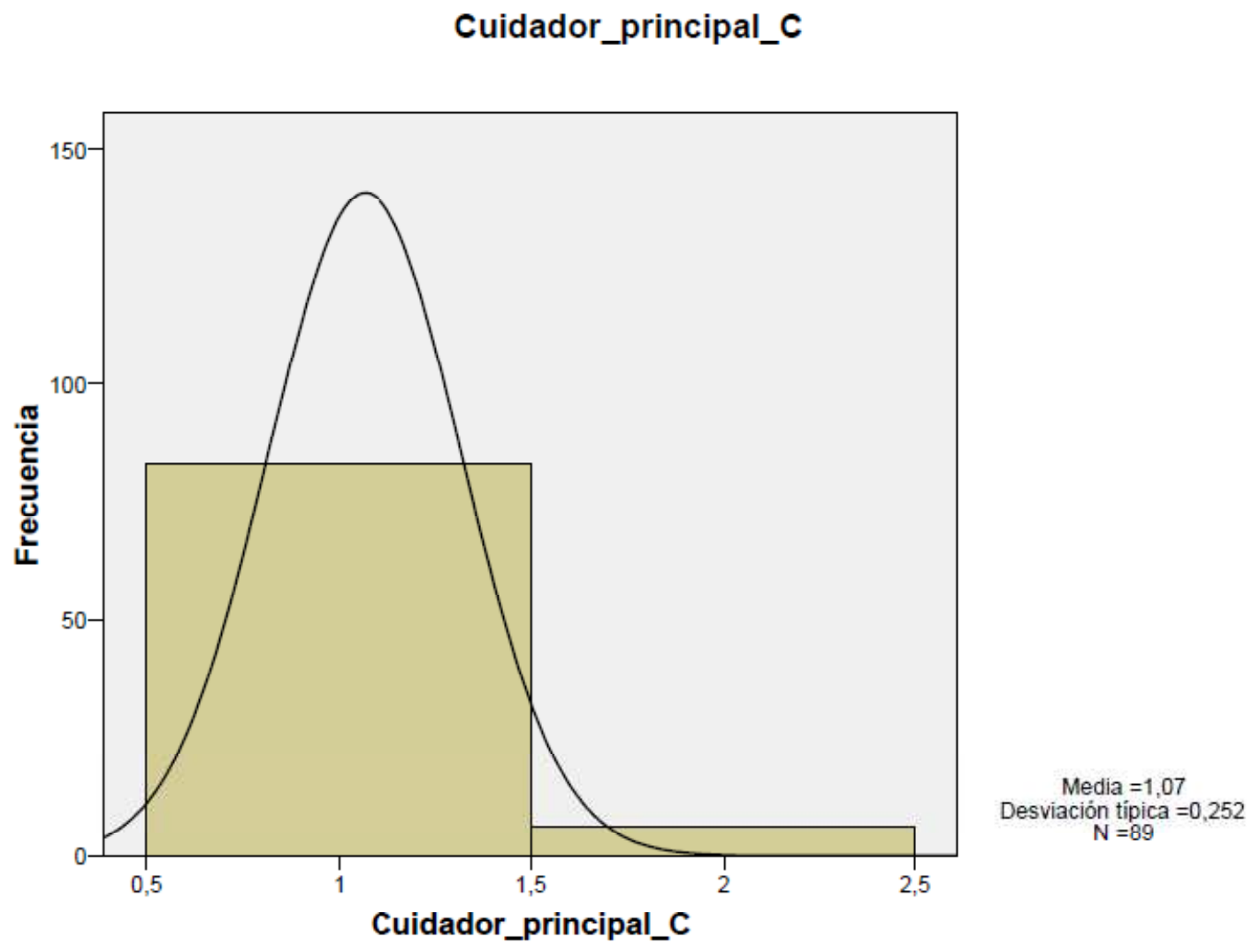

Figura 25. Representación Gráfica de la Variable "Vínculo Cuidador Principal" en Grupo Control. $(1$ = primer grado, 2 = segundo grado, 3 = cuidador contratado $)$ 


\subsubsection{NIVELES DE HEMOGLOBINA (Hb)}

En cuanto a los niveles de hemoglobina presentados, éstos son los siguientes.

En el Grupo experimental (Grupo I), la media es de 11,881 g/dl, mientras que en el Grupo control (Grupo II) la media es de 12,106 g/dl. No se establecen diferencias sustanciales entre ambos grupos.

Los datos se detallan de forma global, y específica a cada grupo anatomopatológico a continuación en la Tabla. Su representación gráfica puede verse en las Figuras.

\begin{tabular}{|c|c|c|c|}
\hline $\begin{array}{c}\text { NIVELES DE } \\
\text { HEMOGLOBINA }\end{array}$ & GRUPO I & GRUPO II & TOTAL \\
\hline MAMA & $12,233 \mathrm{~g} / \mathrm{dl}$ & $11,965 \mathrm{~g} / \mathrm{dl}$ & $12,099 \mathrm{~g} / \mathrm{dl}$ \\
\hline PULMÓN & $12,300 \mathrm{~g} / \mathrm{dl}$ & $11,587 \mathrm{~g} / \mathrm{dl}$ & $11,943 \mathrm{~g} / \mathrm{dl}$ \\
\hline $\begin{array}{c}\text { APARATO } \\
\text { DIGESTIVO }\end{array}$ & $12,048 \mathrm{~g} / \mathrm{dl}$ & $11,918 \mathrm{~g} / \mathrm{dl}$ & $11,983 \mathrm{~g} / \mathrm{dl}$ \\
\hline TOTAL & $11,881 \mathrm{~g} / \mathrm{dl}$ & $12,106 \mathrm{~g} / \mathrm{dl}$ & $11,993 \mathrm{~g} / \mathrm{dl}$ \\
\hline
\end{tabular}

Tabla 8. Estadísticos descriptivos de la Variable "Niveles de Hemoglobina" de los Grupos Experimental (Grupo I) y Control (Grupo II). De forma total y en los diferentes grupo anatomopatológicos. 


\section{Nivel_Hb_E}

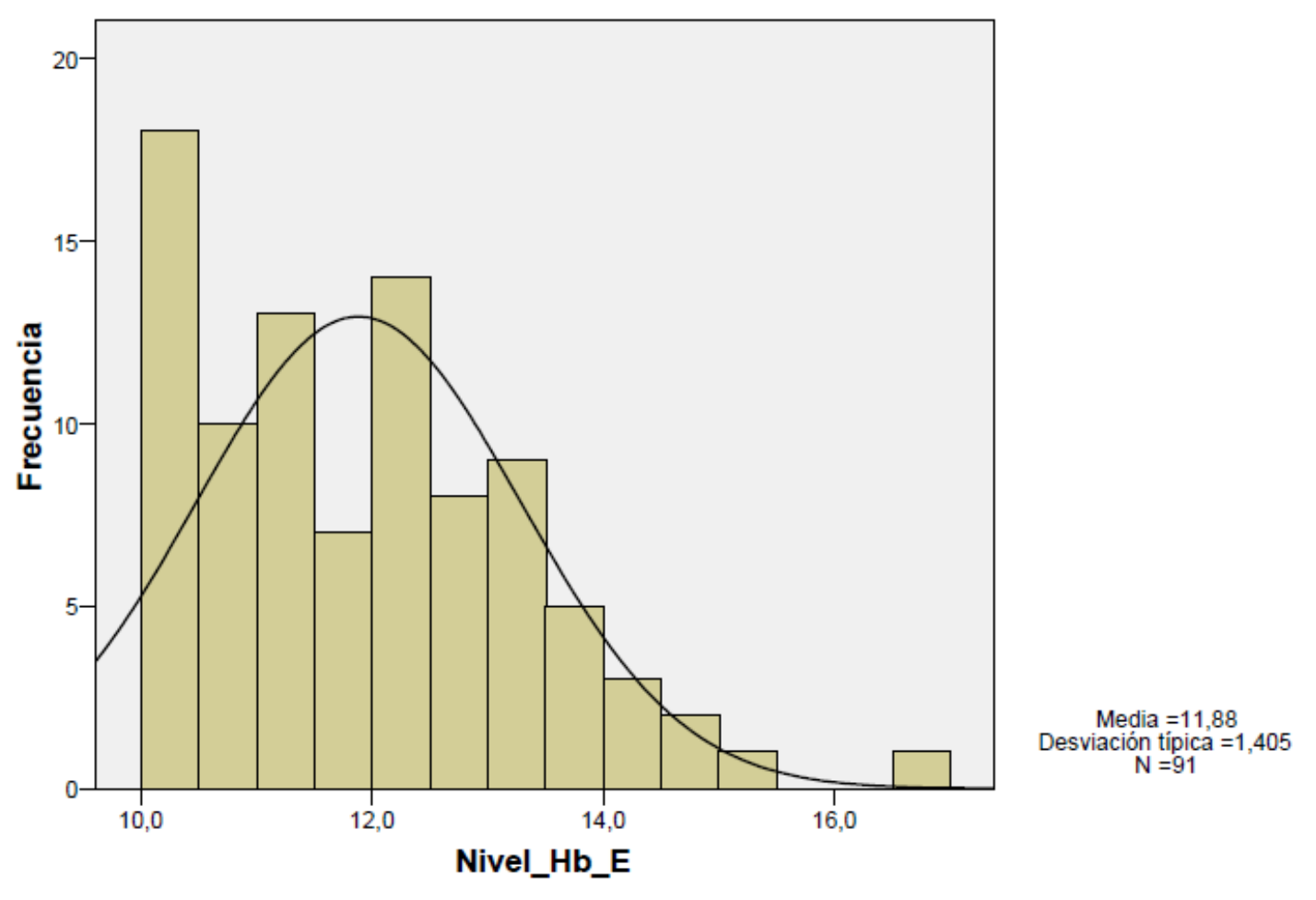

Figura 26. Representación Gráfica de la Variable "Niveles de Hemoglobina" en Grupo 


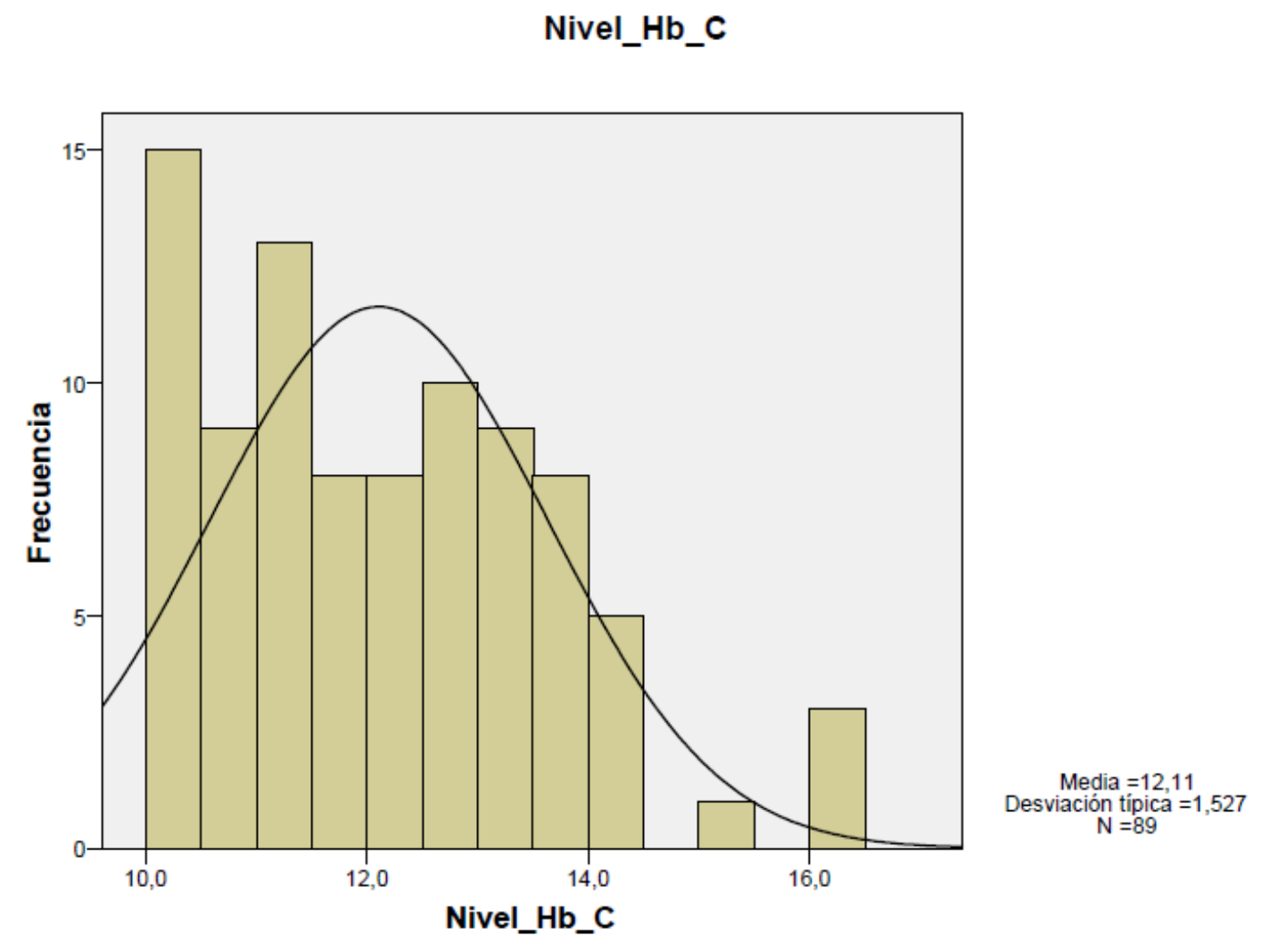

Figura 27. Representación Gráfica de la Variable "Niveles de Hemoglobina" en Grupo Control 


\subsubsection{LÍNEA DE TRATAMIENTO}

A continuación se analizará el número de líneas de tratamiento empleadas en los miembros de la muestra a estudio. En el Grupo experimental (Grupo I), la media de líneas de tratamiento empleadas es de 2,23; mientras que en el Grupo Control (Grupo II) es de 2,42.

Los datos se detallan de forma global, y específica a cada grupo anatomopatológico a continuación en la Tabla. Su representación gráfica puede verse en las Figuras.

\begin{tabular}{|c|c|c|c|}
\hline $\begin{array}{c}\text { NUMERO DE } \\
\text { LÍNEAS DE } \\
\text { TRATAMIENTO }\end{array}$ & GRUPO I & GRUPO II & TOTAL \\
\hline MAMA & 2,81 & 2,90 & 2,85 \\
\hline PULMÓN & 2,03 & 2,19 & 2,11 \\
\hline $\begin{array}{c}\text { APARATO } \\
\text { DIGESTIVO }\end{array}$ & 2,08 & 2,33 & 2,21 \\
\hline TOTAL & 2,23 & 2,42 & 2,33 \\
\hline
\end{tabular}

Tabla 9. Estadísticos descriptivos de la Variable "Líneas de tratamiento" de los Grupos Experimental (Grupo I) y Control (Grupo II). De forma total y en los diferentes grupo anatomopatológicos. 


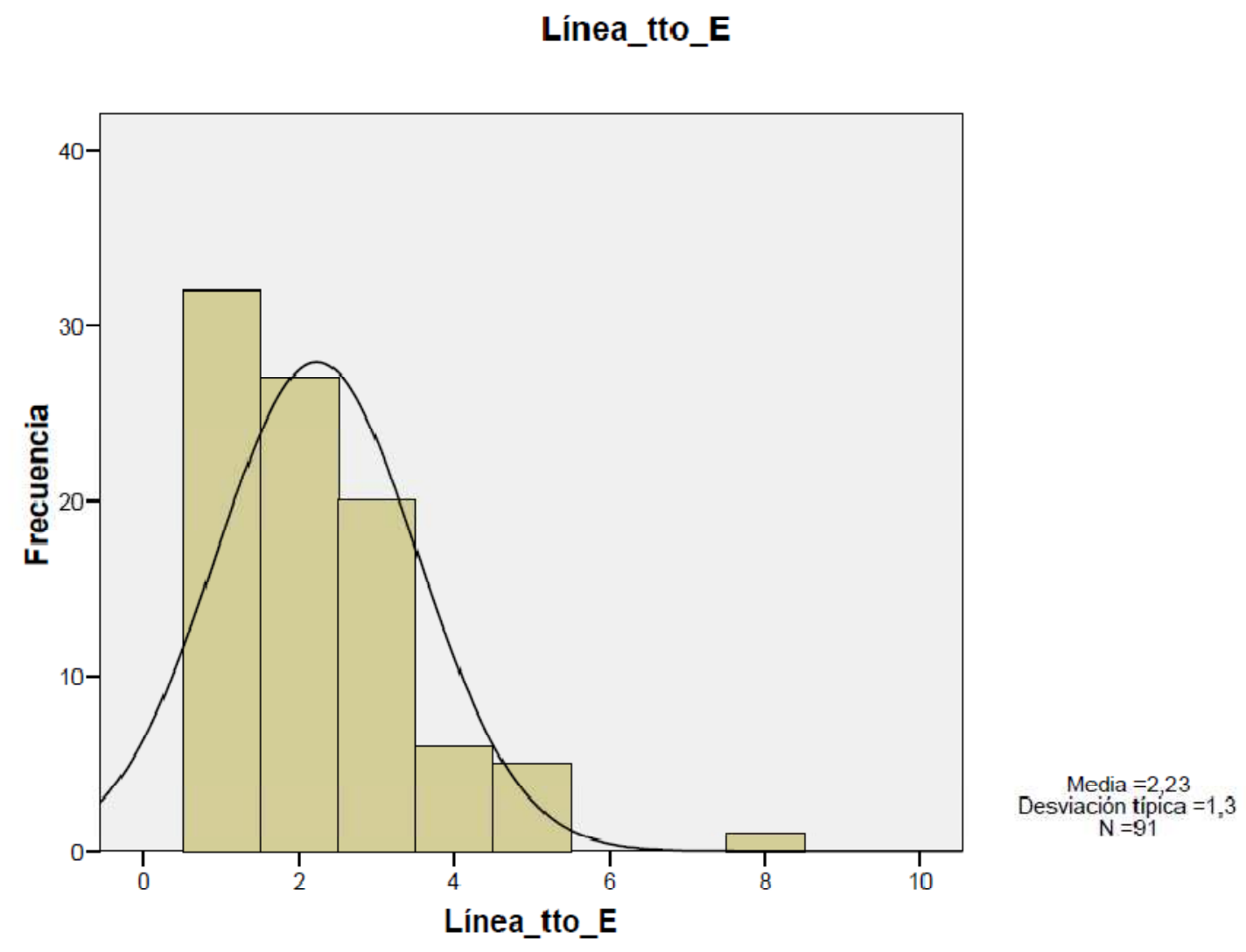

Figura 28. Representación Gráfica de la Variable "Líneas de tratamiento" en Grupo

Experimental 


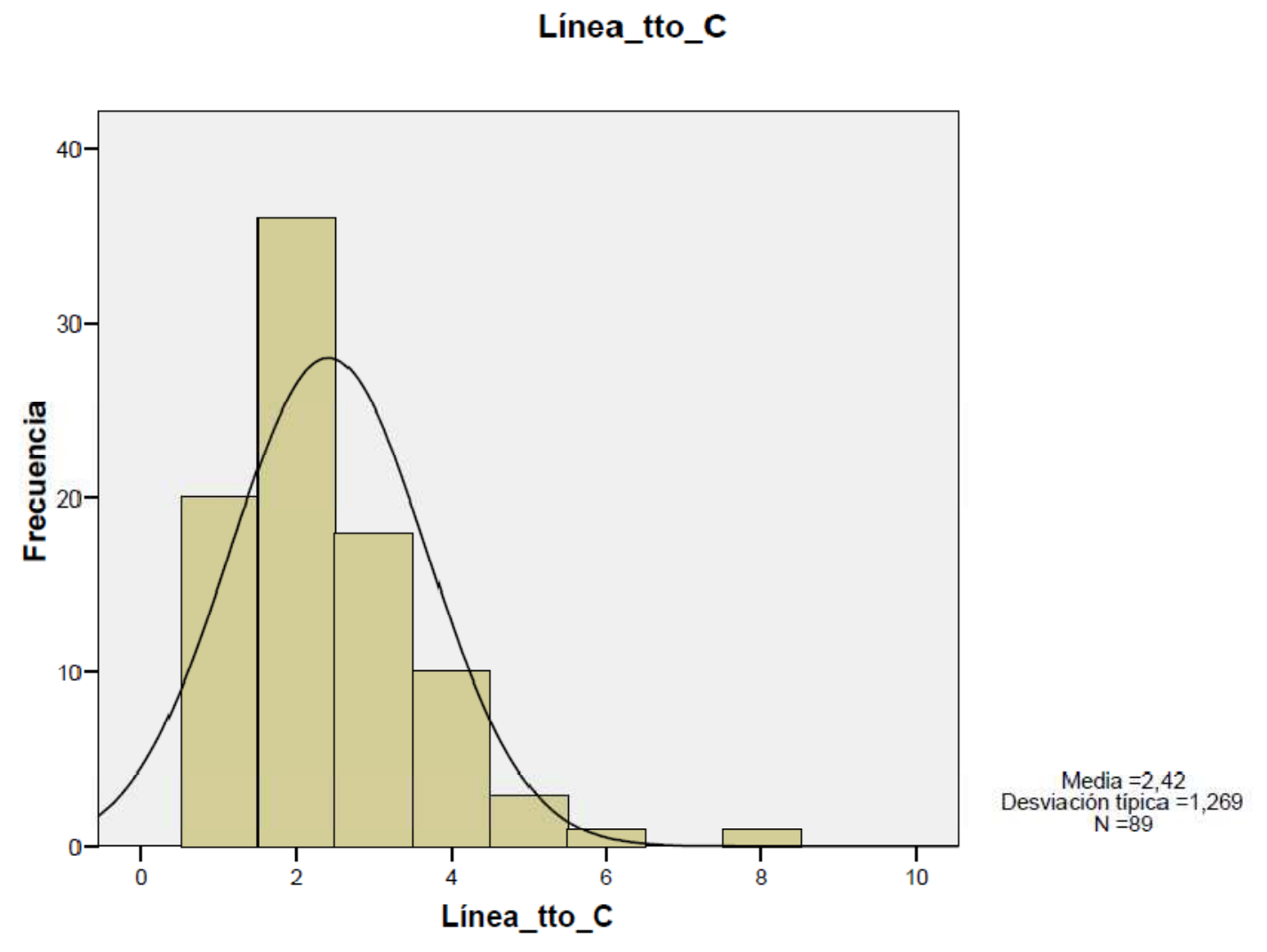

Figura 29. Representación Gráfica de la Variable "Líneas de tratamiento" en Grupo Control 


\subsubsection{TRATAMIENTO FARMACOLÓGICO}

En cuanto al tratamiento farmacológico empleado en la muestra de pacientes con sintomatología de astenia tumoral hemos valorado cuántos de ellos tienen una intervención específica para este síntoma. Los fármacos que hemos incluido han sido los corticoides y los psicoestimulantes.

En el Grupo Experimental (Grupo I) observamos como 35 individuos reciben tratamiento farmacológico, mientras que por el contrario 56 no lo hacen. En el Grupo Control (Grupo II) vemos que 36 individuos mantienen un tratamiento farmacológico, mientras que 53 no lo hacen.

Los datos se detallan de forma global, y específica a cada grupo anatomopatológico a continuación en la Tabla. Su representación gráfica puede verse en las Figuras.

\begin{tabular}{|c|c|c|c|c|c|c|}
\hline \multirow{2}{*}{$\begin{array}{c}\text { TRATAMIENTO } \\
\text { FARMACOLÓGICO }\end{array}$} & \multicolumn{2}{|c|}{ GRUPO I } & \multicolumn{2}{c|}{ GRUPO II } & \multicolumn{2}{c|}{ TOTAL } \\
\cline { 2 - 7 } & SI & NO & SI & NO & SI & NO \\
\hline MAMA & 9 & 12 & 7 & 13 & 16 & 25 \\
\hline PULMÓN & 14 & 16 & 13 & 14 & 27 & 30 \\
\hline $\begin{array}{c}\text { APARATO } \\
\text { DIGESTIVO }\end{array}$ & 12 & 28 & 16 & 26 & 28 & 54 \\
\hline TOTAL & 35 & 56 & 36 & 53 & 71 & 109 \\
\hline
\end{tabular}

Tabla 10. Estadísticos descriptivos de la Variable "Tratamiento Farmacológico" de los Grupos Experimental (Grupo I) y Control (Grupo II). De forma total y en los diferentes grupo anatomopatológicos. 


\section{Farmacos_E}

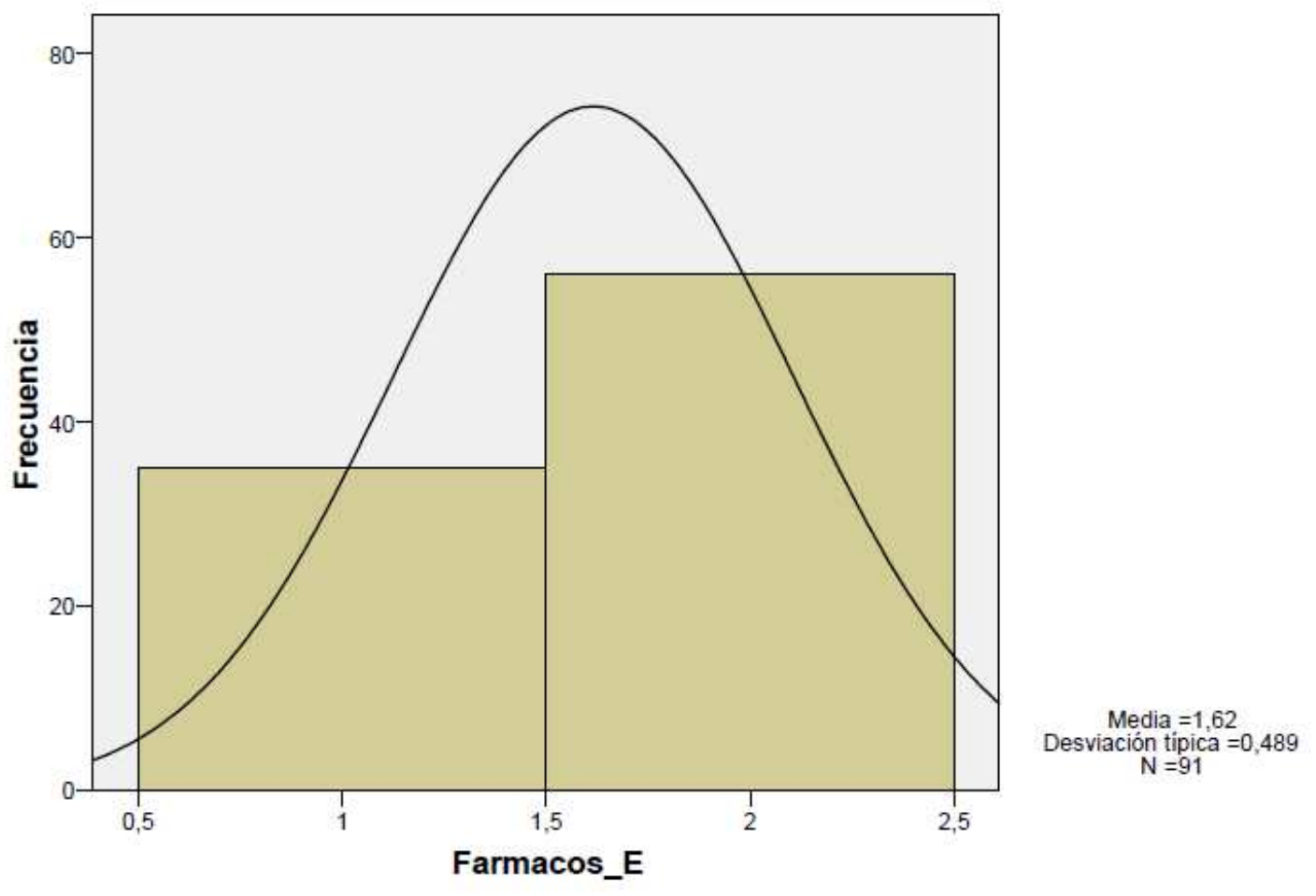

Figura 30. Representación Gráfica de la Variable "Tratamiento farmacológico" en Grupo 


\section{Farmacos_c}

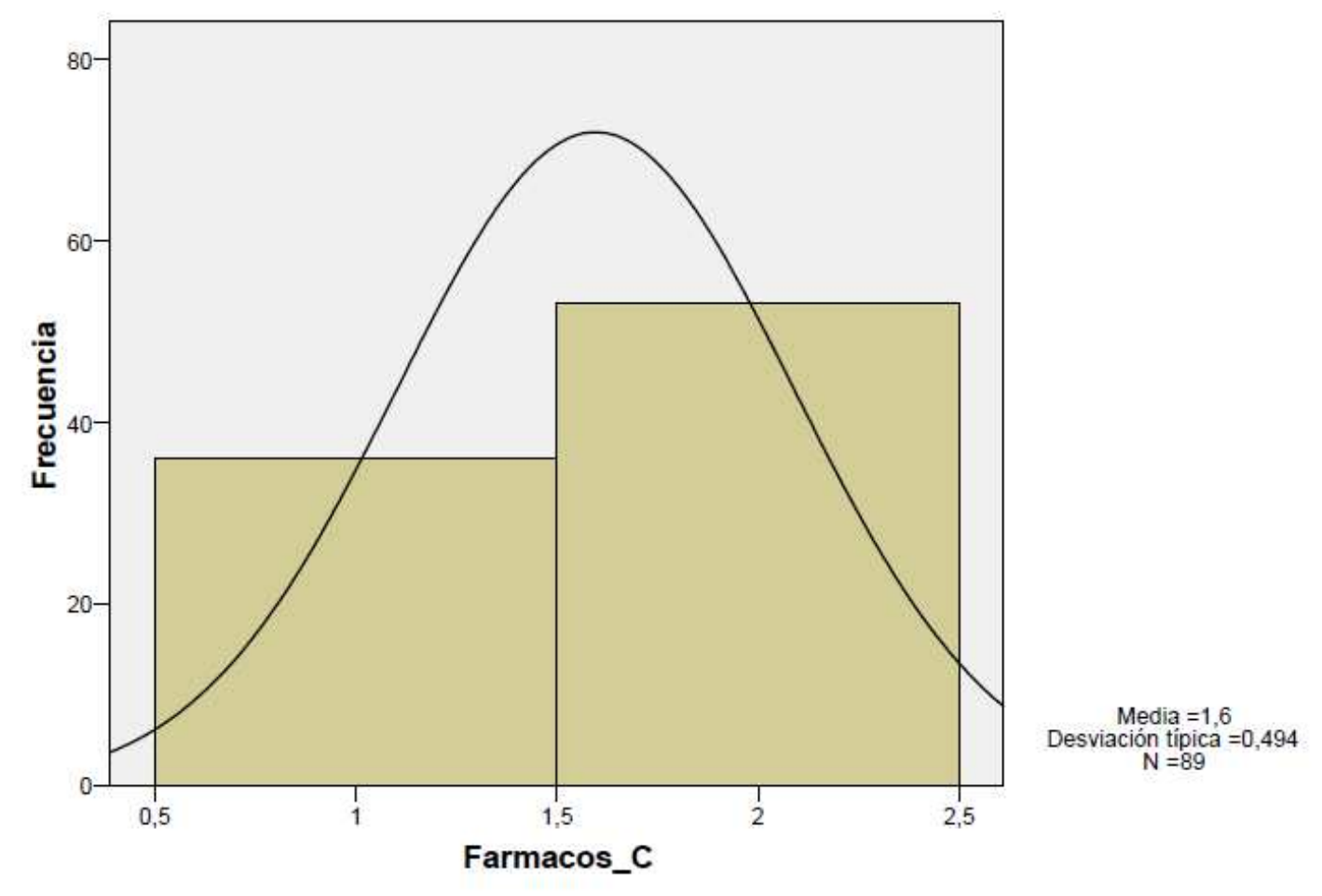

Figura 31. Representación Gráfica de la Variable "Tratamiento farmacológico" en Grupo Control 


\subsubsection{VARIABLES DEPENDIENTES}

\subsubsection{NIVEL DE ASTENIA TUMORAL}

\section{A. Cuestionario PERFORM}

A continuación analizaremos de forma descriptiva las puntuaciones obtenidas en el cuestionario PERFORM.

En la valoración inicial, en el momento de ingreso del paciente, se observan puntuaciones medias de 19,19 en el Grupo Experimental (Grupo I) y de 20,98 en el Grupo Control (Grupo II), en el ítem de puntuación Total del Cuestionario. No hay diferencias en ambos grupos.

En la valoración final, en el momento de alta hospitalaria del paciente, se observan puntuaciones medias de 36,12 en el Grupo Experimental (Grupo I) y de 22,48 en el Grupo Control (Grupo II), en el ítem de puntuación Total del Cuestionario.

En las siguientes tablas se analizarán de forma descriptiva todos las puntuaciones obtenidas, en la primera el Total de los individuos, en ambos grupos, control y experimental, y en las tres siguientes por grupos anatomopatológicos, en este orden, patología mamaria, patología pulmonar y patología del aparato digestivo. Además se analizará no solo el ítem "Puntuación Total" sino también los ítems específicos: 
"Aspecto Físico".

"Aspecto Emocional".

"Actitudes y creencias".

ANÁLISIS DESCRIPTIVO PERFORM TOTAL

\begin{tabular}{|c|c|c|c|c|c|}
\hline & N & Mínimo & Máximo & Media & Desv. típ. \\
\hline Físico_VI_GC & 89 & 4 & 17 & 7,49 & 2,633 \\
Físico_VF_GC & 89 & 4 & 18 & 8,39 & 3,029 \\
Emocional_VI_GC & 89 & 3 & 13 & 6,54 & 2,624 \\
Emocional_VF_GC & 89 & 3 & 13 & 6,79 & 2,613 \\
Creencias_VI_GC & 89 & 4 & 15 & 6,94 & 2,474 \\
Creencias_VF_GC & 89 & 4 & 15 & 7,31 & 2,503 \\
Total_VI_GC & 89 & 11 & 35 & 20,98 & 6,544 \\
Total_VF_GC & 89 & 11 & 42 & 22,48 & 6,856 \\
Físico_VI_GE & 91 & 4 & 14 & 6,38 & 1,919 \\
Físico_VF_GE & 91 & 6 & 20 & 14,30 & 2,510 \\
Emocional_VI_GE & 91 & 3 & 14 & 5,98 & 2,343 \\
Emocional_VF_GE & 91 & 5 & 15 & 9,81 & 2,102 \\
Creencias_VI_GE & 91 & 4 & 12 & 6,47 & 1,946 \\
Creencias_VF_GE & 91 & 5 & 19 & 12,01 & 2,401 \\
Total_VI_GE & 91 & 11 & 56 & 19,19 & 6,420 \\
Total_VF_GE & 91 & 16 & 50 & 36,12 & 5,789 \\
N válido (según lista) & 89 & & & & \\
\hline
\end{tabular}

Tabla 11. Estadísticos descriptivos TOTAL del Cuestionario PERFORM de los Grupos

Experimental (Grupo I) y Control (Grupo II).

VI = Valoración Inicial; VF = Valoración Final; $G C=$ Grupo Control; $G E=$ Grupo Experimental 


\section{ANÁLISIS DESCRIPTIVO PERFORM MAMA}

\begin{tabular}{|c|c|c|c|c|c|}
\hline & N & Mínimo & Máximo & Media & Desv. típ. \\
\hline Físico_VI_GC & 20 & 4 & 12 & 7,20 & 2,687 \\
Físico_VF_GC & 20 & 4 & 13 & 7,95 & 2,724 \\
Emocional_VI_GC & 20 & 3 & 12 & 6,45 & 2,837 \\
Emocional_VF_GC & 20 & 3 & 13 & 6,60 & 2,927 \\
Creencias_VI_GC & 20 & 4 & 11 & 6,70 & 1,867 \\
Creencias_VF_GC & 20 & 4 & 11 & 7,00 & 1,835 \\
Total_VI_GC & 20 & 11 & 33 & 20,35 & 6,683 \\
Total_VF_GC & 20 & 11 & 33 & 21,55 & 6,809 \\
Físico_VI_GE & 21 & 4 & 12 & 6,52 & 2,294 \\
Físico_VF_GE & 21 & 8 & 19 & 14,05 & 2,889 \\
Emocional_VI_GE & 21 & 3 & 14 & 5,52 & 2,522 \\
Emocional_VF_GE & 21 & 5 & 15 & 9,48 & 2,159 \\
Creencias_VI_GE & 21 & 4 & 10 & 6,14 & 1,957 \\
Creencias_VF_GE & 21 & 8 & 17 & 12,10 & 2,587 \\
Total_VI_GE & 21 & 12 & 29 & 18,19 & 5,307 \\
Total_VF_GE & 21 & 25 & 50 & 35,62 & 5,869 \\
N válido (según lista) & 20 & & & & \\
\hline
\end{tabular}

Tabla 12. Estadísticos descriptivos del Grupo anatomo-patológico MAMA del Cuestionario PERFORM de los Grupos Experimental (Grupo I) y Control (Grupo II). $V I=$ Valoración Inicial; VF = Valoración Final; $G C=$ Grupo Control; $G E=$ Grupo Experimental 


\section{ANÁLISIS DESCRIPTIVO PERFORM PULMÓN}

\begin{tabular}{|c|c|c|c|c|c|}
\hline & N & Mínimo & Máximo & Media & Desv. típ. \\
\hline Físico_VI_GC & 27 & 4 & 14 & 6,96 & 2,738 \\
Físico_VF_GC & 27 & 4 & 14 & 7,67 & 2,842 \\
Emocional_VI_GC & 27 & 3 & 11 & 5,63 & 2,003 \\
Emocional_VF_GC & 27 & 3 & 11 & 6,00 & 2,019 \\
Creencias_VI_GC & 27 & 4 & 15 & 6,26 & 2,379 \\
Creencias_VF_GC & 27 & 4 & 15 & 6,63 & 2,436 \\
Total_VI_GC & 27 & 11 & 32 & 18,85 & 5,524 \\
Total_VF_GC & 27 & 11 & 34 & 20,30 & 5,649 \\
Físico_VI_GE & 30 & 4 & 11 & 6,37 & 1,712 \\
Físico_VF_GE & 30 & 6 & 19 & 14,13 & 2,389 \\
Emocional_VI_GE & 30 & 3 & 12 & 6,60 & 2,500 \\
Emocional_VF_GE & 30 & 5 & 15 & 9,87 & 2,255 \\
Creencias_VI_GE & 30 & 4 & 10 & 6,67 & 1,900 \\
Creencias_VF_GE & 30 & 5 & 19 & 11,67 & 2,510 \\
Total_VI_GE & 30 & 11 & 56 & 20,70 & 8,305 \\
Total_VF_GE & 30 & 16 & 47 & 35,67 & 5,967 \\
N válido (según lista) & 27 & & & & \\
\hline
\end{tabular}

Tabla 13. Estadísticos descriptivos del Grupo anatomo-patológico PULMÓN del Cuestionario PERFORM de los Grupos Experimental (Grupo I) y Control (Grupo II). $V I=$ Valoración Inicial; VF = Valoración Final; $G C=$ Grupo Control; $G E=$ Grupo Experimental 


\section{ANÁLISIS DESCRIPTIVO PERFORM APARATO DIGESTIVO}

\begin{tabular}{|c|c|c|c|c|c|}
\hline & N & Mínimo & Máximo & Media & Desv. típ. \\
\hline Físico_VI_GC & 42 & 4 & 17 & 7,98 & 2,513 \\
Físico_VF_GC & 42 & 4 & 18 & 9,07 & 3,196 \\
Emocional_VI_GC & 42 & 3 & 13 & 7,17 & 2,749 \\
Emocional_VF_GC & 42 & 3 & 13 & 7,38 & 2,705 \\
Creencias_VI_GC & 42 & 4 & 13 & 7,50 & 2,698 \\
Creencias_VF_GC & 42 & 4 & 14 & 7,90 & 2,721 \\
Total_VI_GC & 42 & 11 & 35 & 22,64 & 6,771 \\
Total_VF_GC & 42 & 13 & 42 & 24,33 & 7,217 \\
Físico_VI_GE & 40 & 4 & 14 & 6,33 & 1,900 \\
Físico_VF_GE & 40 & 9 & 20 & 14,55 & 2,428 \\
Emocional_VI_GE & 40 & 3 & 11 & 5,75 & 2,072 \\
Emocional_VF_GE & 40 & 6 & 14 & 9,95 & 1,986 \\
Creencias_VI_GE & 40 & 4 & 12 & 6,50 & 2,000 \\
Creencias_VF_GE & 40 & 7 & 18 & 12,23 & 2,247 \\
Total_VI_GE & 40 & 12 & 34 & 18,58 & 5,168 \\
Total_VF_GE & 40 & 25 & 49 & 36,73 & 5,702 \\
N válido (según lista) & 40 & & & & \\
\hline
\end{tabular}

Tabla 14. Estadísticos descriptivos del Grupo anatomo-patológico APARATO DIGESTIVO del Cuestionario PERFORM de los Grupos Experimental (Grupo I) y Control (Grupo II). VI = Valoración Inicial; VF = Valoración Final; $G C=$ Grupo Control; $G E=$ Grupo Experimental 


\section{B. ESCALA TRIPLE EVA DE ASTENIA TUMORAL}

A continuación analizaremos de forma descriptiva las puntuaciones obtenidas en el cuestionario PERFORM.

En la valoración inicial, en el momento de ingreso del paciente, se observan puntuaciones las siguientes puntuaciones medias en los diferentes ítems valorados:

Grupo Experimental

- Nivel de energía: 2,58.

- Realización de AVD: 3,82.

- $\quad$ Calidad de Vida (CV): 3,16.

Grupo Control:

- Nivel de energía: 3,06.

- Realización de AVD: 4,54.

- $\quad$ Calidad de Vida (CV): 3,46. 
En la valoración final, en el momento de alta hospitalaria del paciente, se observan las siguientes puntuaciones medias en los diferentes ítems valorados:

\section{Grupo Experimental}

- Nivel de energía: 6,60.

- Realización de AVD: 6,54.

- $\quad$ Calidad de Vida (CV): 6,63.

Grupo Control:

- Nivel de energía: 3,61.

- Realización de AVD: 4,62.

- $\quad$ Calidad de Vida (CV): 3,74.

En las siguientes tablas se analizarán de forma descriptiva todas las puntuaciones obtenidas. En la primera el Total de los individuos, en ambos grupos, control y experimental, y en las tres siguientes por grupos anatomopatológicos, en este orden, patología mamaria, patología pulmonar y patología del aparato digestivo. 
ANÁLISIS DESCRIPTIVO TRIPLE EVA TOTAL

\begin{tabular}{|c|c|c|c|c|c|}
\hline & N & Mínimo & Máximo & Media & Desv. típ. \\
\hline Energia_GC_VI & 89 & 1 & 7 & 3,06 & 1,368 \\
Energia_GC_VF & 89 & 1 & 8 & 3,61 & 1,466 \\
AVD_GC_VI & 89 & 1 & 9 & 4,54 & 2,379 \\
AVD_GC_VF & 89 & 1 & 9 & 4,62 & 2,343 \\
CV_GC_VI & 89 & 1 & 7 & 3,46 & 1,589 \\
CV_GC_VF & 89 & 1 & 7 & 3,74 & 1,689 \\
Energia_GE_VI & 91 & 1 & 6 & 2,58 & 1,174 \\
Energia_GE_VF & 91 & 3 & 10 & 6,60 & 1,555 \\
AVD_GE_VI & 91 & 1 & 9 & 3,82 & 2,111 \\
AVD_GE_VF & 91 & 2 & 10 & 6,54 & 1,979 \\
CV_GE_VI & 91 & 1 & 7 & 3,16 & 1,551 \\
CV_GE_VF & 91 & 3 & 9 & 6,63 & 1,435 \\
N válido (según lista) & 89 & & & & \\
\hline
\end{tabular}

Tabla 15. Estadísticos descriptivos TOTAL de la Escala TRIPLE EVA de los Grupos Experimental (Grupo I) y Control (Grupo II).

$V I=$ Valoración Inicial; VF = Valoración Final; $G C=$ Grupo Control; $G E=$ Grupo Experimental 
ANÁLISIS DESCRIPTIVO TRIPLE EVA MAMA

\begin{tabular}{|c|c|c|c|c|c|}
\hline & N & Mínimo & Máximo & Media & Desv. típ. \\
\hline Energia_GC_VI & 20 & 1 & 5 & 2,95 & 1,395 \\
Energia_GC_VF & 20 & 1 & 5 & 3,30 & 1,418 \\
AVD_GC_VI & 20 & 1 & 8 & 4,15 & 2,231 \\
AVD_GC_VF & 20 & 1 & 8 & 4,25 & 2,149 \\
CV_GC_VI & 20 & 1 & 7 & 3,65 & 1,725 \\
CV_GC_VF & 20 & 1 & 7 & 3,85 & 1,694 \\
Energia_GE_VI & 21 & 1 & 4 & 2,24 & 1,091 \\
Energia_GE_VF & 21 & 3 & 8 & 5,95 & 1,499 \\
AVD_GE_VI & 21 & 1 & 9 & 3,10 & 2,278 \\
AVD_GE_VF & 21 & 2 & 9 & 5,90 & 1,758 \\
CV_GE_VI & 21 & 1 & 5 & 2,67 & 1,354 \\
CV_GE_VF & 21 & 4 & 8 & 6,38 & 1,322 \\
N válido (según lista) & 20 & & & & \\
\hline
\end{tabular}

Tabla 16. Estadísticos descriptivos del Grupo anatomo-patológico MAMA de la Escala TRIPLE EVA de los Grupos Experimental (Grupo I) y Control (Grupo II).

$V I=$ Valoración Inicial; VF = Valoración Final; $G C=$ Grupo Control; $G E=$ Grupo Experimental

\section{ANÁLISIS DESCRIPTIVO TRIPLE EVA PULMÓN}

\begin{tabular}{|c|c|c|c|c|c|}
\hline & N & Mínimo & Máximo & Media & Desv. típ. \\
\hline Energia_GC_VI & 27 & 1 & 5 & 2,67 & 1,177 \\
Energia_GC_VF & 27 & 1 & 5 & 3,41 & 1,309 \\
AVD_GC_VI & 27 & 1 & 9 & 4,07 & 2,269 \\
AVD_GC_VF & 27 & 1 & 9 & 4,04 & 2,295 \\
CV_GC_VI & 27 & 1 & 6 & 3,11 & 1,368 \\
CV_GC_VF & 27 & 1 & 7 & 3,41 & 1,600 \\
Energia_GE_VI & 30 & 1 & 5 & 2,80 & 1,243 \\
Energia_GE_VF & 30 & 3 & 9 & 6,97 & 1,474 \\
AVD_GE_VI & 30 & 1 & 9 & 4,37 & 2,220 \\
AVD_GE_VF & 30 & 2 & 9 & 6,53 & 2,177 \\
CV_GE_VI & 30 & 1 & 7 & 3,63 & 1,691 \\
CV_GE_VF & 30 & 3 & 9 & 6,60 & 1,567 \\
N válido (según lista) & 27 & & & & \\
\hline
\end{tabular}

Tabla 17. Estadísticos descriptivos del Grupo anatomo-patológico PULMÓN de la Escala TRIPLE EVA de los Grupos Experimental (Grupo I) y Control (Grupo II).

$V I=$ Valoración Inicial; $V F=$ Valoración Final; $G C=$ Grupo Control; $G E=$ Grupo Experimental 
ANÁLISIS DESCRIPTIVO TRIPLE EVA APARATO DIGESTIVO

\begin{tabular}{|c|c|c|c|c|c|}
\hline & N & Mínimo & Máximo & Media & Desv. típ. \\
\hline Energia_GC_VI & 42 & 1 & 7 & 3,36 & 1,428 \\
Energia_GC_VF & 42 & 1 & 8 & 3,88 & 1,565 \\
AVD_GC_VI & 42 & 1 & 9 & 5,02 & 2,474 \\
AVD_GC_VF & 42 & 1 & 9 & 5,17 & 2,388 \\
CV_GC_VI & 42 & 1 & 7 & 3,60 & 1,654 \\
CV_GC_VF & 42 & 1 & 7 & 3,90 & 1,750 \\
Energia_GE_VI & 40 & 1 & 6 & 2,60 & 1,150 \\
Energia_GE_VF & 40 & 4 & 10 & 6,68 & 1,575 \\
AVD_GE_VI & 40 & 1 & 7 & 3,80 & 1,856 \\
AVD_GE_VF & 40 & 2 & 10 & 6,88 & 1,897 \\
CV_GE_VI & 40 & 1 & 7 & 3,08 & 1,474 \\
CV_GE_VF & 40 & 3 & 9 & 6,78 & 1,405 \\
N válido (según lista) & 40 & & & & \\
\hline
\end{tabular}

Tabla 18. Estadísticos descriptivos del Grupo anatomo-patológico APARATO DIGESTIVO de la Escala TRIPLE EVA de los Grupos Experimental (Grupo I) y Control (Grupo II).

$V I=$ Valoración Inicial; VF = Valoración Final; $G C=$ Grupo Control; $G E=$ Grupo Experimental 


\subsubsection{CALIDAD DE VIDA RELACIONADA CON LA SALUD}

\section{A. Cuestionario SF-12}

A continuación analizaremos de forma descriptiva las puntuaciones obtenidas en el cuestionario SF-12.

En la valoración inicial, en el momento de ingreso del paciente, se observan las siguientes puntuaciones medias en los diferentes ítems globales valorados del total de la muestra, "Componente físico" y "Componente mental":

\section{Grupo Experimental}

- Componente físico: 32,72.

- Componente mental: 34,42 .

Grupo Control

- Componente físico: 32,83.

- Componente mental: 36,87 .

En la valoración final, en el momento de alta hospitalaria del paciente, se observan las siguientes puntuaciones medias en los diferentes ítems globales valorados:

\section{Grupo Experimental}

- Componente físico: 45,90.

- Componente mental: 42,07. 
Grupo Control

- Componente físico: 33,02.

- Componente mental: 37,28.

En las siguientes tablas se analizarán los datos de las puntuaciones obtenidas tanto en los ítems globales "componente físico" y "componente mental", como en los ítems específicos que detallamos a continuación:

1. Funcionamiento físico.

2. Rol físico.

3. Dolor corporal.

4. Salud general.

5. Vitalidad.

6. Funcionamiento social.

7. Rol emocional.

8. Salud mental.

En la TABLA, se analizarán los datos del Grupo Experimental; mientras que en la TABLA, se analizarán los del Grupo Control. 


\section{ANÁLISIS DESCRIPTIVO SF-12 TOTAL GRUPO EXPERIMENTAL}

\begin{tabular}{|c|c|c|c|c|}
\hline & Media & N & Desviación típ. & Error típ. de la media \\
\hline Funcionamiento_físico_VI & 30,1636 & 91 & 5,98970 &, 62789 \\
Funcionamiento_físico_VF & 48,9305 & 91 & 6,25769 &, 65598 \\
Rol_físico_VI & 28,8641 & 91 & 7,39261 &, 77496 \\
Rol_físico_VF & 37,7462 & 91 & 8,70090 &, 91210 \\
Dolor_corporal_VI & 42,0691 & 91 & 9,86536 & 1,03417 \\
Dolor_corporal_VF & 48,3135 & 91 & 8,05788 &, 84469 \\
Salud_general_VI & 30,2354 & 91 & 4,80524 &, 50373 \\
Salud_general_VF & 44,6056 & 91 & 6,69058 &, 70136 \\
Vitalidad_VI & 32,5258 & 91 & 4,83822 &, 50718 \\
Vitalidad_VF & 50,5815 & 91 & 5,66292 &, 59364 \\
Funcionamiento_social_VI & 29,5340 & 91 & 5,96481 &, 62528 \\
Funcionamiento_social_VF & 32,3681 & 91 & 6,80511 &, 71337 \\
Rol_emocional_VI & 33,6054 & 91 & 14,50666 & 1,52071 \\
Rol_emocional_VF & 45,0289 & 91 & 11,07427 & 1,16090 \\
Salud_mental_VI & 35,4653 & 91 & 8,90604 &, 93361 \\
Salud_mental_VF & 43,4693 & 91 & 7,44387 &, 78033 \\
Componente_físico_VI & 32,7234 & 91 & 5,49420 &, 57595 \\
Componente_físico_VF & 45,9084 & 91 & 5,24654 &, 54999 \\
Componente_mental_VI & 34,4263 & 91 & 9,44189 &, 98978 \\
Componente_mental_VF & 42,0730 & 91 & 7,36241 &, 77179 \\
\hline
\end{tabular}

Tabla 19. Estadísticos descriptivos TOTAL del Cuestionario SF-12 de CVRS del Grupo

Experimental (Grupo I).

$V I=$ Valoración Inicial; $V F=$ Valoración Final 
ANÁLISIS DESCRIPTIVO SF-12 TOTAL GRUPO CONTROL

\begin{tabular}{|c|c|c|c|c|}
\hline & Media & N & Desviación típ. & Error típ. de la media \\
\hline Funcionamiento_físico_VI & 33,8921 & 89 & 8,07826 &, 85629 \\
Funcionamiento_físico_VF & 34,1574 & 89 & 7,92707 &, 84027 \\
Rol_físico_VI & 28,7440 & 89 & 6,29791 &, 66758 \\
Rol_físico_VF & 29,0770 & 89 & 6,41757 &, 68026 \\
Dolor_corporal_VI & 39,0827 & 89 & 9,78527 & 1,03724 \\
Dolor_corporal_VF & 42,4270 & 89 & 9,93613 & 1,05323 \\
Salud_general_VI & 31,2712 & 89 & 4,37609 &, 46386 \\
Salud_general_VF & 31,7626 & 89 & 4,50438 &, 47746 \\
Vitalidad_VI & 36,2447 & 89 & 6,70049 &, 71025 \\
Vitalidad_VF & 38,0137 & 89 & 7,39014 &, 78335 \\
Funcionamiento_social_VI & 30,4175 & 89 & 7,46384 &, 79117 \\
Funcionamiento_social_VF & 30,5176 & 89 & 7,27767 &, 77143 \\
Rol_emocional_VI & 36,1910 & 89 & 14,99499 & 1,58947 \\
Rol_emocional_VF & 36,5996 & 89 & 14,91874 & 1,58138 \\
Salud_mental_VI & 37,0099 & 89 & 9,99237 & 1,05919 \\
Salud_mental_VF & 37,4612 & 89 & 9,74266 & 1,03272 \\
Componente_físico_VI & 32,8357 & 89 & 5,74359 &, 60882 \\
Componente_físico_VF & 34,1210 & 89 & 5,81336 & 1,08210 \\
Componente_mental_VI & 36,8766 & 89 & 10,35722 & 10,20854 \\
Componente_mental_VF & 37,2810 & 89 & 8786 \\
\hline
\end{tabular}

Tabla 20. Estadísticos descriptivos TOTAL del Cuestionario SF-12 de CVRS del Grupo Control

(Grupo II).

VI = Valoración Inicial; $V F=$ Valoración Final 
A continuación, en las TABLAS, se analizarán las puntuaciones del cuestionario SF-12 tanto en los diferentes grupos anatomo-patológicos como en los distintos subgrupos experimental (Grupo I) y control (Grupo II).

ANÁLISIS DESCRIPTIVO DE LAS PUNTUACIONES INICIALES EN EL SF-12

\begin{tabular}{|c|c|c|c|c|c|c|}
\hline \multirow{2}{*}{$\begin{array}{c}\text { CUESTIONARIO SF- } \\
12\end{array}$} & \multicolumn{2}{|c|}{ MAMA } & \multicolumn{2}{c|}{ PULMÓN } & APARATO DIGESTIVO \\
\cline { 2 - 7 } & Grupo I & Grupo II & Grupo I & Grupo II & Grupo I & Grupo II \\
\hline Funcionamiento físico & 29,70 & 35,41 & 29,77 & 31,70 & 30,69 & 34,57 \\
\hline Rol físico & 29,45 & 27,62 & 28,68 & 29,09 & 28,68 & 29,05 \\
\hline Dolor corporal & 43,12 & 39,69 & 45,10 & 40,02 & 39,23 & 38,18 \\
\hline Salud general & 31,47 & 31,85 & 29,86 & 30,52 & 29,86 & 31,47 \\
\hline Vitalidad & 33,60 & 35,29 & 31,68 & 35,22 & 32,58 & 37,35 \\
\hline Funcionamiento social & 28,94 & 30,66 & 29,03 & 28,57 & 30,21 & 31,48 \\
\hline Rol emocional & 32,52 & 31,59 & 37,39 & 38,37 & 31,33 & 36,97 \\
\hline Salud mental & 34,70 & 33,23 & 38,58 & 37,01 & 33,52 & 38,80 \\
\hline Componente físico & 33,79 & 35,11 & 31,92 & 31,70 & 32,75 & 32,47 \\
\hline Componente mental & 33,62 & 32,60 & 37,01 & 37,47 & 32,90 & 38,52 \\
\hline
\end{tabular}

Tabla 21. Estadísticos descriptivos de las puntuaciones iniciales de los diferentes Grupos anatomo-patológicos del Cuestionario SF-12 de los Grupos Experimental (Grupo I) y Control

(Grupo II). 
ANÁLISIS DESCRIPTIVO DE LAS PUNTUACIONES FINALES EN EL SF-12

\begin{tabular}{|l|c|c|c|c|c|c|}
\hline \multirow{2}{*}{ CUESTIONARIO SF-12 } & \multicolumn{2}{|c|}{ MAMA } & \multicolumn{2}{c|}{ PULMÓN } & \multicolumn{2}{c|}{ APARATO DIGESTIVO } \\
\cline { 2 - 7 } & Grupo I & Grupo II & Grupo I & Grupo II & Grupo I & Grupo II \\
\hline Funcionamiento físico & 45,81 & 35,81 & 49,19 & 32,28 & 50,37 & 34,94 \\
\hline Rol físico & 40,73 & 29,32 & 35,88 & 28,78 & 37,57 & 29,15 \\
\hline Dolor corporal & 47,85 & 43,29 & 49,31 & 43,36 & 47,80 & 41,40 \\
\hline Salud general & 44,91 & 31,86 & 43,57 & 31,63 & 45,21 & 31,80 \\
\hline Vitalidad & 50,47 & 37,26 & 50,70 & 37,40 & 50,54 & 38,76 \\
\hline Funcionamiento social & 31,06 & 31,10 & 31,70 & 28,77 & 33,55 & 31,49 \\
\hline Rol emocional & 42,91 & 32,37 & 45,01 & 39,14 & 46,14 & 36,97 \\
\hline Salud mental & 42,62 & 33,80 & 44,32 & 37,02 & 43,27 & 39,48 \\
\hline Componente físico & 46,16 & 35,80 & 45,24 & 32,44 & 46,26 & 33,01 \\
\hline Componente mental & 40,75 & 33,15 & 42,42 & 38,01 & 42,50 & 38,77 \\
\hline
\end{tabular}

Tabla 22. Estadísticos descriptivos de las puntuaciones finales de los diferentes Grupos anatomo-patológicos del Cuestionario SF-12 de los Grupos Experimental (Grupo I) y Control

(Grupo II). 


\subsubsection{ACTIVIDADES DE LA VIDA DIARIA}

\section{A. Escala de LAWTON - BRODY}

A continuación analizaremos de forma descriptiva las puntuaciones obtenidas en la escala de LAWTON - BRODY, de Actividades Instrumentales de la Vida Diaria (AIVD).

En la valoración inicial, en el momento de ingreso del paciente, se observan las siguientes puntuaciones medias de 4,02 en el Grupo Experimental (Grupo I) y de 4,61 en el Grupo Control (Grupo II).

En la valoración final, en el momento de alta hospitalaria del paciente, se observan puntuaciones medias de 5,55 en el Grupo Experimental (Grupo I) y de 4,92 en el Grupo Control (Grupo II).

Los datos se detallan de forma global (TABLA), y específica a cada grupo anatomo-patológico a continuación en las TABLAS. En ellas se describen las puntuaciones obtenidas en el momento de valoración inicial y final en los diferentes subgrupos experimental y control. 


\section{ANÁLISIS DESCRIPTIVO LAWTON - BRODY TOTAL}

\begin{tabular}{|c|c|c|c|c|c|}
\hline & N & Mínimo & Máximo & Media & Desv. típ. \\
\hline Lawton_Brody_GC_VI & 89 & 0 & 8 & 4,61 & 1,794 \\
Lawton_Brody_GC_VF & 89 & 0 & 8 & 4,92 & 1,920 \\
Lawton_Brody_GE_VI & 91 & 1 & 8 & 4,02 & 1,832 \\
Lawton_Brody_GE_VF & 91 & 3 & 8 & 5,55 & 1,376 \\
N válido (según lista) & 89 & & & & \\
\hline
\end{tabular}

Tabla 23. Estadísticos descriptivos TOTAL del Cuestionario LAWTON - BRODY

$V I=$ Valoración Inicial; VF = Valoración Final; $G C=$ Grupo Control; $G E=$ Grupo Experimental

\section{ANÁLISIS DESCRIPTIVO LAWTON - BRODY MAMA}

\begin{tabular}{|c|c|c|c|c|c|}
\hline & N & Mínimo & Máximo & Media & Desv. típ. \\
\hline Lawton_Brody_GC_VI & 20 & 0 & 7 & 4,40 & 1,847 \\
Lawton_Brody_GC_VF & 20 & 1 & 8 & 5,80 & 1,963 \\
Lawton_Brody_GE_VI & 21 & 1 & 8 & 4,05 & 2,269 \\
Lawton_Brody_GE_VF & 21 & 3 & 8 & 5,71 & 1,678 \\
N válido (según lista) & 20 & & & & \\
\hline
\end{tabular}

Tabla 24. Estadísticos descriptivos MAMA del Cuestionario LAWTON - BRODY

VI = Valoración Inicial; VF = Valoración Final; $G C=$ Grupo Control; $G E=$ Grupo Experimental 


\section{ANÁLISIS DESCRIPTIVO LAWTON - BRODY PULMÓN}

\begin{tabular}{|c|c|c|c|c|c|}
\hline & N & Mínimo & Máximo & Media & Desv. típ. \\
\hline Lawton_Brody_GC_VI & 27 & 0 & 8 & 4,22 & 1,968 \\
Lawton_Brody_GC_VF & 27 & 0 & 8 & 4,11 & 2,063 \\
Lawton_Brody_GE_VI & 30 & 2 & 6 & 4,03 & 1,497 \\
Lawton_Brody_GE_VF & 30 & 3 & 8 & 5,40 & 1,380 \\
N válido (según lista) & 27 & & & & \\
\hline
\end{tabular}

Tabla 25. Estadísticos descriptivos PULMÓN del Cuestionario LAWTON - BRODY VI = Valoración Inicial; VF = Valoración Final; $G C=$ Grupo Control; $G E=$ Grupo Experimental

\section{ANÁLISIS DESCRIPTIVO LAWTON - BRODY APARATO DIGESTIVO}

\begin{tabular}{|c|c|c|c|c|c|}
\hline & N & Mínimo & Máximo & Media & Desv. típ. \\
\hline Lawton_Brody_GC_VI & 42 & 0 & 8 & 4,95 & 1,622 \\
Lawton_Brody_GC_VF & 42 & 0 & 8 & 5,02 & 1,615 \\
Lawton_Brody_GE_VI & 40 & 1 & 7 & 4,00 & 1,854 \\
Lawton_Brody_GE_VF & 40 & 3 & 8 & 5,58 & 1,217 \\
N válido (según lista) & 40 & & & & \\
\hline
\end{tabular}

Tabla 26. Estadísticos descriptivos APARATO DIGESTIVO del Cuestionario LAWTON -

$B R O D Y$

VI = Valoración Inicial; VF = Valoración Final; $G C=$ Grupo Control; $G E=$ Grupo Experimental 


\subsection{ESTADÍSTICA ANALÍTICA}

La comparación de variables cuantitativas con cualitativas se realizó mediante el método "t" de Student para muestras independientes (comparación de dos medias), cuando las variables cuantitativas seguían una distribución normal.

Finalmente se realizará el análisis de las correlaciones bivariadas mediante la prueba de Correlación de Pearson.

Se consideran como significativos valores de $p<0,05$, y como estadísticamente muy significativos aquellos con valores $p<0,001$.

\subsubsection{NIVELES DE ASTENIA TUMORAL}

\subsubsection{Cuestionario PERFORM}

Tras haber efectuado la prueba "t de student" de comparación de medias, los resultados muestran una diferencia estadísticamente significativa entre los siguientes ítems en el total de la muestra:

- Global: $p=0,000$ [IC95:-16,780;-13,804]

- Limitaciones físicas: $p=0,000$ [IC95:-7,576;-6,379]

- Actividades habituales: $p=0,000$ [IC95:-3,945;-3,156]

- Actitudes y creencias: $p=0,001$ [IC95:-5,656;-4,568]

Los datos se detallan de forma global, y específica a cada grupo anatomopatológico a continuación en las Tablas. 
COMPARACIÓN DE MEDIAS “t” STUDENT EN PATOLOGÍA MAMARIA

\begin{tabular}{|c|c|c|c|}
\hline \multirow{2}{*}{$\begin{array}{c}\text { CUESTIONARIO } \\
\text { PERFORM }\end{array}$} & Valor "p" & \multicolumn{2}{|c|}{$\begin{array}{c}\text { diferencia } \\
\text { dintervalo de confianza para la }\end{array}$} \\
\cline { 2 - 4 } & 0,000 & $-8,141$ & $-5,559$ \\
\hline $\begin{array}{c}\text { FIMISICAS } \\
\text { ACTIVIDADES } \\
\text { HABITUALES }\end{array}$ & 0,000 & $-4,883$ & $-2,817$ \\
\hline $\begin{array}{c}\text { ACTITUDES Y } \\
\text { CREENCIAS }\end{array}$ & 0,001 & $-7,001$ & $-4,499$ \\
\hline $\begin{array}{c}\text { PUNTUACIÓN } \\
\text { GLOBAL }\end{array}$ & 0,000 & $-19,564$ & $-13,336$ \\
\hline
\end{tabular}

TABLA 27. ANÁLISIS ESTADÍSTICO, PRUEBA "t” DE STUDENT DE COMPARACIÓN DE MEDIAS EN CUESTIONARIO PERFORM EN PATOLOGIAA MAMARIA

COMPARACIÓN DE MEDIAS “t” STUDENT EN PATOLOGÍA PULMONAR

\begin{tabular}{|c|c|c|c|}
\hline \multirow{2}{*}{$\begin{array}{l}\text { CUESTIONARIO } \\
\text { PERFORM }\end{array}$} & \multirow[t]{2}{*}{ Valor "p" } & \multicolumn{2}{|c|}{$\begin{array}{c}95 \% \text { intervalo de confianza para la } \\
\text { diferencia }\end{array}$} \\
\hline & & Inferior & Superior \\
\hline $\begin{array}{l}\text { LIMITACIONES } \\
\text { FÍSICAS }\end{array}$ & 0,000 & $-8,103$ & $-5,971$ \\
\hline $\begin{array}{l}\text { ACTIVIDADES } \\
\text { HABITUALES }\end{array}$ & 0,000 & $-3,695$ & $-2,231$ \\
\hline $\begin{array}{l}\text { ACTITUDES Y } \\
\text { CREENCIAS }\end{array}$ & 0,001 & $-5,533$ & $-3,578$ \\
\hline $\begin{array}{l}\text { PUNTUACIÓN } \\
\text { GLOBAL }\end{array}$ & 0,000 & $-16,731$ & $-10,010$ \\
\hline
\end{tabular}

TABLA 28. ANÁLISIS ESTADÍSTICO, PRUEBA "t" DE STUDENT DE COMPARACIÓN DE MEDIAS EN CUESTIONARIO PERFORM EN PATOLOGÍA PULMONAR 
COMPARACIÓN DE MEDIAS "t” STUDENT EN PATOLOGÍA APARATO DIGESTIVO

\begin{tabular}{|c|c|c|c|}
\hline \multirow{2}{*}{$\begin{array}{c}\text { CUESTIONARIO } \\
\text { PERFORM }\end{array}$} & Valor "p" & \multicolumn{2}{|c|}{$\begin{array}{r}\text { 95\% intervalo de confianza para la } \\
\text { diferencia }\end{array}$} \\
\cline { 2 - 4 } & 0,000 & $-8,144$ & $-6,156$ \\
\hline $\begin{array}{c}\text { LIMITACIONES } \\
\text { FÍSICAS }\end{array}$ & 0,000 & $-4,475$ & $-3,525$ \\
\hline $\begin{array}{c}\text { ACTIVIDADES } \\
\text { HABITUALES }\end{array}$ & 0,001 & $-6,064$ & $-4,536$ \\
\hline $\begin{array}{c}\text { ACTITUDES Y } \\
\text { CREENCIAS }\end{array}$ & 0,000 & $-18,388$ & $-14,562$ \\
\hline $\begin{array}{c}\text { PUNTUACIÓN } \\
\text { GLOBAL }\end{array}$ & & & \\
\hline
\end{tabular}

TABLA 29. ANÁLISIS ESTADÍSTICO, PRUEBA "t" DE STUDENT DE COMPARACIÓN DE MEDIAS EN CUESTIONARIO PERFORM EN PATOLOGÍA APARATO DIGESTIVO 


\subsubsection{Triple EVA de Astenia Tumoral}

Tras haber efectuado la prueba "t de student" de comparación de medias, los resultados muestran una diferencia estadísticamente significativa entre los siguientes ítems en el total de la muestra:

- Niveles de energía: $p=0,000$ [IC95:-3,812;-3,110].

- Realización de Actividades de la Vida Diaria: p=0,000 [IC95:-3,000;$2,258]$.

- Niveles de Calidad de Vida: $p=0,000$ [IC95:-3,529;-2,763].

Los datos se detallan de forma global (TABLA), y específica a cada grupo anatomo-patológico a continuación en las TABLAS.

COMPARACIÓN DE MEDIAS “t” STUDENT EN PATOLOGÍA MAMARIA

\begin{tabular}{|c|c|c|c|}
\hline \multirow{2}{*}{$\begin{array}{c}\text { TRIPLE EVA DE } \\
\text { ASTENIA } \\
\text { TUMORAL }\end{array}$} & Valor "p" & \multicolumn{2}{|c|}{$\begin{array}{c}\text { 95\% intervalo de confianza para la } \\
\text { diferencia }\end{array}$} \\
\cline { 2 - 4 } $\begin{array}{c}\text { NIVELES DE } \\
\text { ENERGÍA }\end{array}$ & 0,000 & $-4,050$ & $-2,650$ \\
\hline $\begin{array}{c}\text { REALIZACIÓN DE } \\
\text { AVD }\end{array}$ & 0,000 & $-3,657$ & $-2,043$ \\
\hline $\begin{array}{c}\text { CALIDAD DE VIDA } \\
\text { (CV) }\end{array}$ & 0,000 & $-4,467$ & $-2,633$ \\
\hline
\end{tabular}

TABLA 30. ANÁLISIS ESTADÍSTICO, PRUEBA "t" DE STUDENT DE COMPARACIÓN DE MEDIAS EN TRIPLE EVA EN PATOLOGÍA MAMARIA 
COMPARACIÓN DE MEDIAS “t” STUDENT EN PATOLOGÍA PULMONAR

\begin{tabular}{|c|c|c|c|}
\hline $\begin{array}{c}\text { TRIPLE EVA DE } \\
\text { ASTENIA } \\
\text { TUMORAL }\end{array}$ & Valor "p" & \multicolumn{2}{|c|}{$\begin{array}{c}\text { 95\% intervalo de confianza para la } \\
\text { diferencia }\end{array}$} \\
\cline { 3 - 4 } $\begin{array}{c}\text { NIVELES DE } \\
\text { ENERGÍA }\end{array}$ & 0,000 & $-3,980$ & $-2,835$ \\
\hline $\begin{array}{c}\text { REALIZACIÓN DE } \\
\text { AVD }\end{array}$ & 0,000 & $-3,055$ & $-1,538$ \\
\hline $\begin{array}{c}\text { CALIDAD DE VIDA } \\
\text { (CV) }\end{array}$ & 0,001 & $-3,327$ & $-2,154$ \\
\hline
\end{tabular}

TABLA 31. ANÁLISIS ESTADÍSTICO, PRUEBA "t" DE STUDENT DE COMPARACIÓN DE MEDIAS EN TRIPLE EVA EN PATOLOGÍA PULMONAR

COMPARACIÓN DE MEDIAS “t” STUDENT EN PATOLOGÍA APARATO DIGESTIVO

\begin{tabular}{|c|c|c|c|}
\hline \multirow{2}{*}{$\begin{array}{c}\text { TRIPLE EVA DE } \\
\text { ASTENIA } \\
\text { TUMORAL }\end{array}$} & \multirow[t]{2}{*}{ Valor "p" } & \multicolumn{2}{|c|}{$\begin{array}{c}\text { 95\% intervalo de confianza para la } \\
\text { diferencia }\end{array}$} \\
\hline & & Inferior & Superior \\
\hline $\begin{array}{l}\text { NIVELES DE } \\
\text { ENERGÍA }\end{array}$ & 0,000 & $-4,160$ & $-2,940$ \\
\hline $\begin{array}{c}\text { REALIZACIÓN DE } \\
\text { AVD }\end{array}$ & 0,000 & $-3,515$ & $-2,335$ \\
\hline $\begin{array}{l}\text { CALIDAD DE VIDA } \\
\text { (CV) }\end{array}$ & 0,001 & $-4,018$ & $-2,782$ \\
\hline
\end{tabular}

TABLA 32. ANÁLISIS ESTADÍSTICO, PRUEBA "t" DE STUDENT DE COMPARACIÓN DE MEDIAS EN TRIPLE EVA EN PATOLOGÍA APARATO DIGESTIVO 


\subsubsection{CALIDAD DE VIDA RELACIONADA CON LA SALUD}

\section{Cuestionario SF-12}

Tras haber efectuado la prueba "t de student" de comparación de medias, los resultados muestran una diferencia estadísticamente muy significativa $(p<0,001)$ entre los siguientes ítems en el total de la muestra:

1. Funcionamiento físico: $p=0,000$ [IC95:17,060; 19,584].

2. Rol físico: $p=0,000$ [IC95:7,133; 10,173].

3. Salud general: $p=0,000$ [IC95:12,430; 15,125].

4. Vitalidad: $p=0,000$ [IC95:14,633; 17,646].

5. Funcionamiento social: $p=0,000$ [IC95:1,703; 3,692].

6. Rol emocional: $p=0,000$ [IC95:8,383; 13,576].

7. Salud mental: $p=0,000$ [IC95:5,770; 8,791].

8. Componente físico: $p=0,000$ [IC95:10,674; 13,001].

9. Componente mental: $p=0,000$ [IC95:5,650; 8,552].

Y una diferencia estadísticamente significativa $(p<0,05)$ en el siguiente ítem:

10. Dolor Corporal: $p=0,012$ [IC95:0,604; 4,868].

Los datos se detallan de forma global (TABLA), y específica a cada grupo anatomo-patológico a continuación en las TABLAS. 
COMPARACIÓN DE MEDIAS “t” STUDENT EN PATOLOGÍA MAMARIA

\begin{tabular}{|c|c|c|c|}
\hline \multirow{2}{*}{$\begin{array}{l}\text { CUESTIONARIO } \\
\text { SF-12 }\end{array}$} & \multirow[t]{2}{*}{ Valor "p" } & \multicolumn{2}{|c|}{$\begin{array}{l}\text { 95\% intervalo de confianza para la } \\
\text { diferencia }\end{array}$} \\
\hline & & Inferior & Superior \\
\hline $\begin{array}{l}\text { FUNCIONAMIENTO } \\
\text { FÍSICO }\end{array}$ & 0,000 & 13,188 & 17,754 \\
\hline ROL FÍSICO & 0,000 & 5,140 & 14,325 \\
\hline $\begin{array}{c}\text { DOLOR } \\
\text { CORPORAL }\end{array}$ & 0,666 & $-3,407$ & 5,211 \\
\hline SALUD GENERAL & 0,000 & 10,015 & 16,813 \\
\hline VITALIDAD & 0,000 & 11,254 & 18,260 \\
\hline $\begin{array}{l}\text { FUNCIONAMIENTO } \\
\text { SOCIAL }\end{array}$ & 0,187 & $-0,703$ & 3,371 \\
\hline ROL EMOCIONAL & 0,005 & 3,463 & 16,808 \\
\hline SALUD MENTAL & 0,000 & 5,392 & 10,090 \\
\hline $\begin{array}{l}\text { COMPONENTE } \\
\text { FÍSICO }\end{array}$ & 0,000 & 8,276 & 12,362 \\
\hline $\begin{array}{l}\text { COMPONENTE } \\
\text { MENTAL }\end{array}$ & 0,000 & 4,279 & 9,650 \\
\hline
\end{tabular}

TABLA 33. ANÁLISIS ESTADÍSTICO, PRUEBA "t" DE STUDENT DE COMPARACIÓN DE MEDIAS EN SF-12 EN PATOLOGÍA MAMARIA 
COMPARACIÓN DE MEDIAS “t” STUDENT EN PATOLOGÍA PULMONAR

\begin{tabular}{|c|c|c|c|}
\hline \multirow{2}{*}{$\begin{array}{l}\text { CUESTIONARIO } \\
\text { SF-12 }\end{array}$} & \multirow[t]{2}{*}{ Valor "p" } & \multicolumn{2}{|c|}{$\begin{array}{l}\text { 95\% intervalo de confianza para la } \\
\text { diferencia }\end{array}$} \\
\hline & & Inferior & Superior \\
\hline $\begin{array}{l}\text { FUNCIONAMIENTO } \\
\text { FÍSICO }\end{array}$ & 0,000 & 15,645 & 21,664 \\
\hline ROL FÍSICO & 0,000 & 4,371 & 10,360 \\
\hline $\begin{array}{c}\text { DOLOR } \\
\text { CORPORAL }\end{array}$ & 0,731 & $-3,281$ & 4,616 \\
\hline SALUD GENERAL & 0,000 & 9,246 & 15,190 \\
\hline VITALIDAD & 0,000 & 13,962 & 20,290 \\
\hline $\begin{array}{l}\text { FUNCIONAMIENTO } \\
\text { SOCIAL }\end{array}$ & 0,003 & 0,998 & 4,272 \\
\hline ROL EMOCIONAL & 0,012 & 1,555 & 11,537 \\
\hline SALUD MENTAL & 0,001 & 2,524 & 8,942 \\
\hline $\begin{array}{l}\text { COMPONENTE } \\
\text { FÍSICO }\end{array}$ & 0,000 & 8,957 & 14,959 \\
\hline $\begin{array}{l}\text { COMPONENTE } \\
\text { MENTAL }\end{array}$ & 0,004 & 1,693 & 8,080 \\
\hline
\end{tabular}

TABLA 34. ANÁLISIS ESTADÍSTICO, PRUEBA "t" DE STUDENT DE COMPARACIÓN DE MEDIAS EN SF-12 EN PATOLOGIA PULMONAR 
COMPARACIÓN DE MEDIAS “t” STUDENT EN PATOLOGÍA APARATO DIGESTIVO

\begin{tabular}{|c|c|c|c|}
\hline \multirow{2}{*}{$\begin{array}{l}\text { CUESTIONARIO } \\
\text { SF-12 }\end{array}$} & \multirow[t]{2}{*}{ Valor "p" } & \multicolumn{2}{|c|}{$\begin{array}{c}\text { 95\% intervalo de confianza para la } \\
\text { diferencia }\end{array}$} \\
\hline & & Inferior & Superior \\
\hline $\begin{array}{c}\text { FUNCIONAMIENTO } \\
\text { FÍSICO }\end{array}$ & 0,000 & 17,697 & 21,279 \\
\hline ROL FÍSICO & 0,000 & 6,692 & 10,868 \\
\hline $\begin{array}{c}\text { DOLOR } \\
\text { CORPORAL }\end{array}$ & 0,004 & 1,799 & 8,753 \\
\hline SALUD GENERAL & 0,000 & 13,259 & 16,749 \\
\hline VITALIDAD & 0,000 & 14,296 & 18,662 \\
\hline $\begin{array}{c}\text { FUNCIONAMIENTO } \\
\text { SOCIAL }\end{array}$ & 0,000 & 1,668 & 5,000 \\
\hline ROL EMOCIONAL & 0,000 & 11,191 & 18,434 \\
\hline SALUD MENTAL & 0,000 & 6,688 & 11,379 \\
\hline $\begin{array}{l}\text { COMPONENTE } \\
\text { FÍSICO }\end{array}$ & 0,000 & 11,064 & 13,629 \\
\hline $\begin{array}{l}\text { COMPONENTE } \\
\text { MENTAL }\end{array}$ & 0,000 & 7,239 & 11,343 \\
\hline
\end{tabular}

TABLA 35. ANÁLISIS ESTADÍSTICO, PRUEBA "t" DE STUDENT DE COMPARACIÓN DE MEDIAS EN SF-12 EN PATOLOGÍA APARATO DIGESTIVO 


\subsubsection{ACTIVIDADES DE LA VIDA DIARIA}

\subsubsection{Escala de LAWTON-BRODY}

Tras haber efectuado la prueba "t de student" de comparación de medias, los resultados muestran una diferencia estadísticamente significativa entre los ítems en el total de la muestra $p=0,000$ [IC95:-1,487;-0,918]. Los datos se detallan de forma global, y específica a cada grupo anatomo-patológico a continuación en la Tablas.

COMPARACIÓN DE MEDIAS “t” STUDENT EN ESCALA DE LAWTON-BRODY

\begin{tabular}{|c|c|c|c|}
\hline \multirow{2}{*}{$\begin{array}{c}\text { ESCALA DE } \\
\text { LAWTON-BRODY }\end{array}$} & Valor "p" & \multicolumn{2}{|c|}{$\begin{array}{r}\text { 95\% intervalo de confianza para la } \\
\text { diferencia }\end{array}$} \\
\cline { 3 - 4 } & & Inferior & Superior \\
\hline $\begin{array}{c}\text { PATOLOGÍA } \\
\text { MAMA }\end{array}$ & 0,090 & $-0,760$ & 0,060 \\
\hline $\begin{array}{c}\text { PATOLOGÍA } \\
\text { PULMÓN }\end{array}$ & 0,000 & $-2,189$ & $-0,922$ \\
\hline $\begin{array}{c}\text { PATOLOGÍA } \\
\text { APARATO } \\
\text { DIGESTIVO }\end{array}$ & 0,000 & $-1,897$ & $-1,103$ \\
\hline
\end{tabular}

TABLA 36. ANÁLISIS ESTADÍSTICO, PRUEBA "t" DE STUDENT DE COMPARACIÓN DE MEDIAS EN ESCALA LAWTON-BRODY EN DIFERENTES DIAGNÓSTICOS ANATOMO-

PATOLÓGICOS 


\subsection{ANÁLISIS DE LAS CORRELACIONES BIVARIADAS}

En este último bloque del apartado de "Resultados", se analizarán los datos correspondientes a las diferentes correlaciones establecidas entre las diferentes variables a estudio.

Para llevar a cabo el análisis se utilizará la Prueba de Correlación de Pearson, la cual nos dará una serie de valores para el índice de correlación "r", que fluctuarán entre el intervalo [-1,1].

A continuación se procederá al análisis exhaustivo de cada una de las variables.

\subsubsection{EDAD - CALIDAD DE VIDA RELACIONADA CON LA SALUD}

Tras analizar los datos, obtenemos los siguientes resultados en este par de variables analizadas:

a. Edad - CV Componente Físico:

$r=0,007>0$; correlación positiva entre las variables analizadas.

A valores mayores en la variable "Edad", se correlacionan valores mayores en la variable "CV Componente Físico". Aunque hay que decir que ante la proximidad de el índice de correlación "r" a valores de "0", no podemos asegurar esta aseveración. 
b. Edad - CV Componente Mental:

$r=-0,043<0$; correlación negativa entre las variables analizadas.

A valores mayores en la variable "Edad", se correlacionan valores menores en la variable "CV Componente Mental".

\section{Correlaciones}

\begin{tabular}{|ll|c|c|c|}
\hline & & Edad & CV_Físico & CV_Mental \\
\hline Edad & Correlación de Pearson & 1 &, 007 &,- 043 \\
& Sig. (bilateral) & &, 923 &, 571 \\
& $\mathrm{~N}$ & 180 & 180 & 180 \\
\multirow{2}{*}{ CV_Físico } & Correlación de Pearson &, 007 & 1 &,$- 281\left(^{* *}\right)$ \\
& Sig. (bilateral) &, 923 & &, 000 \\
& $\mathrm{~N}$ & 180 & 180 & 180 \\
CV_Mental & Correlación de Pearson &,- 043 &,$- 281\left(^{* *}\right)$ & 1 \\
& Sig. (bilateral) &, 571 &, 000 & \\
& $\mathrm{~N}$ & 180 & 180 & 180 \\
\hline
\end{tabular}

TABLA 37. ANÁLISIS DE LAS CORRELACIONES ENTRE VARIABLE EDAD YCV

\subsubsection{EDAD - NIVEL DE ASTENIA TUMORAL}

Tras analizar los datos, obtenemos los siguientes resultados en este par de variables analizadas:

$r=-0,198<0$; correlación negativa entre las variables analizadas.

A valores mayores en la variable "Edad", se correlacionan valores menores en la variable "Nivel de Astenia Tumoral". 


\section{Correlaciones}

\begin{tabular}{|ll|c|c|}
\hline & & Edad & Nivel_Astenia \\
\hline Edad & Correlación de Pearson & 1 &,$- 198\left(^{* *}\right)$ \\
& Sig. (bilateral) & &, 008 \\
& $\mathrm{~N}$ & 180 & 180 \\
\multirow{2}{*}{ Nivel_Astenia } & Correlación de Pearson &,$- 198\left(^{* *}\right)$ & 1 \\
& Sig. (bilateral) &, 008 & 180 \\
& $\mathrm{~N}$ & 180 & 180 \\
\hline
\end{tabular}

** La correlación es significativa al nivel 0,01 (bilateral).

TABLA 38. ANÁLISIS DE LAS CORRELACIONES ENTRE VARIABLE EDAD Y NIVELES DE

ASTENIA TUMORAL

\subsubsection{EDAD - NIVEL DE ENERGÍA}

Tras analizar los datos, obtenemos los siguientes resultados en este par de variables analizadas:

$r=-0,205<0$; correlación negativa entre las variables analizadas.

A valores mayores en la variable "Edad", se correlacionan valores menores en la variable "Nivel de Astenia Tumoral".

\section{Correlaciones}

\begin{tabular}{|c|c|c|c|}
\hline & & Edad & Nivel_Energía \\
\hline \multirow[t]{3}{*}{ Edad } & Correlación de Pearson & 1 &,$- 205\left(^{* *}\right)$ \\
\hline & Sig. (bilateral) & & ,006 \\
\hline & $\mathrm{N}$ & 180 & 180 \\
\hline \multirow[t]{3}{*}{ Nivel_Energía } & Correlación de Pearson &,$- 205\left(^{* \star}\right)$ & 1 \\
\hline & Sig. (bilateral) & ,006 & \\
\hline & $\mathrm{N}$ & & 180 \\
\hline
\end{tabular}

TABLA 39. ANÁLISIS DE LAS CORRELACIONES ENTRE VARIABLE EDAD Y NIVELES DE

ENERGIA 


\subsubsection{NIVELES DE HEMOGLOBINA - NIVELES DE ASTENIA TUMORAL}

Tras analizar los datos, obtenemos los siguientes resultados en este par de variables analizadas:

$r=0,024>0$; correlación positiva entre las variables analizadas.

A valores mayores en la variable "Nivel de Hemoglobina", se correlacionan valores mayores en la variable "Nivel de Astenia Tumoral".

\section{Correlaciones}

\begin{tabular}{|ll|c|c|}
\hline & & Hemoglobina & Nivel_Astenia \\
\hline Hemoglobina & Correlación de Pearson & 1 &, 024 \\
& Sig. (bilateral) & &, 753 \\
& $\mathrm{~N}$ & 180 & 180 \\
\multirow{5}{*}{ Nivel_Astenia } & Correlación de Pearson &, 024 & 1 \\
& Sig. (bilateral) &, 753 & \\
& $\mathrm{~N}$ & 180 & 180 \\
\hline
\end{tabular}

TABLA 40. ANÁLISIS DE LAS CORRELACIONES ENTRE VARIABLES NIVEL DE HEMOGLOBINA Y NIVELES DE ASTENIA TUMORAL

\subsubsection{NIVELES DE HEMOGLOBINA - NIVELES DE ENERGÍA}

Tras analizar los datos, obtenemos los siguientes resultados en este par de variables analizadas:

$r=0,012>0$; correlación positiva entre las variables analizadas

A valores mayores en la variable "Nivel de Hemoglobina", se correlacionan valores mayores en la variable "Nivel de Energía". 


\section{Correlaciones}

\begin{tabular}{|ll|c|c|}
\hline & & Hemoglobina & Nivel_Energía \\
\hline Hemoglobina & Correlación de Pearson & 1 &, 012 \\
& Sig. (bilateral) & &, 877 \\
& $\mathrm{~N}$ & 180 & 180 \\
Nivel_Energía & Correlación de Pearson &, 012 & 1 \\
& Sig. (bilateral) &, 877 & \\
& $\mathrm{~N}$ & 180 & 180 \\
\hline
\end{tabular}

TABLA 41. ANÁLISIS DE LAS CORRELACIONES ENTRE VARIABLES NIVEL DE HEMOGLOBINA Y NIVELES DE ENERGIA

\subsubsection{NÚMERO LÍNEAS TRATAMIENTO - NIVEL DE ASTENIA TUMORAL}

Tras analizar los datos, obtenemos los siguientes resultados en este par de variables analizadas:

$r=-0,157<0$; correlación negativa entre las variables analizadas.

A valores mayores en la variable "Número de líneas de tratamiento", se correlacionan valores menores en la variable "Nivel de Astenia Tumoral".

\section{Correlaciones}

\begin{tabular}{|ll|c|c|}
\hline & & Línea_tto & Nivel_Astenia \\
\hline Línea_tto & Correlación de Pearson & 1 &,$- 157\left(^{*}\right)$ \\
& Sig. (bilateral) & &, 035 \\
& $\mathrm{~N}$ & 180 & 180 \\
Nivel_Astenia & Correlación de Pearson &,$- 157\left(^{*}\right)$ & 1 \\
& Sig. (bilateral) &, 035 & \\
& $\mathrm{~N}$ & 180 & 180 \\
\hline
\end{tabular}

* La correlación es significante al nivel 0,05 (bilateral).

TABLA 42. ANÁLISIS DE LAS CORRELACIONES ENTRE VARIABLE NÚMERO DE LÍNEAS DE TRATAMIENTO Y NIVELES DE ASTENIA TUMORAL 


\subsubsection{NÚMERO DE LÍNEAS DE TRATAMIENTO - NIVELES DE ENERGÍA}

Tras analizar los datos, obtenemos los siguientes resultados en este par de variables analizadas:

$r=-0,109<0$; correlación negativa entre las variables analizadas.

A valores mayores en la variable "Número de líneas de tratamiento", se correlacionan valores menores en la variable "Nivel de Energía".

\section{Correlaciones}

\begin{tabular}{|ll|c|c|}
\hline & & Nivel_Energía & Línea_tto \\
\hline Nivel_Energía & Correlación de Pearson & 1 &,- 109 \\
& Sig. (bilateral) & &, 145 \\
& $\mathrm{~N}$ & 180 & 180 \\
\multirow{2}{*}{ Línea_tto } & Correlación de Pearson &,- 109 & 1 \\
& Sig. (bilateral) &, 145 & \\
& $\mathrm{~N}$ & 180 & 180 \\
\hline
\end{tabular}

TABLA 43. ANÁLISIS DE LAS CORRELACIONES ENTRE VARIABLE NÚMERO DE LÍNEAS DE TRATAMIENTO Y NIVELES DE ENERGIA 


\subsubsection{NIVEL DE ASTENIA TUMORAL - NIVEL DE ENERGÍA}

Tras analizar los datos, obtenemos los siguientes resultados en este par de variables analizadas:

$r=0,771>0$; correlación positiva entre las variables analizadas.

A valores mayores en la variable "Nivel de Astenia Tumoral", se correlacionan valores mayores en la variable "Nivel de Energía". Valores del índice de correlación "r" próximos a $r=1$; existe una correlación positiva perfecta. El índice indica una dependencia total entre las dos variables denominada relación directa: cuando una de ellas aumenta, la otra también lo hace en proporción constante.

\section{Correlaciones}

\begin{tabular}{|c|c|c|c|}
\hline & & Nivel_Astenia & Nivel_Energía \\
\hline \multirow[t]{3}{*}{ Nivel_Astenia } & Correlación de Pearson & 1 &, $771\left(^{* \star}\right)$ \\
\hline & Sig. (bilateral) & &, 000 \\
\hline & $\mathrm{N}$ & 180 & 180 \\
\hline \multirow[t]{3}{*}{ Nivel_Energía } & Correlación de Pearson &, $771\left({ }^{* *}\right)$ & 1 \\
\hline & Sig. (bilateral) &, 000 & \\
\hline & $\mathrm{N}$ & & 180 \\
\hline
\end{tabular}

TABLA 44. ANÁLISIS DE LAS CORRELACIONES ENTRE VARIABLE NIVEL DE ASTENIA

TUMORAL Y NIVEL DE ENERGÍA 


\subsubsection{DIAGNÓSTICOS ANATOMO-PATOLÓGICOS - CALIDAD DE VIDA}

Tras analizar los datos, obtenemos los siguientes resultados en este par de variables analizadas:

Informe

\begin{tabular}{|ll|c|c|}
\hline Patología & & CV_Físico & CV_Mental \\
\hline Mama & Media & 34,4380 & 33,1295 \\
& $\mathrm{~N}$ & 41 & 41 \\
& Desv. típ. & 4,69809 & 9,56005 \\
& Media & 31,8237 & 37,2295 \\
& $\mathrm{~N}$ & 57 & 57 \\
Aparato Digestivon & Desv. típ. & 6,73999 & 10,62362 \\
& Media & 32,6134 & 35,7856 \\
& $\mathrm{~N}$ & 82 & 82 \\
& Desv. típ. & 5,00174 & 9,52798 \\
Total & Media & 32,7789 & 35,6378 \\
& $\mathrm{~N}$ & 180 & 180 \\
& Desv. típ. & 5,60344 & 9,95339 \\
\hline
\end{tabular}

TABLA 45. ANÁLISIS DE LOS COMPONENTES FISICO Y MENTAL DE CALIDAD DE VIDA RELACIONADA CON LA SALUD EN LOS DIFERENTES GRUPO ANATOMO-PATOLÓGICOS

\subsubsection{DIAGNÓSTICOS ANATOMO-PATOLÓGICOS - NIVEL ASTENIA TUMORAL}

Tras analizar los datos, obtenemos los siguientes resultados en este par de variables analizadas:

Informe

\begin{tabular}{|l|r|r|r|}
\hline Patología & \multicolumn{1}{|c|}{ Media } & N & Desv. típ. \\
\hline Mama & 19,24 & 41 & 6,041 \\
Pulmón & 19,82 & 57 & 7,124 \\
Aparato Digestivo & 20,66 & 82 & 6,344 \\
Total & 20,07 & 180 & 6,525 \\
\hline
\end{tabular}

TABLA 46. ANÁLISIS DE LOS NIVEELS DE ASTENIA TUMORAL EN LOS DIFERENTES GRUPO ANATOMO-PATOLÓGICOS 
Las puntuaciones expresan resultados muy similares en los niveles de astenia tumoral expresados en los diferentes grupos anatomo-patológicos, siendo mayor en el subgrupo "Aparato Digestivo", con una puntuación de 20,66; y menor en el subgrupo "Mama", con una puntuación de 19,24.

\subsubsection{GÉNERO - CALIDAD DE VIDA}

Tras analizar los datos, obtenemos los siguientes resultados en este par de variables analizadas:

Informe

\begin{tabular}{|ll|c|c|}
\hline Sexo & & CV_Físico & CV_Mental \\
\hline Masculino & Media & 32,1492 & 37,6701 \\
& $\mathrm{~N}$ & 95 & 95 \\
& Desv. típ. & 5,57252 & 10,24032 \\
Femenino & Media & 33,4828 & 33,3665 \\
& $\mathrm{~N}$ & 85 & 85 \\
& Desv. típ. & 5,58653 & 9,15827 \\
Total & Media & 32,7789 & 35,6378 \\
& $\mathrm{~N}$ & 180 & 180 \\
& Desv. típ. & 5,60344 & 9,95339 \\
\hline
\end{tabular}

TABLA 47. ANÁLISIS DE LOS COMPONENTES FÍSICO Y MENTAL DE CALIDAD DE VIDA RELACIONADA CON LA SALUD EN LOS DIFERENTES GÉNEROS 


\subsubsection{GÉNERO - NIVEL DE ASTENIA TUMORAL}

Tras analizar los datos, obtenemos los siguientes resultados en este par de variables analizadas:

\begin{tabular}{|l|c|c|c|}
\multicolumn{1}{|c|}{ Sexo } & Media & N & Desv. típ. \\
\hline Masculino & 20,84 & 95 & 6,737 \\
Femenino & 19,21 & 85 & 6,207 \\
Total & 20,07 & 180 & 6,525 \\
\hline
\end{tabular}

TABLA 48. ANÁLISIS DE LOS NIVELES DE ASTENIA TUMORAL EN LOS DIFERENTES GÉNEROS

Las puntuaciones expresan resultados similares en los niveles de astenia tumoral expresados en los diferentes géneros, siendo mayor en el subgrupo "Masculino", con una puntuación de 20,84; y menor en el subgrupo "Femenino", con una puntuación de 19,21. 
5. DISCUSIÓN 
a hipótesis que se planteó en este estudio fue la siguiente: "las intervenciones no farmacológicas llevadas a cabo desde la perspectiva de la Terapia Ocupacional disminuyen los niveles de astenia tumoral en los pacientes oncológicos, aumentando su autonomía y, consecuentemente a todo ello, mejoran su calidad de vida relacionada con la salud", para verificar dicha hipótesis nos planteamos realizar un estudio aleatorizado con un objetivo principal: "Comprobar la eficacia de las medidas de tipo no farmacológico para el control de la astenia referida por el enfermo oncológico".

En la revisión de la literatura encontramos consenso sobre el tratamiento farmacológico empleado para controlar la astenia tumoral 305, 306, 307 y también hay acuerdo sobre los efectos secundarios, entre los que destacamos ansiedad, insomnio o labilidad emocional, que se derivan de ellos 308,309 . Con nuestro estudio, a diferencia de estos tratamientos tradicionales para el control de los niveles de astenia tumoral, planteamos un modo de actuación centrado principalmente en la recuperación funcional del individuo, otorgando total prioridad a la autonomía. En la mayoría de los estudios en pacientes oncológicos se habla de supervivencia, pero quizás la importancia de la misma 
no está en el tiempo estimado, si no en la calidad de vida de los pacientes durante ese tiempo. Por ello consideramos que el principal obstáculo a tener en cuenta para considerar si una supervivencia mayor es digna, es la autonomía, es decir, el hecho de que esa persona sea independiente para realizar las actividades básicas y las actividades instrumentales de la vida diaria que le permitan, adaptarse en la medida de lo posible en su entorno y en su comunidad.

La sintomatología de la astenia tumoral, resulta muy incapacitante para el paciente oncológico, por lo que un control adecuado de la misma se considera imprescindible para conseguir esa dignidad en el paciente con cáncer.

Tradicionalmente se ha hablado de la necesidad de realización de ejercicio físico en pacientes con este tipo de sintomatología, y ha quedado demostrada su utilidad, como hemos expuesto en el apartado de introducción, en numerosos estudios. Algunos de ellos serían los siguientes:

En un meta-análisis publicado en la National Comprehensive Cancer Network (NCCN) de Puetz y Herring, en la guía elaborada en 2013 sobre astenia tumoral, en el cual se incluyen 70 estudios con un total de 4881 pacientes oncológicos en tratamiento, se observa como los niveles de astenia tumoral fueron disminuidos, utilizando el ejercicio físico, con un efecto estadísticamente significativo, durante y posterior al tratamiento, respectivamente ${ }^{310}$. 
En un análisis publicado en Cochrane en 2012 de Mishra y colaboradores, en el cual se incluían 56 estudios randomizados, con una muestra total final de 4826 individuos, se observan resultados estadísticamente significativos en niveles de astenia tumoral tras la intervención con ejercicio físico ${ }^{311}$.

Estudios menores de autores como Cramp, Duijts, Kangas, McMillan o Velthuis nos muestran resultados muy satisfactorios de la utilización del ejercicio físico como medida de control sintomático e incluso de mejora sintomática en pacientes con astenia referida de la enfermedad oncológica, sea cual sea su etiología $312,313,314,315,316$.

Aún así debemos decir que la duración y tipo de ejercicio físico utilizado varía ampliamente. No existe información suficiente para clarificar cuál es el programa de ejercicio físico más apropiado para estos enfermos, dada su diversidad. Este programa debería considerar la edad y sexo del paciente, el tipo de cáncer y su tratamiento, y el estado físico y funcional del individuo ${ }^{317}$.

Además del ejercicio físico se proponen otra serie de medidas como son las técnicas de conservación o ahorro de energía o las intervenciones psicosociales. Todas ellas han quedado validadas en amplios estudios, de autores como Love, Ream, Barsevick, Engstrom, Kangas, Goedendorp o Jacobsen 318, 319, 320, 321, 322, 323, 324. 
Del análisis anterior surgieron los planteamientos siguientes: ¿el paciente debería adaptarse a su nueva sintomatología?, ¿debería ser capaz de continuar, en la medida de lo posible, su vida cotidiana de la forma más normalizada?, por lo que teniendo en cuenta todas estas actuaciones, se han propuesto dos adicionales, que son la "adaptación al esfuerzo" y la "reeducación en actividades de la vida diaria", todas llevadas a cabo desde la disciplina de la terapia ocupacional.

Para poder llevar a cabo este tipo de actuaciones es necesaria una intervención individualizada, ya que los niveles funcionales de cada individuo, en el momento de comenzar con la intervención, serán completamente diferentes.

Otro de los problemas que se observan en la utilización única de estrategias como el ejercicio físico sería la capacidad funcional presente en el paciente. En el caso de individuos cuya funcionalidad se hubiera visto muy reducida, incluso llegando a extremos de pérdida de la marcha o de dependencia total en actividades de la vida diaria, la realización de ejercicio físico sería prácticamente imposible. Estos niveles de funcionalidad, según los estudios, se

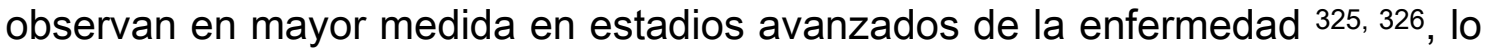
que nos llevó a incluir en nuestro estudio sólo a pacientes con un estadio oncológico avanzado. 
Por todo ello, y teniendo en cuenta los objetivos, se decidió que había que evaluar tres parámetros fundamentales, el nivel de astenia tumoral o nivel de energía, la calidad de vida relacionada con la salud y los niveles de funcionalidad o de realización de actividades de la vida diaria.

Conjuntamente con el análisis exhaustivo de las diferentes variables estudiadas, debemos mencionar que al ser un estudio de contraste entre dos grupos, uno control y otro experimental era muy importante partir en ambos de una situación clínica y funcional similar, lo cual, hemos de decir, que es lo que se ha observado, como se muestra en el apartado de resultados descriptivos.

Además, otro de los parámetros a tener en cuenta que podría ocasionar sesgos en el proyecto sería la intervención de tipo farmacológico. Ya que en caso de que no hubiera un balance entre ambos grupos a estudio podría favorecer o perjudicar las intervenciones que se llevan a cabo desde la perspectiva de la terapia ocupacional. Si hacemos un análisis más exhaustivo de esto último podemos observar como en el grupo control el $40,44 \%$ de los individuos reciben tratamiento farmacológico específico, mientras que en el grupo experimental lo hacen el $38,46 \%$. Estos datos reflejan un gran balance, están muy compensados, lo que hace que no podamos hablar de diferencias significativas que repercutan en los resultados, y en caso de hacerlo lo harían de forma positiva ya que en el grupo control, el cual no recibe ningún tipo de 
intervención adicional, hay más individuos que se encuentran con tratamiento farmacológico que podría mejorar la sintomatología clínica analizada.

A continuación pasaremos a discutir cada uno de los apartados expuestos en el estudio, en un principio analizaremos las variables nivel de astenia, nivel de energía, calidad de vida relacionada con la salud y realización de actividades de la vida diaria; para a continuación pasar a detallar otro tipo de variables intervinientes en el estudio, como son la edad, el género, los niveles de hemoglobina o el número de líneas de tratamiento empleadas.

Comenzaremos a discutir las variables independientes al estudio:

En cuanto a los NIVELES DE ASTENIA TUMORAL, y antes de comenzar con una discusión más profunda, debemos recordar que las puntuaciones en el cuestionario PERFORM se traducen de la siguiente forma: puntuaciones mayores se identifican con menor nivel de astenia tumoral y viceversa.

En cuanto a los niveles de astenia tumoral presentados por los individuos de la muestra observamos como en el grupo experimental se aprecian mejorías estadísticamente muy significativas tanto en las puntuaciones específicas del cuestionario PERFORM de "Aspecto físico", "Aspecto Emocional" y "Creencias y actitudes", como en el apartado "Total", nos confirman que los pacientes que reciben tratamiento farmacológico y no farmacológico presentan menores 
niveles de astenia que los pacientes que solo reciben tratamiento farmacológico.

Estas diferencias grandes estadísticamente significativas se registraron en el total de la muestra y en los diferentes grupos anatomo-patológicos.

Se debe resaltar que en ambos grupos, en la evaluación inicial realizada en el momento de ingreso del paciente en la unidad, no había diferencia en las puntuaciones registradas.

Por último debemos mencionar que si hacemos distinción entre los diferentes diagnósticos anatomo-patológicos en referencia a los niveles de astenia tumoral, observamos como las puntuaciones son muy similares, siendo la mayor la de patología del aparato digestivo y la menor la de patología mamaria.

Si comparamos estos resultados con los obtenidos en la bibliografía podemos hablar de dos apartados diferentes. Vamos a analizarlos con una revisión llevada a cabo por Mock ${ }^{327}$, en la cual se analizan 14 estudios experimentales randomizados. La primera diferencia que encontramos radica en que los estudios se realizan bien en un solo grupo anatomo-patológico, preferentemente patología mamaria, o se habla de "varios tipos de cáncer", sin especificar ni comparar ningún resultado en función del tipo de neoplasia estudiada. La segunda diferencia radica en el tipo de intervención empleada, siempre se plantea el estudio partiendo de un tipo de intervención no 
farmacológica específica, ya sea ejercicio físico o técnicas de ahorro de energía, es decir, se está partiendo de la utilización de una estrategia de tratamiento antes de conocer las características clínicas presentes en el paciente, lo cual consideramos pensamos no es lo más adecuado. Por ello, en nuestro estudio, primero se lleva a cabo una evaluación exhaustiva del individuo y posteriormente se realiza una intervención individualizada acorde a sus necesidades y objetivos.

En un meta-análisis realizado en el año 2011 por Brown y colaboradores ${ }^{328}$ ya se llegó como conclusión a la necesidad de realizar intervenciones individualizadas acorde al estado de salud del individuo y al tipo de patología oncológica. En este se analizaron 44 estudios con un total de 3254 participantes a los cuales se les llevaba a cabo intervenciones de tipo no farmacológico para el control de la astenia referida por la enfermedad oncológica en supervivientes. Tras el análisis de los mismos se llego a la conclusión de la necesidad de llevar a cabo una intervención individualizada, por lo que si es necesaria la individualización en pacientes supervivientes de cáncer, la pregunta que debemos plantearnos es, ¿no sería necesaria una intervención individualizada en pacientes con patología oncológica activa también?

En cuanto a los NIVELES DE ENERGÍA presentados por los pacientes, los cuales se evalúan dentro de uno de los ítems de la escala triple EVA de astenia 
tumoral, conjuntamente a otros dos ítems de calidad de vida y de realización de actividades de la vida diaria, observamos diferencias estadísticamente muy significativas entre ambos grupos a estudio. Estas diferencias se muestran tanto en el total de individuos como en los diferentes grupos anatomopatológicos establecidos de patología mamaria, pulmonar y del aparato digestivo.

Debemos destacar que en ambos grupos, experimental y control, en el momento en el que llevamos a cabo la evaluación inicial no se encuentran diferencias entre las puntuaciones obtenidas en cuanto a los valores de energía, lo cual nos indica que estamos partiendo de situaciones sintomáticas muy similares.

Además destacar que entre el nivel de astenia tumoral y el nivel de energía, se presenta una correlación fuerte y positiva, lo cual nos indica que a valores mayores en la variable "Nivel de astenia tumoral", se corresponden valores mayores en la variable "Nivel de energía", es decir que a menor astenia tumoral los pacientes presentan mayor energía. Además, hay que resaltar que los valores presentados por el índice de correlación son cercanos a "1", que indicaría una correlación positiva perfecta, la cual se traduciría en una dependencia total entre las dos variables, también denominada relación directa, es decir, cuando una aumenta la otra también lo hace en proporción constante. 
Con esto se puede considerar que el cuestionario PERFORM, además de ser válido para determinar "niveles de astenia tumoral totales", así como para establecer puntuaciones en sus ítems específicos de "aspecto físico", "aspecto emocional" y "creencias y actitudes", es muy predictivo en cuanto al estado enérgico de los individuos.

Por otra parte en cuanto a la CALIDAD DE VIDA RELACIONADA CON LA SALUD (CVRS), en la bibliografía revisada aparecen múltiples investigaciones que abordan el estudio de esta variable, uno de los grupos de investigación más importante es el grupo de la EORTC (European Organisation for Research and Treatment of Cancer), el cual tiene gran importancia en nuestro país $329,330,331,332,333,334,335$.

Todos ellos analizan la calidad de vida en los pacientes de diferentes grupos anatomo-patológicos, pero solo se centran en analizarla bien de forma descriptiva o tras la intervención de tipo farmacológica, olvidando todas las intervenciones de tipo no farmacológico, las cuales contribuyen de manera importante en la mejora o el mantenimiento de ésta. Además se centran en el análisis del parámetro sin correlacionarlos con otros grupos sintomáticos, tan válidas o más que las anteriores, lo cual consideramos es ciertamente incompleto; es decir, evalúan los niveles de calidad de vida sin relacionar la mejora o empeoramiento de los mismos debido a las intervenciones realizadas o a los efectos secundarios de los tratamientos. 
En nuestro estudio se utilizó el cuestionario SF-12 v2, el cual te aporta dos puntuaciones globales, el "componente físico" y el "componente mental"; y ocho ítems más específicos, los cuales son: "Funcionamiento físico", "Rol físico", "Dolor corporal", "Salud general", "Vitalidad", "Funcionamiento social", "Rol emocional" y "Salud mental".

Observamos diferencias grandes estadísticamente significativas entre los individuos pertenecientes al grupo control y al grupo experimental en todos los ítems, exceptuando en el de "dolor corporal", el cual cómo podemos observar no presenta una diferencia suficiente, lo cual indica que como en ambos grupos se utilizaban medidas de tipo farmacológico para el control del dolor, ambos grupos de pacientes presentaron una reducción significativa del mismo, es decir, un buen control del dolor en el momento de alta de la unidad.

En el grupo de patología mamaria, observamos diferencias estadísticamente significativas en todos los ítems exceptuando los de "dolor corporal" y "funcionamiento social". En el primer caso, queda evidenciado el tratamiento farmacológico empleado para el control del dolor; mientras que en el segundo, el del "funcionamiento social", pensamos puede deberse a que las pacientes, en este caso todas de género femenino, aún no han podido comprobar cuál es su funcionamiento social por estar ingresadas en el ámbito hospitalario, lo cual se refleja en esa no mejoría evidenciada en las puntuaciones de ambos grupos. 
En el grupo de patología pulmonar, se presentan mejorías estadísticamente significativas en todos los ítems exceptuando en el de "dolor corporal", lo cual vuelve a evidenciar el tratamiento farmacológico empleado para el control del dolor.

En el grupo de patología del aparato digestivo, observamos diferencias estadísticamente significativas en absolutamente todos los ítems del cuestionario, incluyendo el de "dolor corporal". Aún así pensamos se puede analizar más a fondo para poder conocer si existe influencia positiva de las intervenciones no farmacológicas empleadas en el control del dolor, como evidencian algunos estudios al respecto 336,337 .

Un ejemplo de este tipo de estudios es el de Portenoy y colaboradores en 2011 338, el cual habla de la necesidad de utilización de un abordaje multidimensional, donde se combinen tratamientos farmacológicos y tratamientos no farmacológicos para el control del dolor, debido a la evidencia bibliográfica existente de estos últimos.

Además debemos mencionar que si hacemos distinción entre los diferentes diagnósticos anatomo-patológicos en referencia a los niveles de calidad de vida relacionada con la salud, y más concretamente a las puntuaciones globales del "componente físico" y "componente mental", observamos como las puntuaciones son muy similares. En el caso del "componente físico", el grupo 
que presenta una mayor puntuación es el de patología mamaria, mientras que el grupo de patología del aparato digestivo es el de menor puntuación. Por el contrario, en cuanto a la puntuación del "componente mental", el grupo que presenta una mayor puntuación es el de patología pulmonar mientras que el grupo de patología mamaria es el menor.

También debemos mencionar la puntuación obtenida para el ítem de calidad de vida en la triple EVA de astenia tumoral, la cual recordamos valoraba nivel de energía, calidad de vida y nivel de realización de actividades de la vida diaria.

En el caso de la calidad de vida observamos diferencias estadísticamente muy significativas tanto en el total de los grupos como en los diferentes subgrupos anatomo-patológicos.

Por lo que como podemos observar existe una correlación directa entre ambas formas de valorar los niveles de calidad de vida relacionada con la salud, mucho más preciso en el cuestionario SF-12, aunque más lento; mientras que con una gran validez y más rápido en el caso de la escala triple EVA de astenia tumoral.

En cuanto a la REALIZACIÓN DE ACTIVIDADES DE LA VIDA DIARIA (AVD), evidentemente, cuando inicialmente nos planteamos la realización del proyecto, y siendo un estudio en el cual, uno de los objetivos principales no sería otro que conseguir mayor autonomía personal en los pacientes, es evidente que la 
realización de actividades de la vida diaria debería ser pieza clave e imprescindible a valorar.

Tras el análisis bibliográfico existente sobre este apartado observamos como la práctica totalidad de los estudios se centraban en la realización de actividades básicas de la vida diaria 339,340,341,342, sin negar la importancia de las mismas, consideramos un error no tener en cuenta las actividades instrumentales. Por ello decidimos que estas últimas debían ser objeto de estudio por nuestra parte. Podríamos haber decidido estudiar ambas variables pero sería demasiada carga evaluadora para los pacientes, por lo que ante la menor bibliografía presentada sobre las instrumentales incluimos la escala de Lawton y Brody en el proyecto.

Uno de los principales problemas que presenta esta escala es que en población de edad avanzada no está muy validada, ya que puede haber otro tipo de connotaciones culturales que interfieran en los resultados, puesto que generalmente era la mujer la que realizaba este tipo de actividades. Finalmente, y considerando la edad media de los usuarios del estudio, 68 años, descartamos este sesgo para la práctica totalidad de la muestra a estudio.

Observamos diferencias grandes estadísticamente significativas entre los individuos pertenecientes al grupo control y al grupo experimental en el total de los individuos de la muestra. 
En el grupo de patología mamaria no se establecen diferencias estadísticamente significativas; mientras que en los grupos de patología pulmonar y relacionada con el aparato digestivo existen diferencias estadísticamente muy significativas. Esto pensamos puede deberse a que las pacientes de patología mamaria, en este caso todas de género femenino, aún no han podido comprobar cuál es su capacidad en cuanto a la realización de actividades instrumentales de la vida diaria, por estar ingresadas en el ámbito hospitalario, lo cual se refleja en esa no mejoría evidenciada en las puntuaciones de ambos grupos. Consideramos que en un futuro, un estudio que evalúe este tipo de actividades una vez hayan vuelto a la máxima normalidad en su vida cotidiana, podría esclarecer con mayor exactitud cuál es la repercusión en esta variable.

Además también debemos mencionar la puntuación obtenida para el ítem de realización de actividades de la vida diaria en la triple EVA de astenia tumoral, la cual recordamos valoraba además nivel de energía y calidad de vida.

Observamos diferencias estadísticamente muy significativas tanto en el total de los grupos como en los diferentes subgrupos anatomo-patológicos.

Por lo que como podemos observar existe una correlación directa entre ambas formas de valorar la realización de actividades de la vida diaria, más preciso en 
la escala de Lawton - Brody, aunque más lento; mientras que con una gran validez y más rápido en el caso de la escala triple EVA de astenia tumoral.

Para concluir este subapartado, cabe destacar el hecho de que si existe diferencia en un aspecto. En el subgrupo anatomo-patológico de patología mamaria muestra diferencias estadísticamente significativas en la triple EVA de astenia tumoral, mientras que no es así en la escala de Lawton - Brody. La explicación que podemos encontrarle a este hecho no es otra que, mientras que la escala Lawton - Brody valora exclusivamente actividades instrumentales de la vida diaria, la triple EVA evalúa la realización de actividades de la vida diaria de forma general, incluyendo también las básicas y las avanzadas, por lo que parece indicar que el aspecto instrumental no mejora, mientras que el básico si lo hace, aunque se deben realizar más estudios para esclarecer completamente este asunto.

Además en la bibliografía se observa como el análisis de los niveles de autonomía de los individuos se realiza siempre de forma secundaria, es decir, se evalúa partiendo de puntuaciones obtenidas en ítems secundarios de grandes escalas sintomáticas, un ejemplo de esto lo tenemos en un estudio de 2013 de Schlack y colaboradores ${ }^{343}$, los cuales hablan de "bienestar funcional" como parámetro para evaluar autonomía en los individuos, obteniendo esta puntuación de un subapartado de la escala FACT-G. Este es sólo un ejemplo 
de tantos otros que demuestran como el análisis de la autonomía de los individuos siempre se realiza en un segundo plano.

Aparte de lo discutido anteriormente debemos destacar otras variables intervinientes en el estudio, edad y género de los pacientes, niveles de hemoglobina, número de líneas de tratamiento recibidas y el diagnóstico anatomo-patológico.

En cuanto a la EDAD de los individuos, la hemos correlacionado con los niveles de astenia tumoral y la calidad de vida relacionada con la salud.

En el primer caso, se muestra una correlación negativa entre la edad y los niveles de astenia tumoral, aunque una correlación débil y negativa, ya que el índice de correlación es muy próximo a cero, lo cual nos indica que no existe relación lineal, pero esto no necesariamente implica que las variables son independientes: pueden existir todavía relaciones no lineales entre las dos variables. Aunque nos lleva a pensar que la edad no es un factor determinante en los niveles de astenia tumoral de los pacientes.

En cuanto a la calidad de vida, en esta deberemos diferenciar dos aspectos, por una parte el componente físico y por otra el componente mental. 
El componente físico muestra un índice de correlación positivo aunque muy débil, y el componente mental muestra un índice de correlación negativo, aunque al igual que en el aspecto físico, también muy cercano al valor nulo de cero. En concordancia con estos resultados no podemos asegurar que exista una relación lineal entre las variables, con lo cual determinamos que en cuanto a la calidad de vida relacionada con la salud, la edad de los individuos no es un factor determinante en pacientes oncológicos.

Nuestros resultados contrastan con los obtenidos en un estudio llevado a cabo en el año 2011 por Singer y colaboradores ${ }^{344}$, en el cual se intentaron correlacionar los niveles de fatiga con respecto a la edad de los pacientes, en una muestra total de 1494 pacientes, en el se obtuvo que las probabilidades de presentar astenia eran cuatro veces mayor en el grupo de edad más joven, en torno a los 40 años, que aquellos más mayores, con edades superiores a los 60 años.

A continuación analizaremos la influencia del GÉNERO de los individuos en sus niveles de astenia tumoral y en su calidad de vida relacionada con la salud.

Comenzaremos con el nivel de astenia tumoral en el momento de ingreso en la unidad. Observamos como en el género masculino el nivel de astenia tumoral medio es superior que en el género femenino, pudiendo afirmar que en el caso del género femenino, presentan mayor astenia. Lo cual se asemeja a los 
resultados obtenidos en un estudio llevado a cabo en el año 2011 por Singer y colaboradores ${ }^{345}$, en el cual se intentaron correlacionar los niveles de fatiga con respecto al género de los individuos, obteniendo en este caso que en el momento de ingreso, la prevalencia de astenia en el caso de los hombres fue del $28 \%$, mientras que en el caso de las mujeres fue del $39 \%$.

Proseguimos con la calidad de vida. $Y$ en este caso debemos hacer dos subapartados, por una parte el componente físico y por otra el componente mental.

En el caso de los hombres su calidad de vida se encuentra más deteriorada en el aspecto físico, mientras que en las mujeres, ambos componentes, físico y mental, son muy similares. La segunda es que comparando a los dos géneros comprobamos que los hombres presentan mejores puntuaciones en el aspecto mental, mientras que por el contrario las mujeres lo hacen en el aspecto físico. Esto último no podemos verificarlo o compararlo con respecto a ningún estudio realizado, ya que en la bibliografía actual no se analizan estos términos.

Otro de los puntos importantes a discutir en el proyecto sería la correlación existente entre los NIVELES DE HEMOGLOBINA en los pacientes con sus parámetros de astenia tumoral y de energía. La bibliografía habla claramente de la influencia negativa de niveles bajos de hemoglobina en estas dos puntuaciones ${ }^{346}$, pero la mayoría de los estudios desarrollados evalúan niveles 
de hemoglobina por debajo de $10 \mathrm{~g} / \mathrm{dl}$, pero ¿con niveles superiores?, ¿cómo es la influencia de estos datos analíticos?

Comenzaremos estudiando la relación existente entre los niveles de hemoglobina en el momento de ingreso de los pacientes y sus parámetros de astenia tumoral. Tras el análisis observamos cómo hay una correlación positiva entre las variables analizadas, es decir, a valores mayores en una variable se correlacionan valores mayores en la otra, menor astenia tumoral mayor nivel de hemoglobina.

Por otra parte, y analizando ahora los niveles de energía expresados, podemos decir que existe también una correlación positiva entre las diferentes variables estudiadas, a mayor nivel de energía a mayores índices de hemoglobina.

Aunque hemos de decir que en ambos casos el índice de correlación es muy cercano a su valor neutro de cero, por lo que no podemos aseverar rotundamente esta afirmación.

La bibliografía revisada sobre el tema habla de la incidencia de la anemia en la sintomatología de astenia en valores de hemoglobina inferiores a 12g/dl 347, 348; recordando nuestro estudio, los criterios de inclusión y exclusión impuestos solo permitían niveles de hemoglobina superiores a $10 \mathrm{~g} / \mathrm{dl}$ en los pacientes, ya que sino el tratamiento de la anemia podía repercutir de forma significativa en 
los resultados, por ello creemos que los niveles de correlación entre estas variables no dan significativos.

Tras este análisis consideramos importante en estudios posteriores analizar no solo los niveles de hemoglobina presentes en el momento de ingreso, sino que también se debería estudiar en el momento de alta de los pacientes, para poder comprobar si existe alguna repercusión, del tipo que sea, tras la realización del programa de terapia ocupacional y reeducación al esfuerzo propuesto.

Otro de los aspectos a valorar y analizar es la influencia que tiene el NÚMERO DE LÍNEAS DE TRATAMIENTO recibidas en los individuos con respecto a sus niveles de astenia tumoral y de energía. Los estudios hablan de que en la mayoría de los casos, a mayor número de líneas de tratamiento empleadas, se presentan mayores niveles de astenia tumoral y menores niveles de energía ${ }^{349}$, $350,351$.

Nosotros queremos comprobar si esta afirmación se cumplía en la población española, y más concretamente en los pacientes ingresados en el servicio de oncología médica del hospital universitario de Salamanca.

En primer lugar estudiamos el impacto que ha tenido con respecto a los niveles de astenia tumoral. Observamos una correlación negativa entre las variables analizadas. A mayor número de líneas de tratamiento empleadas, se relacionan 
valores menores en la puntuación de astenia tumoral, es decir, mayor astenia tumoral.

En segundo lugar, analizamos esa influencia en los niveles de energía. En este caso hablamos de una correlación negativa, es decir, a mayor número de líneas de tratamiento empleadas se correlacionan niveles menores de energía.

Antes de concluir este análisis debemos mencionar que en este caso los diferentes tratamientos no tienen la misma repercusión en los pacientes, ya que algunos tienen unos efectos secundarios mayores que otros, por lo que esto podría ser un sesgo del estudio en este caso y nos puede llevar en un futuro a analizar más detenidamente el impacto que tienen en los individuos los diferentes tratamientos administrados.

Para finalizar nos gustaría hablar de la importancia que debería tener la autonomía de los individuos con este tipo de patologías oncológicas. Consideramos de vital importancia que los individuos se adapten a la nueva situación, es decir, que sean capaces de continuar con su vida de la forma más normalizada posible, sin que el hecho de tener una enfermedad sea motivo de eliminación o cambio de roles sociales. Evidentemente las circunstancias cambian, hay nuevas metas y nuevos objetivos que modifican la forma de vivir, pero no por ello deben dejar de realizar sus actividades cotidianas. 
En la mayoría de estudios realizados en cáncer se analizan los años de supervivencia ${ }^{352}$, sin considerar si esa supervivencia es digna o si la persona está conforme con esa mayor esperanza de vida. Evidentemente ese es el principal objetivo, pero no debemos olvidar todo lo secundario que nos llevará a mantener una óptima calidad de vida. Creemos que de nada sirve tener una supervivencia mayor si ésta no va acompañada de una serie de valores imprescindibles, como son, desde nuestro punto de vista, la autonomía, la calidad de vida y el bienestar social.

Por ello en nuestro estudio, teniendo en cuenta que la astenia tumoral es el síntoma más quebrantador e incapacitante del paciente oncológico ${ }^{3}$, nos propusimos, en primer lugar controlar el síntoma para evitar sus consecuencias; y posteriormente conseguir, que tras ese control, la persona recuperara la autonomía perdida para que pudiera ser capaz de desenvolverse en sus actividades de la vida diaria.

En este sentido consideramos imprescindible que este programa de rehabilitación se lleve a cabo por un equipo interdisciplinar de trabajo, el cual trabaje de forma conjunta y coordinada para llegar al objetivo principal, el paciente. En muchos casos observamos como la dinámica de trabajo diaria se realiza en equipo pero no de forma interdisciplinar, sino multidisciplinar; no es lo mismo que un grupo de diferentes profesionales trabajen en un área común de forma independiente, valorando al enfermo por separado e interactuando 
entre ellos de manera informal (equipo multidisciplinar), a que lo haga un equipo constituido por diferentes profesionales que trabajen en un área común de forma interdependiente e interactúen entre ellos de manera formal e informal, pudiendo valorar al enfermo por separado pero intercambiando la información de una forma sistemática, compartiendo una metodología de trabajo y trabajando juntos para conseguir unos objetivos conjuntos, colaborando entre ellos en la planificación y puesta en marcha de un plan de tratamiento y cuidados, consensuado tanto por el equipo como por el paciente y los familiares (equipo interdisciplinar). Esta última es, sin ninguna duda, la forma correcta de actuación, y será la que en un futuro próximo, y ya en el presente en muchos lugares, se está llevando a cabo, lo que hará que el ámbito sanitario avance y evolucione en el camino adecuado.

\section{CONSIDERACIONES PARA LA INVESTIGACIÓN FUTURA}

Evidentemente somos conscientes de que la investigación en cualquier ámbito, y más concretamente en el oncológico, debe continuar avanzando. Dentro del terreno tanto de la sintomatología de la astenia tumoral como de la intervención de la terapia ocupacional aún queda un largo camino por recorrer. A pesar de la bibliografía existente sobre ambos temas hemos de decir que en nuestro país aún es algo escasa. Observamos como en países como Reino Unido, Francia, Suecia, Estados Unidos o Japón la figura del terapeuta ocupacional forma parte de los equipos tanto de soporte como de cuidados paliativos, 
mientras que en España se sigue intentando demostrar su utilidad en estos ámbitos. Por otra parte observamos como en la mayoría de centros, el síntoma de astenia se sigue tratando única y exclusivamente de forma farmacológica, olvidando así todos los beneficios que hemos demostrado, tanto en este, como en otros estudios en diferentes países.

Por ello, y teniendo en cuenta que la investigación nunca finaliza planteamos los retos que debemos proponernos en un futuro para continuar mejorando el conocimiento sobre estos dos aspectos. Consideramos que debe ampliarse este tipo de intervenciones terapéuticas a otras sintomatologías asociadas tanto a procesos oncológicos como a sus tratamientos. Una de ellas podría ser la disnea. En ese caso, al igual que ocurre en el paciente con astenia, es necesaria una reeducación al esfuerzo de los individuos que les lleve a mejorar la realización de sus actividades de la vida diaria, por lo que creemos que este tipo de intervenciones serían justificadas. Además, hay que profundizar en los valores analíticos, y observar si estos sufren algún tipo de cambio o modificación tras la intervención terapéutica realizada que nos lleve a comprender mejor la sintomatología. Esto nos otorgará un conocimiento más amplio sobre ella pudiendo ejercer un mayor control sobre la misma. Por otra parte, creemos que este tipo de intervenciones, al aumentar la autonomía de los pacientes pueden ser un gran alivio para familiares y cuidadores, otorgando a estos mayor calidad de vida y permitiendo preservar los roles sociales 
preexistentes. Además, consideramos que al mejorar el estado de salud general de los individuos, habría que analizar si la recaída de los mismos, se distancia en el tiempo, con el consecuente beneficio no solo para el paciente y sus familiares, evitando el reingreso precoz de los mismos, sino también a nivel económico para las instituciones sanitarias. Por último, consideramos que la intervención realizada en el hospital no es suficiente, sino que esta debería ampliarse al domicilio de los pacientes, observando in situ las necesidades y problemas reales que presenta, pudiendo así adaptar lo que considere oportuno para favorecer su autonomía. De este modo, además de que el paciente presentará un mayor control sintomático, estaremos favoreciendo la prevención de nuevas exacerbaciones de la enfermedad o de la propia sintomatología a tratar. 
6. CONCLUSIONES 
1. La intervención de tipo no farmacológico utilizada para el control de la astenia tumoral produce mejoras en los niveles de astenia en los pacientes pertenecientes al grupo experimental de nuestro estudio.

2. En nuestro estudio la utilización de manera conjunta de terapias farmacológicas y no farmacológicas específicas para el control de la astenia tumoral mejora significativamente la calidad de vida relacionada con la salud de los pacientes con respecto a la utilización exclusiva de medidas de tipo farmacológico.

3. La utilización de intervenciones de tipo no farmacológico para el control de la sintomatología de astenia tumoral mejora la funcionalidad de los individuos del estudio.

4. Se establece una correlación muy fuerte y positiva entre los niveles de astenia tumoral medidos con el cuestionario PERFORM y los niveles de energía medidos con la escala triple EVA de astenia

5. No podemos establecer una relación significativa entre la edad de los individuos y los niveles de astenia tumoral presentados en los mismos.

6. En el género femenino se registran mayores índices de astenia tumoral y peor calidad de vida relacionada con la salud que en el género masculino.

7. Mayor número de líneas de tratamiento empleadas se relacionan con mayores índices de astenia presentados por los individuos. 
Conclusión final:

En nuestro estudio queda comprobada la eficacia de la utilización de medidas de tipo no farmacológico para el control de la astenia referida por el enfermo oncológico. 
7. BIBLIOGRAFIA 
1. OMS. Public health: Ten facts on ageing and the life course. [En línea] 2012 [Acceso el 15 de Noviembre de 2013]. Disponible en: http://www.who.int/features/factfiles/ageing/en/index.html

2. Barnett K, Mercer SW, Norbury M, Graham W, Sally W. Epidemiology of multymorbidity and implications for health care, research, and medical education: a cross-sectional study. Lancet. 2012. 380: 37-43.

3. Barco E, Sánchez F. Cuidados continuos en oncología (I): concepto de cuidados continuos. Historia, principios y bases de la medicina paliativa. Principios generales del control de síntomas. La vía subcutánea. En: Cruz JJ, Rodríguez CA, Barco E. Oncología clínica. $4^{\text {a }}$ edición. Madrid: Nova Sidonia; 2008. 217-38.

4. OMS. Cancer: Palliative Care [En línea] 2012 [Citado el 15 de Noviembre de 2013]. Disponibel en: http://www.who.int/cancer/palliative/en/index.html

5. Cooper J. Challenges faced by occupational therapist in oncology and palliative care. En: Cooper J. Occupational therapy in oncology and palliative care. $2^{\mathrm{a}}$ edición. Londres: Jhon Wiley; 2007. 11-27.

6. OMS. GLOBOCAN (IARC 2010). 2008. [Citado el 4 de Noviembre de 2013]. en: http://globocan.iarc.fr/factsheets/populations/factsheet.asp?uno=900 
7. Horneber M, Fischer I, Dimeo F, Ulrich J, Weiss J. Cancer related fatigue: epidemiology, pathogenesis, diagnosis and treatment. Dtsch Arztebl Int 2012; 109(9): 161-72.

8. Ruiz E, Alegre J, García AM, Aliste L, Blázquez A. Chronic fatigue syndrome: study of a consecutive series of 824 cases assessed in two specialized units. Rev Clin. 2012; 211 (8): 385-90.

9. Real Academia Española. Diccionario de la lengua española, $22^{a}$ edición. Espasa Calpe; 2001. 233.

10. González M, Ordoñez A. La astenia tumoral. 19 edición. Madrid: Panamericana; 2004. IX.

11. Gándara I, Feliu J, Casado E. Complicaciones metabólicas del enfermo con cáncer. En: González M, Ordoñez A, Feliu J, Zamora P, Espinosa E. Tratado de medicina paliativa y tratamiento de soporte en el enfermo con cáncer. Panamericana; 1996. 540-57.

12. Theologides A. Asthenia in cáncer. Am J Med. 1982; 73: 1-3.

13. National Cancer Institute. National Institutes of Health. Citado el 5 de Noviembre de 2013. Disponible en: http://www.cancer.gov/cancertopics/pdq/supportivecare/fatigue/HealthP $\underline{\text { rofessional/page4 }}$

14. Sánchez F, Barco E. Cuidados continuos en oncología (IV): control de síntomas más prevalentes: emesis y otras complicaciones digestivas, 
astenia, caquexia, otros síntomas. Cuidados al final de la vida. El duelo.

En: Cruz JJ, Rodríguez CA, Barco E. Oncología clínica. 4ª edición. Madrid: Nova Sidonia; 2008. 299.

15. Sánchez F, Barco E. Cuidados continuos en oncología (IV): control de síntomas más prevalentes: emesis y otras complicaciones digestivas, astenia, caquexia, otros síntomas. Cuidados al final de la vida. El duelo. En: Cruz JJ, Rodríguez CA, Barco E. Oncología clínica. 4ª edición. Madrid: Nova Sidonia; 2008. 299.

16. National Comprehensive Cancer Network. Clinical Practice Guidelines in Oncology: Cancer-related-fatigue. Version 1.2013 [En línea] 2013 [Acceso 7 de Noviembre de 2013]. Disponible en: http://www.nccn.org/professionals/physician_gls/pdf/fatigue.pdf

17. Díaz N, Menjón S, Rolfo C, Gargía-Alonso P, Carulla J, Magro A, et al. Patients' perception of cáncer-related fatigue: results of a survey to assess the impact on their everyday life. Clin Transl Oncol. 2008; 10: 753-57.

18. Stasi R, Abriani L, Beccaglia P. Cancer-related fatigue. Evolving concepts in evaluation and treatment. Cancer. 2003; 98: 1786-801.

19. Smets EM, Garssen B, SchusterUitterhoeve AL. Fatigue in cancer patients. Br J Cancer. 1993; 68 (2): 220-4. 
20. Smets EM, Garssen B, Bonke B. The multidimensional fatigue inventory (MFI): psychometric qualities of an instrument to assess fatigue. J Psychosom Res. 1995; 39 (3): 315-25.

21. Glaus A. Fatigue and cancer, indivisible twins? A comparison between cancer patients, patients with diseases other than cancer and healthy people. Pflege. 2004; 7 (3): 183-97.

22. Prins JB, Bleijenberg G, Klein E. Doctor-patient relationship in primary care of CFS: perspectives of the doctor and the patient. The Bi-Annual Research Conference of the American Association for Chronic Fatigue Syndrome (AACFS). 2002 oct10-11; Cambridge, Massachussets.

23. Curt G, Johnston PG. Cancer fatigue: The way forward. The Oncologist. 2003; 8 (1): 27-30.

24. Curt G, Johnston PG. Cancer fatigue: The way forward. The Oncologist. 2003; 8 (1): 27-30.

25. Passik SD. Oncologist's recognition of depression in their patients with cancer. J Clin Oncol. 1998; 16: 1594-600.

26. Berger A. Treating fatigue in cancer patients. The Oncologist. 2003; 8 (1): $10-4$.

27. Gabrilove JL, Cleeland Cs, Livingston RB. Clinical evaluation of onceweekly dosing of Epoetin alfa in chemotherapy patients: Improvements 
in hemoglobin and QoL are similar to three-times weekly dosing. J Clin Oncol. 2002; 19 (11): 2875-82.

28. Stone $\mathrm{P}$, Richardson $\mathrm{A}$, Ream E. Cansancio relacionado con el cáncer: ¿Inevitable, intratable y sin importancia? Resultado de una encuesta multicéntrica de pacientes. Annals of the Oncology (Edición española). 2002; 9 (10): 1241-5.

29. Raber MN. A patient's perspective on cáncer-related fatigue. "Cancerrelated fatigue: New directions for research". Cancer. 2002; 92: 1662-4.

30. Lobchuck MM, Lesley F. Degner. Symptom experiences: Perceptual accuracy between advanced-stage cancer patients and family caregivers in the home care setting: J Clin Oncol. 2002; 20: 3495-507.

31. Wagner, L.I. and Cella, D. Fatigue and cancer: Causes, prevalence and treatment approaches. British journal of Cancer 2004, 91(5), 822-8.

32. Ahlberg, K., Ekman, T., Wallgreen, A., Gaston-Johansson, F. and Mock, V. Assessment and management of cancer-related fatigue in adults. The Lancet. 2003, 362(9384), 640-66.

33. Rodríguez MA, Lizón J. Concepto y etiopatogenia de la astenia. En: González M, Ordóñez A. La astenia tumoral. $1^{\text {a }}$ edición. Madrid: Panamericana; 2004. 1-11.

34. Morant R. Asthenia: an important symptom in cáncer patients. Cancer Treat Rev. 1996; 22: 117-22. 
35. Theologides A. Asthenia in cancer. Am J Med. 1982; 73: 1-3.

36. Theologides A. Anorexins, asthenins, and cachectins in cancer patients. Am J Med. 1986; 81: 696-8.

37. Bower JE, Ganz PA, Desmond KA, Fahey JL, Cole SW. T-cell homeostastis in breast cancer survivors with persistent fatigue. J Natl Cancer Inst. 2003; 95: 1165-8.

38. Bower JE, Ganz PA, Desmond KA, Fahey JL. Fatigue and proinflammatory cytokine activity in breast cancer survivors. Psychosom Med. 2002; 64 (4): 604-11.

39. Watanabe S, Bruera E. Anorexia and cadhexia, asthenia and lethargy. Hematol Oncol Clin N Am. 1996; 10: 189-206.

40. Bruera E, Brenneis C, Michaud M. Association between astenia and nutritional status, lean body mass, anemia, psycologcal status and tumor mass in patients with advanced breast cáncer. J Pain Sympton Manage. 1989; 4: 59-63.

41. Rodríguez MA, Lizón J. Concepto y etiopatogenia de la astenia. En: González M, Ordóñez A. La astenia tumoral. 1ª edición. Madrid: Panamericana; 2004. 1-11.

42. Roig JL. Sarcopenia: algo más que la disminución de masa muscular. PubliCE Standard. 2002; 8: 125-38. 
43. Prieto LP, Sánchez RT, Vadillo AG . Afectación pulmonar que simula un tumor como manifestación inicial de polimiositis. Semergen. 2009; 1 : 49-52.

44. Proctor SJ, Kernaham J, Taylor P. Depression as a component of postcranial irradiation somnolence syndrome. Lancet. 1981; 1: 1215-6.

45. Maddison P, Newsom-davis J. Tratamiento para el síndrome miasténico de Lambert-Eaton. The Cochrane Library. 2006; 1: 577-596.

46. Carretero Colomer M. Factor de necrosis tumoral. Offarm. 2005; 24 (3): 103-5.

47. Stone P, Richards M, A'Hern R, Hardy J.. Estudio comparativo de la prevalencia, gravedad y correlaciones del cansancio en los pacientes con cáncer frente a un grupo control de voluntarios sin cáncer. Ann Oncol. 2000; 9(7): 834-41.

48. Haylock PJ, Hart LK. Fatigue in patients receiving localized radiation. Cancer Nurs. 1979; 2: 461-7.

49. Proctor SJ, Kernaham J, Taylor P. Depression as a component of postcranial irradiation somnolence syndrome. Lancet. 1981; 1: 1215-6.

50. Barón M G, Rodríguez MA, Gallego AO. La astenia en el paciente con cáncer. Revista de Oncología. 2001; 3(6): 292-299.

51. Cardona D. Tratamiento farmacológico de la anorexia-caquexia cancerosa. Nutrición Hospitalaria. 2006; 21: 17-26. 
52. Reich SG. The tired patient: psychological versus organic causes. Hospital Medicine. 1986; 22: 142-54.

53. Henriksson MM, Isometsa ET, Hietanen PS, Aro HM, Lonnqvist JK. Mental disorders in cancer suicides. J Affect Disord. 1995; 36: 11-20.

54. Bruera E, Brenneis C, Michaud M. Association between astenia and nutritional status, lean body mass, anemia, psycologcal status and tumor mass in patients with advanced breast cáncer. J Pain Sympton Manage. 1989; 4: 59-63.

55. Barón MG, Ordóñez A. La astenia tumoral: un síndrome poco estudiado. Psicooncología: investigación y clínica biopsicosocial en oncología. 2004; 1(2): 25-28.

56. Pickard-Holley S: Fatigue in cancer patients. A descriptive study. Cancer Nurs. 1991; 14 (1): 13-9.

57. Rodríguez CA, Ruiz M, Alonso R, Viotti F, Del Barco E, Cruz JJ et al. Evaluación de la astenia en oncología. Aplicación del cuestionario PERFORM. Psicooncología. 2012; 9(1): 65-79.

58. Barsevick A, Frost M, Zwinderman A, Hall P, Halyard M, GENEQOL Consortium. I'm so tired: Biological and genetic mechanism of cancerrelated-fatigue. Qual Life Res. 2010; 19 (10): 1419-27. 
59. Sephton S, Spiegel D. Circadian disruption in cancer: a neuroendocrine-inmune pathway from stress to disease?. Brain Behav Immun. 2003; 17: 321-8.

60. Ryan JL, Carroll JK, Ryan EP. Karen M. Mustian, Kevin Fiscella, Gary R. Morrow. Mechanisms of cancer-related fatigue. Oncologist. 2007; 12 (1): 22- 34 .

61. Feliu J, López-Santiago S, Martínez-Marín V, Custodio AB, Cruzado JA. Bases biológicas del deterioro de la función cognitiva inducido por los tratamientos antineoplásicos. Psicooncología. 2011; 8(2-3): 201214.

62. Belda C, De Castro J, Fresno JA, Barriuso J, Feliu J, González M. Bases biológicas de la astenia asociada al cáncer (I). En: González M, Ordóñez A. La astenia tumoral. $1^{a}$ edición. Madrid: Panamericana; 2004. 1-11.

63. Belda C, De Castro J, Fresno JA, Barriuso J, Feliu J, González M. Bases biológicas de la astenia asociada al cáncer (I). En: González M, Ordóñez A. La astenia tumoral. 1ª edición. Madrid: Panamericana; 2004. 1-11.

64. Gutstein A. The biologic basis of fatigue. Cancer. 2001; 92: 1678-83. 
65. Miaskowski C, Portenoy RK: Update on the assessment and management of cancer-related fatigue. Principles and Practice of Supportive Oncology Updates 1 (2): 1-10, 1998.

66. Morrow GR, Andrews PL, Hickok JT, et al.: Fatigue associated with cancer and its treatment. Support Care Cancer 10 (5): 389-98, 2002.

67. Aistars J: Fatigue in the cancer patient: a conceptual approach to a clinical problem. Oncol Nurs Forum 14 (6): 25-30, 1987 Nov-Dec.

68. Bower JE, Ganz PA, Aziz N, et al.: Fatigue and proinflammatory cytokine activity in breast cancer survivors. Psychosom Med 64 (4): 604-11, 2002 Jul-Aug.

69. Evans WJ, Lambert CP: Physiological basis of fatigue. Am J Phys Med Rehabil 86 (1 Suppl): S29-46, 2007.

70. Bower JE, Ganz PA, Tao ML, et al.: Inflammatory biomarkers and fatigue during radiation therapy for breast and prostate cancer. Clin Cancer Res 15 (17): 5534-40, 2009.

71. Dantzer R: Cytokine-induced sickness behavior: mechanisms and implications. Ann N Y Acad Sci 933: 222-34, 2001.

72. Hart BL: Biological basis of the behavior of sick animals. Neurosci Biobehav Rev 12 (2): 123-37, 1988.

73. Eisenberger NI, Inagaki TK, Mashal NM, et al.: Inflammation and social experience: an inflammatory challenge induces feelings of social 
disconnection in addition to depressed mood. Brain Behav Immun 24 (4): 558-63, 2010.

74. Bower JE, Ganz PA, Aziz N: Altered cortisol response to psychologic stress in breast cancer survivors with persistent fatigue. Psychosom Med 67 (2): 277-80, 2005 Mar-Apr.

75. Bower JE, Ganz PA, Dickerson SS, et al.: Diurnal cortisol rhythm and fatigue in breast cancer survivors. Psychoneuroendocrinology 30 (1): 92-100, 2005.

76. Jager A, Sleijfer S, van der Rijt CC: The pathogenesis of cancer related fatigue: could increased activity of pro-inflammatory cytokines be the common denominator? Eur J Cancer 44 (2): 175-81, 2008.

77. Gutstein A. The biologic basis of fatigue. Cancer. 2001; 92: 1678-83.

78. Palin K, Bluthé RM, McCusker RH, Levade T, Moos F, Dantzer R, Kelley, KW. The type 1 TNF receptor and its associated adapter protein, FAN, are required for TNFa-induced sickness behavior. Psychopharmacology. 2009; 201(4): 549-556.

79. Bouwman KM, Hawley DM. Sickness behaviour acting as an evolutionary trap? Male house finches preferentially feed near diseased conspecifics. Biology letters. 2010; 6(4): 462-465. 
80. Calle LF, Mejías MJ, Turiño JD. Diagnóstico de la astenia tumoral en Atención Primaria. Propuesta de correlación entre dos escalas. Medicina Paliativa. 2012; 19 (1): 24-30.

81. Belda C, De Castro J, Fresno JA, Barriuso J, Feliu J, González M. Bases biológicas de la astenia asociada al cáncer (II). En: González M, Ordóñez A. La astenia tumoral. $1^{\text {a }}$ edición. Madrid: Panamericana; 2004. 47-56.

82. Dantzer R. Cytokine-induced Sickness behaviour: where do we stand?. Brain Behav Immum. 2001; 15: 7-24.

83. Noguchi Y, Yoshikawa T, Matsumoto A, Svaninger G, Gelin J. Are cytokines possible mediadors of cancer cachexia?. Surg Today. 2000; 26: 467-75.

84. Geinitz H, Zimmermann FB, Stoll P, Thamm R, Kaffenberg W, Ansorg $\mathrm{K}$, et al. Fatigue, serum cytokine levels, and blood cell counts during radiotherapy of patients with breast cancer. Int J Radiat Oncol Biol Phys. 2001; 51: 691-8.

85. Greenberg DB, Gray JL, Mannix CM, Eisenthal S, Carey M. Treatmentrelated fatigue and serum interleukin-1 levels in patients during external beam irradiation for prostate cancer. J Pain Sympton Manage. 2003; 8: 196-200. 
86. Agroyannis B, Kouvaris J, Tzanatos H, Chondros K, Stringou E, Damatopoulou A, et al. Influence of radiation treatment on serum transferrin and tumor necrosis factor-alpha. Anticancer Res. 1992; 12: 1757-9.

87. Bower JE, Ganz PA, Aziz N, Fahey JL. Fatigue and proinflammatory cytokine activity in breast cancer survivors. Psychosom Med. 2002; 64: 604-11.

88. Tang JT, Yamazaki H, Nishimoto N, Inoue T, Nose T, KoizumiM, et al. Effect of radiotherapy on serum level of interleukin 6 in patients with cervical carcinoma. Anticancer Res. 1996; 16: 2005-8.

89. Morant R, Stiefel F, Berchtold W, Radziwill A, Riesen W. Preliminary results of a study assessing asthenia and related psychological and biological phenomena in patients with advanced cancer. Support Care Cancer. 2003; 1: 101-7.

90. Chang HR, Bistrian B. The role of cytokines in the catabolic consequences of infection and injury. JPEN J Parenter Enternal Nutr. 1998; 22: 156-66.

91. Roubenoff R, Freeman LM, Smith DE, Abad LW, Dinarello CA, Kehayias JJ. Adjuvant arthritis as a model of inflammatory cachexia. Arthritis Rheum. 2000; 40: 534-9. 
92. Whitehouse AS, Kahl J, Tisdale MJ. Induction of protein catabolism in myotubes by $15(\mathrm{~S})$-hydroxyeicosatetraenoic acid through increased expression of the ubiquitin-proteasome pathway. $\mathrm{Br} \mathrm{J}$ Cancer. 2003; 89: $737-45$.

93. Watchorn TM, Waddell I, Ross JA. Proteolysis-inducing factor differentially influences transcriptional regulation in endothelial subtypes. Am J Physiol Endocrinol Metab. 2002; 282: 763-9.

94. Barber MD, Fearon KC, Tisdale MJ, McMillan DC, Ross JA. Effect of a fish oil-enriched nutritional supplement on metabolic mediators in patients with pancreatic cancer cachexia. Nutr Cancer. 2001; 40: 11824.

95. Kelley KW, Bluthe RM, Dantzer R, Zhou JH, Shen WH, Johnson RW, et al. Cytokine-induced sickness behaviour. Brain Behav Immumm. 2003; 17: $112-8$.

96. Dantzer R. Cytokine-induced Sickness behaviour: where do we stand?. Brain Behav Immum. 2001; 15: 7-24.

97. Okuyama T, Akechi T, Kugaya A. Development and validation of the cancer fatigue scale: a brief, three-dimensional, self-rating scale for assessment of fatigue in cancer patients. 2000. J Pain Symptom Manage; 19 (1): 5-14. 
98. Cruz JJ, Rodríguez CA, del Barco E. Oncología Clínica (4ª Ed.) Ed. Nova Sidonia, 2008; 17: 299-302.

99. Cella D, Peterman A, Passik S. Progress toward guidelines for the management of fatigue. Oncology (Huntingt). 2000; 12 (11A): 369-77.

100. Hofman M, Ryan JL, Figueroa-Moseley CD Morrow GR. Cancer-related fatigue: The scale of the problem. Oncologist. $2007 ; 12$ ( 1) : 4-10.

101. Lacasta MA, Calvo CM, Barón MG. Psicopatología de la astenia. En. Barón MG, Ordóñez A. La astenia tumoral. $1^{\text {a }}$ edición. Madrid: Panamericana; 2004. 91-117.

102. Pearson PG. The development and validation of a checklist measur subjetive fatigue. Report no 556-115. Texas: School of Aviation, Usaf, Randolf AFB; 1956.

103. McNair D, Lorr M, Droppelman L. Profile of Mood States. San Diego, Calif: Educational and Industrial Testing Service, 1971.

104. Rhoten D. Fatigue and postsurgical patient. En: Norris CM. Ed. Concept clarification in nursing. Rockville: MD, Aspen Publishers 1982; 277-300. 105. Krupp LB, La Rocca NG, Muir-Nash J, Steinberg AD. The fatigue severity scale. Application to patients with multiple sclerosis and systemic lupus erythematosus. Arch Neurol. 1989; 46: 1121-3. 
106. Smets EM, Garssen B, Bonke B, de Haes JCJM. The multidimensional fatigue inventory (MFI) psychometric qualities of an instrument to assess fatigue. J Psychosom Res. 1995; 39: 315-25.

107. Lee KA, Hicks G, Nino G. Validity and reliability of a scale to assess fatigue. Psychiatry Res. 1991; 36: 291-8.

108. Fisk JD, Ritvo PG, Ross L, Haase DA, Marrie TJ, Schlech WF. Measuring the functional impact of fatigue initial validation of the fatigue impact scale. Clin Inf Dis. 1994; 18 (1): 79-83.

109. Aaronson NK. A quality of life instrument for use in international clinical trials in oncology. Journal of the National Cancer Institute. 1993; 85: $365-76$.

110. Arraras JL. El cuestionario de calidad de vida de la EORTC. Estudio estadístico de validación con una muestra española. Revista de psicología y Salud. 1996; 7: 13-33.

111. Kobashi JM, Hanewald GJ, Van Dam FS, Bruning PF. Assessment of malaise in Cancer patients treated with radiotherapy. Cancer Nurs. 1985; 8: 306-14.

112. Piper BF, Lindsey AM, Dodd MJ. The development of an instrument to measure the subjective dimension of fatigue. En: Funk SG, Tornquist EM, Capagne MT. Key aspects of Confor, Management of Pain, Fatigue and Nausea. New York: Springer Publishing; 1989. 3: 156-80. 
113. Pipper BF, Dibble SL, Dodd MJ, Weiss MC; Slaughter RE, Paul SM. The revised Piper Fatigue Scale: Psychometric evaluation in women with breast cancer. Oncol Nurs Forum. 1998; 25: 677-84.

114. Kaasa T, Loomis J, Gillis K, Bruera E, Hanson J. The Edmonton Functional Assessment Tool: preliminary development and evaluation for use in palliative care. J Pain Symptom Manage. 1997; 13: 10-19.

115. Morant R, Stiefel F, Berchtold W, Radziwill A, Riesen W. Preliminary results of a study assessing and related psychological and biological phenomena in patients with advanced cancer. Supp Care cancer. 1995; 1: $101-7$.

116. Schwartz JE, Jandorf L, Krupp LB. The measurement of fatigue: a new instrument. J Psychosom Res. 1993; 37: 753-62.

117. Scwartz AL. The schawrtz cancer Fatigue Scale: Testing reliability and validity. Oncol Nurs Forum. 1998; 25: 711-7.

118. Yellen SB, Cella DF, Webster K. Measuring fatigue and other anemiarelated symptoms with the Functional Assessment of Cancer TherapyFatigue (FACT-F) measuring system. J Pain Symptom Manag. 1997; 13: $63-74$.

119. Cella D. Manual of the Functional Assessment of chronic Illness Therapy (FACIT) Scales. Chicago, III: Evanston Northwestern Healthcare. 1997; 4. 
120. Hann DM, Jacobsen PB, Azzarello LM, Martin SC. Fatigue in women treated with bone marrow transplantation for breast cancer: a comparison with no history of cancer. Supp Care Cancer. 1997; 5: 4452.

121. Hann DM, Jacobsen PB, Azzarello LM. Measurement of fatigue in cancer patients: development and validation of the fatigue Symptom Inventory. Qual Life Res. 1998; 7: 301-10.

122. Stein KD, Martin SC, Hann DM, Jacobsen PB. A multidimensional measure of fatigue for use with cancer patients. Cancer Pract. 1998; 6: $143-52$.

123. Cleeland CS, Wang XS. Measuring and understanding fatigue. Ocnology. 1999; 13: 91-7.

124. Mendoza TR, Wang XS, Cleeland CS. The rapid assessment of fatigue severity in cancer patients: use of the Brief fatigue Inventory. Cancer. 1999; 85: 1186-96.

125. Cella D. The Functional Assessment of Cancer Therapy Anemia 8FACT-An Scale: a new tool for the assessment of outcomes in cancer anemia and fatigue. Semim Hematol. 1997; 34 (3): 13-19.

126. Okuyama T, Akechi T, Kugaya A. Development and validation of the cancer fatigue scale: a brief, three-dimensional, self-rating scale for 
assessment of fatigue in cancer patients. J Pain and Symptom Mange. 2000; 19: 5-14.

127. Smets EMA, Garssen B, Bonke B, De Haes JCJM. The multidimensional fatigue inventory (MF) psychometric qualities of an instrument to assess fatigue. J Psychosom Res. 1995; 39: 315-25.

128. Chalder T, Berelowitz G, Pawlikowska T. Development of a fatigue scale. J Psychosom Res. 1993; 37: 147-53.

129. García-Mata J, Colomer R, Cassinello J, et al. Evaluación de las propiedades psicométricas del primer cuestionario español para medir las percepciones de los pacientes con fatiga relacionada con el cáncer. Congreso Nacional de la Sociedad Española de Oncología Médica (SEOM). 2007; 248.

130. Havard J. Unpacking fatigue. The Journal of the European Association for Palliative Care. 8 Congress of the European Association for Palliative Care (EAPC). The Hague, 2003. Plenary lectures: 14-20.

131. Herdman M, Fox-Rushby J, Badia X. A model of equivalence in the cultural adaptation of HRQoL instruments: The universalist approach. Qual Life Res. 1998; 7(4):323- 35.

132. Scientific Advisory Committee of the Medical Outcomes Trust. Assessing health status and quality-of-life instruments: Attributes and review criteria. Quality of Life Research. 2002; 11: 193-205. 
133. Rodríguez CA, Ruiz M, Alonso R, Viotti F, El-Hayak M, Del Barco E, Cruz JJ. Evaluación de la astenia en oncología. Aplicación del cuestionario PERFORM. Psicoonc. 2012; 9 (1): 65-79.

134. Baró E, Carulla J, Cassinello J, Colomer R, Mata JG, Gascón P, et al. Development of a new questionnaire to assess patient perceptions of cancer-related fatigue: item generation and item reduction. Value Health. 2009; 12(1):130-8.

135. Rodríguez C, Gascón P, García-Mata J, Colomer R, Cassinello J, Carulla J, et al. Validation of a new questionnaire to assess the patient perception of cancer-related fatigue (CRF): the Perform Questionnaire (PQ). Journal of Clinical Oncology, 2007 ASCO Annual Meeting Proceedings Part I. Vol 25, No. 18S (June 20 Supplement), 2007: 19533.

136. Herdman M, Fox-Rushby J, Badia X. A model of equivalence in the cultural adaptation of HRQoL instruments: The universalist approach. Qual Life Res. 1998;7(4):323- 35.

137. Rodríguez C, Gascón P, García-Mata J, Colomer R, Cassinello J, Carulla J, et al. Validation of a new questionnaire to assess the patient perception of cancer-related fatigue (CRF): the Perform Questionnaire (PQ). Journal of Clinical Oncology, 2007 ASCO Annual Meeting 
Proceedings Part I. Vol 25, No. 18 S (June 20 Supplement), 2007: 19533.

138. Rodríguez CA, Viotti F, Gómez A, Seijas A, López R, Del Barco E, et al. Evaluación de la astenia en pacientes con cáncer de mama y tratamiento sistémico. Resultados preliminares. III Congreso SEOM de Cuidados Continuos en Oncología Médica 2008; Abs P-28.

139. Rodríguez CA, Viotti F, El-Hallaj M, Reguero V, Leno R, Bratos R, et al. Aplicación del cuestionario perform en la evaluación de la astenia en pacientes con cáncer de mama y tratamiento sistémico en condiciones de práctica clínica asistencial. XII Congreso de la Sociedad Española de Oncología Médica 2009; Abs P-126.

140. Alonso R, Rodríguez CA, Soria P, Vidal R, Galeazzi V, Rivas B, et al. Evaluación de la astenia durante el tratamiento con radioterapia (RT). Aplicación del cuestionario Perform. Resultados preliminares. XIII Congreso de la Sociedad Española de Oncología Médica 2011; Abs P97.

141.Demetri GF. Anaemia and its functional consequences in cancer patients: current challenges in management and prospects for improving therapy. Br J Cancer. 2001; 84 (1): 31-7.

142. Tchekmedyan NS. Anemia in cancer patients: significance, epidemiology and current therapy. Oncology. 2002; 16 (10): 17-24. 
143. Pérez Carrión R, Donnay O, Lázaro M. Anemia, indicación de la transfusión de hematíes. En: González M y colaboradores. Tratado de medicina paliativa. Madrid: Panamericana; 1996. 379-90.

144. Dicato M, Deum C, Berchem G, Ries F. Clinical benefit from erythropoietin. Curr Opin Oncol. 2000; 12: 297-302.

145. Espinosa E, Zamora P, Redondo A, Castelo B. Astenia y anemia en pacientes oncológicos. En: González M, Ordóñez A. La astenia tumoral. $1^{\text {a }}$ edición. Madrid: Panamericana; 2004. 79-90.

146. Aguilar AL. Astenia y anemia ¿Cuál es el diagnóstico?. Semergen. 2012; 38 (3): 185-7.

147. Groopman JE, Loretta MI. Chemotherapy-induced anemia in adults: incidence and treatment. J Natl Cancer Inst. 2000; 91: 1616-34.

148. Coiffier B, Guastalla JP, Pujade-Lauraine E, Bastit P. Predicting cáncerassociated anaemia in patients receiving non-platinum chemotherapy: results of a retrospective survey. Eur J Cancer. 2001; 37: 1617-23.

149. Harrison LB, Shasha D, White C, Ramdeen B. Radiotherapy-associated anaemia in patients receiving non-platinum chemotherapy: results of a retrospective survey. Eur J Cancer. 2001; 37: 1617-23.

150. Aaronson NK, Ahmedzai S, Bergman B, et al. The European Organization for Research and Treatment of Cancer QLQ-30: a quality 
of life instrument for use in international clinical trials in oncology. J Natl Cancer Inst. 1993; 85: 65-76.

151. Weitzner MA, Meyers CA, Gelke CK, Byrne KS, Cella DF, Levin VA. The Functional Assessment of Cancer Therapy scale. Cancer. 1995; 75: 1151-60.

152. Silva M, Grillot D, Benito A, Richard C, Núñez G, Fernández JL. Erythropoietin can promote erythroid progenitor survival by repressing apoptosis through bcl-X $\mathrm{X}_{\mathrm{L}}$ and bcl-2. Blood. 1996; 88: 1576-82.

153. Silva M, Grillot D, Benito A, Richard C, Núñez G, Fernández JL. Erythropoietin can promote erythroid progenitor survival by repressing apoptosis through bcl- $\mathrm{X}_{\mathrm{L}}$ and bcl-2. Blood. 1996; 88: 1576-82.

154. Boorgaerts M, Coifier B, Kainz C. Impact of epoetin beta on quality of life in patients with malignant disease. Br J Cancer. 2003; 88: 988-95.

155. Brower V. Normal and neoplastic prostate cells have EPO receptors. Lancet Oncol. 2003; 4: 69.

156. Acs G, Zhang PJ, Rebbeck TR, Acs P, Verma A. Immunohistochemical expression of erythropoietin and erythropoietin receptors in breast carcinoma. Cancer. 2002; 95: 969-81.

157. Ordóñez A, González M, Feliu J. Tratamiento de soporte en el enfermo con cáncer. Algunas propuestas basadas en nuestra experiencia. Rev Oncología. 2001; 3: 266-9. 
158. Fallowfield L, Gagnon D, Zagari M, et al. Multivariate regression analyses of data from randomized double-blind, placebo controlled study confirm quality of life benefit of epoetin alfa in patients receiving non-platinum chemotherapy. Br J Cancer. 2002; 87: 1341-53.

159. Dicato M, Deum C, Berchem G, Ries F. Clinical benefit from erythropoietin. Curr Opin Oncol. 2000; 12: 297-302.

160. Plata CR. Anorexia during acute and chronic disease. Nutrition. 2002; 12: 69-78.

161. Chance WT, Balasubramaniam A, Thompson H, Mohapatra B, Ramo J, Fischer JE. Assessment of feeding response of tumor-bearing rats to hypothalamic injection and infusion of neuropeptide Y. Peptides. 2000; 17: 797-801.

162. Inui A. Cancer anorexia-caquexia syndrome: are neuropeptides the key?. Cancer Res. 2000; 59: 4493-5401.

163. Argilés JM, Busquets S, López FJ. Mediadores bioquímicos den el síndrome de la anorexia-caquexia. En: González M, Ordóñez A. La astenia tumoral. $1^{a}$ edición. Madrid: Panamericana; 2004. 57-79.

164. Sanz J, Rivera F, López JM, López C, López A, Vega ME. El síndrome anorexia-caquexia. Psicoonc. 2004; 1 (2-3): 101-106.

165. Bruera E. Anorexia, cachexia and nutrition. Br Med J. 1997; 315: 121922. 
166. Barton BE. IL-6-Like cyttokines and cancer cachexia. Immunol Res. $2001 ; 23$ (1): 41-58.

167. Argilés JM, Busquets S, López FJ. Mediadores bioquímicos den el síndrome de la anorexia-caquexia. En: González M, Ordóñez A. La astenia tumoral. 1ª edición. Madrid: Panamericana; 2004. 57-79.

168. Dewys WD, Begg C, Lavin PT, Band PR, Bennett JM, Bertino JR, et al. Prognostic effect of weight loss prior to chemotherapy in cancer patients Am J Med 1980; 69: 491-7.

169. Page R, Takimoto C. Principles of chemotherapy. En: Richard Pazdur, Lawrence R, William J, Lawrence D. Cancer management: a multidisciplinary approach. 7th edition. USA, Md: The Oncology Group; 2003. 21-38.

170.Sosa R, Sánchez K, Motola D, Green D. Síndrome de anorexiacaquexia en el paciente oncológico. Gac Med Mex. 2008; 144 (5): 43540.

171. Argilés JM, Busquets S, López FJ. Mediadores bioquímicos den el síndrome de la anorexia-caquexia. En: González M, Ordóñez A. La astenia tumoral. $1^{a}$ edición. Madrid: Panamericana; 2004. 57-79.

172. Sanz Ortiz J. El factor humano en la relación clínica. El binomio razónemoción. Med Clin (Barc) 2000; 114: 222-6. 
173. Body JJ. The syndrome of anorexia-cachexia. Curr Opin Oncol. 1999; 11: $225-34$.

174. Varin D, Levy M, Chabert A. Cuidados paliativos en el adulto: aspectos clínicos. EMC-Tratado de Medicina. 2013; 17 (2): 1-10.

175. Fonseca M, Schlack C, Mera E, Muñoz O, Peña J. Evaluación de la calidad de vida en pacientes con cáncer terminal. Rev Chil Cir. 2013; 65 (4): 321328

176. Espinosa E, Zamora P. Calidad de vida. En: Barón MG. Tratado de medicina paliativa y tratamiento de soporte en el paciente con cáncer. $2^{\mathrm{a} e d i c i o ́ n . ~ M a d r i d: ~ P a n a m e r i c a n a ; ~ 2007 . ~ 43-51 . ~}$

177. Fortuno Godes J. Medida de la capacidad funcional y la calidad de vida relacionada con la salud de un grupo de personas mayores que llevan a cabo un programa de caminatas: estudio piloto. Rev Esp Geriatr Gerontol. 2011; 46: 147-50.

178. Badia X, del Llano J. Investigación de resultados en salud. Med Clin. 2000; 114: 1-7.

179. Nezer I. El envejecimiento: aspectos bioéticos, políticos, económicos y sociales. Gac Méd Caracas. 2009; 117 (2): 35-39.

180. The Whoqol group. The World Health Organization Quality of Life Assessment (WHOQOL): Development and general psychometric properties. Soc Sci Med. 1998; 46: 1569-85. 
181. Bowling A. Measuring health: a review of quality of life measurement scales, 2nd ed. Buckingham, Philadelphia: Open University Press, 1997.

182. Cuadras Lacasa F, Alcaraz Benavides M, Llort Mateu M et al. Índice de Karnofsky para medir la calidad de vida. Revista Rol de Enfermería. 1998; 21 (233): 18-20.

183. Mather KJ, Hunt AE, Steinberg HO, Paradisi G, Hook G, Katz, A, Baron AD.. Repeatability characteristics of simple indices of insulin resistance: implications for research applications. Journal of Clinical Endocrinology \& Metabolism. 2001; 86(11): 5457-5464.

184. Fayers PM, Aaronson NK, Bjordal K, Curran D., Grønvold M. EORTC QLQ-C30 scoring manual. 2000. EORTC.

185. Arraras J, Martínez M, Manterota A, Laínez N. La evaluación de la calidad de vida en el paciente oncológico. El grupo de calidad de vida de la EORTC. Psicoonc. 2004; 1 (1), 87-98.

186. Cella D. The Functional Assessment of Cancer Therapy-Anemia (FACT-An) Scale: a new tool for the assessment of outcomes in cancer anemia and fatigue. In Seminars in hematology. 1997; 34 (3): 13-19.

187. Arrarás JI, Arias de la Vega F, Illarramendi JJ, Manterola A, Salgado E, Domínguez MA, Vera R. Calidad de vida relacionada con la salud en los servicios de Oncología del Hospital de Navarra: Grupo de Calidad 
de Vida de la EORTC. Anales del Sistema Sanitario de Navarra. 2011; 34 (1): 9-20.

188. Montorio I, Fernández MI, López A, Sánchez M. La Entrevista de Carga del Cuidador. Utilidad y validez del concepto de carga. 1998.

189. Vilagut G, Ferrer M, Rajmil M, Rebollo P, Permanyer-Miralda G, Quintana J. M, Santed R, Valderas J. M, Ribera A, Domingo-Salvany A, and Alonso J. El cuestionario de salud SF-36 español: una década de experiencia y nuevos desarrollos. Gac Sanit 2005; 19 (2):135-50.

190. Alonso J, Regidor E, Barrio G, Prieto L, Rodríguez C y de la Fuente L. Valores poblacionales de referencia de la versión española del Cuestionario de Salud SF-36. Med Clin Barc 1998; 111:410-416.

191. Ware JE Jr, Kosinski M, Keller SD. A 12-Item Short-Form Health Survey: construction of scales and preliminary tests of reliability and validity. Med Care. 1996;34:220-33.

192. Gandek B, Ware JE, Aaronson NK, Apolone G, Bjorner JB, Brazier JE, et al. Crossvalidation of item selection and scoring for the SF-12 Health Survey in nine countries: results from the IQOLA Project. International Quality of Life Assessment. J Clin Epidemiol. 1998;51:1171-8.

193. World Health Organization. Disabilities and rehabilitation. [En línea] 2010 [Acceso 22 de Noviembre de 2013]. Disponible en: http://www.who.int/disabilities/care/en/index.html 
194. World Federation of Occupational Therapists. Definition of Occupational Therapy. [En línea] 2012 [Acceso el 22 de Noviembre de 2013]. Disponible en: http://www.wfot.org/AboutUs/AboutOccupationalTherapy/DefinitionofOc cupationalTherapy.aspx

195. The American Occupational Therapy Association. About Occupational Therapy. [En línea] 1986 [Acceso el 22 de Noviembre de 2013]. Disponible en: http://www.aota.org/en/About-Occupational$\underline{T h e r a p y . a s p x}$

196. Canadian Association of Occupational Therapists. What is Occupational Therapists? [En línea] 1993 [Acceso el 22 de Noviembre de 2013]. Disponible en: http://www.caot.ca/default.asp?pageid=3824

197. Council of Occupational Therapists for the European Countries. Summary of the OT profession for 2013. [En línea] 2013 [Acceso el 22 de Noviembre de 2013]. Disponible en: http://www.coteceurope.org/eng/627/

198. Asociación Profesional Española de Terapeutas Ocupacionales.¿Qué es la terapia ocupacional? [En línea] 1999 [Acceso el 22 de noviembre de 2013]. Disponible en: http://apeto.com/index.php?option=com_content\&view=article\&id=66\&lt $\underline{\text { emid }=79}$ 
199. Romero DM. Historia de la terapia ocupacional en España. En: Moruno P, Talavera MA. Compiladores. Terapia ocupacional: una perspectiva histórica. 90 años después de su creación. TOG. 2007; 9: 241-62.

200. Kielhofner G. Práctica de la terapia ocupacional. En: Kielhofner G. Fundamentos conceptuales de terapia ocupacional. $1^{\text {a }}$ edición. Buenos Aires: Panamericana; 2006. p. 4-6.

201. Kielhofner G. Conceptual Foundations of Occupational Therapy. $1^{\text {a }}$ edición. Buenos aires: Panamericana; 2006. P. 264-71.

202. Tchekmedyian E, Gotay CC, Korn EL, McCabe MS, Moore TD, Cheson BD. Quality-of-life assessment in cancer treatment protocols: research issues in protocol development. Journal of the National Cancer Institute. 1992; 84(8): 575-79.

203. Cooper J. Occupational Therapy Approach in Symptom Control. En: Cooper J. Occupational Therapy in Oncology and Palliative Care. $2^{\text {a }}$ edición. Londres: Wiley; 2007. p. 27-40.

204.Penfold S. The role of the occupational therapist in oncology. Cancer treatment. 1996; 22: 75-81.

205. American Cancer Society. Learn about vcancer. Retrieved February . [En línea] 2011 [Acceso el 25 de Noviembre de 2013]. Disponible en : http://www.cancer.org/Cancer/index 
206. Barsevick AM, Whitmer K, Walker L. In their own words: using the common sense model to analyze patient descriptions of cancer-related fatigue. Oncol Nurs Forum. 2003; 28 (9): 1363-9.

207. Badger C. Management of patients with advanced cancer. Professional Nurse. 2000; 2 (4): 100-2.

208. Cooper J. Occupational therapy in oncology and palliative care. Whurr. 1997; 2: 32-47.

209. Orre IJ, Fosså SD, Murison R. Chronic cancer-related fatigue in longterm survivors of testicular cancer. J Psychosom Res. 2008; 64 (4): 363-7.

210. The American Occupational Therapy Association. The role of occupational therapy in oncology. [En línea] 2011 [Acceso el 25 de Noviembre de 2013]. Disponible en: http://www.aota.org/ /media/Corporate/Files/AboutOT/Professionals/W hatlsOT/MH/Facts/Oncology $\% 20$ fact $\% 20$ sheet.ashx

211. Barco E, Sánchez F. Cuidados continuos en oncología (I): concepto de cuidados continuos. Historia, principios y bases de la medicina paliativa. Principios generales del control de síntomas. La vía subcutánea. En: Cruz JJ, Rodríguez CA, Barco E. Oncología clínica. $4^{\text {a }}$ edición. Madrid: Nova Sidonia; 2008. 217-38. 
212. Law E. Mesure Canadiense du rendement occupationel. Ottawa: ACE, 1994.

213. Simó S, Urbanowski R. El Modelo Canadiense del Desempeño Ocupacional. Revista Gallega de Terapia Ocupacional. 2006; 3: 1-27.

214. Hagedorn R. Foundations for practice in occupational therapy. $2^{\text {a }}$ edición. Edimburg: Churchill Livingstone, 1997.

215. Moruno P. Modelo Canadiense del Rendimiento Ocupacional. En: Romero D, Moruno P. Terapia ocupacional: teoría y técnicas. $1^{\text {a }}$ edición. Barcelona: Masson; 2003. P. 135-41.

216. Townsend E. Promouvoir l'occupation: une perspective de l'ergotherapie. Ottawa: ACE, 1997.

217. Moruno P. Modelo Canadiense del Rendimiento Ocupacional. En: Romero D, Moruno P. Terapia ocupacional: teoría y técnicas. $1^{\text {a }}$ edición. Barcelona: Masson; 2003. P. 135-41.

218. Moruno P. Modelo Canadiense del Rendimiento Ocupacional. En: Romero D, Moruno P. Terapia ocupacional: teoría y técnicas. $1^{\mathrm{a}}$ edición. Barcelona: Masson; 2003. P. 135-41.

219. Rogers CR, Tubert S, Carmichael L. Psicoterapia centrada en el cliente: práctica, implicaciones y teoría. $1^{\mathrm{a} e d i c i o ́ n . ~ M a d r i d: ~ M a s s o n . ~}$ 1981. 
220. Trujillo S, Tovar C, Lozano M. Formulación de un modelo teórico de la calidad de la vida desde la psicología. Universitas Psychologica. 2004; 3(1): 89-98.

221. De las Heras CM. Rehabilitación y vida. Modelo de Ocupación Humana. $1^{\text {a }}$ edición. Santiago de Chile: Reencuentros, 1999.

222. Kielhofner G. A model of human occupation. Theory and application. $1^{\mathrm{a} e}$ edición. Baltimore: Williams and Wilkins, 1985.

223. Kielhofner G. A model of human occupation. Theory and application. 2ªedición. Baltimore: Williams and Wilkins, 1995.

224. Kielhofner G. Model of human occupation. Theory and application. 3ªedición. Baltimore: Lippincott-Williams and Wilkins, 2002.

225. Kielhofner G. Conceptual foundations of occupational therapy. $2^{\text {a }}$ edición. Philadelphia: FA Davis, 1997.

226. American Occupational Therapy Association. Occupational therapy practice framework: Domain and process. American Journal of Occupational Therapy. 2002; 56: 609-39.

227. Kielhofner G, Forsyth K. The model oh Human Occupation: An overview of current concepts. Br J Occup Ther. 1997; 40: 551-6.

228. Verhoef J. Kielhofner: Master or magician? Amsterdam, Free University, Faculty of Human Movement Sciences, 2000. 
229. Moruno P. Modelo de la Ocupación Humana. En: Romero D, Moruno P. Terapia ocupacional: teoría y técnicas. $1^{\text {a }}$ edición. Barcelona: Masson; 2003. P. $141-51$.

230. Kielhofner G. A model of human occupation. Theory and application. 2ªedición. Baltimore: Williams and Wilkins, 1995.

231.Portenoy RK, Itri LM. Cancer-related-fatigue: guidelines for evaluation and management. Oncologist. 1999; 4: 1-10.

232. Cella D, Peterman A, Passik S. Progress towards guidelines for the management of fatigue. Oncologist (Huntingt). 1998; 12: 369-77.

233. Berger A. Treating fatigue in cáncer patients. Oncologist. 2003; 8(1): $10-14$.

234. Manzullo EF, Escalante CP. Research into fatigue. Hematol Oncol Clin N Am. 2002; 16: 619-28.

235. Stone $\mathrm{P}$, Richards M, Hardy J. Fatigue in patients with cancer. Eur J Cancer. 1998; 34: 1670-6.

236. Mock V, Atkinson A, Barsevick A, et al. NCCN practice guidelines for cáncer-related-fatigue. Rockledge (PA). 2000; National Comprehensive Cancer Network.

237. Jacobsen PB, Hann DM, Azzarello LM. Fatigue in women receiving adjuvant chemotherapy for breast cáncer: characteristics, course and correlates. J Pain Symptom Manage. 1999; 18: 233-42. 
238. Portenoy RK, Miaskowski C. Assessment and management of cáncerrelated fatigue. En: Berger A, Portenoy RK, Weissman DE. Principles and Practice of Supportive Oncology. Filadelfia: Lippincott-Raven. 1998. P. 109-18.

239. World Health Organization. Cancer Pain Relief and Palliative Care. Geneva: World Health Organization; 1990.

240. Hancock SL, Cox RS, McDougall IR. Thyroid diseases after treatment of Hodgkin's disease. N Engl J Med. 1991; 325: 599-605.

241. Cella D, Dobrez D, Glaspy J. Control of cáncer-related anemia with erythropoietic agents: a review of evidence for improved quality of life and clinical outcomes. Ann Oncol. 2003; 14: 511-9.

242. Groopman JE, Itri LM. Chemotherapy-induced anemia in adults: incidence and treatment. J Natl Cancer Inst. 2000; 91: 1616-34.

243. Mercadante S, Gebbia V, Marazzo A. Anemia in cáncer: pathophysiology and treatment. Cancer Treat Rev. 2000; 26: 303-11.

244. Armitage JO. Management of anemia in patients with cáncer. Clinical Oncology Updates. 2000; 1: 1-12.

245. Cella D. Factors influencing quality of life in cáncer patients: anemia and fatigue. Semin Oncol. 2000; 25: 2-6. 
246. Cella D. The Functional Assessment of Cancer Therapy-Anemia (FACT-An) Scale: a new tool for the assessment of outcomes in cancer anemia and fatigue. Semin Hematol. 1997; 34: 13-9.

247. Yellen SB, Cella D, Webster K. Measuring fatigue and other anemiarelated symptoms with the Functional Assessment of Cancer Therapy (FACT) measurement symptom. J Pain Symptom Manage. 2000; 13: 63-74.

248. Lee WR, Berkey B, Marcial V. Anemia is associated with decreased survival and increased locoregional failure in patients with locally advanced head and neck carcinoma: a secondary analysis of RTOG 85-27. Int Radiat Oncol Biot Phys. 1998; 42: 1069-75.

249. Glaspy JA. The potential for anemia treatment to improve survival in cancer patients. Oncology (Huntingt). 2002, 16: 35-40.

250. Vansteenkiste J, Pirke R, Massutti B. Double-blind, placebo-controlled, randomized phase III trial of darbapoietin in lung cancer patients receiving chemotherapy. J Natl Cancer Inst. 2002; 94: 1211-20.

251. Littlewood TJ, Bajetta E, Nortier J. Effects of epoietin alpha on hematologic parameters and quality of life in cancer patients receiving non-platinum chemotherapy: results of a randomized, doublé-blind, placebo-controlled trial. J Clin Oncol. 2001; 19: 2865-74. 
252. Demetri GD. Anaemia and its functional consequences in cancer patients: current challenges in management and prospects for improving therapy. Br J Cancer. 2001; 84: 31-7.

253. Abels R. Erythropoietin for anaemia in cancer patients. Eur J Cancer. 2003; 29: 2-8.

254. Glaspy J, Bukowski R, Steinberg D. Impact of therapy with epoietin alfa on clinical outcomes in patients with nomyeloid malignancies during cancer chemotherapy in community oncology practice. Procrit Study Group. J Clin Oncol. 1997; 15: 1218-34.

255. Demetri GD, Kris M, Wade J. Quality of life benefit in chemotherapy patients treated with epoietin alfa is independent of disease response or tumor type: results from a prospective community oncology study. Procrit Study Group. J Clin Oncol. 1998; 16: 3412-25.

256. Gabrilove JL, Cleeland C, Livingston RB. Clinical evaluation of onceweekly doing on epoietin alfa in chemotherapy patients: improvements in hemoglobin and quality of life are similar to three times weekly dosing. J Clin Oncol. 2001; 19: 2875-82.

257. Osterborg A, Brandberg Y, Molostova V. Epoietin beta Hematology Study Group: randomized, doublé-blind, placebo controlled trial of recombinant human erythropoietin, epoetin beta, in hematologic malignances. J Clin Oncol. 2002; 20: 2486-94. 
258. Dunphy FR, Harrison BR, Dunleavy TL. Erythropoietin reduces anemia and transfusions: a randomised trial with or without erythropoietin during chemotherapy. Cancer. 1999; 86: 1362-67.

259. Cleeland CS, Demetri GD, Glaspy J. Identifying hemoglobin level for optimal quality of life: results of an incremental analysis. Proc Am Soc Clin Oncol. 1999; 18: 574-2215.

260. Rizzo JD, Lichtin AE, Woolf SH. Use of epoietin in patients with cancer: evidence-based clinical practice guidelines of the American Society Clinical Oncology and the American Society of Hematology. Blood. 2002; 100: 2303-20.

261. Valentine AD, Meyers CA. Cognitive and mood disturbance as causes and symptoms of fatigue in cancer patients. Cancer. 2001; 92: 1694-98.

262. Reich SG. The tired patient: psychological versus organic causes. Hosp Med. 1996; 22: 142-54.

263. Henriksson MM, Isometsa ET, Hietanaen PS. Mental disorders in cancer suicides. J Affect Disord. 1995; 36: 11-20.

264. Passik SD, Dugan W, McDonald MV. Oncologists' recognition of depression in their patients with cancer. J Clin Oncol. 1998; 16: 15941600.

265. Block SD, Assessing and managing depression in the terminally ill patient. ACP-ASIM End-of-life Care Consensus Panel. American 
College of Physicians-American Society of Internal Medicine. Ann Intern Med. 2000; 132: 209-18.

266. Lynch ME. The assessment and prevalence of affective disorders in advanced cancer. J Palliant Care. 1995; 11: 10-18.

267. Roth AJ, Holland JC. Psychiatric complications in cancer patients. En: Brain MC, Carbone PP. Current therapy in Hematology-Oncology. $5^{\text {a }}$ edición. St Louis, Mo: Mosby Year-Book Inc. 1995. P. 609-18.

268. Williams JW, Mulrow CD, Chiquette E. A systematic review of newer pharmacotherapies for depression in adults: evidence report summary. Ann Inter Med. 2000; 132: 743-56.

269. Nordin K, Glimelius B. Predicting delayed anxiety and depression in patients with gastrointestinal cancer. Br J Cancer. 1999; 79: 525-9.

270. Whooley MA, Simon GE. Managing depression in medical outpatients. N Engl J Med. 2000; 343: 1942-50.

271. Fernández F, Adams F, Holmes VF. Methylphenidate for depressive disorders in cancer patients: an alternative to standard antidepressants. Psychosomatics. 1987; 28: 455-61.

272. Homsi J, Nelson KA, Sarhill N. A phase III study of methylphenidate for depression in advanced cancer. Am J Hosp Palliat Care. 2001; 18: 4037. 
273. Breitbart W, Mermelstein H. Pemoline. An alternative psychoestimulant for the management of depressive disorders in cancer patients. Psychosomatics. 1992; 33: 352-6.

274. Portela MA, Sanz A, Martínez M, Centeno C. Astenia en cáncer avanzado y uso de psicoestimulantes. In Anales del Sistema Sanitario de Navarra. Gobierno de Navarra. Departamento de Salud. 2011; 34 (3): 471-79.

275. Bruera E, Roca R, Cedaro L. Action of local oral pethylprednisolone in terminal cancer patients: a retrospective randomized doublé blind study. Cancer Treat Rep. 1985; 69: 751-4.

276. Tannock I, Gospodarowicz M, Meakin W. Treatment of metastasic prostatic cancer with low-dose prednisone: evaluation of pain and quality of life as pragmatic indexes of response. J Clin Oncol. 1989; 7: 590-7.

277. Progression NL, Pacients LR. Treatment of pemphigus and pemphigoids. Med Oral Patol Oral Cir Bucal. 2005; 10: 410-1.

278. Portenoy RK, Itri LM. Cancer-related fatigue: guidelines for evaluation and management. Oncologist. 1999; 4: 1-10.

279. Portenoy RK, Itri LM. Cancer-related fatigue: guidelines for evaluation and management. Oncologist. 1999; 4: 1-10. 
280. Mustian KM, Morrow GR, Carroll JK. Integrative non-pharmacological behavioral interventions for the management of cancer-related-fatigue. Oncologist. 2007; 12 (1): 52-67.

281. Servaes P, Verhagen C, Bleijenberg G. Fatigue in cancer patients during and after treatment: prevalence, correlates and interventions. Eur J Cancer. 2002; 38: 27-43.

282. MacVicar SB, Winningham ML. Promoting functional capacity of cancer patients. Cancer Bull. 1996; 38: 235-9.

283. Schwartz AL. Patterns of exercise and fatigue in physically active cancer survivors. Oncol Nurs Forum. 1998; 25: 485-91.

284. Puetz TW, Herring MP. Differential effects of exercise on cancerrelated-fatigue during and following treatment: a meta-analysis. Am J Prev Med. 2012; 43: 1-24.

285. Mishra SI, Scherer RW, Snyder C. Exercise interventions on heatlhrelated quality of life for people with cancer during active treatment. Cochrane Database Syst Rev. 2012; 8: CD008465.

286. Cramp F, Daniel J. Exercise for the management of cancer-related fatige in adults. Cochrane Database Syst Rev. 2008: CD006145.

287. Duijts SF, Faber MM, Oldenburg HS. Effectiveness of behavioral techniques and physical exercise on psychosocial functioning and 
health-related quality of life in breast cancer patients and survivors-a meta analysis. Psychooncology. 2011; 20: 115-26.

288. Kangas M, Bovberg DH, Montgomery GH. Cancer-related fatigue: a systematic and meta-analytic review of non-pharmacological therapies for cancer patients. Psychol Bull. 2008; 134: 700-41.

289. McMillan Em, Newhouse IJ, Exercise is an effective treatment modality for reducing cancer-related fatigue and improving physical capacity in cancer patients and survivors: a meta-analysis, Appl Physiol Nutr Metab. 2011; 36: 892-903.

290. Velthius MJ, Agasi-Idemburg SC, Aufdemkampe G, Wittink HM. The effect of physical exercise on cancer-related fatigue during cancer treatment: a meta analysis of randomized controlles trials. Clin Oncol. 2010; 22: 208-21.

291. Winningham ML. Strategies for managing cancer-related fatigue: a rehabilitation approach. Cancer. 2001; 92: 988-97.

292. Love RR, Leventhal H, Easterling DV. Side effects and emotional distress during cancer chemotherapy. Cancer. 1999; 63: 604-12.

293. Ream, E., Browne, N., Glaus, A., Knipping, C. and Frei, IA. Quality and efficacy of educational materials on cancer-related fatigue: Views of patients from two European Countries. European Journal of Oncology Nursing 2003, 7(2), 99-109. 
294. Engstrom CA, Strohl RA, Rose L. Sleep alterations in cancer patient. Cancer Nurs. 1999; 22: 143-8.

295. Díaz R, Segura A, Montalar J. Tratamiento de la astenia tumoral. En: Barón M, Ordóñez A. La astenia tumoral. $1^{\text {a }}$ edición. Madrid: Panamericana; 2004. P. 137-57.

296. Barsevick AM, Whitmer K, Seeney C, Nail LM. A pilot study examining energy conservation for cancer treatment-related fatigue. Cancer Nurs. 2002; 25: 333-41.

297. Kangas M, Bovbjerg DH, Montgomery GH. Cancer-related fatigue: a systematic and meta-analytic review of non-pharmacological therapies for cancer patients. Psychol Bull. 2008; 134: 700-41.

298. Goedendorp MM, Gielissen MF, Verhagen CA, Bleijenberg G. Psychosocial interventions for reducing fatigue during cancer treatment in adults. Cochrane Database Syst Rev. 2009: CD006953.

299. Jacobsen PB, Donovan KA, Vadaparampil ST, Small BJ. Systematic review and meta-analysis of psychological and activity-based interventions for cancer-related fatigue. Health Psychol. 2007; 26: 66067.

300. Kangas M, Bovbjerg DH, Montgomery $\mathrm{GH}$. Cancer-related fatigue: a systematic and meta-analytic review of non-pharmacological therapies for cancer patients. Psychol Bull. 2008; 134: 700-41. 
301. Goedendorp MM, Gielissen MF, Verhagen CA, Bleijenberg G. Psychosocial interventions for reducing fatigue during cancer treatment in adults. Cochrane Database Syst Rev. 2009: CD006953.

302. Jacobsen PB, Donovan KA, Vadaparampil ST, Small BJ. Systematic review and meta-analysis of psychological and activity-based interventions for cancer-related fatigue. Health Psychol. 2007; 26: 66067.

303. Watanabe S, Bruera E. Anorexia and cachexia, astenia and lethargy. Hematol Oncol Clin North Am. 1996; 10: 189-206.

304. Winningham ML. Strategies for managing cancer-related fatigue: a rehabilitation approach. Cancer. 2001; 92: 988-97.

305. Portenoy RK, Itri LM. Cancer-related-fatigue: guidelines for evaluation and management. Oncologist. 1999; 4: 1-10.

306. Cella D, Peterman A, Passik S. Progress towards guidelines for the management of fatigue. Oncologist (Huntingt). 1998; 12: 369-77.

307. Berger A. Treating fatigue in cáncer patients. Oncologist. 2003; 8(1): 10-14.

308. Portela MA, Sanz A, Martínez M, Centeno C. Astenia en cáncer avanzado y uso de psicoestimulantes. In Anales del Sistema Sanitario de Navarra. Gobierno de Navarra. Departamento de Salud. 2011; 34 (3): 471-79. 
309. Progression NL, Pacients LR. Treatment of pemphigus and pemphigoids. Med Oral Patol Oral Cir Bucal. 2005; 10: 410-1.

310. Puetz TW, Herring MP. Differential effects of exercise on cancerrelated-fatigue during and following treatment: a meta-analysis. Am J Prev Med. 2012; 43: 1-24.

311. Mishra SI, Scherer RW, Snyder C. Exercise interventions on heatlhrelated quality of life for people with cancer during active treatment. Cochrane Database Syst Rev. 2012; 8: CD008465.

312. Cramp F, Daniel J. Exercise for the management of cancer-related fatige in adults. Cochrane Database Syst Rev. 2008: CD006145.

313. Duijts SF, Faber MM, Oldenburg HS. Effectiveness of behavioral techniques and physical exercise on psychosocial functioning and health-related quality of life in breast cancer patients and survivors-a meta analysis. Psychooncology. 2011; 20: 115-26.

314. Kangas M, Bovberg DH, Montgomery GH. Cancer-related fatigue: a systematic and meta-analytic review of non-pharmacological therapies for cancer patients. Psychol Bull. 2008; 134: 700-41.

315. McMillan Em, Newhouse IJ, Exercise is an effective treatment modality for reducing cancer-related fatigue and improving physical capacity in cancer patients and survivors: a meta-analysis, Appl Physiol Nutr Metab. 2011; 36: 892-903. 
316. Velthius MJ, Agasi-Idemburg SC, Aufdemkampe G, Wittink HM. The effect of physical exercise on cancer-related fatigue during cancer treatment: a meta analysis of randomized controlles trials. Clin Oncol. 2010; 22: 208-21.

317. Winningham ML. Strategies for managing cancer-related fatigue: a rehabilitation approach. Cancer. 2001; 92: 988-97.

318. Love RR, Leventhal H, Easterling DV. Side effects and emotional distress during cancer chemotherapy. Cancer. 1999; 63: 604-12.

319. Ream, E., Browne, N., Glaus, A., Knipping, C. and Frei, IA. Quality and efficacy of educational materials on cancer-related fatigue: Views of patients from two European Countries. European Journal of Oncology Nursing 2003; 7(2), 99-109.

320. Engstrom CA, Strohl RA, Rose L. Sleep alterations in cancer patient. Cancer Nurs. 1999; 22: 143-8.

321. Barsevick AM, Whitmer K, Seeney C, Nail LM. A pilot study examining energy conservation for cancer treatment-related fatigue. Cancer Nurs. 2002; 25: 333-41.

322. Kangas M, Bovbjerg DH, Montgomery GH. Cancer-related fatigue: a systematic and meta-analytic review of non-pharmacological therapies for cancer patients. Psychol Bull. 2008; 134: 700-41. 
323. Goedendorp MM, Gielissen MF, Verhagen CA, Bleijenberg G. Psychosocial interventions for reducing fatigue during cancer treatment in adults. Cochrane Database Syst Rev. 2009: CD006953.

324. Jacobsen PB, Donovan KA, Vadaparampil ST, Small BJ. Systematic review and meta-analysis of psychological and activity-based interventions for cancer-related fatigue. Health Psychol. 2007; 26: 66067.

325. Haro LM, Ortega C, de las Heras MT, Poyatos A, Molina MJ, Muñoz MM et al. Evaluación de la astenia en pacientes oncológicos avanzados y una propuesta de protocolo de intervención psicológica. Psicoon. $2011 ; 8$ (1): 21-30.

326. Bruera E, Brenneis C, Michaud M, Rafter J, Magnan A, Tennant A et al. Association between asthenia and nutritional status, lean body mass, anemia, psychological status and tumor mass in patients with advanced breast cancer. J Pain Symptom Manage 1989; 4: 59-63.

327. Mock V. Evidence-based treatment for cancer-related fatigue. Journal Nat Can Inst Monographs. 2004. 32: 112-18.

328. Brown C, Huedo B, Pescatello S. Efficacy of exercise in modulating cancer-related fatigue among adult cancer survivors: a meta-analysis. Cancer Epidemiol Biomakers Prev 2011; 20: 123-133. 
329. Fayers P, Bottomley A. EORTC Quality of Life Group, Quality of Life Unit. Quality of life research within the EORTC - the EORTC QLQC30. European Organisation for Research and Treatment of Cancer. Eur J Cancer 2002; 38 Suppl 4: S125-133.

330. Bjordal K, de Graeff A, Fayers PM, Hammerlid E, Van Pottelsberghe C, Curran D et al. A 12 country field study of the EORTC QLQ-C30 (version 3.0) and the head and neck cancer specific module (EORTC QLQ-H\&N35) in head and neck patients. Eur J Cancer 2000; 1; 36 (14): 1796-1807.

331. Bottomley A, Aaronson NK. European Organisation for Research and Treatment of Cancer. International perspective on healthrelated qualityof-life research in cancer clinical trials: the European Organisation for Research and Treatment of Cancer experience. J Clin Oncol 2007; 25: $5082-5086$.

332. Whistance RN, Conroy T, Chie W, Costantini A, Sezer O, Koller M et al. Clinical and psychometric validation of the EORTC QLQ-CR29 questionnaire module to assess health-related quality of life in patients with colorectal cancer. Eur J Cancer 2009; 45: 3017-3026.

333. Arrarás JI, Villafranca E, Arias de la Vega F, Domínguez MA, Lainez N, Manterola A et al. The EORTC quality of life questionnaire QLQ- 
C30(version 3.0). Validation study for Spanish prostate cancer patients. Arch Esp Urol 2008; 61: 949-954.

334. Arrarás JI, Villafranca E, Arias de la Vega F, Romero P, Rico M, Vila M et al. The EORTC Quality of Life Questionnaire for patients with prostate cancer: EORTC QLQ-PR25. Validation study for Spanish patients. Clin Transl Oncol 2009; 11:160-164.

335. Arrarás JI, Arias F, Illarramendi J, Manterola A, Salgado E, Dominguez MA, Vega E. Calidad de vida relacionada con la salud en los servicios de Oncología del Hospital de Navarra. Grupo de Calidad de Vida de la EORTC. An. Sist. Sanit. Navar. 2011; 34 (1): 9-20.

336. Exercise recommendations in cancer-related fatigue, cognitive impairment, sleep problems, depression, pain, anxiety, and physical dysfunction: A review. Oncol Hematol Rev. 2012; 8(2): 81-88.

337. Effectiveness of Mindfulness-Based Stress Reduction in Mood, Breastand Endocrine-Related Quality of Life, and Well-Being in Stage 0 to III Breast Cancer: A Randomized, Controlled Trial. Hoffman J, Ersser J, Hopkinson B, Nicholls G, Harrington E, Thomas W. J Clin Oncol. 2012; $30: 1335-1342$.

338. Portenoy K. Treatment of cancer pain. The Lancet. 2011; 377(9784): 2236-2247. 
339. Fonseca C, Schlack V, Mera M, Muñoz S, Peña L. Evaluación de la calidad de vida en pacientes con cáncer terminal. Rev Chil Cir. 2013; 65: 321-328.

340. Justin W.L. Keogh, PhD, and Roderick D. Body Composition, Physical Fitness, Functional Performance, Quality of Life, and Fatigue Benefits of Exercise for Prostate Cancer Patients: A Systematic Review. Journal of pain and symptom management. 2012; 43 (1): 96-110.

341. Mock V. Evidence-Based Treatment for Cancer-Related Fatigue. Journal of the National Cancer Institute Monographs. 2004; 32: 112118.

342. Ann M, Lynn H, Deborah K. Cancer-Related Fatigue. Implications for Breast Cancer Survivors. Cancer. 2012; 118 (8) :2261-9.

343. Schlack C, Fonseca C, Muñoz S, Peña L. Evaluación de la calidad de vida en pacientes con cáncer terminal. Rev Chil Cir. 2013; 65(4): 32128.

344. Singer S, Kunht S, Zwerenz R, Eckert K, Hofmeister D, Dietz A et al. Age and sex standarised prevalence rates of fatigue in a large hospital based sample of cancer patients. British Journal of Cancer. 2011; 105: $445-451$. 
345. Singer S, Kunht S, Zwerenz R, Eckert K, Hofmeister D, Dietz A et al. Age and sex standarised prevalence rates of fatigue in a large hospital based sample of cancer patients. British Journal of Cancer. 2011; 105: $445-451$.

346. Aaronson NK, Ahmedzai S, Bergman B, et al. The European Organization for Research and Treatment of Cancer QLQ-30: a quality of life instrument for use in international clinical trials in oncology. J Natl Cancer Inst. 1993; 85: 65-76.

347. Harrison LB, Shasha D, White C, Ramdeen B. Radiotherapy-associated anaemia in patients receiving non-platinum chemotherapy: results of a retrospective survey. Eur J Cancer. 2001; 37: 1617-23.

348. Aaronson NK, Ahmedzai S, Bergman B, et al. The European Organization for Research and Treatment of Cancer QLQ-30: a quality of life instrument for use in international clinical trials in oncology. J Natl Cancer Inst. 1993; 85: 65-76.

349. Stone P, Richards M, A'Hern R, Hardy J.. Estudio comparativo de la prevalencia, gravedad y correlaciones del cansancio en los pacientes con cáncer frente a un grupo control de voluntarios sin cáncer. Ann Oncol. 2000; 9(7): 834-41.

350. Haylock PJ, Hart LK. Fatigue in patients receiving localized radiation. Cancer Nurs. 1979; 2: 461-7. 
351. Proctor SJ, Kernaham J, Taylor P. Depression as a component of postcranial irradiation somnolence syndrome. Lancet. 1981; 1: 1215-6.

352. Maryska L, Heijnen J, Gondos A, Bray F, Hakulinen T, Brewster A et al. Clinical relevance of conditional survival of cancer patients in Europe: Age-specific analyses of 13 cancers. J Clin Onco. 2011; 28: 2520-2528. 
8. ANEXOS 
ANEXO I.

CUESTIONARIO

PERFORM 


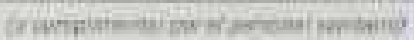

Fecha:

if

$-1$

Nemero historia canicai

\section{Cuestionario PERFORM}

\section{Instrucciones para el paciente}

- A continuación, encontrará distintas afirmaciones realizadas por personas que tienen fatiga o cansancio relacionado con ef cáncer.

- Quisiéramos saber con qué frecuencia se ha encontrado Usted con estas situaciones o ha tenido estos sintomas, estas ultimas 2 semanas.

- Por favor, para responder marque con una " $x$ " la casilla de la respuesta que mejor se ajuste a su opinión.

- No hay respuestas correctas ni incorrectas: lo más importante es conocer su opinión.

- Por favor, mientras responda el cuestionario no consulte sus respuestas con nadie.

MUCHAS GRACIAS POR SU COLABORACIÓN. 


\section{EL Cuestionario PERFORM}

\begin{tabular}{|c|c|c|c|c|c|c|c|}
\hline & $\begin{array}{l}\text { EN LAS ULTIMAS } 2 \text { SEMANAS } \\
\text { ¿Con que freciencia se hB encontrado } \\
\text { con esta situecion o sintoma? }\end{array}$ & Siempre & $\begin{array}{l}\text { Muchas } \\
\text { veces }\end{array}$ & $\begin{array}{l}\text { La mitad } \\
\text { de as } \\
\text { veces }\end{array}$ & $\begin{array}{l}\text { Pocas } \\
\text { veces }\end{array}$ & Nunca & \\
\hline & $\begin{array}{l}\text { Plestizar un ejercicis minimo me he } \\
\text { supuesto un cansancio desproporcionade. }\end{array}$ & 1 & 2 & 3 & 4 & 5 & \\
\hline & 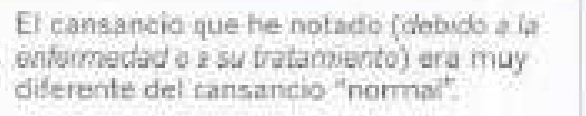 & 1 & 2 & 3 & 4 & 5 & \\
\hline 3. & He estado cansado/a todo al día. & 1 & 2 & 3 & 4 & 5 & \\
\hline 4. & $\begin{array}{l}\text { Me ne pasado todo ef dia sentadofil } \\
\text { a causa de m cansancio. }\end{array}$ & 1 & 2 & 3 & 4 & 5 & \\
\hline & $\begin{array}{l}\text { Cuando he estado carisato/a he tenido } \\
\text { que interrumpir lo due estabs haciendo } \\
\text { y descansar para poder seguir. }\end{array}$ & 1 & 2 & 3 & 4 & 5 & \\
\hline & $\begin{array}{l}\text { Me he notadamuy lentio/s hacende ini } \\
\text { actividad diars. }\end{array}$ & 1 & 2 & 3 & 4 & 5 & \\
\hline 7. & $\begin{array}{l}\text { He necesitade ayuda para hacer las } \\
\text { tareas de casa, a cause de mi cansencio. }\end{array}$ & 1 & 2 & 3 & 4 & 5 & \\
\hline 8. & 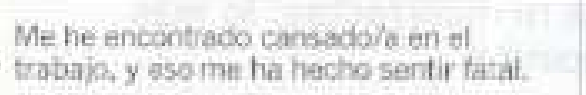 & 1 & 2 & 3 & 4 & 5 & $\begin{array}{l}\text { No } \\
\text { pracede }\end{array}$ \\
\hline & $\begin{array}{l}\text { En general croo que trivide ha } \\
\text { ampoorado at causa dal cansencio. }\end{array}$ & 1 & 2 & 3 & 4 & 5 & \\
\hline 10. & $\begin{array}{l}\text { He seritido qua me estoy viniando aifajo: } \\
\text { a causa cle mi cansancip. }\end{array}$ & 1 & 2 & 3 & 4 & 5 & \\
\hline 11. & $\begin{array}{l}\text { Siento que ef arsancip me ho } \\
\text { impedida haver una vida nommal. }\end{array}$ & 1 & 2 & 3 & 4 & 5 & \\
\hline 12. & $\begin{array}{l}\text { He dejado de hacer lo que me gustaba } \\
\text { in causa de } \mathrm{m} \text { cansancio: }\end{array}$ & 1 & 2 & 3 & 4 & 5 & \\
\hline \multicolumn{8}{|c|}{ Desiny } \\
\hline \multicolumn{8}{|c|}{ 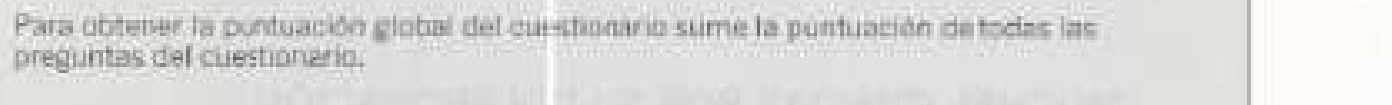 } \\
\hline
\end{tabular}




\section{ANEXO II. \\ CUESTIONARIO}

SF $12 \mathrm{~V} 2$ 


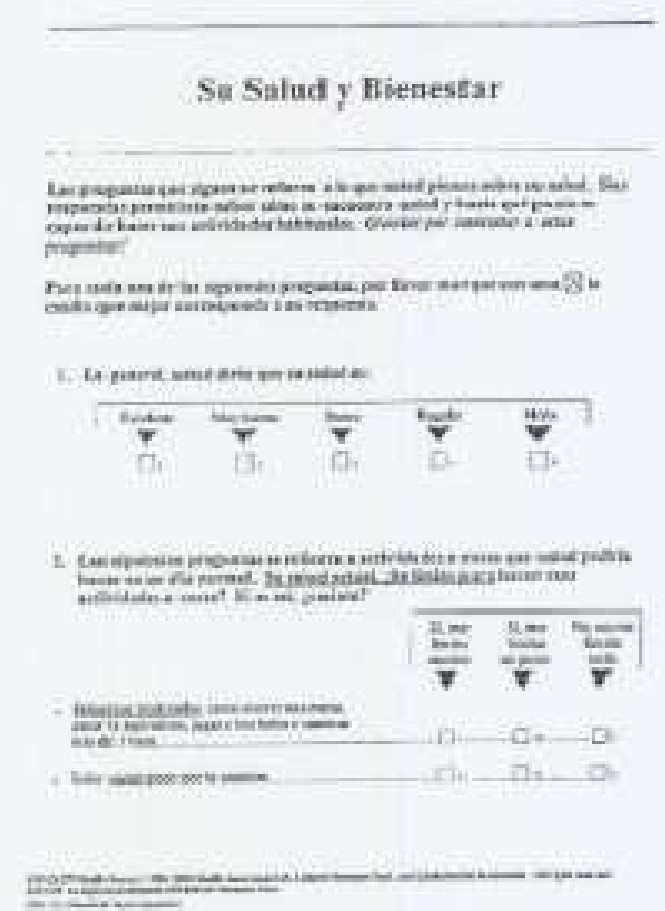

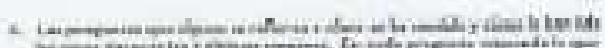

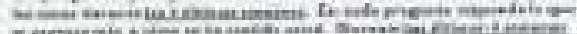

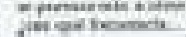

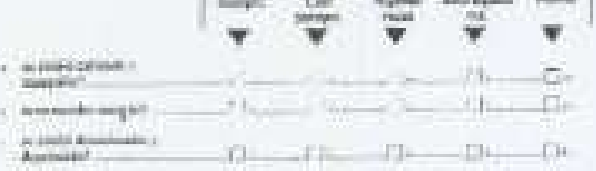

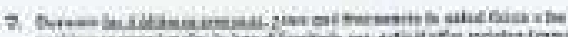

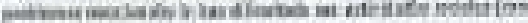

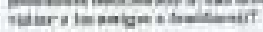

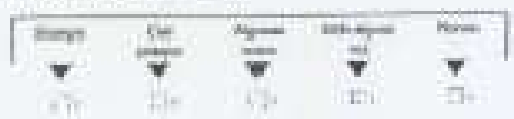

Grodas par chatarar e enlas poetwalin

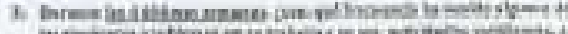

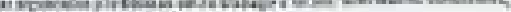

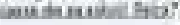

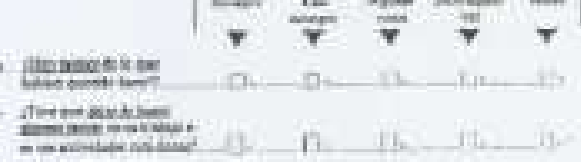

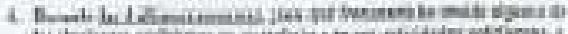

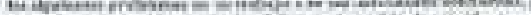
Ty tintes

$$
\lim _{\tau}^{\sin } \frac{\bar{v}}{\nabla} \bar{\gamma}
$$
Hannakin.

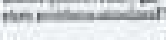

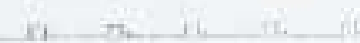

20.1.

and

ilenes.

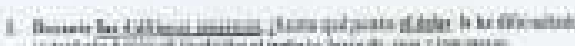

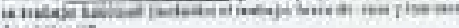
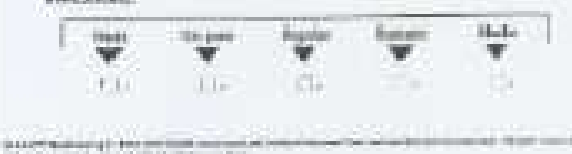
ANEXO III. PROYECTO

PILOTO 


\section{RESUMEN}

Objetivos: Comprobar la eficacia de la utilización de medidas de tipo no farmacológico para el control de la astenia referida por la enfermedad oncológica desde la perspectiva de la Terapia Ocupacional.

Emplazamiento: Unidad de Oncología del Complejo Hospitalario Universitario de Salamanca.

Material y métodos: Estudio experimental, aleatorizado, estratificado, prospectivo longitudinal mediante un esquema paralelo de asignación fija con grupo experimental y grupo control, con una muestra constituida por 30 pacientes. Se midieron: Cuestionario SF-12, cuestionario PERFORM, triple EVA de astenia, escala de Lawton y Brody, además de considerar una serie de variables intervinientes, tales como el sexo, los niveles de hemoglobina o el diagnóstico patológico. Para el análisis estadístico se utilizó el paquete de datos SPSS 21.0, estableciéndose la correlación entre las diferentes variables en los diferentes grupos, con un nivel de significación (intervalo de confianza [IC] del 95\%) $p<0,05$.

Resultados: Diferencias estadísticamente significativas $(p<0,05)$ entre grupo experimental y grupo control en SF-12, PERFORM, triple EVA de astenia y Lawton y Brody. No diferencias estadísticamente significativas entre sexos y niveles de astenia. Relación directa entre edad, niveles de hemoglobina y número de líneas de tratamiento y niveles de astenia $(r=1)$.

Conclusiones: Queda comprobada la eficacia de la utilización de medidas de tipo no farmacológico para el control de la astenia referida por la enfermedad oncológica desde la perspectiva de la Terapia Ocupacional. A partir de la misma se continuará con la realización de la tesis doctoral. 
ANEXO IV.

CRONOGRAMA 


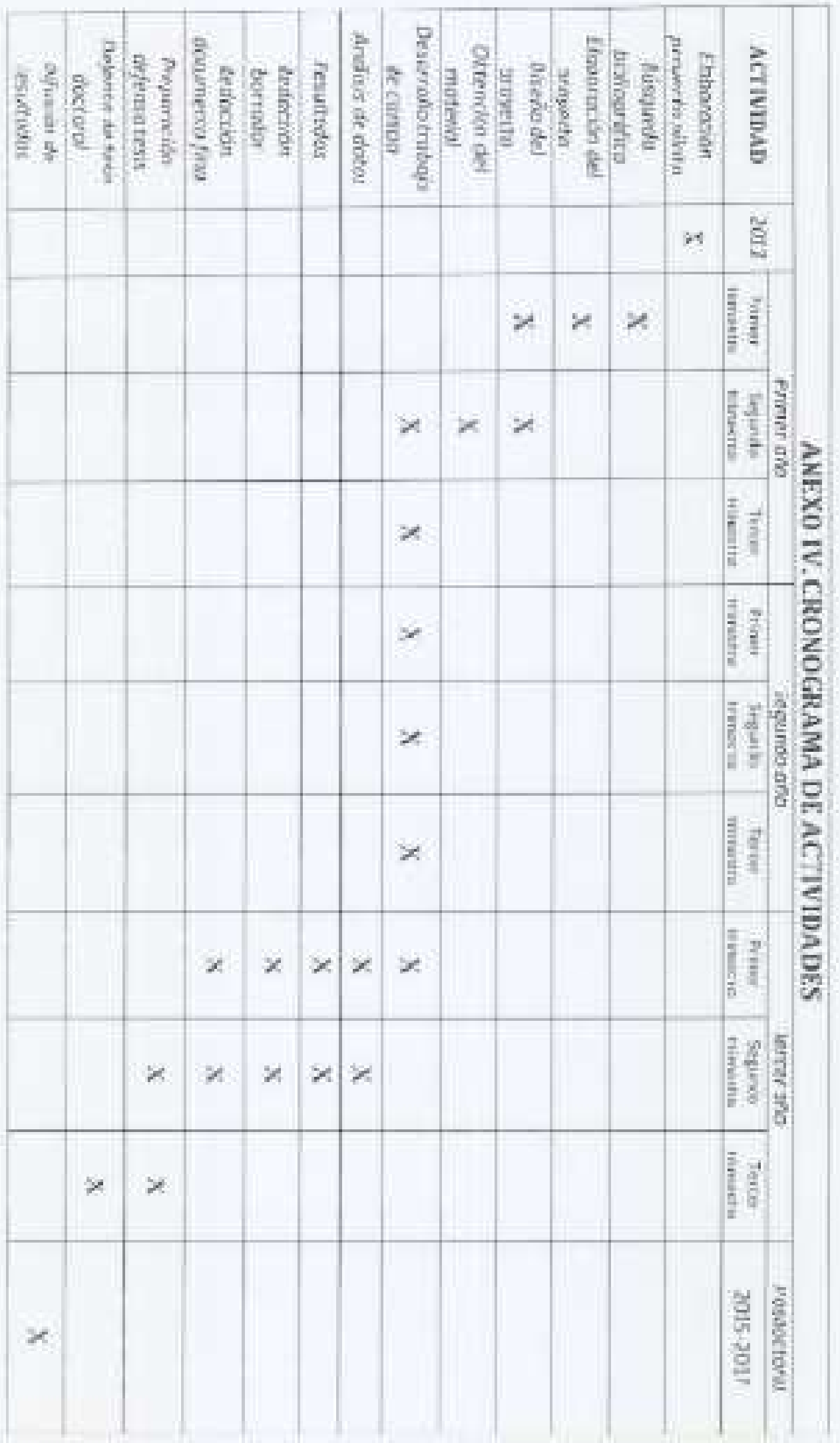


ANEXO V. LISTADO DE

NÚMEROS

ALEATORIOS 


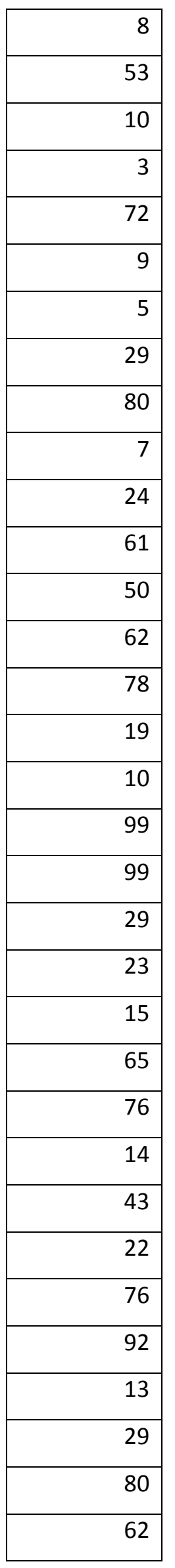

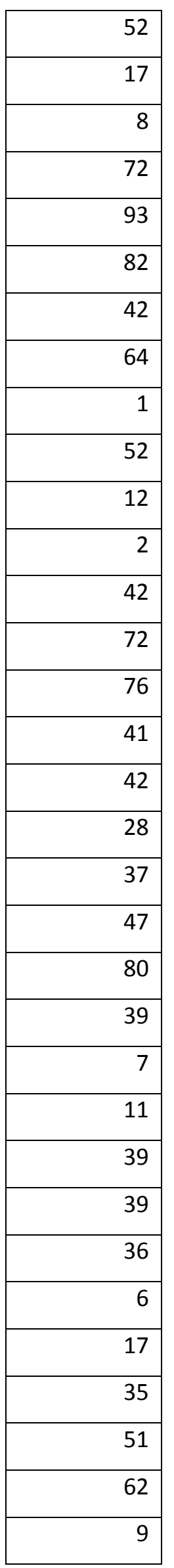

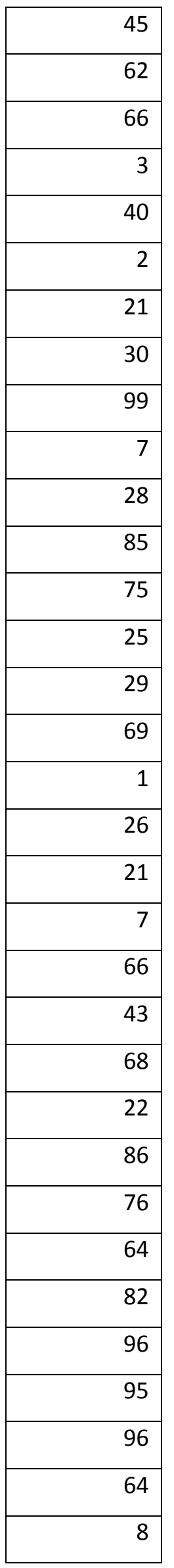

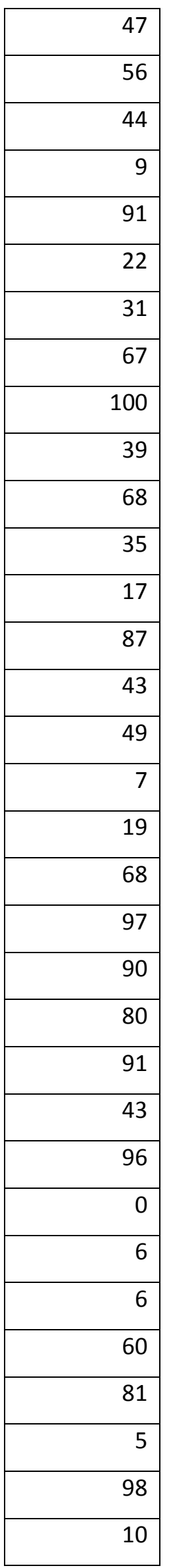

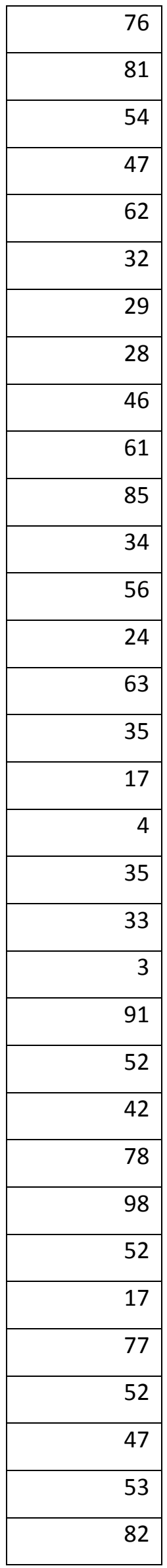




\begin{tabular}{|r|}
\hline 87 \\
\hline 60 \\
\hline 14 \\
\hline 34 \\
\hline 67 \\
\hline 29 \\
\hline 57 \\
\hline
\end{tabular}

\begin{tabular}{|r|}
\hline 1 \\
\hline 78 \\
\hline 38 \\
\hline 34 \\
\hline 51 \\
\hline 29 \\
\hline 20 \\
\hline
\end{tabular}

\begin{tabular}{|r|}
\hline 87 \\
\hline 14 \\
\hline 54 \\
\hline 81 \\
\hline 50 \\
\hline 26 \\
\hline 13 \\
\hline
\end{tabular}

\begin{tabular}{|r|}
\hline 7 \\
\hline 21 \\
\hline 28 \\
\hline 14 \\
\hline 33 \\
\hline 84 \\
\hline 65 \\
\hline
\end{tabular}

\begin{tabular}{|r|}
\hline 2 \\
\hline 79 \\
\hline 18 \\
\hline 66 \\
\hline 71 \\
\hline 28 \\
\hline 66 \\
\hline
\end{tabular}




\title{
ANEXO VI. HOJA DE
}

SEGUIMIENTO DE LOS

\author{
PACIENTES
}




\section{SEGUIMIENTO PACIENTE}

\begin{tabular}{|c|c|c|c|c|c|c|c|}
\hline HORAS & LUNES & MARTES & MIÉRCOLES & JUEVES & VIERNES & SÁBADO & DOMINGO \\
\hline $9-10$ & & & & & & & \\
\hline $10-11$ & & & & & & & \\
\hline $11-12$ & & & & & & & \\
\hline $12-13$ & & & & & & & \\
\hline $13-14$ & & & & & & & \\
\hline $14-15$ & & & & & & & \\
\hline $15-16$ & & & & & & & \\
\hline $16-17$ & & & & & & & \\
\hline $17-18$ & & & & & & & \\
\hline $18-19$ & & & & & & & \\
\hline $19-20$ & & & & & & & \\
\hline $20-21$ & & & & & & & \\
\hline $21-22$ & & & & & & & \\
\hline $\begin{array}{l}\text { HORAS } \\
\text { DORMIR }\end{array}$ & & & & & & & \\
\hline
\end{tabular}

Por favor introduzca los siguientes datos:

1. Tiempo que permanece encamado.

2. Tiempo que permanece sentado.

3. Tiempo que permanece dormido.

4. Tiempo que camina. 
ANEXO VII.

RESOLUCIÓN COMITÉ ÉTICO DE

INVESTIGACIÓN 
MTSPrTal

UNinecherthard

DISAT AMANCA

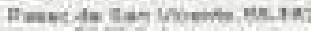

TiDor Ssimmanes

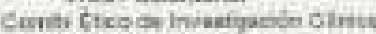

Twothe 323 ox 7519

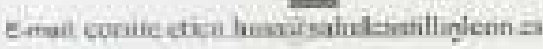

EL COMITE ETICO DE INVESTIGACION CLINICA DEL AREA DE SALUU LE SALAMANCA,

INFOR IA:

Que of Frovecto de investigación presentado por D. EDURRDO JOSE ITRNANCEZ ROORIGUEZ

Titusedo:

"Estudio abierto, aleatorizado de la intervención no farmacológica on el control de la astenia referida por la enfermadad oncologica",

Que presenta como Investigador responisiste, Proyedio de Tess Doctoral, y que ouenta con is aprobeción de Dr. Juan vesus Crue Hemandaz SE AJUSTA A LAS NOFOMAS ETICAS Y DE BUENA PRACTICA CLINICA, EOlabieunlas para tales estudios.

Y para que conste lo firma on Salamanea cen fecha 14 de noviembre de 2011

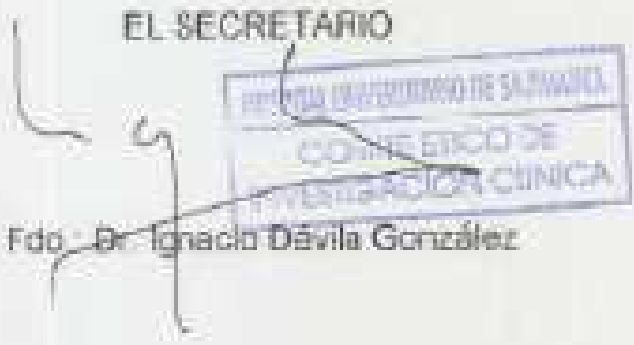

